\title{
Partnering for mobility? : three-level games in EU external migration policy
}

Citation for published version (APA):

Reslow, N. (2013). Partnering for mobility? : three-level games in EU external migration policy. [Doctoral Thesis, Maastricht University]. Datawyse / Universitaire Pers Maastricht. https://doi.org/10.26481/dis.20130905nr

Document status and date:

Published: 01/01/2013

DOI:

10.26481/dis.20130905nr

Document Version:

Publisher's PDF, also known as Version of record

\section{Please check the document version of this publication:}

- A submitted manuscript is the version of the article upon submission and before peer-review. There can be important differences between the submitted version and the official published version of record.

People interested in the research are advised to contact the author for the final version of the publication, or visit the DOI to the publisher's website.

- The final author version and the galley proof are versions of the publication after peer review.

- The final published version features the final layout of the paper including the volume, issue and page numbers.

Link to publication

\footnotetext{
General rights rights.

- You may freely distribute the URL identifying the publication in the public portal. please follow below link for the End User Agreement:

www.umlib.nl/taverne-license

Take down policy

If you believe that this document breaches copyright please contact us at:

repository@maastrichtuniversity.nl

providing details and we will investigate your claim.
}

Copyright and moral rights for the publications made accessible in the public portal are retained by the authors and/or other copyright owners and it is a condition of accessing publications that users recognise and abide by the legal requirements associated with these

- Users may download and print one copy of any publication from the public portal for the purpose of private study or research.

- You may not further distribute the material or use it for any profit-making activity or commercial gain

If the publication is distributed under the terms of Article $25 \mathrm{fa}$ of the Dutch Copyright Act, indicated by the "Taverne" license above, 


\section{Partnering for mobility?}

Three-level games in EU external migration policy 
(c) Copyright Natasja Reslow, Maastricht 2013

ISBN 9789461592477

Printed by Datawyse bv | Universitaire Pers Maastricht 


\section{Partnering for mobility?}

\section{Three-level games in EU external migration policy}

\section{PROEFSCHRIFT}

ter verkrijging van de graad van doctor aan de Universiteit Maastricht, op gezag van de Rector Magnificus, Prof. dr. L. L. G. Soete volgens het besluit van het College van Decanen

in het openbaar te verdedigen op donderdag 5 september 2013 om 16.00 uur

door

NATASJA RESLOW

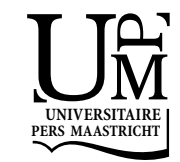




\section{Promotores}

Prof. dr. S. Vanhoonacker

Prof. dr. M. P. Vink

Beoordelingscommissie

Prof. dr. T. Blom (voorzitter)

Prof. dr. T. Conzelmann

Prof. dr. S. Lavenex (Universität Luzern)

Prof. dr. H. Schneider

Dr. M. Siegel 


\section{Table of contents}

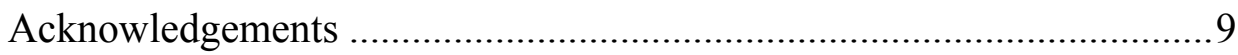

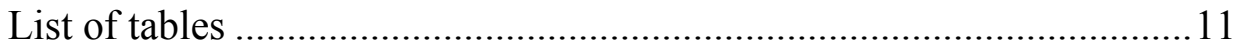

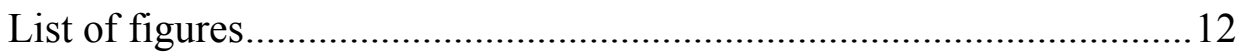

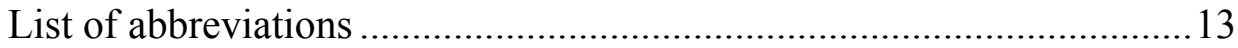

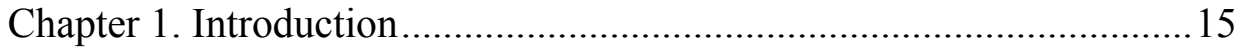

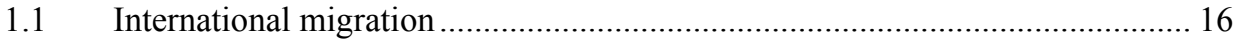

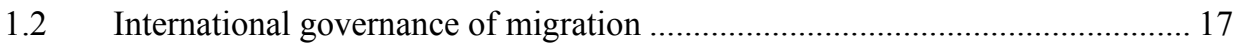

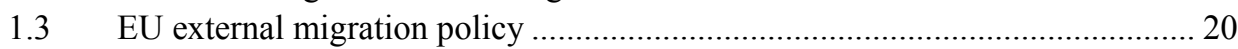

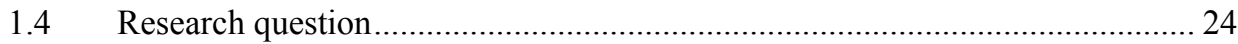

1.4.1 First puzzle: the member states and the EU institutions .................................2 24

1.4.2 Second puzzle: cooperation between third countries and the EU .....................26

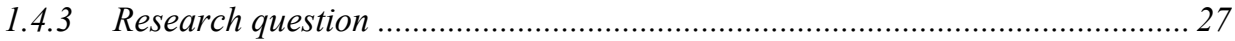

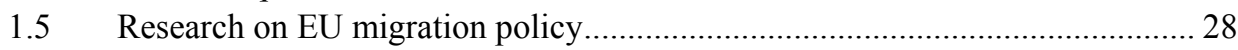

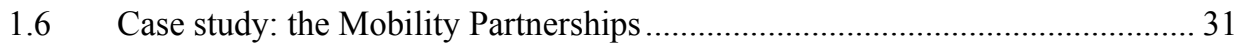

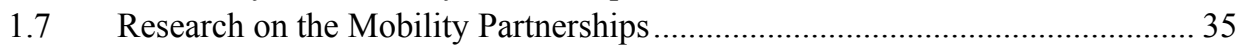

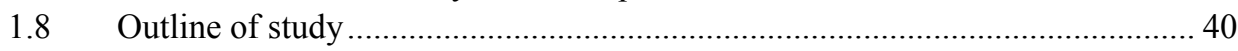

Chapter 2. Theoretical framework .................................................. 41

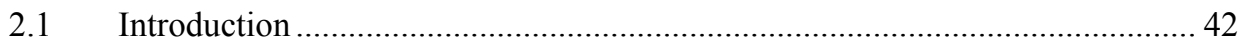

2.2 Conceptualising EU external migration policy as a three-level game ............... 44

2.2.1 Criticism of the two-level game approach....................................................... 44

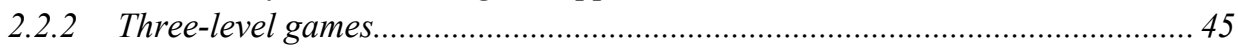

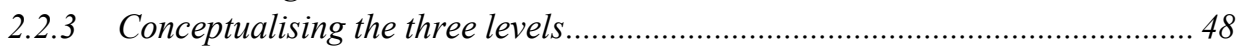

2.2.4 Conceptualising the two interactions: determining the size of win-sets............ 49

2.2.5 The role of strategy and the Commission as 'chief negotiator'..........................51

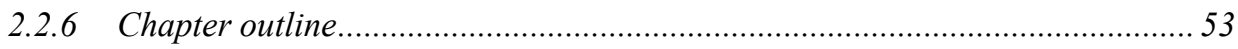

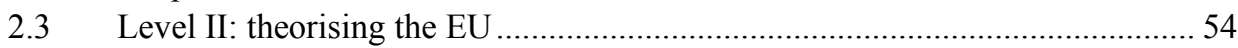

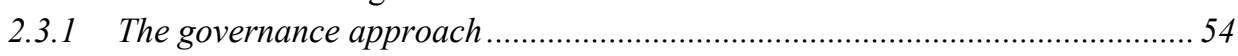

2.3.2 The governance of EU external migration policy .............................................. 57

2.4 Level III: the domestic politics of the member states.............................................. 60

2.4.1 Explaining member states' preferences on EU external migration policy ........ 62

2.4.2 Mapping member states' participation in EU external migration policy........... 66

2.5 Level I: explaining third countries' preferences .................................................. 69

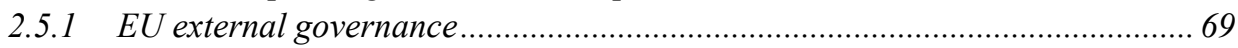

2.5.2 Mapping the external governance of EU migration policy ............................... 73 
2.6 Explaining the size of the win-sets in the three-level game ............................ 75

2.6.1 EU-member state interaction: size of the win-set.............................................. 76

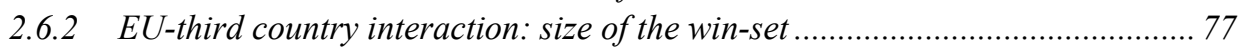

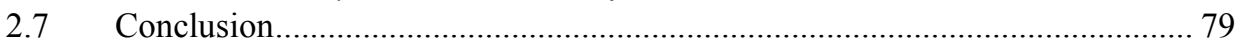

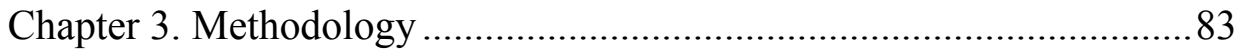

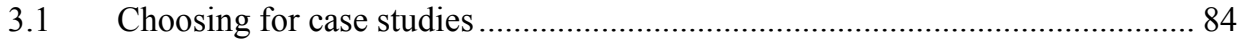

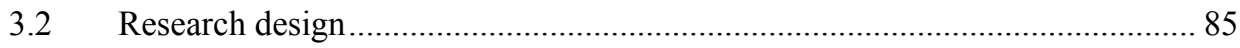

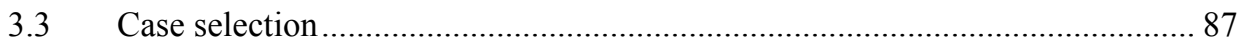

3.3.1 Case selection - member states ..................................................................... 89

3.3.2 Case selection - third countries ................................................................. 96

3.4 Process-tracing and causal process observations......................................... 101

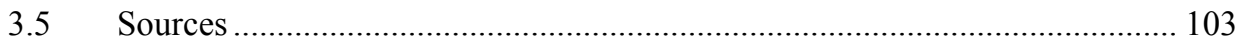

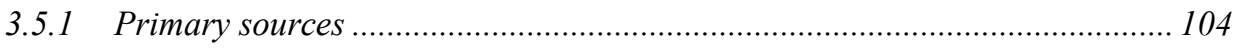

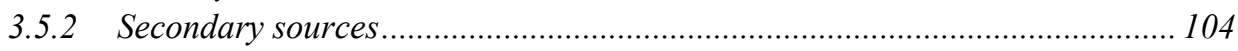

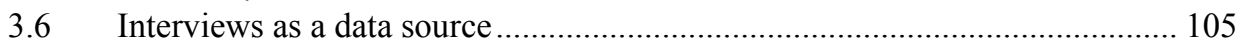

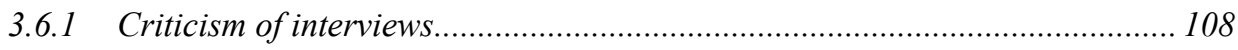

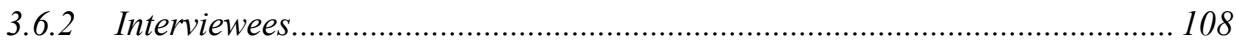

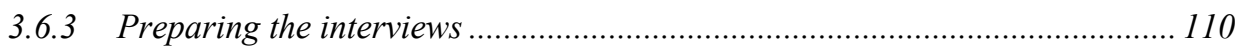

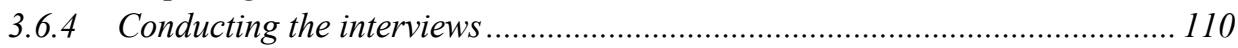

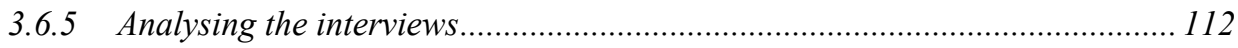

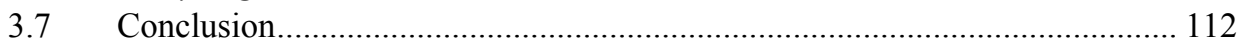

Chapter 4. The EU level ................................................................. 113

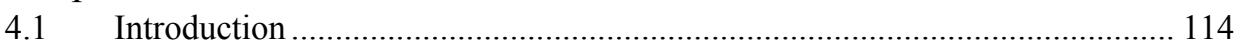

4.2 Policy-making in the EU ............................................................................ 116

4.3 Agenda-setting: the policy background to the Mobility Partnerships ............. 117

4.4 Policy formulation: the Commission communication on Mobility

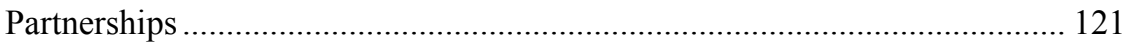

4.4.1 The role of the Commission............................................................................. 121

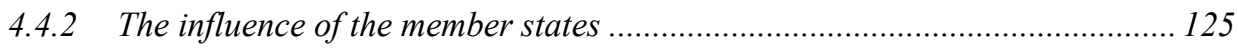

4.5 Decision-making: deciding on the Mobility Partnerships .............................. 128

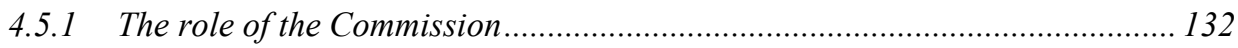

4.5.2 The role of the member states........................................................................... 134

4.5.3 The European Parliament and other EU institutions .................................... 143

4.6 Conclusion............................................................................................... 146

Chapter 5. The EU-member state interaction ................................... 149

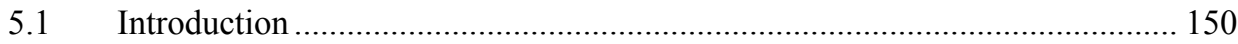

5.2 External migration policy in France, Austria and the Netherlands................. 151

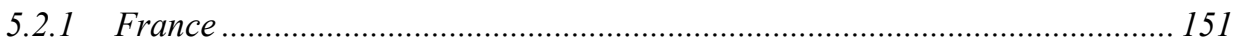

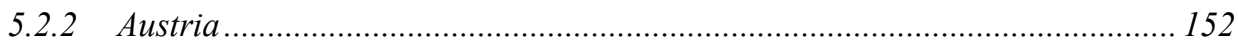

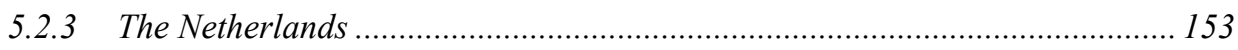


5.3 The coordination of EU and migration-policy making in France, Austria

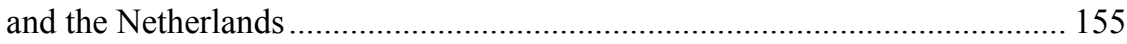

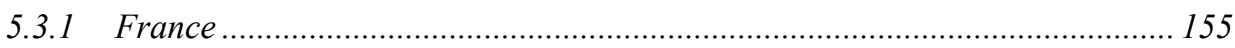

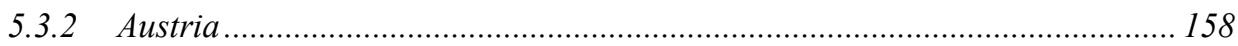

5.3.3 The Netherlands .................................................................................... 160

5.4 The member state level: Mobility Partnerships matching with national identity? ........................................................................................... 163

5.5 The member state level: costs and benefits of participation in the Mobility Partnerships .............................................................................. 168

5.6 EU-member state interaction: size of the win-sets ...................................... 179

5.6.1 Cost of no agreement for the EU ................................................................ 179

5.6.2 Cost of no agreement for the member states ..................................................... 180

5.6.3 Ratification procedure within the EU...................................................... 182

5.6.4 Ratification procedure within the member states ........................................... 182

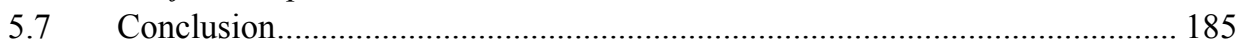

Chapter 6. The EU-third country interaction .....................................189

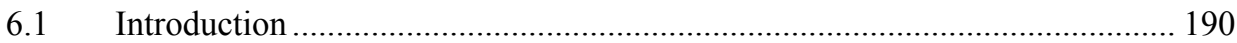

6.2 EU external migration policy in Senegal and Cape Verde ............................. 190

6.3 Negotiations on the Mobility Partnerships ....................................................... 191

6.4 The international level: a process of persuasion and dialogue? ....................... 193

6.5 The international level: policy conditionality and domestic preference

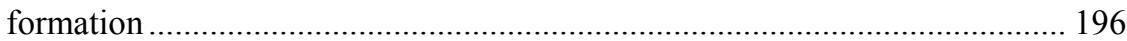

6.5.1 Resonance of EU policy with national policy objectives ................................. 197

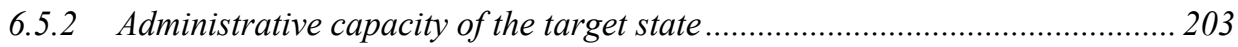

6.5.3 Domestic costs of adopting the EU policy..................................................... 207

6.6 EU-third country interaction: size of the win-sets ........................................ 211

6.6.1 Cost of no agreement for the EU ................................................................... 211

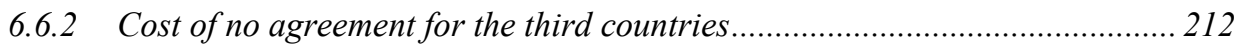

6.6.3 Ratification procedure within the EU............................................................. 217

6.6.4 Ratification procedure within the third countries ......................................... 218

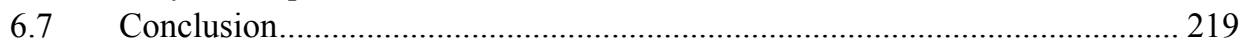

Chapter 7. Conclusion .............................................................. 221

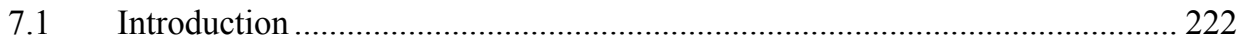

7.2 The three-level game model .......................................................................... 223

7.3 The governance of EU external migration policy.............................................. 225

7.3.1 What was the role of the EU institutions and the member states in the negotiation of the Mobility Partnerships? What implications does this have for the form of the partnerships?....

7.3.2 Why do some member states choose to participate in the Mobility Partnerships while others do not?........................................................ 227

7.3.3 Why do third countries choose to join a Mobility Partnership?....................... 228 
7.4 Three-level games and negotiators' strategies.......................................... 229

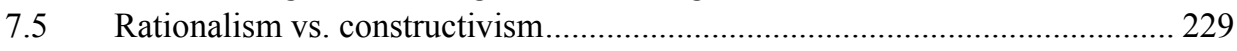

7.6 Suggestions for further research................................................................ 232

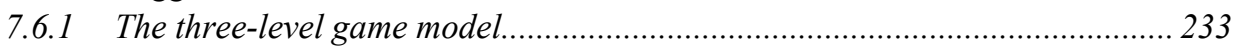

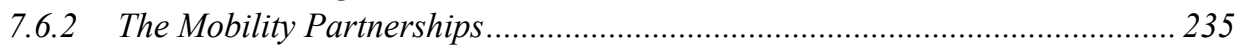

7.7 The human impact of EU external migration policy .................................... 238

Annex I: List of interviews .................................................. 240

Annex II: Projects proposed in the Mobility Partnerships ...................243

Annex III: Legal and illegal immigration to the EU from Global Approach to Migration countries..................................................248

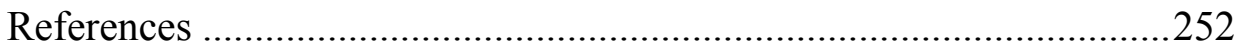

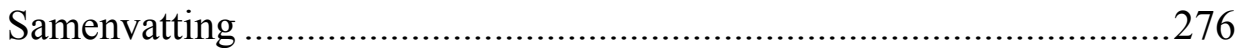

Curriculum vitae ................................................................... 280 


\section{Acknowledgements}

Setting out on a Ph.D. trajectory is quite daunting. I've really enjoyed my time as a Ph.D. student - the writing, the teaching, the conferences, the fieldwork - but there have been (several) moments where I have doubted my abilities and my project. At those times, I've been lucky to be able to call on a wide network of support. I will never be able to mention everyone here, but still I will try.

My first and most important thanks go to my two supervisors, Maarten and Sophie. You two are the perfect supervision team: Maarten encourages me to think big, whilst Sophie reins the project in and keeps it manageable. You have both always been generous to me with your time and advice, whilst allowing me to grow as a researcher, and I really appreciate this. Maarten, thanks for believing that I could do this. You've opened a lot of doors for me and always encouraged me to aim high. You have a knack for taking my muddled thoughts and making something of them. Sophie, you're an inspiration to me. I've learned a lot from you about what it means to be a researcher. Thanks for all your support, feedback, and kind words.

My research has been greatly enabled by a number of people. Interviews are an absolutely essential source of information for qualitative research. I want to thank all my interviewees for taking time out of their busy schedules to talk to me, and for being patient with me as I tried to trace back the process of decision-making on the Mobility Partnerships. My research has been part of the IS-Academy cooperation on migration and development, coordinated by the Maastricht Graduate School of Governance. Thanks to Melissa for her tireless efforts in coordinating this research group. The ISAcademy provided funding for my research trips and for the publication of this thesis. The migration department at the Dutch Ministry of Foreign Affairs hosted me whilst I conducted research in their archives - for this hospitality I thank Paul Gosselink. Rene Spitz has provided up-to-date information on the state of play of the Mobility Partnerships, information which is simply not available in the public domain. I am grateful to Maarten Gischler for arranging work space at the Dutch embassy in Dakar while I was conducting my Senegalese interviews, and at the Dutch consulate in Praia while I was conducting my Cape Verdean interviews. In Maastricht, my student assistants Valerie van Zutphen and Lorena dos Santos Spülbeck provided valuable help with arranging the research trips to France and Senegal, and Cape Verde respectively. 'On the ground', Edouard de la Roche assisted with the interviews in Paris, Ulrich Dossou assisted with the interviews in Dakar, and Lembem Essamai Manga assisted with the interviews in Praia. I could not have done the fieldwork without these five, helping with the practical arrangements and the necessary translations. In Dakar, Bob and Valérie-Anne opened their home to me. I thank them for their kindness, for introducing me to Senegalese music, and for showing me something of the Senegalese countryside. Finally, my dear husband went above and beyond the call of duty by translating a summary of this thesis into Dutch. 
Enormous thanks go to my two paranymphs, Tessa and Christoph. I'm really glad that you both agreed to take on this task. Tessa, I'm in awe of you - you truly are wonder woman! Thanks for all your help, support and especially organisational skills leading up to the defence, and for the chats, coffees, play-dates and pregnant-ladies-lunches. Christoph, thanks for Friday-afternoon-chats, thesis-brainstorming sessions, footballeducation, lethal games, borrowed coffee, and for generally being a great office-mate.

I've been truly privileged to 'grow up' in the academic community at the Faculty of Arts and Social Sciences. I have had really wonderful colleagues, many of whom have also become my friends. Special thanks to Claudia for all the Coffeelovers dates, cookie-baking sessions, reading suggestions, the shared baby experience, and the many chats, both work-related and especially non-work related - the Ph.D. experience would not have been the same without you. Thanks to Eefje, Marijke, and Constance for coffees, cocktails and chats. Ruud and Rik have done a wonderful job putting up with me in the office, despite my motherly lectures about the importance of a good night's sleep and the dangers of unhealthy eating habits. Many colleagues have offered advice and support on research, teaching, and family matters, as well as some seriously entertaining conferences and capgroep dinners. For this I thank Aneta, Ashley, Christine Neuhold, Esther, Heidi, Karolina, Maria, Meike, Natalia, Patrick, Paul and Petar. Like me, Walter has stayed around after the MA European Studies - thanks for all the lunches. Thanks to my fellow migration-Ph.D.s Katharina, Sonja, Katie and Özge for migration seminars, conferences, trips to the Hague, and migration dinners.

Friends and family outside of university have provided much-needed distraction from the thesis. I want to thank my parents for making everything possible, and my sister for reminding me that there's more to life than work. My family in Denmark put us up every summer - Ruben and I look forward to these holidays for a long time. Thanks to Anita for girly evenings with chick flicks, hot chocolate with marshmallows, and holidays around Europe.

Last but by no means least, there's the home front. My office-mates know that I'm not one to hang around at work until late, and that's because I know who's waiting for me at home. Ruben, who would have thought that Erasmus in Vienna was the start of our little European family? The Maastricht-chapter is just the latest in our adventure together - I can't wait to find out where our next move takes us. I love you very much, and I couldn't have done this without your support. Many women who have children themselves told me that having a baby would change my priorities completely. And that's true: my first 'baby' (the Ph.D. thesis) has had to deal with having a lot less attention since Noah was born. Noah, mummy loves you more than you could ever imagine. This book is dedicated to you. 


\section{List of tables}

1.1 Member states' participation in the Mobility Partnerships up to 2009

2.1 The three levels of EU external policy

2.2 Determinants of size of win-sets

2.3 Explaining member states' decisions to participate in EU external migration policy

2.4 Member states' participation in migration missions in Eastern Europe

2.5 Member states awarded funding from the Thematic programme to carry out projects in third countries

2.6 Explaining third countries' decision to cooperate with the EU

2.7 Rationalist and constructivist explanations for member states' and third countries' preferences

3.1 Member states' participation in the Mobility Partnerships up to 2009

3.2 Case selection (member states)

3.3 Top 5 countries of origin of non-EU nationals present in 2007

3.4 Partner countries for Mobility Partnerships

3.5 Case selection (third countries)

3.6 Causal process observations at level III

3.7 Causal process observations at level I

3.8 Overview of fieldwork

3.9 Number of interviews conducted

4.1 Possible commitments to be made in a Mobility Partnership

4.2 Existing frameworks for cooperation between the EU and the third country concerned

4.3 Objectives of the Mobility Partnerships

4.4 Project proposals in the Mobility Partnerships to date

5.1 Number of migrants present in France in 2005

5.2 Application of the national identity explanation to the case studies

5.3 Application of the cost-benefit explanation to the case studies

6.1 Projects implemented in Senegal and Cape Verde under the Thematic Programme on Cooperation with Third Countries in the Areas of Migration and Asylum

6.2 Cape Verdeans legally resident in selected EU member states in 2010

6.3 Cape Verde compared to other ECOWAS countries

6.4 Senegalese legally resident in selected EU member states in 2010

7.1 Participation by Ireland and the UK in EU readmission agreements 


\section{List of figures}

1.1 Global migration governance structures

2.1 Links between the three levels in the game

2.2 Governance in the European Union

2.3 Agreement possible

2.4 No agreement possible

2.5 Agreement possible

2.6 No agreement possible

2.7 The link between the two interactions in a three-level game

2.8 Summary of the three-level model

3.1 Research design

3.2 Comparing the foreign populations of EU member states in 2007

3.3 Comparing rates of immigration to the EU member states in 2007

4.1 Timeline of decision-making process on Mobility Partnerships

4.2 Decision-making process leading up to the signature of Mobility Partnerships

4.3 Legal immigration flows to the EU 27 in 2007

4.4 Illegal immigration flows to the EU 27 in 2008

5.1 Decision-making on French EU policy

5.2 Decision-making on French migration policy

5.3 Decision-making on Austrian EU policy

5.4 Decision-making on Austrian migration policy

5.5 Decision-making on Dutch EU policy

5.6 Decision-making on Dutch migration policy

5.7 Immigrants from the new member states in Austria

5.8 EU-member state interaction (including the change in Dutch preference)

6.1 Countries of emigration for Cape Verdeans

6.2 Countries of emigration for Senegalese

6.3 The organisation of Cape Verdean migration policy

6.4 The organisation of Senegalese migration policy

6.5 EU-third country interaction

7.1 The three-level game model 


\title{
List of abbreviations
}

\author{
ACP African, Caribbean and Pacific Group of States \\ BNC Beoordeling Nieuwe Commissievoorstellen (Working group Evaluation New \\ Commission proposals) \\ BZÖ Bündnis Zukunft Österreich (Alliance for the Future of Austria) \\ CAMM Common Agenda on Migration and Mobility \\ CFP Common Fisheries Policy \\ CICI Comité Interministériel de Contrôle de l'Immigration (Inter-ministerial \\ Committee for Immigration Control) \\ Co-Co Coördinatie Commissie voor Europese Integratie- en Associatieproblemen \\ (Coordination Committee for European Integration and Association Issues) \\ DCI Development Cooperation Instrument \\ DG Directorate-General \\ DT\&V Dienst Terugkeer en Vertrek (Repatriation and Departure Service) \\ ECJ European Court of Justice \\ ECOWAS Economic Community of West African States \\ EEC European Economic Community \\ ENP European Neighbourhood Policy \\ EU European Union \\ FIDH International Federation for Human Rights \\ FPÖ Freiheitliche Partei Österreichs (Freedom Party of Austria) \\ GAERC General Affairs and External Relations Council \\ GAM Global Approach to Migration \\ GAMM Global Approach to Migration and Mobility \\ GCIM Global Commission on International Migration \\ GFMD Global Forum on Migration and Development \\ GDP Gross domestic product \\ GNI Gross national income \\ HLWG High Level Working Group on Asylum and Migration \\ IND Immigratie- en Naturalisatiedienst (Immigration and Naturalisation Service) \\ IOM International Organisation for Migration \\ JAIEX JHA-Relex Working Party \\ JHA Justice and Home Affairs \\ JLS Justice, liberté et sécurité (Justice, Freedom and Security) \\ MIDA Migration for Development in Africa \\ NGO Non-governmental organisation \\ OFII L'Office Français de l'Immigration et de l'Intégration (French Agency for \\ Immigration and Integration) \\ ÖVP Österreichische Volkspartei (Austrian People's Party) \\ PCA Partnership and Cooperation Agreement \\ PVV Partij voor de Vrijheid (Freedom Party)
}


SGAE Secrétariat Général des Affaires Européennes (Secretariat General for European Affairs)

SPÖ Sozialdemokratische Partei Österreichs (Social Democratic Party of Austria)

TFEU Treaty on the Functioning of the European Union

TRQN Temporary Return of Qualified Nationals

UK United Kingdom

UNHCR United Nations High Commissioner for Refugees

UMP Union pour un Mouvement Populaire (Union for a Popular Movement) 
Chapter 1

Introduction 


\subsection{International migration}

On the $29^{\text {th }}$ of September 2005, five African migrants died trying to cross from Morocco into the Spanish enclave of Ceuta. Hundreds of migrants had been living outside the enclave for up to two years, and eventually tried to storm the fences separating Ceuta from Morocco. Some migrants were either trampled to death or died climbing over the barbed wire fence. Hospital staff in a nearby Moroccan city also reported that bodies had been brought there with wounds from rubber bullets, which are used by Spanish border guards. Spain, however, accused the Moroccan border guards of firing on the migrants (Nash, 2005; Carling, 2007a, pp.23-24; de Haas, 2008, p.1312). These were not isolated incidents: in total in 2005, 12,000 migrants attempted to enter Melilla alone (Bosch and Haddad, 2007, p.7).

On the $5^{\text {th }}$ of October 2006, twenty African migrants drowned when their boat, bound for the Canary Islands, sank. In total, Spanish immigration officials estimated that 6,000 migrants died or went missing during 2006 attempting the sea crossing from the west coast of Africa to the Canary Islands. More than six times as many migrants attempted the crossing in 2006 compared to 2005. The boats used were flimsy, ramshackle structures and therefore often came into difficulty on the open seas. Most of the African migrants are unable to swim and therefore drown in a matter of seconds if their boat capsizes (BBC, 2006a; 2006b; Carling, 2007b, p.329).

The extensive media coverage of these events in 2005-2006 drew the attention of politicians and the public in Europe to international migration and its human costs. In particular, they highlighted two separate but related features of the migratory phenomenon: firstly, the extent of illegal immigration to Europe; and secondly the role played by third countries ${ }^{1}$ (for instance their border guards) in policing Europe's borders.

Developing countries' labour forces are increasing rapidly due to high birth rates. As a result, there are more workers than jobs and therefore widespread unemployment and underemployment. At the same time, economic differences between nation states are widening: "The world's gross domestic product (GDP) was $\$ 30$ trillion in 2000, making the average per capita income $\$ 5,000$ a year, but the range was from $\$ 100$ per person in Ethiopia to $\$ 38,000$ per person in Switzerland" (Martin et al., 2006, p.15). It is therefore not surprising that migrants will take huge risks to reach developed countries. Olesen (2002, p.141) estimates that emigration from a country will only begin to decline once a per capita income of $\$ 8,000$ is reached. Links with existing communities of migrants in Europe and conflict in the country of origin make it likely that future migration from Africa to Europe will increase rather than decrease (Carling, 2007a).

These various factors resulted in an exponential increase in the number of international migrants during the second half of the twentieth century. In 1965 there were an estimated 75 million international migrants worldwide; by 2000 , this number was estimated at 150 million, although the real number is likely to be much higher due to the prevalence of illegal migration (Castles and Miller, 2003, p.4). Most national immigration policies of European countries, however, aim to prevent or limit permanent immi-

\footnotetext{
1 'Third countries' are understood in this thesis to be non-EU countries
} 
gration, particularly of low-skilled migrants (Castles, 2006, p.744; Straubhaar, 2000, p.10). These developed welfare states would "go bankrupt overnight if literally everyone could reap [the] benefits" and they therefore reject mass immigration (Joppke, 1998, p.7). Immigration has also been an important element of public debate. Public opinion in developed countries is increasingly hostile to immigration, and many European countries have seen the emergence or growth of far-right political parties with an anti-immigration platform (Cornelius and Tsuda, 2004, p.19). Europe and the European Union (EU) are popularly referred to as 'Fortress Europe' due to the tendency towards restrictive immigration policies. Most of these policies, however, fail (Boswell, 2003; Cornelius and Tsuda, 2004). European countries may be able to prevent migrants from entering legally 'through the front door', but migratory flows are redirected to the 'side door' (asylum and family reunification) or the 'back door' (illegal immigration) (Straubhaar, 2000, p.11). Nation states are limited in their ability to apply a restrictive immigration policy, for instance by an activist judiciary which applies constitutional norms to protect immigrants (Joppke, 1998; Guiraudon, 2000). However, electorates continue to be concerned with preventing illegal migration (Betts, 2011, p.35).

Immigration is thus clearly an important political issue in European countries, and yet European governments have, over the past few years, come to realise that they alone cannot control immigration. They have therefore sought to cooperate with the countries of origin of migrants in order to prevent illegal immigration (Boswell, 2003). The EU has also developed cooperation with third countries on migration issues (see section 1.3). This 'external migration policy' of the EU is the subject of this thesis. Governing migration in this way brings together three sets of actors - the EU institutions, the EU member states, and the third countries - in a complex interaction. It is not always clear that these actors have the same interests (see section 1.4), so the question is how and why is EU external migration policy decided upon? The thesis develops a three-level game model to explain how and why decisions on EU external migration policy are made.

\subsection{International governance of migration}

As a result of the 'gap' between immigration policy objectives and outcomes (Cornelius and Tsuda, 2004), international migration has become a topic of global governance. Countries of destination (the developed countries) have objected to the introduction of a binding, UN-based system of multilateralism to regulate migration, but nevertheless want to influence the scope of international migration. Migration is therefore discussed in various international (non-binding) fora (Betts, 2011; Lavenex and Kunz, 2008), as illustrated in figure 1.1. These include the UN High-Level Dialogue on Migration and Development, the Global Commission on International Migration (GCIM), the Global Forum on Migration and Development (GFMD), and the Berne Initiative (Lavenex, 2011, p.7). International migration governance is also 'embedded' in numerous other areas of public international law, such as human rights law, humanitarian law, WTO 
law, maritime law and labour law (Betts, 2011). Numerous international organisations deal with migration, such as the International Organisation for Migration (IOM), the International Centre for Migration Policy Development (ICMPD) and the Organisation for Security and Cooperation in Europe (OSCE) (Geiger and Pécoud, 2010). Migration is reflected in aspects of the work of several other international organisations, such as the International Labour Organisation, the Office of the UN High Commissioner for Human Rights (UNHCR), the UN Population Fund, and the World Bank (Betts, 2011).

Migration is also increasingly the subject of trans-regional governance (ibid.). Developed countries, concerned to prevent illegal migration, seek "to find ways to exert direct and indirect extra-territorial control over migration from and among 'sending' states in the developing world" (p.29). One way in which this has been achieved is by fostering the creation of regional consultative processes (RCPs) to "facilitate the development of 'good practice' and to allow coordination of policies between states" (p.33). By 2001 IOM counted eleven (non-binding) RCPs dealing with migration (Castles and Miller, 2003, p.12). These include the Migration Dialogue for Southern Africa (part of the Southern African Development Community; SADC) and the Migration Dialogue for Western Africa (part of the Economic Community of West African States; ECOWAS) (Lavenex, 2011, p.16). These regions then become linked with European countries in a migration dialogue. One example is the EU-AU (European Union-African Union) Joint Declaration on Migration and Development (Betts, 2011, p.37).

At the national level of European countries, immigration has become an important issue of public and political debate. Before the onset of the economic crisis in 2008, immigration was seen by citizens of EU countries as one of the top issues facing their country, behind economic, health, and public safety issues (Eurobarometer, 2008a). Even after the onset of the crisis, immigration is still seen as a more important issue than pensions, terrorism and education (Eurobarometer, 2009). Economists point out that labour immigration has positive effects for a country, such as boosting productivity and growth, and contributing to innovation. However, ideas about the negative impacts of immigration are still marshalled in public debates (Boswell and Geddes, 2011, p.87). These ideas include the possibility that labour immigration leads to a downward pressure on the salaries of indigenous workers, and that some sectors such as domestic work and construction will be particularly affected because these types of workers compete with immigrants for jobs (pp.86-87). Some political parties have seized on these ideas. Particularly since the 1990 s, radical right-wing parties, propagating an anti-immigration message, have gained electoral success in Europe. Indeed, they have formed part of government coalitions in Austria, Denmark, Italy, the Netherlands and Norway (de Lange, 2008). It is thus hardly surprising that immigration, and particularly issues of border control, have become important topics for European governments. 

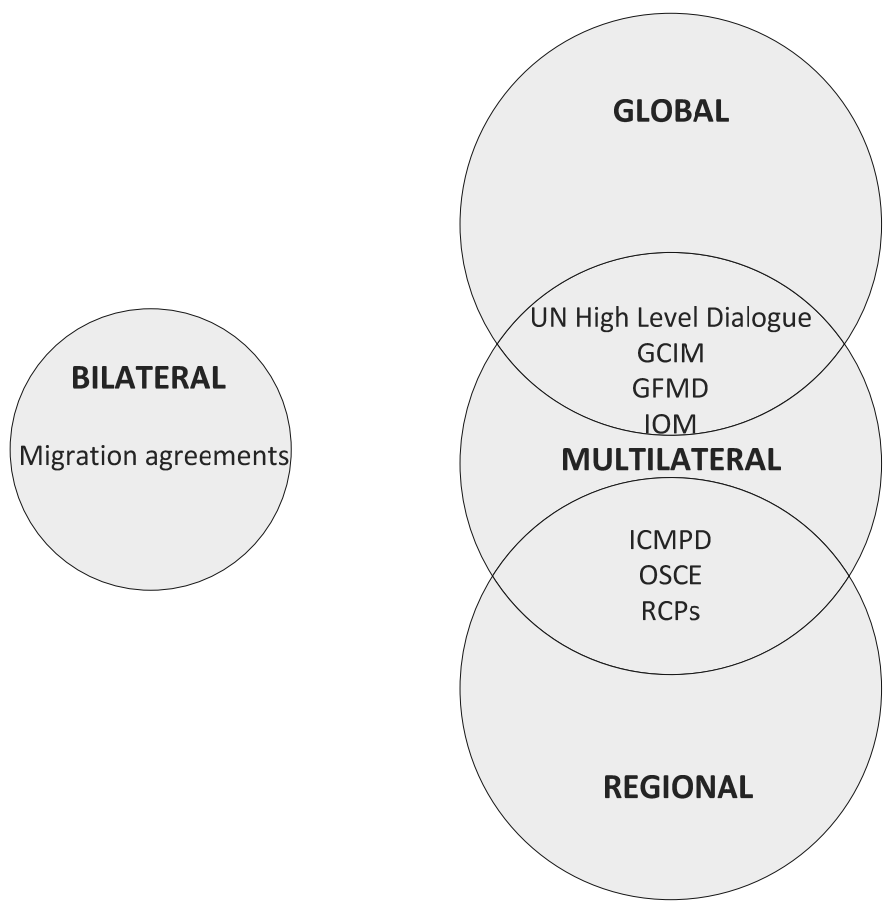

Figure 1.1: Global migration governance structures

European countries have therefore, alongside the regional processes outlined above, become involved in bilateral migration agreements with migrant-sending countries (Adepoju et al., 2010). Such partnerships generally "include agreements between governments to better regulate migration" (Migration DRC, 2008). The "most high profile bilateral partnerships have been Italy-Libya, France-Mali, France-Senegal, DenmarkKenya, and the UK-Tanzania" (Betts, 2011, p.37). Agreements cover illegal migration and/or legal migration. Nigeria, for instance, has signed bilateral agreements with multiple European countries on illegal migration: the agreement with Ireland concerns the readmission of illegal migrants; the agreements with Spain and the United Kingdom (UK) aim to prevent trafficking of human beings; and the agreement with Italy concerned capacity-building in the area of illegal migration, through the donation of equipment and goods by Italy to Nigeria (Adepoju et al., 2010, pp.49-50). Agreements on legal migration are often related to cooperation on illegal migration; Italy, for instance, granted Nigeria a quota for legal migration in 2002, in recognition of Nigerian cooperation on preventing illegal migration (p.53). France has long linked migration to development policy (which the government calls 'co-development', involving existing networks of migrants); with Mali, for instance, a Consultation on Migration was established in 2000, allowing for regular discussion on the integration of Malians in France and cooperative development projects in Malian regions affected by emigration (pp.63- 
64; Martin et al., 2006, p.136). This trend has not been limited to EU countries: in 2008, Switzerland created a legal basis for establishing migration partnerships with third countries. These partnerships, which can be either binding international treaties or nonbinding memoranda of understanding, are composed of projects or programmes on migration, covering topics such as voluntary return, reintegration of migrants, prevention of smuggling and trafficking of human beings, visa facilitation, capacity-building in partner countries, migration and development, and exchanges in the fields of education and training (Rittener et al., 2011).

The result of these regional and bilateral agreements is a patchwork of connections between different countries. Italy and Libya, for instance, are connected on migration through the EU's relationship with Libya, the EU-AU cooperation on migration, the $5+5$ dialogue (on migration in the Western Mediterranean), and the bilateral readmission agreement between Libya and Italy (Betts, 2011, p.30). These various migration agreements constitute an 'externalisation' of migration control, whereby control has shifted further away from the borders of European countries (this has also been termed 'remote control') (Lavenex, 2009a, p.334). European countries experience difficulties expelling migrants from their territory, so for a restrictive immigration policy to be effective it is better to prevent 'illegal' migrants from arriving on the territory in the first place (Guiraudon, 2000). For this, European countries rely to an ever greater extent on third countries to carry out border controls (Samers, 2004; Wunderlich, 2010).

\subsection{EU external migration policy}

Ever since its inception, citizens of the European Economic Community (EEC) (as the EU was then called) have had the right of free movement throughout the territory of the community. ${ }^{2}$ This was one of the 'four freedoms' (free movement of goods, capital, services and people) upon which the internal market should be based. This freedom has developed over time, most significantly with the Schengen Treaty. In 1985, the governments of Belgium, France, Germany, Luxembourg and the Netherlands agreed in this treaty to gradually abolish border controls between themselves. With the signing of the Treaty of Amsterdam in 1997, the Schengen Agreement was incorporated into EU law, and as of July 2013 the borderless Schengen area consists of 22 EU member states ${ }^{3}$ and 4 non-EU countries (Iceland, Liechtenstein, Norway and Switzerland).

The free movement of EU citizens has inevitably brought an EU dimension to migration policy. Writing in 1991, the Commission argued that "in a Community where there will no longer be passport checks at the internal borders, it is essential that this new freedom is not misused to bypass the legal/administrative system established to

\footnotetext{
2 This thesis is not concerned with this original 'internal' migration policy of the EU. While this has been relevant in bringing about an EU dimension to migration policy, this thesis understands 'migration policy' as addressing third country nationals (non-EU citizens).

${ }^{3}$ Austria, Belgium, Czech Republic, Denmark, Estonia, Finland, France, Germany, Greece, Hungary, Italy, Latvia, Lithuania, Luxembourg, Malta, Netherlands, Poland, Portugal, Slovakia, Slovenia, Spain and Sweden.
} 
control immigration" (Commission, 1991, p.4). In an EU with no internal border controls, member states may face disadvantages from the disparities between their immigration policies. A member state with a restrictive immigration policy may find that migrants enter the EU through a neighbouring member state, then cross an internal border with relative ease to take up illegal residence on the territory of the first member state (Straubhaar, 2000, p.13). There is therefore a rationale for a common EU migration policy.

The member states and the European institutions have been gradually constructing a common EU migration policy for some thirty years now (see e.g. Guiraudon, 2003; Lahav and Messina, 2005; Lavenex, 2009b; de Lobkowicz, 1994; Messina, 2007; Stetter, 2000; Walters, 2010). Building on intergovernmental cooperation in fora such as the Trevi Group and the Ad Hoc Immigration Group during the 1970s and 1980s, the Maastricht treaty designated migration and asylum as "matters of common interest" (article K.1). The Amsterdam Treaty formally delegated powers over asylum and migration to the EU level and the Lisbon Treaty extended the use of qualified majority voting and co-decision with the European Parliament. Since the European Council meeting in Tampere in 1999, the EU adopts 5-year programmes for justice and home affairs (JHA) policy: the Tampere programme for 1999-2004, the Hague Programme for 2005-2009, and the Stockholm Programme for 2010-2014. EU policy documents replicate the discourse of national immigration policies by focusing on the prevention of illegal migration and enhancing related measures such as border controls (see e.g. Bendel, 2007; Bouteillet-Paquet, 2003; Guiraudon, 2000; Haddad, 2008; Walters, 2010). Several documents refer to the 'fight against illegal immigration' (e.g. Commission, 2008a; 2006a; Council, 2003).

In recent years the 'external dimension' of EU migration policy has become increasingly emphasised (see e.g. Bosch and Haddad, 2007; Haddad, 2008; Lavenex and Uçarer, 2004; Sterkx, 2008). External migration policy can be defined as a policy whereby third countries are drawn in to agreements, information exchanges, cooperation mechanisms or negotiations with the EU on migration issues. In this way, "third countries ... take partial responsibility for managing migratory flows" (Rodier, 2006, p.6). The EU thereby "move[s] control of the borders beyond the borders themselves" (ibid.) by involving third countries in the control of immigration (see also Lavenex, 2006, p.330). In other words, migration policy is integrated into foreign policy (see e.g. Council, 2002a, p.10). This is different from internal migration policy, which is decided within the EU even if it impacts on third countries. So the requirements for obtaining a Schengen visa would be an instance of internal migration policy, because these requirements are determined within the EU. A visa facilitation agreement would be an instance of external migration policy, because such an agreement is signed by both the EU and the third country concerned. The Lisbon treaty provided a legal basis for EU external migration policy in article 78(2)g which states that measures shall be adopted on "partnership and cooperation with third countries for the purpose of managing inflows of people". 
This link between migration policy and foreign policy has long been made at the EU level - for instance, already in 1991 the Commission called for migration to be integrated into EU external policy (Commission, 1991). However, it was with the Tampere programme that the external dimension of EU migration policy began to gain in importance. The Tampere programme (1999-2004) called for a common EU asylum and migration policy to be based on, among other elements, partnership with countries of origin (Council, 1999a). In a 2001 communication, the Commission acknowledged the importance of linking migration policy and foreign policy:

bearing in mind that any action to counter irregular migratory flows should take place as close as possible to the irregular migrants concerned, the EU should promote actions in, and support actions of, countries of origin and transit . . . To that end, migration issues should be integrated in the existing partnerships, which are the general framework of our relations with third countries (Commission, 2001a, pp.3-8).

In order for migration policies to be effective, the Commission emphasised that it is necessary to cooperate with third countries (Commission, 2006b, p.4). To support this policy discourse, an EU fund for migration-related action (budget line B7-667) was created in 2001 (Haddad, 2008, p.192). This was replaced by the Aeneas programme (2004-2006) and afterwards by the Thematic Programme for Cooperation with Third Countries in the areas of Migration and Asylum (since 2007). In the wake of events in Ceuta and Melilla, the European Council informal meeting at Hampton Court in October 2005 underscored again that responses to illegal migration must be based on cooperation with countries of origin (Bosch and Haddad, 2007, p.8). In December 2005, the Council (following a Commission communication) adopted the Global Approach to Migration (GAM). One of the pillars of the approach was to be dialogue with African countries (Council, 2005a), given the events that year in Ceuta and Melilla (Weinar, 2011, p.5). By 2006, the Commission declared that "migration is at the heart of the political debate in Europe and is one of the strategic priorities in the external relations of the Union" (Commission, 2006b, p.3).

The tools of the EU's external migration policy have been multi-faceted, including both legally binding and non-legally binding measures (see Poli, 2012). Arguably the first tools of external migration policy were the action plans produced by the High Level Working Group on Asylum and Migration (HLWG). These action plans concerned the migration situation in selected third countries (Sterkx, 2008). Clauses on migration have been included in broader international agreements, such as Stabilisation and Association Agreements, Association Agreements, and Partnership and Cooperation Agreements (PCAs). The Actions Plans on JHA issues concluded with neighbouring countries under the European Neighbourhood Policy (ENP) have also addressed migration. Cooperation with third countries has also been operational in nature, such as capacity-building missions to train third countries' border guards, and information campaigns in third countries to warn migrants of the dangers of illegal migration (Boswell, 2003, pp.626-627; Sterkx, 2008, p.123). 
Next to international cooperation on JHA more broadly, the EU has also concluded agreements specifically related to migration. The most important examples of such agreements are readmission agreements and visa facilitation agreements. Readmission agreements were the original cornerstone of EU external migration policy, and are still the only tool explicitly regulated by law (Hernández i Sagrera and Korneev, 2012, p.4). Article 79(3) TFEU gives the EU the competence to "conclude agreements with third countries for the readmission to their countries of origin or provenance of third-country nationals who do not or who no longer fulfil the conditions for entry, presence or residence in the territory of one of the Member States”. In 2002 the Council recommended criteria to be taken into consideration when selecting third countries for readmission agreements: the migratory pressure from the country; countries with an association or cooperation agreement; neighbouring countries; the potential for added value resulting from a readmission agreement; and the geographical balance between countries and regions of origin and transit (Council, 2002b). Significantly, EU readmission agreements go beyond the requirements of international law by obligating signatories also to take back third-country nationals or stateless persons if these transited through their territory on their way to the EU (Trauner and Kruse, 2008a; Coleman, 2009; Panizzon, 2012).

Article 77(2(a)) TFEU gives the EU the competence to set "the common policy on visas and other short-stay residence permits". Regulation 539/2001 sets out lists of those countries whose nationals do and do not require short-stay visas to enter the EU. ${ }^{4}$ In the Hague programme (2005-2009), the European Council invited "the Council and the Commission to examine . . . whether in the context of the EC readmission policy it would be opportune to facilitate, on a case by case basis, the issuance of short-stay visas to third-country nationals" (Council, 2004a, p.18). Visa facilitation agreements can cap the price of a visa, set a deadline within which member states must issue a visa to citizens of the third country, and facilitate the issuance of multiple-entry visas to certain groups in society (e.g. members of parliament) (Trauner and Kruse, 2008a).

These two instruments have been linked: several policy documents by the Commission and Council make clear that third countries will only be offered a visa facilitation agreement once they have signed a readmission agreement (e.g. Council, 2005b, p.3). However, member states have been reluctant to "close a door on irregular immigration only to open a window on new potential irregular flows of visa overstayers, already the largest category of irregular migrants in the EU" (Roig and Huddleston, 2007, p.377). Therefore the link between readmission and visa facilitation agreements is not automatic: 10 of 18 readmission agreements in place by February 2011 had been linked to a visa facilitation agreement (Commission, 2011c).

In the mid-2000s the policy discourse on migration policy and foreign policy was complemented by reference to development policy. In 2003 the Council declared that "an effective and coherent development policy is an essential part of an effective migration policy" (Council, 2003, p.4). A 2005 communication from the Commission high-

\footnotetext{
${ }^{4}$ Council Regulation (EC) No. 539/2001 of 15 March 2001
} 
lighted the main policy areas which should be incorporated into migration policy in order to contribute to development: facilitating migrants' financial transfers to their countries of origin; better links between countries of origin and their emigrant communities; encouraging migrants to return (temporarily) to their countries of origin to foster the transfer of skills to developing countries; and preventing the emigration from developing countries of skills/professions that are in short supply there (Commission, 2005a). Migration is one of the policy areas covered by the EU's reports on policy coherence for development (e.g. Commission, 2009a). The thematic programme for cooperation with third countries in the areas of migration and asylum, which focuses on capacity-building in third countries, is funded through the Development Cooperation Instrument (DCI) (Commission, 2011a).

Clearly much has changed in EU migration policy - from the beginnings of an internal migration policy for EU citizens, to the construction of a common migration and asylum policy, and most recently linking this policy area with foreign policy and development policy.

\subsection{Research question}

The previous section outlined the incremental development of an external migration policy at the EU level. The member states have gradually allowed the EU institutions to become involved in migration policy more generally, and together the member states (in the Council) and the Commission have agreed that it is important for the EU to cooperate with third countries if its migration policy is to be effective. This introduces yet another set of actors to the governance of migration, namely the third countries with which such cooperation should take place. EU external migration policy thus incorporates several different actors. This section presents two puzzles regarding the role and interests of these actors in participating in such policies. These puzzles guide the overarching research question of this thesis (see sub-section 1.4.3).

\subsubsection{First puzzle: the member states and the EU institutions}

External migration policy sits at the crossroads of migration policy and foreign policy. These are two policy areas which are politically sensitive and important to a state's sovereignty. This raises questions about the process of decision-making between the various EU institutions and the member states which leads to the adoption of measures in external migration policy.

Despite the incremental development of a common migration policy (as outlined above), there has been some tension within the EU (between the EU institutions and the member states) concerning the scope and content of such a policy. Although the Treaty of Rome provided for the free movement of EEC citizens, agreement on measures related to immigration from outside of the EU has been much more difficult (Geddes, 2001). Particularly control over who enters a country's territory "is often seen as one of the last bastions of national sovereignty" (Lavenex, 2011, p.2). Some legislation on 
legal migration has been passed at the EU level, concerning for example the admission of highly-skilled workers, students and researchers, and the rights of long-term resident third-country nationals in the EU including their right to family reunification. However, labour immigration has been a particularly contentious issue. In 2001 the Commission proposed a directive on the admission of third country nationals (of all skill levels) but this was withdrawn in 2006 due to opposition in the Council. In 2007 the Commission proposed a new directive on a single permit for third country nationals wishing to work and reside in the EU. The directive was finally agreed after two readings in December 2011 (directive 2011/98/EU), although it is still "without prejudice to the Member States' powers concerning the admission of third-country nationals to their labour markets" (article 1(b)). This reluctance of the member states to cede control to the EU level on labour migration has been codified in the treaties: article 79 (5) TFEU states that "this Article shall not affect the right of Member States to determine volumes of admission of third-country nationals coming from third countries to their territory in order to seek work".

Foreign policy is often said to be at the core of national identity and national sovereignty. EU member states have, over the years, come to conduct a significant proportion of their foreign policy objectives through the EU context (Manners and Whitman, 2000a, p.243) and some scholars argue that a 'coordination reflex' has emerged amongst diplomats of EU member states, implying that working patterns have changed as a result of EU membership (Nuttall, 1992). As evidence, William Wallace (2005, p.454) notes that EU member states take a common line on more than $90 \%$ of votes taken in international organisations. However, foreign policy ultimately remains the preserve of national sovereignty (Featherstone, 2003, p.11). Member states have remained reluctant "to submit their diplomacy to the strait-jacket of EU decision-making . . Individual states have maintained distinct national foreign policies" (Tonra and Christiansen, 2004, p.1). In many cases the member states simply lack the political will to agree a common EU approach to an issue or a region, preferring instead to prioritise their national interests (Cameron, 2003, p.124; Wagner, 2003, p.589). Member states have privileged relationships with different third countries, depending on their own historical, geographical or linguistic situation. It is therefore not surprising that their foreign policy priorities differ. The most spectacular example of the EU's foreign policy falling apart due to different national interests was the disagreement over the war in Iraq in 2003.

In external migration policy, migration policy concerns meet foreign policy concerns. Given the sensitivities involved in these two policy areas, it might be expected that no progress can be made at the EU level on external migration policy. The combination of different migration policies and different foreign policy interests of the member states will make agreement within the EU impossible. And yet some measures have been agreed. An external borders agency (Frontex) has been established to coordinate operational cooperation between the member states. The Commission concludes EU readmission and visa facilitation agreements with third countries, based on negotiating mandates issued by the member states in the Council. Several EU policy documents 
highlight the complementarity between EU and member state actions in the area of migration (e.g. Council, 2005a, p.9). These are tentative steps towards a common external migration policy, and EU policy documents continue to emphasise that actions will be taken according to the division of competences between the EU and its member states. In the Commission's 2011 communication on the Global Approach to Migration and Mobility (GAMM), for instance, mobility from partner countries is to be encouraged whilst "fully respecting Member States' competence to manage their labour markets" (Commission, 2011b, p.12).

This raises questions about the governance of EU external migration policy: when is a common policy possible? Under which circumstances do member states accept measures to be taken at the EU level? When are the EU institutions able to play a role, and when are they side-lined?

\subsubsection{Second puzzle: cooperation between third countries and the EU}

Cooperation with third countries has been emphasised as a central aspect of EU migration policy. Cooperation with third countries has obvious benefits for EU member states: "it reduces the burden of control at their immediate borders and increases the chances of curtailing unwanted inflows before they reach the common territory" (Lavenex, 2006, p.337). Once a migrant reaches the territory of an EU member state there are legal and constitutional constraints in place which makes their removal difficult. From a migration control point of view, it is therefore preferable to prevent their entry in the first place (p.338), by cooperating with the countries of origin of these migrants. However, in many cases the interests of these third countries on migration issues are very different to those of the EU and its member states. Whereas the EU is primarily concerned with the prevention of illegal migration, "sub-Saharan African countries are not necessarily interested in curbing the migration of their own citizens and are not interested in cooperation on readmission of non-nationals, fearing the impact it may have on their capacity to deal with migration flows" (Weinar, 2011, p.71; cf. Coleman, 2009; Lavenex, 2006). Readmission is costly for the readmitting state: "repatriation nearly always constitutes the loss of vital foreign currency [in remittances] . . . the return of émigrés regularly puts further pressure on already-saturated labour markets . . . [and] reintegration can pose significant social challenges where deportees have engaged in criminal or 'subversive' political activity abroad or where migrants return with only a rudimentary knowledge of their 'native' language and culture" (Ellermann, 2008, p.171). Cooperating with the EU in preventing their citizens from moving affects the sovereignty of these third countries and is unpopular with the local populations (Wunderlich, 2010, p.251). Third countries are particularly opposed to the obligation contained in EU readmission agreements to readmit also stateless persons and other nationals that have transited through their territory. Opposition to this clause has caused negotiations on readmission agreements with Turkey and Morocco, in particular, to drag on (Panizzon, 2012, p.117). The Commission has recommended that this obligation should be removed in order to ease the process of negotiation with third countries 
(Commission, 2011c), but the member states in the Council have insisted that this clause must be maintained (Council, 2011a; Council, 2004a; Coleman, 2009, p.166). ${ }^{5}$

The Commission recognises that it is, therefore, necessary to offer third countries an incentive to cooperate with the EU and to secure in particular the conclusion of readmission agreements (e.g. Commission, 2011c; 2002a; 2002b). The problem is that the incentives on offer in return for cooperation are not very significant - generally only some funding and the prospect of a "more favourable international reputation" (Ellermann, 2008, p.171). Signing a readmission agreement is no guarantee that a third country will be offered a visa facilitation agreement (Council, 2005b). Indeed, the "readmission-relevant ACP [African, Caribbean and Pacific] states currently do not fully meet the criteria and/or standards that would allow linking readmission agreements with visas" (Klavert and van Seters, 2012, p.3). The EU also lacks the competence over immigration and labour migration policy to offer such incentives in return for signing a readmission agreement (Panizzon, 2012, p.119). Ellermann (2008, p.171; cf. Martin et al., 2006, p.123) argues that such incentives are anyway not adequate and that more concrete benefits, such as the prospect of EU membership, are required. EU membership is, however, clearly not on offer to all third countries.

This raises questions about the external governance of migration policy: under which circumstances do third countries choose to cooperate with the EU on migration policy? Given that their interests are very different from the EU, what role are they able to play in the policy-making process?

\subsubsection{Research question}

The overarching research question of this research is:

How does the interaction between EU institutions, member states and third countries shape the governance of the EU's external migration policy?

This research question is divided into four sub-questions:

- What was the role of the EU institutions and the member states in the negotiation of the Mobility Partnerships? (puzzle 1)

- What implications does this have for the form of the partnerships? (puzzle 1)

- Why do some member states choose to participate in the Mobility Partnerships while others do not? (puzzle 1)

- Why do third countries choose to join a Mobility Partnership? (puzzle 2)

The study thus brings together the two puzzles of decision-making within the EU (between the EU institutions and the member states) and between the EU and third countries. Chapter 2 argues that, in order to understand how EU external migration policy is made, it is necessary to conceptualise the process of decision-making as a three-level game. The decision-making process is a three-level game because three groups of actors are involved: the member states; the EU institutions; and the third countries. However, simply indicating the existence of these three different levels of actors is not adequate

\footnotetext{
${ }^{5}$ Despite the fact that varying use is made of this clause by member states: some member states only ever return migrants to their country of origin (Klavert and van Seters, 2012, p.2).
} 
for understanding policy outcomes: it is necessary to understand how the three levels are connected and what the conditions are for agreements to be reached. Within this three-level game, the focus is on the two sets of interactions involving the EU: firstly between the member states and the EU institutions, and secondly between the EU and the third country. These two interactions are linked, as the outcome of the first interaction becomes the subject of negotiation in the second interaction. This does not mean, however, that the interaction between EU member states and third countries is irrelevant. It will be shown that this interaction can affect third countries' decisions on whether or not to cooperate with the EU on migration issues (chapter 6). However, given that the thesis attempts to account for the outcomes of $E U$ external migration policy, the EU-member state and EU-third country interactions structure the empirical chapters.

The following section gives a brief overview of the research conducted on EU migration policy so far, in order to situate this research in the body of literature. It shows that scholars have tended to focus either on interactions between the EU institutions and the member states, or on interactions between the EU and third countries. To date, these levels of analysis have not been combined. And yet, without understanding how the different interactions within the process of decision-making are linked, it will not be possible to understand fully how or why the EU cooperates with third countries on migration issues.

\subsection{Research on EU migration policy}

A growing body of scholarship deals with the governance of the EU's migration policy. This scholarship can be divided according to the puzzles presented above: contributions concern either the 'internal' or 'external' dimension of decision-making.

Many of the contributions on the internal governance of EU migration policy outline the historical development of this policy area and the roles of the member states and EU institutions in the policy-making process (e.g. Geddes, 2003; Guiraudon, 2003; Luedtke, 2006; Menz, 2011; Papagianni, 2006; Walters, 2010). Generally, authors conclude that the Commission and European Parliament have gained increased competence over time (e.g. Papagianni, 2006; Uçarer, 2001). Despite this extension of competences of the EU institutions, "national representatives have maintained strong control over the policy process" (Schain, 2009, p.101). For this reason, several authors examine member states' preferences on EU migration policy. Guiraudon (2000) argues that member states' governments engage in 'venue-shopping': in other words, they choose the policy venue most suitable to achieve their policy objectives. The EU level is 'used' to achieve a more restrictive policy than that which would be possible at the national level (due to constitutional protections for migrants, enforced by domestic courts and advocated by pressure groups). Member states may also push for the inclusion in EU law of provisions that allow them some room for manoeuvre, such as the setting of only minimum standards. Alternatively, member states may attempt to maintain control over migration 
policy by exporting their vision of migration law to the EU level (Barbou des Places and Oger, 2005).

In terms of policy content, EU migration policy is often said to be 'restrictive', favouring controls on immigration and low minimum standards for migrants' rights (e.g. Bendel, 2005; Huysmans, 2000; Schain, 2010; 2009). Readmission agreements, for example, have been interpreted as an attempt by the member states to transfer their responsibility for treating asylum requests to countries outside the EU, often with lower levels of protection than that granted by EU member states (Bouteillet-Paquet, 2003, p.360). Several authors argue that restrictive policies are a result of the constellation of decision-making in the EU: officials from interior ministries dominate the Council working groups, so that the Council has a rather restrictive focus. Both the Commission and European Parliament favour a more liberal policy, but the Council only approves policy proposals which are restrictive (Schain, 2009; Barbou des Places and Oger, 2005; Lavenex, 2006). In truth, the picture is somewhat more nuanced. Servent (2010) argues that the European Parliament, despite its image as pro-migrants' rights, deliberately did not push through a liberal policy on the returns directive. The reason for this was the desire for the Parliament to prove itself as a responsible partner of the Council in the codecision legislative procedure. The Parliament is often assumed to have an integrationist stance on most policy issues, yet Lahav and Messina (2005) find that support amongst MEPs for the communitarisation of migration policy has actually decreased. The Commission is also not uniformly liberal: Lavenex and Kunz (2008, p.443) argue that the then-Directorate General (DG) JLS (Justice, Freedom and Security) tended to align with the interior ministers in the Council. DGs Relex (External Relations) and Development, on the other hand, aim to prevent the use of development funding for migration purposes (Boswell, 2003, p.626). Some scholars also dispute the commonly-held notion that EU migration policy is becoming 'securitised': Boswell (2007) shows that the 9/11 terrorist attacks did not lead to a link being made between terrorism and immigration in policy discourses in Europe.

The literature on the external dimension of EU migration policy focuses on two main aspects: (i) the nature of external migration policy and the decision-making process that produces such policies (though without considering member states' domestic preferences), and (ii) case studies of particular (groups of) third countries or particular instruments of the EU's external migration policy.

Chou (2006) defines two approaches to EU external migration policy: a 'comprehensive' approach and a 'coercive' approach. ${ }^{6}$ A comprehensive approach to migration "takes into consideration the needs of all three parties involved (EU member states, sending countries and the migrants) and attempts to reach a balanced distribution of risks and benefits among all three" (p.2). A coercive approach, on the other hand, "uses development aid or related incentives in exchange for third countries' cooperation in achieving EU migration objectives, such as the tackling of irregular migration" (ibid.). Chou argues that the coercive approach is favoured by the EU, due to the role of the

\footnotetext{
${ }^{6}$ In another contribution the distinction is between 'repressive' and 'progressive' measures (Chou, 2009a).
} 
different actors in the decision-making process on migration policy. She highlights the following factors: migration policy remains a sensitive issue for the member states, so they play a significant role in the production of policy proposals by the Commission; unanimous voting in the Council results in security-driven policies favoured by the member states; and officials of national interior ministries dominate the decisionmaking process through the JHA Council and the HLWG (pp.15-19; cf. Chou, 2009a; Lavenex and Kunz, 2008). However, she treats 'the member states' as a group, rather than separate entities that may have different preferences. Boswell (2008; cf. Sterkx, 2008; Lavenex and Kunz, 2008) examines the Commission and shows that the different DGs in the Commission have had very different preferences on the external dimension of EU migration policy: DG (Directorate-General) JLS was quick to adopt the new policy agenda, whereas DGs Relex and Development were much more reticent. Louis Michel, the Commissioner for Development from 2004 to 2009, had a liberal view of migration and favoured mobility of all people. This is in stark contrast to the preferences of DG JLS and the member states in the Council (Boswell, 2008, p.505).

The EU's external migration policy differs depending on the third countries concerned. Uçarer and Lavenex (2002) define four circles of countries, ranging from those closest to the EU to those furthest away: Western European non-EU countries; candidate countries for EU membership; the Mediterranean and Balkan countries; and all other countries that have concluded agreements with the EU that incorporate migration. Some academic contributions consist of case studies of particular third countries and their migration relations with the EU. Kruse (2006) examines the impact of the EU's readmission policy on Albania. Despite concerns of the Albanian government about the scope of the agreement, the long-term EU membership perspective was an important factor which eased the negotiations. Betts and Milner (2007) show that financial inducement may not be sufficient to secure African countries' cooperation on asylum issues. Coleman (2009) describes the process of readmission negotiations with Morocco, Pakistan, Russia, Sri Lanka, Hong Kong, Macao, Ukraine, Albania, Algeria, China, Turkey, the Western Balkans and Moldova. He identifies different strategies by the third countries to counter a readmission agreement which they are not keen to accept. Algeria, for instance, has managed to delay the opening of readmission negotiations. Ukraine and Russia monitor each other's negotiations with the EU in order to insist on the same compromises (pp.184-185).

This overview of the literature on EU migration policy clearly shows a cleavage: the literature on the internal and external dimension of decision-making is kept separate, rather than being analysed together. The internal governance literature examines the member states and the EU institutions, but does not include third countries' interests and preferences. The external governance literature which considers the EU institutions tends to black-box the third countries, and that which considers the interests of third countries is not nuanced about member states' interests. Generally, most contributions concern policy-making at the EU level, focusing on the EU institutions and their interactions with either the member states or third countries. No contribution to date attempts to 'open the black box' by examining both member states' and third countries' 
preferences, and linking them through the EU level. And yet EU external migration policy is a story of three sets of actors: the EU institutions, the member states, and the third countries. The interests and role of all these actors must be considered for a complete understanding of the policy-making process. An understanding of the interaction between the EU institutions and the member states might explain the policy content and why member states favour/do not favour such a policy, but it will not explain why third countries choose to cooperate with the EU or not. An understanding of the interaction between the EU and the third countries might explain why cooperation is successful or unsuccessful, but it obscures the fact that member states play a central role in shaping the policy that is the subject of this cooperation.

This is a young body of literature, due to the fact that the EU has only recently gained extensive competences in migration policy. Scholars have therefore taken the first steps towards mapping the governance of EU migration policy. They have identified the three levels of actors that are important. This research contributes to this body of literature by taking the next logical step: conceptualising how these different actors are linked in the decision-making procedure, in order to explain policy outcomes. Chapter 2 argues that this process should be understood as a three-level game. The following section introduces the policy instrument which will form the object of the study.

\subsection{Case study: the Mobility Partnerships}

This thesis concerns a particular element of the EU's external migration policy, namely the Mobility Partnerships in the time period 2006-2009. The partnerships are one of the tools of the GAM, adopted in 2005. This section begins by briefly outlining the nature of the other tools of the Global Approach, before explaining the concept of the Mobility Partnerships.

The tools of the Global Approach include migration missions, cooperation platforms on migration and development, and migration profiles (Council, 2009b, p.61). Migration missions and cooperation platforms both aim to foster cooperation between the EU (Commission and member states) and the authorities of non-EU countries. Since 2006, the EU has conducted approximately four migration missions per year to third countries (Weinar, 2011, p.10). By 2011, migration missions had been conducted in 10 Sub-Saharan African countries ${ }^{7}$ and 5 Eastern European countries ${ }^{8}$ (Commission, 2011d). The aim of migration missions is to "explore the potential of establishing or deepening dialogue and practical cooperation on migration and mobility with third countries" (Council, 2012a, p.3). A migration mission takes the form of an initial meeting between EU and senior government representatives from the third countries concerned. This is followed by a larger meeting with all government stakeholders, as well as a separate meeting with non-governmental organisations (NGOs) (Council, 2007a, p.6). Past migration missions have been co-chaired by the Commission and the Presi-

\footnotetext{
${ }^{7}$ Cameroon, Cape Verde, Ethiopia, Ghana, Kenya, Mauritania, Nigeria, Senegal, South Africa and Tanzania.

${ }^{8}$ Armenia, Azerbaijan, Belarus, Georgia, and Ukraine.
} 
dency of the Council, and have included representatives of interested member states, up to a maximum of 12 participants for practical reasons (Council, 2012a, p.6). Following a mission, a joint report is sent to the HLWG for discussion, and the local EU delegation and Presidency of the Council organise a follow-up meeting and write a work plan, which is also sent to the HLWG (Council, 2008a, 3).

Migration missions may result in the establishment of a cooperation platform on migration and development (Council, 2007a, p.10); this has been the case in Ethiopia and South Africa (Commission, 2009b, p.3). The idea of the cooperation platform is "to strengthen cooperation on migration between actors in a country or region and to intervene more effectively in the best interests of all" (Commission, 2011d). The cooperation platform therefore institutionalises the dialogue established by the migration mission, and in addition may be a regional initiative between the EU and more than one third country. Platforms may also involve international organisations (Council, 2008a, p.6). Cooperation platforms also supervise the implementation of the Mobility Partnerships a cooperation platform for the Mobility Partnership with Moldova was set up in 2008 (Commission, 2009c, p.7).

Migration profiles provide information on the migratory situation in a third country (Bosch and Haddad, 2007) and thus form the basis for the dialogue which may be established by a migration mission or cooperation platform (Commission, 2011d). Migration profiles are more unilateral instruments as they are not explicitly based on dialogue with partner countries' governments. Other tools have also been used in migration cooperation with third countries. In Mali, for instance, the EU has established a Migration Information and Management Centre which provides information to Malians wanting to emigrate or return from abroad. The experiences acquired with the centre in Mali should be used to develop Migration and Mobility Resource Centres in other countries (Commission, 2011b, p.14).

The Mobility Partnerships were introduced in 2007 and aim to "identify novel approaches to improve the management of legal movements of people between the EU and third countries" (Commission, 2007a, p.2). They will "take into account the current state of the EU's relations with the third country concerned as well as the general approach towards it in EU external relations" (ibid.). Mobility Partnerships therefore clearly belong to the external dimension of EU migration policy. They will be negotiated "with third countries that have committed themselves to cooperating actively with the EU on management of migration flows, including by fighting against illegal migration, and that are interested in securing better access to EU territory for their citizens" (p.3). In other words, legal migration opportunities will be offered to third countries in return for their cooperation on preventing illegal migration. The communication highlights that Mobility Partnerships will be tailored to suit each partner country, and contents will therefore depend on the specifics of the country concerned and the EU's relations with that country. However, it does give some ideas as to the commitments which might be expected from partner countries, including a commitment to readmit both their own nationals and stateless persons; initiatives to discourage illegal migration; efforts to improve border control, including cooperation with EU member states; measures to 
combat human trafficking; and commitments to improve domestic social and economic conditions (p.4). Commitments by the EU and its member states will also depend on the specific circumstances, but may fall into four categories: improved opportunities for legal migration for nationals of the third country, for instance by facilitating labour market access; financial or technical assistance to help third countries develop their capacity to manage migration; measures to address the risk of brain drain and promote circular migration; and improvement of the procedures for issuing visas to nationals of the third country, for instance extending opening hours in member states' embassies (pp.5-8).

In terms of internal governance, the Commission communication acknowledges that Mobility Partnerships "will necessarily have a complex legal nature, as they will involve a series of components, some of which will fall in the Community's remit, and others in the Member States"' (p.3). The communication refers to the participation of 'interested member states', indicating that the Mobility Partnerships will not be compulsory for member states to join. Those member states that do want to participate will bring particular dimensions to each partnership "influenced by their own legal frameworks (in particular on the admission of third country nationals) and by political constraints and priorities" (p.4). In other words, the precise content of the Mobility Partnerships will depend on what the participating member states are willing and able to offer.

The Mobility Partnerships are therefore a perfect test-case for understanding the puzzles of EU external migration policy. They clearly belong to the external dimension of EU migration policy, drawing third countries into a partnership arrangement. In December 2007 the General Affairs and External Relations Council (GAERC) invited the Commission "in close liaison with Member States and/or the Presidency, in order to ensure a close involvement of the Council, to open dialogue with Moldova and Cape Verde, with a view to launching pilot mobility partnerships" (Council, 2007b, p.5). In May 2008, Mobility Partnerships were agreed with Moldova and Cape Verde (although they were not signed until September 2008) (Council, 2008b; 2008c). In June 2008 the JHA Council further invited the Commission, "in close liaison with Member States and the Presidency, to take forward exploratory talks with Georgia and Senegal and to open dialogue with these countries, with a view to launching additional pilot Mobility Partnerships" (Council, 2008d, p.4). Although negotiations with Senegal were unsuccessful, a Mobility Partnership with Georgia was signed in November 2009 (Council, 2009a). Negotiations for Mobility Partnerships are currently underway with Ghana (Commission, 2010a). A partnership was signed with Armenia in 2011 (Council, 2011b). As of June 2012 negotiations were pending with Tunisia (Council, 2012b, p.13) and about to start with Azerbaijan (Commission, 2012a). Egypt, Jordan and Libya are also being considered for Mobility Partnerships (Commission, 2011e; Council, 2012c). A Mobility Partnership with Morocco was signed in June 2013 (Council, 2013). How and why do these third countries choose to participate in the Mobility Partnerships? What role do they play in the negotiations leading up to the signature of a partnership?

At the same time the voluntary nature of the partnerships also makes it possible to examine member states' motivations for taking part. Table 1.1 shows which member 
states take part in the three Mobility Partnerships signed by the end of 2009. It shows that only one member state (France) participated in all the partnerships, most member states participated in one or two partnerships, and four member states (Austria, Finland, Ireland and Malta) chose not to participate in any partnerships. Why is this the case? How did member states' preferences on the Mobility Partnerships influence the role of the EU institutions such as the Commission? What did the policy-making process underlying the Mobility Partnerships look like?

Table 1.1: Member states' participation in the Mobility Partnerships up to 2009.

\begin{tabular}{|c|c|c|c|}
\hline Member state & MP Moldova (2008) & MP Cape Verde (2008) & MP Georgia (2009) \\
\hline \multicolumn{4}{|l|}{ Austria } \\
\hline Belgium & & & $\mathrm{X}$ \\
\hline Bulgaria & $\mathrm{X}$ & & $\mathrm{X}$ \\
\hline Cyprus & $\mathrm{X}$ & & \\
\hline Czech Republic & $\mathrm{X}$ & & $\mathrm{X}$ \\
\hline Denmark & & & $\mathrm{X}$ \\
\hline Estonia & & & $\mathrm{X}$ \\
\hline \multicolumn{4}{|l|}{ Finland } \\
\hline France & $\mathrm{X}$ & $\mathrm{X}$ & $\mathrm{X}$ \\
\hline Germany & $\mathrm{X}$ & & $\mathrm{X}$ \\
\hline Greece & $\mathrm{X}$ & & $\mathrm{X}$ \\
\hline Hungary & $\mathrm{X}$ & & \\
\hline \multicolumn{4}{|l|}{ Ireland } \\
\hline Italy & $\mathrm{X}$ & & $\mathrm{X}$ \\
\hline Latvia & & & $\mathrm{X}$ \\
\hline Lithuania & $\mathrm{X}$ & & $\mathrm{X}$ \\
\hline Luxembourg & & $\mathrm{x}$ & \\
\hline \multicolumn{4}{|l|}{ Malta } \\
\hline Netherlands & & $\mathrm{X}^{9}$ & $\mathrm{X}$ \\
\hline Poland & $\mathrm{X}$ & & $\mathrm{X}$ \\
\hline Portugal & $\mathrm{X}$ & $\mathrm{X}$ & \\
\hline Romania & $\mathrm{X}$ & & $\mathrm{X}$ \\
\hline Slovakia & $\mathrm{X}$ & & \\
\hline Slovenia & $\mathrm{X}$ & & \\
\hline Spain & & $\mathrm{X}$ & \\
\hline Sweden & $\mathrm{X}$ & & $\mathrm{X}$ \\
\hline UK & & & $\mathrm{X}$ \\
\hline
\end{tabular}

\footnotetext{
${ }^{9}$ The Netherlands did not participate in the Mobility Partnership with Cape Verde from the outset and therefore did not sign the declaration, but joined later in 2008. In June 2008 the Council highlighted that Mobility Partnerships are open to member states joining later (Council, 2008d, p.4). This table is correct as of July 2013 , but it is possible that member states will join partnerships at a later date.
} 
The empirical and conceptual insights provided by this thesis are especially important and timely given that the Mobility Partnerships look set to become more frequently used in the future. The Commission's 2008 communication on an Eastern Partnership (which aims to provide a specific eastern dimension to the ENP) states that Mobility Partnerships will be the main tool in so-called 'Mobility and Security Pacts' to be offered to the eastern neighbours (Commission, 2008b, p.6). The Stockholm programme calls for "continued and expanded use of the Mobility partnership instrument as the main strategic, comprehensive and long-term cooperation framework for migration management with third countries" (Council, 2009b, p.61). In its 2009 evaluation of the Mobility Partnerships, the Commission concludes that the Mobility Partnerships "are promising, innovative and comprehensive tools" which "merit being further developed, improved and replicated" (Commission, 2009d, p.8). In 2011 the Commission stated that the conclusion of Mobility Partnerships with the Southern Mediterranean countries is "a crucial tool, beneficial for both sides to ensure better and more effectively managed migration and mobility" (Commission, 2011e, p.7). It therefore proposed to open dialogue with Tunisia, Morocco and Egypt with the aim, among others, of concluding Mobility Partnerships. As a result, a Mobility Partnership with Morocco was signed in June 2013 (Council, 2013). The Commission's 2011 communication on the GAMM stated that Mobility Partnerships should be the principal framework for cooperation with third countries (Commission, 2011b, p.10).

\subsection{Research on the Mobility Partnerships}

This research is the first piece of academic work to examine in detail both the internal and external governance of the Mobility Partnerships. As they are a relatively new policy instrument, little has so far been written about the partnerships and most contributions deal with only one aspect of the partnerships. This section identifies four different types of contributions, and positions the thesis in the existing body of work on Mobility Partnerships.

One group of contributions, particularly those published soon after the creation of the Mobility Partnerships, places the partnerships in the broader context of the EU's other policies. Parkes (2009a; 2009b) compares the Mobility Partnerships to the provisions of the ENP. In one article he concludes that, although the Mobility Partnerships do not actively clash with the mobility agenda of the ENP, they add little to it. The Mobility Partnerships are presented as a weaker tool than the instruments developed under the ENP to foster compliance: the Mobility Partnerships do not contain mechanisms to foster joint ownership; the incentives offered, particularly in terms of provisions of free movement, are limited; and they do not contain a sanctioning mechanism (Parkes, 2009a, p.340). The other article is more decisive, concluding that "the mobility partnership was forged as a response to a range of policy goals with little or no connection to the ENP" (Parkes, 2009b, p.2). Parkes (2009a) also discusses the difficult task that the Commission will face in coordinating the disparate activities of the Mobility Partner- 
ships - a task not made easier by the voluntary nature of the Mobility Partnerships for the member states, which has resulted in "fragmented schemes" (p.344). The article provides some insights into the functioning of the Mobility Partnerships, although as it deals with the ENP it concerns only the partner countries in Eastern Europe. The partnerships are a pragmatic tool, which is evidenced by the fact that criteria for the choice of partner countries are fluid - Georgia was selected rather for geopolitical reasons than migration reasons (p.331). The article also captures the 'wrangling' between member states, for instance on the selection of partner countries (see also chapter 4 of this thesis).

In a similar vein, Ward (2008) compares the Mobility Partnerships to the provisions for free movement in the Economic Partnership Agreement (EPA) between the EU and the Caribbean Forum (Cariforum) countries. She concludes that the Mobility Partnerships allow for mobility provisions more favourable to third countries than those of the EPA. The EPA is biased towards highly-skilled migrants, does not allow for direct entry into the labour market, and does not allow for periods of stay as long as those that are possible under the Mobility Partnership. However, the commitments required from third countries signing a Mobility Partnership are so onerous that the possibility of better provisions for mobility may not be a strong enough incentive. In a later contribution, Ward (2011) concludes that bilateral migration agreements between EU member states and developing countries have the greatest potential to facilitate mobility. It should be noted that the first article dates from 2008, when the implementation of the first two Mobility Partnerships (with Moldova and Cape Verde) was still at an early stage. As will be explained in chapter 4, in reality the Mobility Partnerships have not provided for new forms of mobility.

A second group of academic contributions deals with the provisions contained in the Mobility Partnerships. Lavenex and Stucky (2011) outline the structure and content of Mobility Partnerships, and argue that projects relating to migration control are more numerous than those relating to the promotion of mobility or development. Carrera and Hernández i Sagrera (2009) conclude that the Mobility Partnerships are 'insecurity partnerships' for third country nationals: third country nationals are treated as economic units rather than human rights holders due to the preference for circular migration; the nature of the Mobility Partnerships as 'soft law' makes it difficult to ensure that individuals' rights will be upheld; and different treatment is established for individuals depending on their nationality (pp.2-3). The authors also argue that illegal migration and border control are emphasised in the Mobility Partnerships (see also chapter 4). In a later contribution (Carrera and Hernández i Sagrera, 2011), the authors assess the extent of circular migration provisions in the Mobility Partnerships with Moldova, Cape Verde and Georgia and conclude that they offer "few tangible examples of effective "circular migration' initiatives" (p.101; see also chapter 4).

In 2009, the European Parliament's Committee on Civil Liberties, Justice and Home Affairs commissioned a briefing paper on the Commission communication on Mobility Partnerships and circular migration. However, the briefing paper which resulted concerns Mobility Partnerships only in terms of circular migration. Circular mi- 
gration is defined as a "potentially effective tool for fostering economic development in sending countries" (Wiesbrock and Schneider, 2009, p.1). The paper goes on to give examples of circular migration in national settings (the Netherlands and Sweden). Whilst it is true that a scheme for circular migration could form part of a Mobility Partnership, the partnerships are broader in nature as they include also cooperation on illegal migration.

A third group of contributions examines how and why the Mobility Partnerships were concluded, both from the point of view of member states and the third countries. Ward (2011) considers the motivations for member states to join Mobility Partnerships and outlines three possible rationales: firstly, member states are actually resisting delegation of competence over migration issues to the EU level by joining Mobility Partnerships but maintaining bilateral cooperation at the same time; secondly, Mobility Partnerships replicate the approach taken at national level; or thirdly, "in a few cases participation in the MPs should be interpreted within the context of domestic political considerations" (p.151). There are two problems with these conclusions: firstly, they are based on secondary (literature) research; and secondly, as will be argued in this thesis, the domestic political context is the basis for understanding member states' preferences in all cases. Carrera and Hernández i Sagrera (2009) show that member states have made a conscious choice that the Mobility Partnerships should be an instrument of soft law, as a result excluding the European Court of Justice (ECJ) from this policy. Member states' participation in a Mobility Partnership is determined by their interest in and relationship with the third country concerned (p.31). Lavenex and Stucky (2011) mention the problem of division of competences in the Mobility Partnerships, namely that "those issues that would interest partner countries most . . . are in the competence of the Member States, and the Commission has no leverage" (p.117). This is an important aspect of the Mobility Partnerships because it affects the interest of third countries in joining such a partnership (see chapter 6).

EU member states played a decisive role in the selection of third countries for Mobility Partnerships, by indicating which countries they prioritised for cooperation (Lavenex and Stucky, 2011). Some third countries were proactive in requesting a Mobility Partnership: Moldova and Georgia submitted non-papers expressing their interest in taking part in Mobility Partnerships (Carrera and Hernández i Sagrera, 2011; cf. chapter 6 on the role of Senegal and Cape Verde in becoming candidate countries). However, there is evidence that IOM played a significant role in the production of these nonpapers (Lavenex and Stucky, 2011; Potaux, 2011). Once selected, negotiations were brokered by the Commission, and the "scope for third countries to express their concerns [was] limited" (Lavenex and Stucky, 2011, p.132).

Chou (2009b) examines the origins and outlooks of the Mobility Partnerships with Cape Verde and Senegal. She argues that a 'repressive' approach dominates in EU external migration policy; in other words, measures are implemented that "primarily benefit the Union at the expense of migrants, countries of origin or transit and other private actors" (p.8). This is due to the dominance of interior officials in the EU's migration policy. The HLWG, for instance, is institutionally under the General Affairs and Exter- 
nal Relations Council of the EU, and yet is made up of officials from member states' interior or migration ministries (p.18). With regards to the Mobility Partnerships she concludes that "the Commission recommendation to conclude a readmission agreement with Cape Verde and the negotiation stalemate with Senegal do suggest that the repressive dimension is again instrumentalised in the first instance" (p.10).

Chou and Gibert examine the negotiations on a Mobility Partnership with Senegal in particular. They argue that the proposed Mobility Partnership would duplicate the Cotonou Agreement which already contains an article (Article 13) on readmission. It is therefore puzzling that the EU would push Senegal to sign a separate readmission agreement (Chou and Gibert, 2010). However, they neglect that article 13 of the Cotonou agreement does not include provisions for the direct readmission of third country nationals. Indeed, it states that, at the request of a party to the agreement, negotiations on a readmission agreement may be initiated: "These agreements shall also cover, if deemed necessary by any of the Parties, arrangements for the readmission of third country nationals and stateless persons" (Cotonou Agreement, article 13(5)ii). It is therefore not surprising that the EU pushes for the conclusion of precisely such a readmission agreement. A later contribution by Chou and Gibert (2013) reaches conclusions about why the negotiations on a Mobility Partnership failed: both the Senegalese and French governments were at best ambivalent about the negotiations; the Senegalese government was not convinced of the added value of an agreement due to the legal and financial uncertainties surrounding the Mobility Partnership; the EU's 'our-size-fits-all' approach to relations with third countries failed spectacularly in this case; and there was a lack of political leadership on both the Senegalese and EU sides (Chou and Gibert, 2012). This thesis agrees with some of these findings, and challenges others. Chapter 6 shows that the prospect of a readmission agreement was a main reason for the Senegalese reluctance to sign a Mobility Partnership; this is something that is not emphasised enough in the article by Chou and Gibert. Chou and Gibert assign explanatory power to the ambivalent position of the French government, based on an interview in the French embassy in Dakar; chapter 5 of this thesis shows, however, that decisions on the Mobility Partnerships were taken for the French government by the ministry of immigration in Paris. Officials in the ministry of foreign affairs (and thus also the embassies) were bypassed.

Finally, some scholars misunderstand the nature of the Mobility Partnerships completely. Cassarino (2009) refers to the Mobility Partnerships as "a new generation of temporary labour-migration schemes", whereas this thesis will show that labour migration is not a major component of the Mobility Partnerships agreed to date (see chapter 4). Cassarino does, however, also point out that Mobility Partnerships "belong to an existing political framework based on a form of quid pro quo" (ibid.) - chapter 6 discusses this quid pro quo in the cases of Senegal and Cape Verde. Barnes and Cherino (2011) equally misunderstand the extent of circular migration included in the Mobility Partnerships. Such misunderstandings can perhaps be explained by the fact that the Commission communication introducing the concept of Mobility Partnerships also deals with circular migration (Commission, 2007a). 
This research contributes to the existing body of academic work on the Mobility Partnerships in two main ways. Firstly, at an empirical level, this is the first study to conduct systematic, in-depth research into the Mobility Partnerships. Many contributions were published very early (2008 or 2009) when the Mobility Partnerships were still a very new policy tool. In addition, they tend to rely largely on document analysis. The problem with relying on document analysis is that there are not many documents about the Mobility Partnerships officially available, and the various Council conclusions provide only a superficial insight into the negotiation of the partnerships. The Commission's 2007 communication was essentially only charting out a possible route for the partnerships. The texts of the concluded partnerships are available online (because they take the form of Council documents), but the scoreboards (internal Commission documents, giving information about all the projects being implemented in the framework of the Mobility Partnership) are not published.

Interviews are therefore an important source of information on the Mobility Partnerships (see chapter 3). Some researchers have conducted interviews on the Mobility Partnerships in the EU institutions in Brussels (e.g. Lavenex and Stucky, 2011; Carrera and Hernández i Sagrera, 2011; 2009; Chou and Gibert, 2012; 2010). Fewer have conducted interviews in third countries, and there has certainly been no extensive research done in third countries. Chou and Gibert (2012) reach conclusions about the failure of the Mobility Partnership with Senegal, but these conclusions are based mostly on interviews with officials in the Council Secretariat and Commission, and member states' embassy staff in Dakar (17 of the 20 interviews cited). Only three interviews were conducted in the Senegalese government, covering only two ministries (the ministry of youth and the ministry of foreign affairs). Carrera and Hernández i Sagrera (2011) and Lavenex and Stucky (2011) rely on only two interviews each in the Moldovan and Georgian missions to the EU. There is no in-depth research on Mobility Partnerships based on interviews conducted in the EU member states, the exception being two interviews by Lavenex and Stucky (2011).

Much of the in-depth research that has been conducted so far focuses on the Mobility Partnerships with Moldova and Georgia (e.g. Carrera and Hernández i Sagrera, 2011; Lavenex and Stucky, 2011; Parkes 2009a; 2009b), probably due to the fact that in the east three partnerships have now been concluded, whereas concluding partnerships with African countries has proven more difficult (see chapter 6). Contributions which deal with third countries' role and preferences on the Mobility Partnerships tend not to be detailed on member states' preferences (e.g. Carrera and Hernández i Sagrera, 2011; Lavenex and Stucky, 2011; Chou and Gibert, 2012). In empirical terms, this research benefits from some temporal distance from the events being studied, as well as extensive interviews not only in Brussels but also in third countries and EU member states (including the first interviews conducted on the issue with officials in Cape Verde, France, Austria and the Netherlands). It therefore brings together and substantiates the insights from the various contributions so far published on what the Mobility Partnerships look like and how they are concluded. 
Secondly, at a conceptual level, this is the first study to bring together different levels of analysis (see also chapter 2). Some researchers have studied the internal governance of the Mobility Partnerships (Carrera and Hernández i Sagrera, 2009), capturing the interactions of the Commission and the member states. Some have studied the external governance of the Mobility Partnerships (Chou and Gibert, 2012), capturing the interactions between the EU and the third countries concerned. The contributions by Carrera and Hernández i Sagrera (2011) and Lavenex and Stucky (2011) to a certain extent deal with both interactions, in that they consider the set-up and functioning of the Mobility Partnerships at the EU level, as well as the selection and negotiation of the partnerships with the third countries (albeit not in much detail). However, no single contribution to date combines the EU and third country levels with an analysis of member states' preferences. In other words, scholars have begun to tackle the question of why and how third countries cooperate with the EU on Mobility Partnerships, but have not addressed in an in-depth or systematic manner the role that member states play in this policy instrument. This oversight is problematic because the member states' preferences are central to understanding the shape that the Mobility Partnerships take (see chapter 4). This thesis argues that in order to understand this policy instrument completely it is necessary to bring these three levels of analysis together. Chapter 2 proposes to conceptualise the decision-making procedure on EU external migration policy as a three-level game, in which the interaction between the EU institutions and the member states is linked to the interaction between the EU and the third country. Only by understanding how these interactions are linked can a full explanation of the decision-making procedure be given.

\subsection{Outline of study}

Chapter 2 outlines the sub-questions and the theoretical framework guiding the analysis. It argues in particular that the process of decision-making on EU external migration policy should be understood as a three-level game. Chapter 3 sets out the case study methodology used to conduct the research and justifies the case selection (France, the Netherlands and Austria at the member state level; Senegal and Cape Verde at the third country level). Chapter 4, the first empirical chapter, concerns the EU governance of the Mobility Partnerships. It examines the role of the EU institutions and the member states, and the implications this pattern of governance has had for the form of the partnerships. Having established that the member states played a central role in the decision-making process on the Mobility Partnerships, chapter 5 asks why different member states had different preferences on this policy instrument. It sets out the case studies of the three EU member states. Chapter 6 concerns the third countries and explains why Senegal and Cape Verde had different preferences regarding a Mobility Partnership. The conclusion reflects on the utility of the three-level model and suggests some routes for future research. 


\section{Chapter 2 \\ Theoretical framework}




\subsection{Introduction}

This research is concerned with understanding the decision-making process on EU external migration policy, in other words those policy instruments which draw third countries into a cooperation on migration issues. Chapter 1 demonstrated that there are three sets of actors involved in EU external migration policy: the member states; the EU institutions; and the third countries. Decision-making on EU external migration policy therefore takes place at different levels: at the member state-level; at the EU level between the EU institutions and the member states (in the Council); and at the international level between the EU and third countries. These different levels are constantly engaging with each other: the Commission finances migration projects in third countries; member states have bilateral migration agreements with third countries; member states meet at the EU level in bodies such as the HLWG to determine the EU's approach to external migration policy. This thesis is a first attempt to bring together these different levels into a comprehensive model in order to understand how the EU's external migration policy is made.

Chapter 1 showed that there has to date been a cleavage in the academic literature, which tends to focus on one of two strands: relations between the member states and the EU ('internal' governance); or relations between the EU and third countries ('external' governance). Schimmelfennig and Sedelmeier (2004) make an explicit distinction between internal governance (how EU rules are created) and external governance (how these rules are then transferred to and adopted by third countries). Scholars working on the internal governance of the EU do not take into account the role of third countries in these policies, despite the fact that EU policies in areas such as JHA, environment and energy increasingly have an external dimension (Lavenex, 2004; Lavenex and Wichmann, 2009). The literature on 'new' modes of governance highlights the role of nonstate actors in EU governance (Héritier, 2003), but neglects the fact that third countries play a role in external policies. Equally, scholars working on the EU's external governance do not account for member states' preferences. Several contributions argue that the internal mode of EU policy-making is reflected in external governance (Lavenex and Wichmann, 2009; Lavenex and Schimmelfennig, 2009), but they fail to incorporate member states' preferences into their explanations. The conditionality model of EU influence on third countries (Schimmelfennig and Sedelmeier, 2004) emphasises the decision-making process in and preferences of third countries, but this alone does not explain policy outcomes. Indeed, the model simplifies policy-making by referring only to 'EU' conditionality and 'EU' rules, without analysing the process within the EU (between the member states and the EU institutions) that leads to the adoption of these rules.

Such approaches overlook the fact that internal and external governance - how EU rules are created and how they are adopted by third countries - are linked. These different aspects of the decision-making process therefore cannot be modelled independently of each other (Putnam, 1988, p.434; Patterson, 1997, p.142). Putnam (1988) has characterised international negotiations as a two-level game, in which national executives try 
to find an agreement that can be accepted at both the international and the domestic levels. Hubel (2004) has built on Putnam's two-level game model: he argues that the EU's external policies should be understood as the outcome of a three-level game: the domestic policies of member states; the decision-making process between the EU institutions and the member states; and the negotiation between the EU and third countries (see table 2.1). This research adopts such a three-level approach to EU external migration policy. The three levels are linked through two interactions: one interaction between the EU institutions and the member states; and a second interaction between the EU and the third countries. At levels I and III, a 'national' preference on EU external migration policy emerges through discussions and negotiations between the actors involved. In the interactions, the member states or the third countries negotiate with the EU over the substance and form of EU external migration policy, based on the national preference.

The thesis makes both a theoretical and an empirical contribution to the fledgling literature on three-level games in the EU: theoretically, it aims to clearly conceptualise how the three levels are linked and what the conditions are for agreement to be reached; empirically, it extends the application of the three-level game to a new policy field, as contributions to date have dealt mainly with (agricultural) trade policy.

Table 2.1: The three levels of EU external policy. ${ }^{10}$

\begin{tabular}{ll}
\hline Level I & International level \\
Level II & EU level \\
Level III & Member state level \\
\hline
\end{tabular}

This chapter first outlines the nature of the three-level game (section 2.2). It outlines the actors present at each level, and explains under which conditions agreements can be reached. Section 2.3 concerns the EU level (level II), and outlines the nature of governance of EU external migration policy. Section 2.4 concerns the member state level (level III), and explains why member states choose to participate in EU external migration policy. Section 2.5 concerns the international level (level I) of the game and examines why third countries choose to cooperate with the EU on migration issues. Based on these sections, section 2.6 outlines expectations about the cost of no agreement and the ratification procedure for both interactions within the game. The chapter concludes by reiterating the expectations about preferences and consequences at each of the three levels.

\footnotetext{
10 The thesis follows Putnam's (1998) system for numbering the levels. Putnam refers to the international level as level I, and therefore to the domestic level as level II. This thesis also refers to the international level as level I. It adds the EU level as level II, and the member state level as level III.
} 


\subsection{Conceptualising EU external migration policy as a three-level game}

Robert Putnam (1988) developed the notion of two-level games to explain the 'entanglement' of domestic and international politics and the outcome of international negotiations (see also Moravcsik, 1993a). ${ }^{11}$ In a two-level game, the domestic and international levels are linked by national political leaders, who are present at both levels: at the domestic level, these political leaders construct an agreement between different domestic groups on the national preference in the international negotiations; at the international level, national political leaders must negotiate an agreement that is acceptable to their domestic groups (Putnam, 1988). Statesmen involved in international negotiations therefore "simultaneously [calculate] the domestic and international implications of their actions ... Diplomatic tactics and strategies are constrained simultaneously by what other states will accept and what domestic constituencies will ratify" (Moravcsik, 1993a, p.4). Traditional theories of international relations, which focus either on systemic (international-level) or domestic explanations for states' foreign policies, are not adequate to explain interstate relations. Systemic theories make restrictive assumptions about domestic politics as nothing more than a 'black box'. Empirical reality does not support such assumptions - indeed, most authors working within this tradition do acknowledge the importance of domestic factors for explaining interstate relations, but employ such domestic explanations in a rather ad-hoc way to explain only those aspects which cannot be explained satisfactorily by systemic theory (pp.6-15; see also Smith, 1986). Similarly, a domestic view alone cannot account for the outcome of interstate bargaining. The two-level game approach combines the international and domestic view, without privileging either: statesmen "seek to manipulate domestic and international politics simultaneously . . . Diplomacy is a process of strategic interaction in which actors simultaneously try to take account of and, if possible, influence the expected reactions of other actors, both at home and abroad" (Moravcsik, 1993a, p.15; emphasis added). The two-level game does not simply posit the significance of two levels of decision-making, rather it emphasises the interaction between the two levels (p.17). The two levels are intertwined because "expectations and unfolding developments in one arena affect negotiations in the other arena" (p.23).

\subsubsection{Criticism of the two-level game approach}

This thesis attempts to overcome some of the criticisms directed at two-level game approaches. Firstly, the two-level game model has been criticised for focussing on national political leaders because this "precludes investigation of the origins of [chief

\footnotetext{
${ }^{11}$ The distinction between traditional game theory and two-level games should be clarified. Game theory is, broadly speaking, concerned with modelling the interactions between decision-makers. The two-level game approach is concerned with the interaction between two levels of negotiations: the domestic and the international. Individual decision-makers link these two levels because they take part in both negotiations and seek to reach agreement that can be accepted at both levels. The two-level game approach has not been formalised in the same way as game theory: "both Putnam and Moravcsik explicitly state that the original article used game theory only as a metaphor and did not derive propositions through conventional choice theoretic analysis" (Knopf, 1993, p.604).
} 
executives'] preferences so that we see only through the "eyes of the executive" (Jacobsen, 1996, pp.98-99). This research overcomes this criticism by examining how and why EU member states and third countries reached a certain domestic preference on the issue of Mobility Partnerships. Chapters 5 and 6 account also for the role of other domestic actors, and how various preferences came together to form one national preference.

Secondly, Putnam's (1988) original article might be criticised for drawing mainly on examples of economic cooperation (Moravcsik, 1993a, p.17). Several of the threelevel game models developed to date (e.g. Larsén, 2007; Patterson, 1997, Collinson, 1999; Young, 2003) also focus on EU external economic cooperation. This thesis makes an empirical contribution to the literature on two- and three-level games by employing a three-level game approach in a rather different policy field, namely migration.

The two-level game approach has also been criticised for being a metaphor rather than a full-fledged theory (Trumbore, 1998). Moravcsik (1993a, p.23) argues that, in order to move the from the two-level game as a metaphor towards the two-level game as a model of state behaviour, Putnam's framework must be more restrictively defined. Drawing on Waltz's three levels of analysis in international relations, Moravcsik outlines three elements that must be specified when the two-level game model is applied: the domestic politics of the issue; the international negotiating environment; and the statesman's preferences. This chapter will specify these elements for the three-level game. The domestic politics of international migration cooperation is considered for both the member states and the third countries. The politics of external migration policy is also highlighted at the EU level, by examining the roles of the different EU institutions in making external migration policy. There are two 'international negotiating environments' in a three-level game: between the member states and the EU, and between the EU and the third countries. This chapter outlines expectations about the nature of the international negotiating environment in both of these cases. Finally, the preferences of member states' and third countries' governments and of the EU institutions are central to this chapter, which outlines explanations for member states and third countries' decision-making procedures on EU external migration policy.

\subsubsection{Three-level games}

Several authors (mainly from the US) have applied or refined Putnam's model of twolevel games in the field of international relations (e.g. Trumbore and Boyer, 2000; Carment and James, 1996; Mo, 1995; Knopf, 1993; Schoppa, 1993). The model has also been applied to the EU - to parliamentary oversight of the EU (Pahre, 1997), to negotiations on EMU (Hosli, 2000), and to the open method of coordination (Büchs, 2008), to name a few examples. Moravcsik's (1993b) liberal intergovernmentalism is a two-level model, combining an assumption of rational state action, a liberal theory of domestic preference formation (highlighting the importance of economic factors), and an intergovernmental theory of EU negotiations. National executives are the privileged actors. Governments "are assumed to act purposively in the international arena . . . on the basis of goals that are defined domestically" (p.481). 
Putnam (1988, p.449) already acknowledged in his original article that some institutional arrangements consist of more than two levels, citing the (then) European Community as an example:

Consider negotiations between the United States and the European Community over agricultural trade ... Modifications of the Common Agricultural Policy require unanimous ratification by [the member states in the Council of Ministers]. In turn, each of those governments must, in effect, win ratification for its decision within its own national arena.

Some contributions in the field of EU studies have therefore adapted the two-level model and conceptualised negotiations between the EU and third countries as a three-level game because "the EU constitutes an international organisation in itself and as such it serves both as the international arena in the negotiations between the EU member states and as the domestic arena in the negotiations between the EU and the third party" (Larsén, 2007, p.859). ${ }^{12}$

Hubel (2004) is an example of an author utilising a three-level model to explain EU policy-making. He discusses EU policy towards Russia and Turkey, and argues that it is a three-level game composed of the following levels: the domestic policies of member states; the decision-making process between the EU institutions and the member states; and the negotiation between the EU and third countries. He seems to imply that the member states are the privileged actors, as he discusses their preferences when discussing each of the three levels, but he does not precisely conceptualise how the different levels of the game are linked or what the conditions are for an agreement to be reached. Wood adopts Hubel's model, but limits his analysis to a simple statement that "Turkey's bid to join the EU entwines at least three levels of politics" $(2004$, p.19) without conceptualising how the levels are linked. Moyer (1993) examines the role of the European Community (EC) in the GATT Uruguay round, and argues that the three-level game in EC decision-making explains the reluctance of the EC to make changes to the Common Agricultural Policy. The three levels identified by Moyer are the EC decisionmaking process (level II), the national decision-making processes of the member states (level III), and the EC GATT negotiating team (level I). Moyer refers to constraints imposed on one level by another level as an explanation for the outcome of the GATT negotiations, but does not clearly outline expectations about how these constraints arise and how they influence decision-making. Falkner (2002) identifies different actors than Moyer: in her conceptualisation, the three levels are the member state level; the negotiations between member states; and the 'game' between member states and the EU institutions. However, she does not provide an accurate model of how the levels are linked

\footnotetext{
${ }^{12}$ Knopf (1993) also identifies security negotiations as involving three levels because "there are sometimes divisions within a military bloc that is itself just one party to the negotiations . . In such cases, it may be necessary to treat the governments of alliance partners or the outside bloc as a third layer in the analysis" (pp.610-611; emphasis added). However, he does not specify that the alliance itself may be an actor. The EU is generally acknowledged to be unique amongst international organisations, given the strength of its supranational institutions. This might therefore be the only international organisation which can justifiably be regarded as an actor in international negotiations.
} 
or the conditions for agreement to be reached. Leal-Arcas (2004) also examines the EC in the WTO, and identifies the roles and powers of the three levels of actors involved in decision-making: the national (member state level); the supranational (Brussels level); and the international level (within the WTO in Geneva). However, this contribution also does not outline a specific model of the three-level game. Panke (2013) has an empirical and theoretical focus on the conditions under which the EU can develop a common position in the UN, and the conditions under which the EU is successful in UN negotiations. She hypothesises that member states' win-sets will be large if their foreign ministries have few capacities and if the issue at stake is not salient domestically - this is a rather different conceptualisation than that adopted in this thesis (see sub-section 2.2.4). Her second set of hypotheses link the existence/non-existence of a common EU approach to the choice of negotiation strategies at level I; again, a rather different conceptualisation than that adopted in this thesis, which sees negotiation strategies as stemming from the size of win-sets (see sub-section 2.2.5).

The central conceptual difference between a two-level game and a three-level game is the interactions involved. In a two-level game, there is one interaction: between the domestic level and the international level (Putnam, 1988). A three-level game of EU decision-making is more complex, with linkages and "reverberation among negotiation levels" (Patterson, 1997, p.151). The three levels are linked in three different ways. Firstly, there are two interactions: (1) between the EU institutions and the member states and (2) between the EU and the third countries. These interactions are linked because the policy that is decided upon in the first interaction becomes the subject of negotiation in the second interaction. Secondly, EU member states and third countries may be linked independently of the EU level (represented by the dashed line in figure 2.1). The existence of such a link can affect third countries' decisions on whether or not to cooperate with the EU on migration issues (see chapter 6). Finally, member states are 'present' in the EU-third country interaction by virtue of their central role in determining the content of the policy being negotiated (see sub-section 2.2.5).

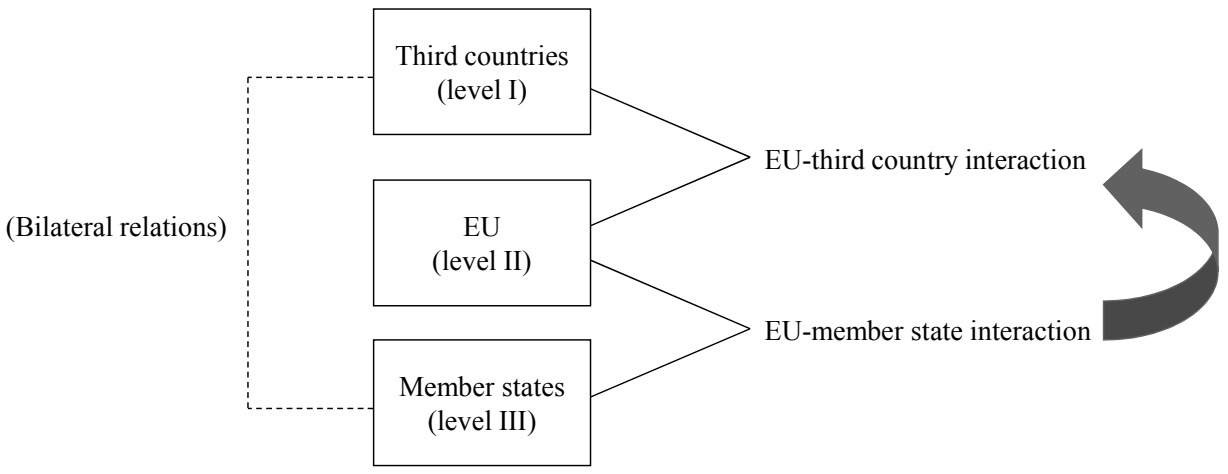

Figure 2.1: Links between the three levels in the game. 


\subsubsection{Conceptualising the three levels}

Most applications conceptualising EU international negotiations as a three-level game deal with external trade policy (Larsén, 2007; Patterson, 1997; Collinson, 1999; Young, 2003). Larsén (2007) examines the negotiations leading to the Trade, Development and Cooperation Agreement with South Africa in 1999. She conceptualises the negotiations as a three-level game with the Commission as the privileged actor that is present at all three levels (domestic, EU and international). It is essential, she argues, to understand the dynamics of decision-making within the Commission in order to understand the outcome of external trade policies. The 'domestic' level is therefore the intraCommission negotiations between different DGs in order to establish a common Commission position. The EU level is the negotiations between the Commission and the member states in the Council. The international level is the negotiations between the third country and the Commission. Larsén acknowledges that "by moving the domestic focus from the Member States to the internal game played inside the Commission, the dynamics within the Member States are neglected" (p.861). This is an important acknowledgement, because the member states are still the constituents of the Commission: the member states (in the Council) authorise the Commission to open trade negotiations with third countries, and appoint a committee to supervise the Commission in its negotiations with third countries. Although the Commission negotiates on behalf of the EU, the Council must still approve the conclusion of trade agreements. Nevertheless, an argument could be made that a focus on the Commission (at the expense of the member states) is justified in a policy field like trade, where the EU has significant competences. However, it is not appropriate for external migration policy, given the central role of the member states (see chapter 4).

This thesis therefore proposes a different conceptualisation of the three-level game in EU external migration policy. This conceptualisation is in line with that proposed by Patterson (1997), Collinson (1999) and Young (2003). These authors have developed the clearest conceptualisation of the three-level model to date. At the international level (level I), the EU and third countries negotiate on migration issues. In order to understand the outcome of these international negotiations, it is essential to understand third countries' domestic preferences on cooperating with the EU. The EU level (level II) is the decision-making process within the EU, between the EU institutions and the member states in the Council, on external migration policy. The member state level (level III) refers to the domestic preference formation of the member states on EU external migration policy. It is important to understand member states' domestic preferences in order to understand the outcome of decision-making within the EU. The model developed in this research goes further than the models by Collinson and Young by considering the size of the win-set for each level of the game. Neither of these authors formulate clear hypotheses about the size of the win-sets, although Young (2003, p.56) rightly notes that "one might expect the [EU's] win-set to be smaller than those of other governments. This is due to the [EU's] win-set being the product of pre-negotiation among (currently) 15 governments". Section 2.2.4 discusses the determinants of the size of win-sets in a three-level game. 
The three-level game developed here also goes further than previous conceptualisations by theoretically accounting for the preference formation of member states and third countries. Patterson (1997), in her discussion of negotiations within GATT in general, ends up focusing only rather superficially on the preferences and strategies of the United States. This is understandable given the number of countries represented in GATT. Within the EU, she focuses on the preferences of France, Germany and the UK, which is again understandable given the impossibilities of focusing on all member states. Panke (2013), who identifies level I as 'the UN', ends up focusing on the role of the EU member states - again understandable, given the number of other countries and groups represented in the UN and the impossibility of accounting for all of their preferences. This research systematically accounts for the preferences of a small number of countries by selecting case studies for in-depth process-tracing (see chapter 3 ).

\subsubsection{Conceptualising the two interactions: determining the size of win-sets}

Putnam outlines the importance of the notion of 'win-sets' for understanding the outcome of negotiations. A win-set "for a given Level II constituency [is] the set of all possible Level I agreements that would 'win' - that is, gain the necessary majority among the constituents - when simply voted up or down" (Putnam, 1988, p.437). So in order to reach a successful outcome, international negotiations must produce an agreement that can also be ratified at the domestic level. Putnam outlines three main determinants of the win-set: the cost of no agreement; the domestic ratification procedure; and the strategies of negotiators. Patterson (1997) is the only author whose work on the three-level game model sketches conditions for agreement to be reached based on these determinants outlined by Putnam. However, she does not clearly separate the determinants for the different actors. This is a significant oversight: the EU institutions will, for instance, have a different view of the cost of no agreement than the member states. Each actor therefore has a win-set - the range of possible agreements that are acceptable and where the win-sets of different actors overlap agreement is possible. This thesis focuses on the first two of the determinants - the cost of no agreement and the domestic ratification procedure - and takes into account that they differ for the different actors in the three-level game.

Firstly, win-sets are large if the cost of no agreement is high. This is because "ratification pits the proposed agreement, not against an array of other (possibly attractive) alternatives, but only against 'no-agreement"' (Putnam, 1988, p.442). This resembles the BATNA (Best Alternative to a Negotiated Agreement) in negotiation theory: "both parties [to a negotiation] have an alternative to a negotiated settlement: no settlement. They can always choose an alternative ending: no agreement" (Carrell and Heavrin, 2008 , p.29). If a party would be worse off with the status quo than the proposed agreement, it is preferable to continue negotiations. If, however, a party is better off or no worse off under the status quo, it is preferable to walk away from the negotiations. The cost to a particular constituency of no agreement can be altered, for example by offering a package deal, but in general those constituencies that face low costs of no agreement will be sceptical of an international agreement. 
Secondly, win-sets are large if the domestic ratification procedure is 'easy'. Domestic ratification is easy if, for example, there is strong discipline within the governing party, only a simple majority is required in the national parliament for ratification, or no domestic group has a veto right over the issue being negotiated (Putnam, 1988, pp.448449). Ratification is ordinarily understood as parliamentary approval of government agreements. However, this thesis broadens the concept of ratification. This is necessary for empirical reasons: the Mobility Partnerships, which form the object of this study, are non-legally binding political declarations, adopted by governments (see chapter 4). It can therefore be expected that the role of parliaments will be less significant than for the legally binding international treaties envisaged by Putnam. It is thus more appropriate to conceive of the ratification procedure as the autonomy of the central decision-maker(s) to take a decision: if central decision-makers can act relatively autonomously then the win-set is large because an agreement must not be approved by many other domestic institutions (Patterson, 1997, p.144; Collinson, 1999, p.216). Functionally, this is similar to the classical understanding of ratification, which also concerns the room for manoeuvre of negotiators. This room for manoeuvre depends on various factors, one of which is whether the agreement must be ratified by parliament; however, negotiators can be constrained even when there is no parliamentary ratification required, for example if the decision to go ahead with the agreement must be approved by several other government officials within the own ministry or from different ministries. It might be more appropriate to term this the domestic 'consent' for or 'approval' of an agreement; however, in order to maintain the link to Putnam's two-level game, this thesis will continue to refer to 'ratification'.

The expectations regarding the size of the win-set for each actor are set out in table 2.2. When the cost of no agreement is low and the ratification procedure is difficult, the win-set is small - the actor concerned can only accept a limited number of possible agreements. When the cost of no agreement is high and the ratification procedure is easy, the win-set is large - the actor concerned is willing and able to accept a larger number of possible agreements. For the remaining two configurations (low cost of no agreement and easy ratification procedure; high cost of no agreement and difficult ratification procedure) the win-set is somewhere between 'large' and 'small' - it is 'medium'. To say something meaningful in terms of the size of these two win-sets, it is useful to distinguish between the two determinants. If one is a more important determinant, then it is possible to categorise the win-sets as 'large/medium' and 'medium/small'. Putnam does not specifically make such a distinction, but seems to prioritise the cost of no agreement by devoting more space to it. This research goes along with this assumption that the cost of no agreement is the more important determinant because it seems logical: a difficult ratification procedure can be overcome if it is considered urgently necessary to have an agreement. However, an easy ratification procedure cannot necessarily overcome a low cost of no agreement. This distinction between the two determinants is shown in table 2.2 . 
Table 2.2: Determinants of size of win-sets.

\begin{tabular}{|ll|l|l|}
\hline & \multicolumn{2}{|c|}{ Ratification procedure } \\
& & Easy & Difficult \\
\hline $\begin{array}{l}\text { Cost of } \\
\text { no agreement }\end{array}$ & High & Large & Large/medium \\
\cline { 3 - 4 } & Low & Medium/small & Small \\
\hline
\end{tabular}

\subsubsection{The role of strategy and the Commission as 'chief negotiator'}

Putnam states that "the size of the win-set depends also on the strategies of the Level I negotiators" (1988, p.450). The two-level game model assigns a privileged position to 'statesmen', 'national political leaders' or 'chief negotiators' - in other words, the national government representatives who are conducting international negotiations. These negotiators "appear at both game boards" (p.434), and the strategies that they adopt can therefore affect the shape of the final agreement. In a three-level game, the privileged actor would seem to be the one that is present at both interactions - between levels I and II, and between levels II and III. In terms of the EU, this would appear to be the Commission, which is present in the EU-member state interaction, and also plays the international game on behalf of the EU.

Strategies for two-level action fall into four categories: statesmen and domestic actors may reshape the domestic win-set; reshape the foreign win-set; form transnational alliances; or attempt to undermine a foreign leader. Moravcsik (1993a) outlines examples of strategies used by negotiators:

- Statesmen can gain influence by pushing an international agreement towards their personally preferred position, so long as they remain within the domestic win-set (so that the agreement will be ratified)

- Statesmen can make threats during the bargaining procedure, although the threat will only be effective if there is a real prospect of it being carried out

- Statesmen can attempt to reshape the domestic win-set by changing the rules for ratification, offering side-payments to alter the domestic balance of coalitions or manipulating information about the agreement

- Statesmen can employ international actions to change expected outcomes at the domestic level, for example by setting the international agenda or joining an international regime

Much has been written about negotiation theory and negotiation strategies in general. Pruitt (2002), for instance, distinguishes between three main strategies: contending, problem solving, and yielding. Contending involves holding firm, making threats and arguing vigorously for one's position; problem solving involves seeking a solution that satisfies all parties to the negotiation; yielding implies conceding one's own interest in order to reach an agreement. Carrell and Heavrin (2008, pp.202-206) distinguish between negotiation strategies that are seen to be appropriate, and those that involve "lapses in truth-telling" and are therefore seen as inappropriate. Examples of inappropriate negotiation strategies might include deceiving the other party about the issue being negotiated, misrepresenting one's position, bluffing, and providing false information. 
Scholars examining negotiations in the EU have also developed typologies of negotiation strategies. Dür and Mateo (2010), for instance, distinguish between 'hard bargaining' and 'soft bargaining' negotiation styles. Strategies characteristic of hard bargaining are public statements of a firm position, criticising the other side, creating a defensive coalition, or making threats. Negotiators employing a soft bargaining style might signal flexibility, stress the common interest bringing the sides together, praise the other side, seek partners for compromise, or make several proposals so that the other side can indicate their preference.

Despite the importance assigned by Putnam to strategies of negotiators, they are not hypothesised in this thesis to determine the size of the win-set. Putnam is himself rather ambiguous on this point: he does not make a concise argument about a certain type of strategy causing the win-set to be large or small, and indeed includes arguments about the effect of the size of the win-set on the choice of strategy by the negotiator. It is therefore not clear whether negotiation strategies result from, or determine, the size of the win-set. Patterson (1997, p.144) seems to imply that negotiation strategies result from the size of the win-set: she argues that "the smaller the win-set, the greater the chance that a country will get exactly what it wants". This is intuitively plausible: negotiation strategies are determined according to the negotiation situation, and that situation might change during the course of the negotiations (Carrell and Heavrin, 2008, p.11).

The issue of negotiation strategies adopted by the chief negotiator is all the more interesting because there is reason to doubt that the Commission actually has such a privileged position in EU external relations. This thesis argues that, although the Commission plays the international game on behalf of the EU, the member states are 'present' in the EU-third country interaction in two ways: firstly, member states play the central role in determining the type of foreign policy adopted at the EU level. Figure 2.1 showed that it is this policy, the outcome of the EU-member state interaction, which feeds into the EU-third country interaction. By extension of their central role at the EU level, the member states are therefore also 'present' in the EU-third country interaction - they have played a central role in determining the policy that is being negotiated. Some of the literature on the EU's external migration policy hints at this connection. Several authors argue that EU migration policy is restrictive in nature, due to the dominance of member states' interior ministers in negotiations at the EU level (e.g. Chou, 2009a; Schain, 2009; Weinar, 2011). Schain (2009) shows that between 1999 and 2002 the Commission was only able to gain support from the member states for its proposals if they were restrictive in nature. Third countries are often shown to be dissatisfied with this restrictive approach by the EU (e.g. Chou and Gibert, 2010; Council, 2000, p.7) and may choose not to cooperate with such a policy. The Commission is constrained and does not have the mandate to offer the third country more than that which has been agreed at the EU level (where the member states dominate). This is hardly surprising in a policy area which sits at the crossroads of migration policy and foreign policy, two sensitive issues for member states' sovereignty (see chapter 1).

Secondly, member states are present at the international level through their existing bilateral agreements concluded independently of any EU external migration policy 
towards a country/region (represented by the dashed line in figure 2.1). The existence of such bilateral migration agreements can undermine the Commission's negotiating position, because member states may offer more attractive alternative agreements for third countries. When discussing the EU's GAM in relation to Africa, Weinar (2011, p.5) argues that "the EU has had a difficult time competing with established bilateral relations in the region, as the agenda of the political dialogue is still led by the same few Member States". Panizzon (2008) argues that the competition between France and Spain for migration cooperation with Senegal has increased the Senegalese government's confidence and therefore hindered negotiations between the EU and Senegal on migration issues (see also chapter 6 ). ${ }^{13}$

Negotiation strategies are thus certainly important: strategies employed by negotiators may mould the agreement reached, and several different strategies might be used in the course of a single round of negotiations. Negotiation strategies are not hypothesised to be a determinant of the size of the win-set, but are rather expected to be an outcome of the size of the win-set. They are thus included in the analysis, and the conclusion will return to the issue and reflect on the strategies employed by the different actors.

\subsubsection{Chapter outline}

As the policy which is being examined originates at the EU level, this is an appropriate place to begin the analysis (cf. Moyer, 1993, p.99). Section 2.3 therefore concerns the EU level (level II of the three-level game) and the roles of the EU institutions and member states in EU external migration policy. Section 2.4 concerns the member states (level III) and outlines two competing explanations for member states' preferences on EU external migration policy. Section 2.5 concerns the international level (level I) and outlines two competing explanations for third countries' decisions to cooperate with the EU on migration issues. Putnam does not privilege a particular theoretical framework, but rather claims that "the two-level conceptual framework could in principle be married to . . . diverse [theoretical] perspectives" on domestic politics (1988, p.442). Sections 2.4 and 2.5 outline competing rationalist and constructivist explanations for the preferences of both the member states and the third countries. Rationalism and constructivism are two contrasting 'images' of decision-making (Lewis, 2003). These two theoretical images differ on why decision-makers arrive at certain preferences: according to a rationalist account, decision-makers consider the material benefits and costs of a certain decision, and seek the best overall outcome; according to 'conventional' constructivism, decision-makers' interests are constructed by social facts such as norms and culture (Jupille et al., 2003). The distinction is thus between preferences based on material interests and preferences based on ideas (Panke, 2004). These two theoretical approaches are compared in terms of their suitability to account for both member states'

\footnotetext{
${ }^{13}$ The effect of the existence of bilateral relations on member states' preferences is difficult to predict. If participation in an instrument of EU external migration policy would allow member states to achieve objectives that cannot be realised at the bilateral level, participation can be expected to be high. If, on the other hand, member states favour their bilateral relationship, participation will be low, further weakening EU external migration policy and thus the role of the Commission.
} 
and third countries' decisions on participation in the Mobility Partnerships. The aim is to compare the empirical fit between theory and evidence for each of the theoretical approaches (Jupille et al., 2003, p.21). The application of these approaches is necessarily slightly different at these two different levels of the three-level game (see sections 2.4 and 2.5$)$.

It is necessary to understand the preferences of the actors at each of the three levels, in order to account for the outcomes of the two interactions in the three-level game. Section 2.6 therefore concludes by outlining some expectations about the size of the win-sets for both the EU-member state interaction and the EU-third country interaction.

\subsection{Level II: theorising the EU}

The first two sub-questions of this Ph.D. project concerns the decision-making process at the EU level: what was the role of the EU institutions and the member states in the negotiation of the Mobility Partnerships? And what implications does this have for the form of the partnerships? The interest is in the different actors present at the EU level and the role that they are able to play in the governance of migration policy. This will affect the type of policy adopted. The focus is on the member states and the Commission because (as will become clear in chapter 4) these are the central actors in the Mobility Partnerships.

\subsubsection{The governance approach}

In the past, scholarly debates on the European integration project centred on the process and nature of integration. Intergovernmentalists claimed that the member states control the pace and future direction of integration, while neofunctionalists claimed that initial integration in a few sectors will lead to pressure to integrate in other, related sectors, with this process being promoted by the supranational Commission. During the 1990s, however, it became increasingly clear that intergovernmentalism and neofunctionalism cannot provide a subtle enough account of the realities of decision-making in the EU (Kassim and Menon, 2003, p.126). Scholars agreed that a dynamic and complex political system is emerging at the EU level (Rosamond, 2000, p.105), in which no single actor or level is entirely in control of the pace of integration. Indeed, "the EU has become a polity where authority is dispersed between levels of governance and amongst actors" (p.110; cf. Marks et al., 1996). It is not even clear that a single governance pattern holds across all policy areas - rather, “the Union's capacity and legitimacy for institution-building has varied across institutional spheres such as competition policy, monetary affairs, external and internal security, and culture, and the ongoing development from (primarily) market-building to polity-building creates a need to attend to the different dynamics of various institutional spheres and policy sectors" (Olsen, 2007, p.78; cf. Moravcsik, 1998, p.54).

We have therefore witnessed a governance turn in EU studies (Kohler-Koch and Rittberger, 2006). Governance is a term that was first used in the field of international 
relations to "conceptualize the emergence of political order at the international level in the absence of a global public regime let alone a world government" (Lavenex and Schimmelfennig, 2009, p.795). Governance is defined in various ways by the scholars applying the governance approach. Peters and Pierre (2009, p.91), for instance, point out that "at its most fundamental level governance implies the capacity of a society to develop some means of making and implementing collective choices". Smith (2004, p.743) defines governance as "the authority to make, implement, and enforce rules in a specified policy domain".

The governance approach in European Studies lacks a central paradigm and is rather made up of various scattered (sometimes contrasting) strands: studies of Europeanisation; a focus on new modes of governance and regulatory policy-making; and the concept of multi-level governance. Scholars applying the governance approach have a common interest in EU institutions, decision-making procedures and rules (Bulmer, 1994, p.355). These scholars seek to understand the EU as a political system and how this system functions in a day-to-day context, rather than focusing on the process of integration as such, as the debate between intergovernmentalism and neofunctionalism did. Whereas classical integration theory takes the shape of the Euro-polity as the dependent variable (the outcome to be explained), the governance approach instead takes it as the independent variable, and seeks to understand how the shape of the polity impacts on the policies adopted (Jachtenfuchs, 2001). As Lavenex and Kunz (2008, p.443) argue, "the distribution of power among the actors involved in framing processes, and the institutional procedures guiding their access and interaction in the relevant policy arena are crucial in examining the emergence and the effects of particular policy frames".

Governance approaches do not purport to explain every aspect of the EU polity, but rather particular elements or specific policy areas (Rosamond, 2000, p.126; Bulmer, 1994, p.356). As integration has proceeded unevenly across policy areas, scholars ask why a particular mode of governance has emerged in a given policy area (Stone Sweet and Sandholtz, 1997). The edited volume by Wallace, Pollack and Young (2010), for instance, deals with policy-making by policy area, including competition policy, the common agricultural policy, environmental policy, and energy policy. The member states and the EU institutions have different interests, roles and powers across these various policy areas, and this affects the type of policies adopted. Helen Wallace has identified five variants of the EU policy process: the community method; the EU regulatory mode; the EU distributional mode; policy coordination; and intensive transgovernmentalism. Foreign policy is an example of a policy area that touches sensitive issues of state sovereignty. In such policy areas, a policy mode of 'intensive transgovernmentalism' prevails: the European Council and Council of Ministers play a central role in setting policy direction; the Commission is marginalised; the European Parliament is excluded from policy-making; and the ECJ has limited or no jurisdiction. EU foreign policy has therefore not been based on legislation, but instruments such as joint actions and joint declarations. At the other end of the spectrum, a 'Community method' of policy-making has applied to a policy area such as agriculture. Here there is a strong pol- 
icy-making role for the Commission and the European Parliament, and the ECJ has the power to enforce the legal authority of EU legislation (Wallace, 2005a). Stone Sweet and Sandholtz (1997) propose a continuum of modes of governance, ranging from intergovernmental politics at one end to supranational politics at the other (see figure 2.2). The modes of governance differ according to three dimensions: the influence of the EU institutions; the formalisation and clarity of EU rules; and the role of transnational actors. Each of these three dimensions gains in importance as a policy area moves from intergovernmental politics to supranational politics.

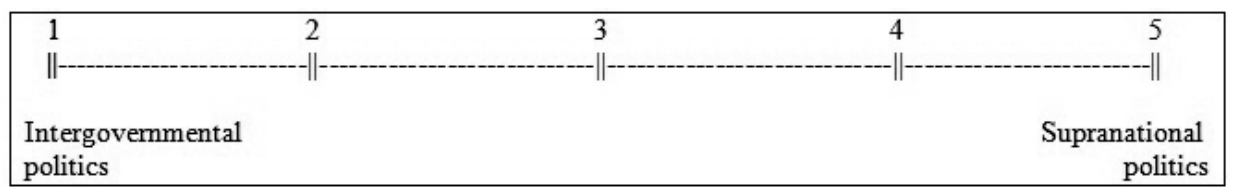

Figure 2.2: Governance in the European Union (Stone Sweet and Sandholtz, 1997).

JHA is the traditional example of a policy area governed by intensive transgovernmentalism (see Lavenex, 2009b). Member states have cooperated outside of the EU framework (e.g. in the Schengen agreement), thereby limiting the role of the Commission and excluding the European Parliament and ECJ. The use of the intensive transgovernmentalism mode of policy-making in JHA is hardly surprising, given that this is a policy area that "touch[es] core aspects of state sovereignty" (Lavenex, 2001, p.19). However, both the typology by Wallace and that by Stone Sweet and Sandholtz may be misleading in that they seek to assign an entire policy area to one mode of governance. Instead, modes of governance can differ within a policy area, so some elements of a policy are more intergovernmental while others are more supranational. Indeed, as far as migration policy is concerned, there is evidence of "a patchwork of supranational and national immigration policies located at different levels of governance and in different institutional areas, which allow for the full Europeanization of some aspects of migration policy while leaving others to the discretion of the member states" (ibid.). Even within legal migration policy, family reunification is regulated at the EU level, whereas labour migration is still very much a national competence.

The governance approach is thus interested in understanding the "overall functioning of the institutions" within the EU political system (Bulmer, 1994, p.356) and in particular the roles that different actors are able to play. Several contributions focus on the role of the member states. Jachtenfuchs and Kohler-Koch $(2003$, p.7) argue that "in the entire system, member states are still very important". Despite the emergence of a system of multi-level governance in which policy-making power is shared across several governance levels (Marks et al., 1996), member states remain important actors in EU decision-making. They are "powerful actors who cannot always impose their preferred outcomes on other players in the EC political system ... [they are] repositories of immense resources, both material (e.g. financial) and non-material (e.g. legitimacy)" (Stone Sweet and Sandholtz, 1997, pp.312-314; cf. Marks et al., 1996). On the other 
hand, the EU institutions are 'competence-maximisers' that seek to increase the competences of the EU level on any given issue area in order to increase their own competences in the policy-making process (Pollack, 2003, p.35).

It is possible to criticise the governance approach as a description (rather than explanation) of the patterns of decision-making at the EU level. Indeed, multi-level governance has been criticised for being "an attempt to depict complexity as the principal feature of the EU's policy system" (Rosamond, 2000, p.111; emphasis in original), rather than being a coherent theory of the EU. Such a description of the patterns of decision-making at the EU level is already more productive than the traditional theoretical debate between intergovernmentalism and neofunctionalism. However, a description of the complexity of EU governance is less interesting than an explanation for this complexity. Why has a certain pattern of governance emerged in a particular policy area? This thesis will follow such an approach by first mapping the governance of the Mobility Partnerships, and then explaining this governance in terms of the role of the member states and the EU institutions.

\subsubsection{The governance of EU external migration policy}

The previous sub-section reviewed the literature on the governance of the EU, which is concerned with understanding how the EU's political system functions. One of the most important findings of this literature is that governance patterns vary between different policy areas. This raises the question for this research: how is the EU's external migration policy determined? Lavenex (2001) identifies intensive transgovernmentalism as the dominant policy mode in EU JHA policy (albeit with elements of the community method appearing). But is this true for external migration policy as well? This subsection outlines the roles played in EU external migration policy by the member states, the Commission, the ECJ, and the European Parliament.

The member states, in the Council and the European Council, have certainly been central in the development of the EU's external migration policy. In terms of the external dimension of JHA more broadly, the European Council has been a "strategic guide" for the development of this policy (Poli, 2012, p.26). Already in 1992, the European Council adopted a declaration on governing external aspects of migration policy, which stated that "co-ordination of action in the fields of foreign policy, economic cooperation and immigration and asylum policy . . . could contribute substantially to addressing the question of migratory movements" (Council, 1992, p.47). Since 1999, the European Council adopts multi-annual programmes on JHA, all of which have emphasised the importance of the external dimension (Council, 2009b; 2004b; 1999a). The Tampere conclusions are seen as a milestone in the development of EU external migration policy. In these conclusions, the European Council recommended that the instruments of the EU's external policy should be used to achieve goals in JHA (Council, 1999a). The Stockholm programme reaffirms the "need for EU migration policy to be an integral part of EU external policy" (Council, 2009b, p.60). The European Council's role in this respect was codified by the Lisbon Treaty, which states that it shall "define the strategic guidelines for legislative and operational planning within the area of free- 
dom, security and justice" (article 68 TFEU). The EU's external migration policy has been the subject of many Council meetings and resulting policy documents. In 2005, for instance, the Council adopted a strategy for the external dimension of JHA policy, which introduced the notion of "partnership with third countries to tackle common problems and meet shared policy objectives" (Council, 2005c, p.5).

There have been countless policy documents published by the Commission on the external dimension of JHA. Through these many communications, reports and recommendations, the Commission tries to act as an agenda-setter (cf. Schain, 2009, p.100). Already in 1991, the Commission called for migration to be integrated into EU external policy (Commission, 1991). It repeated this call in 1994, arguing that migration should be integrated into all of the EU's external policies, including trade, development, human rights, and security policy (Commission, 1994). During the 1990s, however, the Commission, particularly DGs Relex and Development, was sidelined in EU external migration policy due to its reluctance to use development funding to prevent immigration to the EU. This changed in the early 2000s when these DGs came to the realisation that it would be better to take the initiative on external migration policy in order to be able to set the agenda. This led to a series of communications being published by the Commission (Boswell, 2003).

The Commission and the Council work closely together on EU external migration policy: they are the institutions responsible for implementing the strategic guidelines set by the European Council (Poli, 2012, p.32). DG JLS of the Commission was responsible for drafting the 2005 strategy on the external dimension of JHA (Pawlak, 2009, p.33). Once it was adopted by the Council, the Commission drafted a report on the implementation of the strategy, and this report was then also adopted by the Council (Wolff et al., 2009, p.14). Commission officials participate in Council meetings and working bodies dealing with external migration policy. The Commission negotiates visa facilitation and readmission agreements with third countries on behalf of the EU, but must act on a mandate issued by the Council.

Despite this close cooperation between the Commission and the Council, migration is, like foreign policy, an issue of 'high' politics (Messina 2007, p.138; Caviedes 2004, p.289; Lahav and Messina, 2005, p.854). The notion of borders and territory are inherent in the idea of national sovereignty (namely that the state has supreme power within its borders), and border control has long been a core part of state activity (Andreas, 2003, p.78). As Börzel (2005, p.225) points out: "Defence and war pertain to the core of state sovereignty. So do law and order, which are merely the domestic flipside of the legitimate monopoly of force of the modern state". Member states' interior ministries, which can be seen as 'policemen of sovereignty', have therefore sought to dominate EU external migration policy (Lavenex, 2006; Lavenex and Kunz, 2008; Chou, 2009a). Whereas 'internal' migration policy is now largely communitarised at the EU level, the EU institutions have less power and influence over external migration policy (Lavenex, 2006, p.346). As Sterkx (2008, p.135) concludes: "Member States are in a position of power, and their influence on the implementation of the external aspects of asylum and 
migration policy is substantial”. Geddes (2005) agrees, arguing that EU external migration policy has domestic roots.

This has led to some tension between the Commission and the member states (in the Council). Poli argues that "some Member States do not take the EU's prerogatives in the [area of freedom, security and justice] into serious consideration" (2012, p.36). There is sometimes little coordination at the EU level on such issues, and no regard for the Commission's role. Member states continue their bilateral cooperation with third countries on JHA issues (see Wolff, 2009). The Commission has, for instance, threatened to open an infringement action against Germany for concluding a bilateral readmission agreement with China after the Commission received a mandate to negotiate with China on behalf of the EU (Poli, 2012, p.34). Some member states concluded bilateral memoranda of understanding with the USA on visa waivers, despite the Commission's ongoing negotiations with the USA on a general agreement for EU citizens (p.35). The member states (acting in the Council) are also quick to check the Commission when they feel its proposed measures are too far-reaching. In 2010, the Council issued a rebuke to the Commission in response to its action plan on the implementation of the Stockholm programme. The Council pointed out that "some of the actions proposed by the Commission are not in line with the Stockholm Programme" and urged the Commission to comply with the Stockholm programme (Council, 2010a, p.2). Particularly interior ministries' representatives in the HLWG and external relations and development officials in the Commission have failed to see eye-to-eye on whether and how the EU's development cooperation budget should be used to control migration flows (Boswell, 2003, p.631). ${ }^{14}$ Where the European Council meeting in Seville in 2002 threatened to carry out "a systematic assessment of relations with third countries which do not cooperate in combating illegal immigration" (Council, 2002a, p.11), the Commission in the same year focused on providing positive incentives for third countries to cooperate on migration management (e.g. Commission, 2002b, p.25). The role that the Commission plays also depends on the exact nature of the policy: it "plays the role of policy entrepreneur more in some areas (external dimension of borders, visa, asylum) than others (external dimension of legal migration)" (Weinar, 2011, p.7).

The role of the European Parliament in EU external migration policy has been limited. Before the entry into force of the Lisbon treaty, the Parliament was only entitled to express its opinion on readmission agreements (Poli, 2012, p.37). The use of Council and European Council conclusions to set external migration policy limits the possibility for the Parliament to influence the policy-making process. Nevertheless, the Parliament has "shown a constant interest in influencing the course of action in this field, by adopting regular Resolutions and Recommendations, emphasizing the lack of democratic accountability of the JHA external dimension" (Wolff et al., 2009, p.14; cf. Coleman, 2009, p.168). In 2002, for instance, the Parliament adopted a resolution in which it stressed "the shortcomings in the EU's external strategy in the JHA area, in which noth-

\footnotetext{
${ }^{14}$ Lavenex and Kunz (2008, p.443) point out that DG JLS (now DG Home Affairs) has tended to align with the Council, in opposition to DGs Relex and Development (see also Boswell, 2008, on the differences between the DGs).
} 
ing is done to involve Parliament" (European Parliament, 2002). It has also criticised the substance of EU external migration policy on human rights grounds and raised concerns that third countries are not enough involved in dialogue with the EU (Sterkx, 2008, p.121). Generally, the Parliament (like the Commission) has argued for a more liberal migration policy (Servent, 2010; Acosta, 2009), bringing it into conflict with member states' preferences for a more restrictive policy.

The role of the ECJ in external migration policy is limited, due to the prevalence of 'soft law' in this area. The Court has no jurisdiction over matters such as European Council conclusions or instances of operational cooperation with third countries. Most tools of external migration policy (such as capacity-building missions) are not mentioned in the treaties. Given the sensitivity of both migration policy and foreign policy for the member states, this is not surprising: in such policy areas, they will tend to favour modes of governance not based on binding legislation, in order to preserve their sovereignty (Héritier, 2003; Citi and Rhodes, 2007). These modes of governance sideline the Court. This has been the case also in internal migration policy: the member states have sought to limit the role of the Court, because the Court has tended to try to advance integration by interpreting the provisions on the free movement of workers expansively (Papagianni, 2006, p.258; Guiraudon, 2000, p.262).

Overall, it is clear that external migration policy remains rather intergovernmental. Few of the instruments used in cooperation with third countries are mentioned in the treaties, and there is no binding legislation in this area. The Commission and the Council work closely together, although the member states (in the Council and the European Council) remain the central actors. The Commission is merely "a broker of deals in the name of its Member States, and a manager of financial aid. The objectives of the deals are laid down by the Member States" (Weinar, 2011, p.3). The European Parliament and ECJ are for the most part not included in the policy-making process. Chapter 4 shows that this picture of the governance of EU external migration policy was reflected in the negotiations on the Mobility Partnerships.

\subsection{Level III: the domestic politics of the member states}

The previous section examined the institutional dynamics of EU external migration policy. It showed that the member states (in the European Council and the Council) play a central role in the decision-making procedure. EU external migration policy is for the most part not based on binding legislation. Member states therefore have the choice of whether or not to contribute to operational cooperation with third countries. Chapter 1 showed that different constellations of member states have participated in the various Mobility Partnerships. The question therefore raised for this research is: when and why do member states choose to conduct external migration policy at the EU level? Specifically, the third sub-question addressed is: why do some member states chose to participate in the Mobility Partnerships while others do not? 
This thesis highlights the importance of the member states' domestic preferences for understanding EU governance (see Mastenbroek and Kaeding, 2006). These domestic preferences determine a member state's choice for or against cooperation at the EU level (Dowding and King, 1995). Moravcsik (1993b, p.481; cf. Moravcsik and Nicolaïdis, 1998, p.68) emphasises that "an understanding of domestic politics is a precondition for, not a supplement to, the analysis of the strategic interaction among states" at the EU level. The domestic politics approach (Bulmer, 1983) holds that "too much literature has concentrated on ... the formal institutional framework of the [EU] without examining the domestic sources of national negotiating positions" (p.353). "The member states" are not a unitary actor (Kassim and Menon, 2003, p.133). Indeed, one of the problems of early intergovernmentalist theory (Hoffmann, 1966) was precisely this tendency to treat governments as unitary actors and member states as 'black boxes', which would all react in broadly the same way to the 'threat' of European integration (Bulmer and Lequesne, 2005, p.3). In reality, member states' preferences vary across policies and time, and governments do not consist of only one decision-maker; rather, policies are the outcome of bargaining between various players in the national government (Allison, 1971; Allison and Halperin, 1972; Kassim, 2001). Scholars have observed empirically that member states' preferences on migration differ and they are sometimes at odds over how to deal with an issue. In 2006, for instance

Spain, Italy and Malta complained about the limited support for border patrolling from ... northern countries. Some northern European governments (such as France, Austria and the Netherlands) responded by blaming Spain and Italy for their recent mass regularisations, which they believe pull in even more irregular migrants (de Haas, 2008, p.1314).

In 2004, Italy proposed an EU immigration quota system as an incentive for third countries to sign readmission agreements, but this was rejected by the European Council and particularly opposed by France and Germany (Coleman, 2009, p.199). The southern member states (Spain, Italy and Malta) and the northern member states (Germany and the Scandinavian countries) also have different positions on the role of Frontex and the amount of funding which the agency should receive (Wolff et al., 2009, p.20). Member states favour readmission agreements with different third countries depending on the countries of origin of the immigration flows that they face (Sterkx, 2008, p.126). Within member states, several different ministries tend to be involved in setting migration policy (European Migration Network, 2010a), and this can affect the type of policy preferred at the national level: for example, interior ministries tend to be more inwardlooking' than foreign ministries (van Selm, 2005). ${ }^{15}$ While interior ministries may favour the signature of readmission agreements with third countries, foreign ministries may view such agreements suspiciously because they spoil diplomatic relations (Pawlak, 2009, p.37). Different ministries may also be responsible for representing member

\footnotetext{
${ }^{15}$ This resembles the different approaches within the Commission between DG JLS on the one hand and DGs Relex and Development on the other (see above, and Boswell, 2003).
} 
states in Council working groups, which may affect EU policy outcomes (Chou, 2009a; Lavenex and Kunz, 2008, p.453; Papagianni, 2006, p.222; Schain, 2009, p.103).

The previous section argued that member states have maintained their dominant position in external migration policy due to the sensitive nature of this issue, which lies between migration policy and foreign policy. This section goes one step further by developing explanations to understand why member have states have different preferences on the same policy instrument.

\subsubsection{Explaining member states' preferences on EU external migration policy}

Given that external migration policy sits at the crossroads of migration policy and foreign policy, this thesis combines the literature on EU migration policy with the literature on EU foreign policy to explain member states' preferences on participation in the Mobility Partnerships. This sub-section outlines two competing explanations. The first is a rationalist explanation, according to which a cost-benefit calculation of the consequences of participating in EU external migration policy determines member states' preferences. The second is a constructivist explanation, according to which member states' preferences on EU external migration policy result from a certain national identity and role conception. These two explanations will be compared in chapter 5 to determine which provides the most convincing account of why member states chose to join/not join the Mobility Partnerships.

Firstly, according to a rationalist explanation, member states will choose whether to conduct external migration policy at the EU level based on a cost-benefit calculation of the consequences of doing so. In general terms, rationalism explains policy-makers' actions and decisions in terms of the outcomes expected (Fearon and Wendt, 2002). Writing on foreign policy, Manners and Whitman (2000b, p.10) argue that conducting policy through the EU can be either a constriction on member states' foreign policy choice or an opportunity for foreign policy action. Member states assess whether the EU level amounts to a constriction or opportunity and decide accordingly whether to participate in EU-level action or not. Cooperation at the EU level is selected when it strengthens the state, rather than weakening it (cf. Guiraudon and Lahav, 2000). This explanation relies on a 'logic of consequences': “actors choose among alternatives by evaluating their likely consequences for personal or collective objectives . . . [The choice for a certain policy] is 'explained' by providing an interpretation of the outcomes expected from it" (March and Olsen, 1998, pp.949-950). ${ }^{16}$ The benefits expected from participating in EU policy do not necessarily have to be material: actors may adhere to norms for reasons such as gaining an enhanced international standing. A cost-benefit explanation is characterised by the fact that the underlying logic of the state's preferences is still means-ends in nature (Thielemann, 2003, p.255). An example of this distinction is provided by Checkel (1997, p.478): in the 1990s, the United States adopted

\footnotetext{
${ }^{16}$ Rationalist approaches are criticised for tending to 'black-box' the interactions which lead to a certain policy being chosen (Checkel, 2001, p.556). Regardless of whether the rationalist approach will be shown to explain member states' choices on the Mobility Partnerships or not, this thesis seeks precisely to open up this black box and examine the interaction between member states' different administrative departments.
} 
the global norm of outlawing child sweatshops not due to a logic of appropriateness, but rather as a rationalist decision to try to head off criticism by NGOs.

There are various potential benefits to member states of conducting external migration policy through the EU. Guiraudon $(2001 ; 2000)$ developed the 'venue-shopping' argument, according to which national governments choose to conduct migration policy at the EU level in order to achieve policy objectives which cannot be realised at the domestic level. The venue-shopping argument assumes that governmental actors and other political actors have different preferences on an issue, which constrains the government in its ability to act. For example, national courts or parliaments may resist the government's migration policy agenda. ${ }^{17}$ There are several examples of member states' governments applying a venue-shopping approach to circumvent opposition to their migration policy objectives from domestic political actors. In the early 1990s, for instance, EU migration policy allowed the German government to justify a restrictive policy change requiring a constitutional amendment which was opposed at the domestic level (Koslowski, 1998, p.175; Henson and Malhan, 1995). France has made extensive use of this tactic. The French government used discussions at the EU level on detention of asylum-seekers to modify the national law on detention without entering into a national discussion about the topic (Barbou des Places and Oger, 2005, p.362). Guiraudon assumes that member states' governments seek a more restrictive migration policy than other domestic actors, but the opposite situation could easily be imagined: a government, which is balancing the wishes of the public against the labour requirements of the national economy and the reality of a declining and ageing population, may actually favour a more liberal migration policy than publics and parliaments. Indeed, since 2000, many European governments have "argued that selective labour migration could help boost productivity and growth, by filling labour and skills shortages" (Boswell and Geddes, 2011, p.79).

According to Guiraudon's argument, the EU is used by the national government as an 'excuse' for having to adopt a policy that it secretly favours; in other words, there is no consensus at the national level on migration policy objectives. A different take on the venue-shopping argument would be that there is consensus on migration policy objectives amongst domestic political actors and the government, but that these objectives cannot be effectively achieved at the national level. Choosing policy action in a different venue (namely the EU level) is thus a way of addressing national concerns (Börzel, 2002, p.196; Moravcsik, 1993b, p.485). Joppke (1998) has argued that the migratory phenomenon may present challenges which cannot be addressed adequately by individual countries. The sheer volume of immigration, coupled with ethnic diversity and resulting social change, means that EU member states are becoming less able to 'control' migration through national policies alone. They are therefore more likely to conduct policy at the EU level in order to achieve their national policy goals. For example, in the early 1990s the German government pushed for the supranationalisation of migration

\footnotetext{
${ }^{17}$ National executives have a privileged position in the venue-shopping explanation because they represent their country in the European Council and the Council of Ministers. They use this privileged position to pursue their preferred policy. The venue-shopping explanation thus relies on the logic of a two-level game.
} 
policy in the hope that responsibility for migrants from Central and Eastern Europe could be shared with other EU member states (Herz, 2006, p.228).

Another possible benefit of EU external migration policy is that it offers member states more 'clout' internationally, through a politics of scale (Ginsberg, 2001). National "preferences, ideals and policy models" can be pursued at the EU level (Wong, 2007, p.332), for instance if EU external migration policy is targeting a third country with which the member state has important (diplomatic) relations. This strengthens national foreign policy objectives because it allows "member states to pursue and even expand foreign policy objectives . . . beyond those attainable with domestic capabilities" (Keukeuleire and MacNaughtan, 2008, p.144). Member states acting together at the EU level may, for instance, have more incentives to offer a third country in return for its cooperation on issues such as readmission. This is particularly the case for smaller member states, which may not be able to negotiate a readmission agreement with some of the larger developing countries (Klavert and van Seters, 2012, p.4). ${ }^{18}$

On the other hand, participation in EU external migration policy will be costly if there is a substantial 'misfit' with national policy objectives. The literature on Europeanisation develops the notion of 'goodness of fit' (Börzel, 2002, Börzel and Risse, 2000; Falkner and Laffan, 2005), which is applied to explain the implementation of binding EU legislation: member states will face more difficulties with implementation when there is a substantial misfit between EU legislation and existing national legislation. Although this research is not dealing with an instance of binding legislation, a misfit between national policy and a proposed EU external migration policy instrument would imply societal, financial or administrative costs to the member state of participating. Such costs must be weighed against potential benefits of the EU-level cooperation, in order for a member state's government to decide whether or not to participate. A member state might also consider cooperation at the EU level too costly if it encroaches on a special bilateral relationship or a 'special issue' that is considered particularly sensitive at the domestic level (Manners and Whitman, 2000b, p.11).

Where rationalism focuses on costs, benefits and expected outcomes, constructivism focuses on ideas, identities, norms and values as the basis for decisions. According to a constructivist explanation, member states' preferences on EU external migration policy are shaped by their own national identities and role conceptions (Aggestam, 2004; Keukeleire and MacNaughtan, 2008, pp.137-138; Holsti, 1987). Broadly speaking, constructivists hold that "what actors do in international relations... [is] defined by social norms and ideas rather than by objective or material conditions" (Barkin, 2003, p.326). Policy preferences are therefore not related to a calculation about means and ends, but rather relate to "identity politics" (Jørgensen, 2004, p.23) and a norm-based rationale (Thielemann, 2003, p.254). Jørgensen (2004, p.23), writing about foreign policy, argues that it is determined by questions such as "Is [state X] a great power?

\footnotetext{
${ }^{18}$ Panizzon (2012, p.104) argues the opposite: that third countries tend to prefer bilateral readmission agreements with individual EU member states, because such agreements are more likely to contain offers of labour market access, and the readmission obligation covers only one state, rather than all (or rather most of) the EU member states as with an EU readmission agreement.
} 
Ought [state $\mathrm{X}]$ to be represented in the [UN] Security Council? Is [state X] a civilian power?" Alons (2007, p.215) refers to this as the "ideological" dimension of national interest. National identity concerns ideas about the 'we' of the national political community: the norms and values that the state stands for and seeks to promote in its international relations, and the way in which "foreign policy-makers view past history, the present and the future political choices they face" (Aggestam, 2004, p.83). A role conception

includes the policymakers' own definitions of the general kinds of decisions, commitments, rules, and actions suitable to their state, and of the functions, if any, their state should perform on a continuing basis . . It is their image of the appropriate orientations or functions of their state (Holsti, 1987, p.12).

Such an explanation of policy preferences therefore relies on a 'logic of appropriateness': "action involves invoking an identity or role and matching the obligations of that identity or role to a specific situation" (March and Olsen, 1998, p.951). Such an approach is inherently able to account for the different preferences of the member states, because member states have different national identities and role conceptions (see Reynolds, 2004). These identities or role conceptions are anchored in the domestic context: a government's domestic popularity may well depend on the policy adopted, so a domestic-generated role conception is likely to be favoured as the 'road-map' for action (Aggestam, 2004, p.88). ${ }^{19}$ For this reason, the thesis does not focus on the emergence of shared norms or role conceptions at the EU level (see Checkel, 2001); rather, it is assumed that existing domestic norms and role conceptions are the foundation for the decision to participate/not participate in EU policy proposals: if the EU policy is considered appropriate in terms of domestic norms, then the member state will decide to participate. Aggestam aims to explore the extent to which national identities are becoming shaped by the exchange with other member states in the framework of the EU; however, she concludes that France, Germany and the UK "conceptualise foreign policy objectives first and foremost in a national mind-set" (p.97). Applying such an explanation to the specific case being studied (the Mobility Partnerships), member states will choose to participate if the concept of migration cooperation with third countries inherent in the Mobility Partnerships matches their national identities and role conceptions.

Table 2.3 summarises how these two explanations account for member states' decisions to participate in EU external migration policy measures. Chapter 5 assesses which of these explanations is more convincingly able to account for member states' preferences on the Mobility Partnerships.

\footnotetext{
${ }^{19}$ It is important to note that states do not just have one conception of their nationality identity (Holsti, 1987, p.28); rather the course of action that policy-makers see as being appropriate may depend on the issue at stake. An EU member state might, for instance, have a very different idea of its role in the EU's external migration policy than its role in the Common Security and Defence Policy.
} 
Table 2.3: Explaining member states' decisions to participate in EU external migration policy.

\begin{tabular}{ll}
\hline & Explanation for participation \\
\hline Cost-benefit & Expected benefits of participation outweigh expected costs \\
National identity & EU external migration policy matches national identity/role conception \\
\hline
\end{tabular}

\subsubsection{Mapping member states' participation in EU external migration policy}

The EU member states are affected by different migratory flows, both in terms of magnitude and origin, and have different histories of external migration policy (see chapter 5). It can therefore be expected that they will make different choices concerning their participation in EU external migration policy. This thesis concerns their choices on one policy instrument, namely the Mobility Partnerships. However, this sub-section illustrates that member states' preferences have differed on other aspects of EU external migration policy as well. It is clearly beyond the scope of this sub-section to outline fully the participation of all 27 member states in all aspects of EU external migration policy, and it therefore focuses on migration missions, the Thematic Programme for Cooperation with Third Countries in the Areas of Migration and Asylum, and Frontex operations.

Migration missions had been conducted to fifteen countries by $2011 .^{20}$ Different constellations of member states have taken part in these missions. Using the migration missions in Eastern Europe as an example, table 2.4 shows member states' participation. Poland and Sweden have participated in all three of these migration missions, whilst some member states have participated in none.

\footnotetext{
${ }^{20}$ Armenia, Azerbaijan, Belarus, Cameroon, Cape Verde, Ethiopia, Georgia, Ghana, Kenya, Mauritania, Nigeria, Senegal, South Africa, Tanzania, Ukraine.
} 
Table 2.4: Member states' participation in migration missions in Eastern Europe (Council, 2011c, p.2; Delegation of the European Union to Belarus, 2009; Public Radio of Armenia, 2008).

\begin{tabular}{|c|c|c|c|}
\hline Member state & Armenia (2008) & Belarus (2009) & Azerbaijan (2011) \\
\hline \multicolumn{4}{|l|}{ Austria } \\
\hline \multicolumn{4}{|l|}{ Belgium } \\
\hline \multicolumn{4}{|l|}{ Bulgaria } \\
\hline \multicolumn{4}{|l|}{ Cyprus } \\
\hline Czech Republic & $\mathrm{X}$ & & $\mathrm{X}$ \\
\hline \multicolumn{4}{|l|}{ Denmark } \\
\hline Estonia & & $\mathrm{X}$ & \\
\hline Finland & & $\mathrm{X}$ & \\
\hline France & $\mathrm{X}$ & & \\
\hline Germany & $\mathrm{X}$ & $\mathrm{X}$ & \\
\hline \multicolumn{4}{|l|}{ Greece } \\
\hline Hungary & & & $\mathrm{X}$ \\
\hline \multicolumn{4}{|l|}{ Ireland } \\
\hline \multicolumn{4}{|l|}{ Italy } \\
\hline Latvia & & $\mathrm{X}$ & \\
\hline Lithuania & & $\mathrm{X}$ & \\
\hline \multicolumn{4}{|l|}{ Luxembourg } \\
\hline \multicolumn{4}{|l|}{ Malta } \\
\hline Netherlands & & & $\mathrm{X}$ \\
\hline Poland & $\mathrm{X}$ & $\mathrm{X}$ & $\mathrm{X}$ \\
\hline Portugal & $\mathrm{X}$ & $\mathrm{X}$ & \\
\hline Romania & $\mathrm{X}$ & & \\
\hline Slovakia & & $\mathrm{X}$ & \\
\hline Slovenia & & & $\mathrm{X}$ \\
\hline Spain & & $\mathrm{X}$ & \\
\hline Sweden & $\mathrm{X}$ & $\mathrm{X}$ & $\mathrm{X}$ \\
\hline UK & & & \\
\hline
\end{tabular}

Member states have made varying use of the EU's Thematic Programme for Cooperation with Third Countries in the Areas of Migration and Asylum. Table 2.5 shows which governments have received funding from the programme to carry out projects in third countries. The Czech, Italian and Spanish governments have been the most successful in acquiring funds from the thematic programme. 
Table 2.5: Member states awarded funding from the Thematic programme to carry out projects in third countries (Commission, 2011f; 2010d; 2008c).

\begin{tabular}{|c|c|c|c|}
\hline Member state & Call 2007-2008 & Call 2009-2010 & Call 2011-2012 \\
\hline \multicolumn{4}{|l|}{ Austria } \\
\hline \multicolumn{4}{|l|}{ Belgium } \\
\hline \multicolumn{4}{|l|}{ Bulgaria } \\
\hline \multicolumn{4}{|l|}{ Cyprus } \\
\hline Czech Republic & $\mathrm{X}$ & & $\mathrm{X}$ \\
\hline \multicolumn{4}{|l|}{ Denmark } \\
\hline \multicolumn{4}{|l|}{ Estonia } \\
\hline \multicolumn{4}{|l|}{ Finland } \\
\hline France & $\mathrm{X}$ & & \\
\hline \multicolumn{4}{|l|}{ Germany } \\
\hline \multicolumn{4}{|l|}{ Greece } \\
\hline \multicolumn{4}{|l|}{ Hungary } \\
\hline \multicolumn{4}{|l|}{ Ireland } \\
\hline Italy & $\mathrm{X}$ & & $\mathrm{X}$ \\
\hline \multicolumn{4}{|l|}{ Latvia } \\
\hline \multicolumn{4}{|l|}{ Lithuania } \\
\hline \multicolumn{4}{|l|}{ Luxembourg } \\
\hline \multicolumn{4}{|l|}{ Malta } \\
\hline \multicolumn{4}{|l|}{ Netherlands } \\
\hline \multicolumn{4}{|l|}{ Poland } \\
\hline Portugal & $\mathrm{X}$ & & \\
\hline \multicolumn{4}{|l|}{ Romania } \\
\hline \multicolumn{4}{|l|}{ Slovakia } \\
\hline \multicolumn{4}{|l|}{ Slovenia } \\
\hline Spain & $\mathrm{X}$ & $X$ & \\
\hline Sweden & $\mathrm{X}$ & & \\
\hline UK & $\mathrm{X}$ & & \\
\hline
\end{tabular}

Finally, member states have participated to varying extents and in different ways in Frontex operations. All member states, with the exception of the UK and Ireland, participated in the Rapid Border Intervention Teams deployed to the Greek-Turkish border in 2010 (Frontex, 2011). France, Germany, Italy, Luxembourg, Portugal and Spain 
contributed to Operation Hera which aimed to patrol the waters near Senegal and Mauritania and detect migrants being transported by sea to Europe (Frontex, 2012).

\subsection{Level I: explaining third countries' preferences}

International migration is by its very nature a matter of foreign policy. Indeed, "to view migration management as a domestic issue alone neglects important foreign policy considerations" (Geddes, 2004, p.8). The EU therefore increasingly attempts to "influence migration from, and the migration policies of, non-EU states" (Geddes, 2008, p.170). There are a number of tools used for this purpose, such as readmission agreements, migration dialogues (such as the EU-African Rabat process), and the funding of projects (such as the creation of a migration information centre in Mali, to warn potential migrants about the dangers of migrating illegally and to promote legal migration) (see chapter 1; Bosch and Haddad, 2007; Pastore, 2007). In order to understand the outcome of the interaction between the EU and third countries, this thesis asks under which circumstances third countries choose to cooperate with the EU on migration issues, in this case the Mobility Partnerships. The final sub-question to be addressed in this research is therefore: why do third countries choose to join a Mobility Partnership?

\subsubsection{EU external governance}

There is a growing body of literature on the external governance of the EU. External governance refers to the EU "exporting forms of political organization" to third countries (Bulmer, 2007, p.47). The difference between internal and external governance is that "while the former concerns primarily the creation of rules as well as their implementation in national political systems, the external dimension is exclusively about the transfer of given EU rules and their adoption by non-member states" (Schimmelfennig and Sedelmeier, 2004, p.661; emphasis in original). External governance, however, is more than simply the transfer of rules by the EU to third countries; it implies the participation of third countries in the process of policy-making. This thesis defines external governance as a policy-making process whereby "third countries participate in the definition of relevant EU policies" (Lavenex and Schimmelfennig, 2009, p.796). ${ }^{21}$

The concept of external governance has been developed by scholars writing about the enlargement process. In order to differentiate between external governance in countries that are candidates for EU membership and countries that are not candidates, Lavenex (2004, p.683) defines external governance as "the extension of the legal boundary of authority [of the EU] beyond institutional integration". In other words, non-member states become drawn into the pursuit of the EU's internal policy goals, without the prospect of eventual accession to the Union.

There are two main strategies that the EU employs in its relations with third countries. Conditionality (or 'external incentives') is the best-known model of EU influence on third countries (Schimmelfennig, 2009). Conditionality is a rationalist model "based

\footnotetext{
${ }^{21}$ Lavenex and Schimmelfennig actually coin the term 'extended governance' for this definition.
} 
on the direct, sanctioning impact of the EU on the target government" (p.8). There are two types of conditionality: positive and negative. Positive conditionality "involves promising . . . benefit(s) to a state if it fulfils the conditions; negative conditionality involves reducing, suspending, or terminating those benefits if the state in question violates the conditions" (Smith, 1998, p.256). There is then a cost-benefit calculation by the third country, which will choose to cooperate "if the benefits of EU rewards exceed the domestic adoption costs" (Schimmelfennig and Sedelmeier, 2004, p.664). Various factors determining this cost-benefit balance have been proposed by different authors. In his piece on conditionality and aid donors (more broadly than only the EU), Killick (1997) argues that there is a minimum level of coherence required between donor and recipient objectives, and that the threat of punishment must be credible. Schimmelfennig and Sedelmeier argue that the success of the conditionality model depends on: the clarity of the EU's requirements; the credibility that both the reward and sanction will actually be administered by the EU; and the cost to the third country of adopting the requirements (ibid.). Adoption costs "may take the form of opportunity costs of forgoing alternative rewards offered by adopting rules other than EU rules ... [or] they may produce welfare or power costs for private and public actors" (Schimmelfennig and Sedelmeier, 2004, p.664). It is in this context that existing bilateral relations between the third country and EU member states is important: EU member states may be offering cooperation that is less costly or more beneficial than that proposed by the EU. This can affect the third country's decision on whether or not to cooperate with the EU - in effect, the member states are 'undermining' EU policy.

Lavenex and Schimmelfennig (2009, pp.804-805) emphasise the importance of domestic structures: external governance is effective when EU rules resonate well with domestic rules, traditions and practices; when the number of veto players incurring significant costs from the adoption of EU rules is low; and when state capacity in the third country is high. In terms of state capacity, Lavenex and Schimmelfennig (2009, p.805) highlight the compatibility of domestic institutions in the third country with the EU system. This is highly relevant in an enlargement context: if a third country seeks to join the EU, they will have to apply the entire EU acquis and officials will need to be integrated into the EU's decision-making bodies. However, in a case of external governance, where membership of the EU is not at stake, state capacity should be measured differently. Even in the enlargement process, when the EU made accession conditional on 'administrative capacity', it was unclear what was meant by this (Dimitrova, 2002). Several definitions of administrative capacity have been suggested: staffing levels; internal organisation and coordination structures; sectoral capacity; and the ability to implement policies (Laffan, 1997; Dimitrova, 2002). As the thesis deals with decisionmaking (rather than implementation), administrative capacity will be understood as being dependent on staffing levels and the existence of sectoral coordination structures.

Some of the factors identified in the literature as part of the cost-benefit calculation by third countries are not relevant for the instance of EU external migration policy examined in this thesis. For instance, there is no clear sanction that is threatened if a third country refuses to sign a Mobility Partnership. This is in contrast to the conditionality 
imposed on countries wanting to become members of the EU, which may find their accession funding through the Instrument for Pre-Accession Assistance withheld if they do not comply with the accession criteria (under Council Regulation EC 1085/2006). Some EU member states have in the past favoured withholding development aid to countries that do not cooperate on migration objectives, but this was rejected by the Council as a whole (Chou, 2006). This thesis therefore argues that the cost-benefit calculation made by third countries will depend on three factors: (i) the resonance of the EU policy with national policy objectives; (ii) the administrative capacity of the target state; and (iii) the domestic costs of adopting the EU policy.

Under such a conditionality approach, third countries are not involved in the definition of the policy. Hettne and Söderbaum (2005) define this as 'soft imperialism': it is "an asymmetric relationship and the imposition of norms in order to promote the EU's self-interest rather than a genuine (interregional) dialogue as a foundation for sustainable global governance" (p.549). Chou (2006, p.2) defines the EU approach as "coercive' because it "uses development aid or related incentives in exchange for third countries' cooperation in achieving EU migration objectives, such as the tackling of irregular migration”. Lavenex and Wichmann (2009) argue that, in a policy area such as internal security, the relationship between the EU and third countries is highly asymmetric, as the EU has much stronger interest in cooperation. Betts (2011, p.24) agrees that there is a fundamental power asymmetry in migration relations: "receiving states have discretion to open or close their borders and are thus implicit 'rule-makers', while sending states have to generally accept the decisions of receiving states and are thus implicit 'rule-takers"'.

The conditionality model has been developed in relation to the enlargement process (Schimmelfennig and Sedelmeier, 2004). Lavenex (2012) identifies distinctive features of external governance and conditionality in the context of enlargement: there is a supranational acquis which must be adopted by the third countries; monitoring mechanisms exist to check compliance by third countries; and the reward on offer for compliance - eventual membership in the EU - is significant. Indeed, "the lack of membership prospects or other attractive incentives poses serious limits to external governance" (Lavenex, 2004, p.694). Trauner (2009) nevertheless argues that conditionality can be applied in a non-enlargement context, by focusing on 'policy conditionality'. Policy conditionality refers to "material rewards that do not relate to EU accession" (p.776). The example that Trauner gives is the promise of visa liberalisation for third countries in return for signing a readmission agreement and making reforms in the sector of JHA (p.775). He applies this additional element of conditionality to Macedonia, whose membership perspective is less certain than for countries like Croatia. However, policy conditionality can also be considered in cases where no membership perspective exists at all. Visa liberalisation, for instance, could be a powerful incentive for African countries to cooperate with the EU on migration. Even visa facilitation could lead to concessions by African countries on the issue of readmission (Klavert and van Seters, 2012, p.4). 
The other explanation for third countries' decision to cooperate with the EU is a 'social learning' approach in which third countries are persuaded of the legitimacy and appropriateness of EU policies (Schimmelfennig and Sedelmeier, 2004). ${ }^{22}$ This explanation implies voluntarism on the part of the third country which "adopts EU rules depend[ing] on the degree to which it regards EU rules ... as appropriate" (p.667). This in turn depends on a group of factors: member states being subject to the rules as well; deliberation with the EU on rule transfer; EU rules being shared by other international organisations; and the target state identifying with the EU community (p.668).

A central aspect of the social learning model is that governments of third countries "do not so much engage in cost/benefit calculations as puzzle, debate and argue with international interlocutors over the scope and direction of change" in a "policy dialogue' (Checkel, 2000, p.15). Epstein (2005) highlights the differences between the conditionality and social learning models with reference to reforms implemented in Poland in preparation for EU accession. Central bank independence was adopted in advance of EU requirements, as a result of extensive interactions between Polish and EU officials which led to acceptance of EU rules through a process of social learning; in the case of agricultural reform, on the other hand, the Polish government complied with EU requirements because accession was conditional on reform being implemented, but the norms associated with the reform were not internalised and remained domestically controversial. In one case, therefore, reform came to be seen as the 'right' thing to do based on a process of dialogue with EU officials (social learning explanation), in the other case, reform was adopted because the costs of the reform were outweighed by the benefit of EU membership (conditionality explanation).

A process of dialogue and persuasion is therefore central to the social learning model. Risse (1999) argues that "the goal of [such] discursive interaction . . . is to achieve voluntary argumentative consensus and truth seeking, not to push through one's own view of the world or moral values" (p.534). Participants in this search for argumentative consensus are assumed to be equal: "relationships of power, force and coercion are assumed absent ... This implies respect for two principles: universal respect as the recognition of all interested parties as participants in the argumentative discourse and the recognition of equal rights to all participants concerning making an argument or challenging a validity claim" (p.535). Lavenex and Wichmann (2009) refer to "participatory governance". In relation to EU external migration policy, Chou (2006, p.2) refers to a 'comprehensive' approach by the EU which "takes into consideration the needs of all three parties involved (EU member states, sending countries and the migrants)". This is in line with the EU's emphasis on 'ownership' of policies by partner countries (e.g. Commission, 2010b).

\footnotetext{
${ }^{22}$ Schimmelfennig and Sedelemeier (2004) also list the 'lesson-drawing' model of EU influence. However, this model does not depend on any contact or negotiation between the EU and the third country. Instead, third countries "adopt EU rules without incentives or persuasion" (p.668). Policy-makers in the third country search for a solution to a domestic problem by reviewing policies of other countries, and adopt the rules that they deem suitable for this purpose. This model is not appropriate for analysing the Mobility Partnerships (which are a negotiated agreement between the EU and a third country) and will therefore not be considered.
} 
Table 2.6 outlines the two competing explanations for third countries' decisions to cooperate with the EU on migration issues. Chapter 6 assesses which of these explanations is more convincingly able to account for third countries' preferences on cooperating with the EU in a Mobility Partnership.

Table 2.6: Explaining third countries' decision to cooperate with the EU.

\begin{tabular}{ll}
\hline & Explanation for participation \\
\hline Policy conditionality & Expected benefits of cooperation outweigh expected costs \\
Social learning & $\begin{array}{l}\text { Third country is persuaded of the legitimacy and appropriateness of EU poli- } \\
\text { cies in a process of dialogue with the EU }\end{array}$ \\
\hline
\end{tabular}

\subsubsection{Mapping the external governance of EU migration policy}

There has been much criticism in the academic literature of the EU's approach towards third countries in the area of migration. Chou (2009b, p.19), for instance, argues that "for the migration ministers the idea of 'cooperation with third countries' [is] less centred on how both partners could obtain shared advantage and more concentrated on formulating a common EU approach in the first instance, and then subsequently enforcing it on third country "partners"'. This sub-section sets out the approach adopted by the EU and gives examples of third countries' responses. It outlines the nature of the external governance of EU migration policy and is therefore not concerned with judging the normative aspect of the EU approach. Just as with the member states (see section 2.4.2), third countries have made different decisions on whether or not to cooperate with the EU on migration issues. As this thesis deals only with one policy instrument, namely the Mobility Partnerships, this sub-section aims to illustrate third countries' varying preferences on some other aspects of EU external migration policy.

The Commission has on several occasions emphasised the need to cooperate with third countries in order to achieve migration policy objectives (e.g. Commission, $2002 \mathrm{~b}$ ), and this was again acknowledged with the introduction of the Global Approach (Council, 2005a). Some authors have argued that this has enabled third countries to play a role in EU migration policy, with African countries increasingly involved in processes of dialogue (Collyer, 2009). Dialogue is a key component of a 'social learning' explanation, because it is a forum through which the EU can persuade third countries of the appropriateness of its policies. The Commission emphasises the importance of "developing dialogue and cooperation on migration related issues" with African countries (Commission, 2009e, p.27). In November 2006, an EU-Africa ministerial conference on migration and development (involving all EU and African heads of state/government) was held in Tripoli. At the regional level, EU and West African heads of state/government are involved in the Rabat process on migration and development. Meetings were held in Rabat in 2006, Paris in 2008, and Dakar in 2011 (Commission, $2011 \mathrm{~g}$ ). The pillar on dialogue and cooperation with Africa in the Global Approach recommends regular meetings between senior officials of the EU and partner countries in order to "make migration a shared priority for political dialogue between the EU and 
the African Union" (Council, 2005a, p.11). At the bilateral level, the EU sends migration missions to third countries to foster dialogue on migration issues. To date, migration missions have been sent to the following sub-Saharan African countries: Cameroon, Cape Verde, Ethiopia, Ghana, Kenya, Mauritania, Nigeria, Senegal, South Africa and Tanzania (Commission, 2011g).

Such an approach of dialogue with third countries is not, however, uniformly applied. In many cases, 'dialogue with countries of origin of migrants' means "dialogue on the implementation of the EU's plans, not on the drafting of those plans" (van Selm, 2002, p.154). When the HLWG produced action plans for several third countries, for example, it did so without consulting officials of these countries. This led to an angry reaction by the Moroccan government, which refused to discuss the plan with EU officials (Boswell, 2003, p.631; Pastore, 2002, p.113; Council, 2000, p.7). Rather than attempting to persuade third countries of the legitimacy of its migration policy, the EU focus is more often on making certain benefits conditional on third countries' cooperation. The Commission has argued that this is necessary because the interests of the EU and third countries on migration issues may differ substantially (Commission, 2002b). Whereas the EU is primarily concerned with the prevention of illegal migration, "subSaharan African countries are not necessarily interested in curbing the migration of their own citizens and are not interested in cooperation on readmission of non-nationals, fearing the impact it may have on their capacity to deal with migration flows" (Weinar, 2011 , p.7). It is particularly readmission agreements that are costly for the readmitting state: "repatriation nearly always constitutes the loss of vital foreign currency [in remittances] . . . the return of émigrés regularly puts further pressure on already-saturated labour markets ... [and] reintegration can pose significant social challenges where deportees have engaged in criminal or 'subversive' political activity abroad or where migrants return with only a rudimentary knowledge of their 'native' language and culture" (Ellermann, 2008, p.171; cf. Roig and Huddleston, 2007).

Nevertheless, readmission agreements remain central to EU migration policy (Council, 2011a). The Commission has therefore long recognised the need to offer third countries an incentive for their cooperation (Commission, 2002b), in the form of a visa facilitation agreement, financial assistance, or legal migration opportunities (Commission, 2011c). There is a difference between the rhetoric of the Commission and European Parliament on the one hand, and some member states in the Council on the other, on the approach towards third countries. At the Seville European Council meeting in 2002, Spain and the UK proposed to limit the provision of development aid to third countries that do not cooperate with the EU on migration issues (Chou, 2006, p.4). Although this was rejected by other member states, it was agreed that measures may be adopted (under the Common Foreign and Security Policy or other policies) against countries that do not cooperate on migration (Council, 2002a). In contrast, the Commission has stated that "introducing aid conditionality . . . is not an effective way of addressing the problem, and that the global approach is the best conduct to follow" (Commission, 2009f, p.123). The European Parliament has also emphasised that techni- 
cal and financial aid should not be made conditional on a third country's performance on the issue of readmission (European Parliament, 2006a, p.11).

The greatest reward the EU can offer for third countries' cooperation is the prospect of entry into the EU. However, enlargement is clearly not on the cards for all countries in the world, and such a reward cannot be offered to countries in Africa (Ellermann, 2008). The EU can therefore only offer rewards that fall short of enlargement. For instance, visa liberalisation dialogue have been offered to selected third countries including Macedonia, Montenegro, Serbia (Lavenex, 2012, p.128), Ukraine (Council, 2010b), Albania, Bosnia and Herzegovina (Council, 2010c), Georgia (Commission, 2012b), Kosovo (Commission, 2012c) and Moldova (Council, 2012d). Under visa liberalisation dialogues, progress on document security, border management, and asylum policy is eventually rewarded with visa-free travel to the EU.

Faced with such an approach by the EU, third countries make different decisions on whether and how to cooperate. Van Criekinge (2010) shows that Senegal chooses to cooperate on migration issues only where the government expects to benefit. It has adopted a strategy of non-compliance and resistance towards the EU where benefits are not expected in return for cooperation. Morocco has responded to EU pressure by positioning itself as "Europe's leading partner in the "fight against illegal migration"”. This strategy has the benefit of strengthening the Moroccan position in negotiations with the EU and diverting attention away from the fact that Morocco is the most important source country of migrants in the EU (de Haas, 2008, p.1316).

\subsection{Explaining the size of the win-sets in the three-level game}

So far, this chapter has dealt with the three different levels of analysis rather separately. Section 2.3 outlined the still rather intergovernmental nature of EU external migration policy, which is due to the fact that this policy area sits at the crossroads of two policies that are significant for member states: migration policy and foreign policy. Section 2.4 developed two explanations for member states' preferences on EU external migration policy: a rationalist, cost-benefit explanation, and a constructivist explanation based on national identity and role conception. Section 2.5 developed two explanations for third countries' preferences on migration cooperation with the EU: the rationalist policy conditionality model and the constructivist social learning model.

This section briefly outlines the implications of these theoretical expectations for the size of the win-sets in the three-level game. As noted above, there are two main interactions in EU external migration policy: one between the EU institutions and the member states; and one between the EU and third countries. These interactions are distinct, but linked. In each interaction, the possibility for agreement depends on the size of the win-set for each actor. The size of the win-set is determined by the cost of no agreement and the ratification procedure. If these win-sets overlap, for instance if both actors have a large win-set, agreement is possible. If there is no overlap, for instance if 
both actors have a small win-set, there is no common ground between the actors and agreement is not possible.

\subsubsection{EU-member state interaction: size of the win-set}

For the EU-member state interaction, the cost of no agreement differs for the EU as compared to the member states. This thesis assumes the EU institutions to be 'competence-maximisers' that seek to increase their competences in the policy-making process. Sub-section 2.3.2 showed that the Commission has cooperated closely with the member states, but that there has also been some tension as this is a policy area which member states consider a national prerogative. Sub-section 2.5.2 showed that the Commission has been vocal on the need to cooperate with third countries on migration issues and offer them incentives for their cooperation. It can therefore be assumed that the cost of no agreement for the Commission is high - if there is no agreement, the Commission role is by default reduced to nothing. The Commission cannot conduct an EU external migration policy on its own. Indeed, the member states (acting through the Council) can withdraw permission for the Commission to conduct the EU's external migration policy if they are dissatisfied with the Commission's actions. They threatened to do just this in 2004 due to a lack of progress on readmission negotiations (Coleman, 2009, p.146; Casarino, 2012, p.203). For the member states, on the other hand, the cost of no agreement depends on one of two factors: whether the benefits of an agreement outweigh its costs; or whether the policy matches with national identity. In cases where there are significant benefits from EU cooperation or where EU cooperation matches with conceptions of national identity, the cost of no agreement is high.

The ratification procedure used at the EU level depends on the type of policy being agreed on. The European Parliament is primarily involved with legislation. Most aspects of external migration policy are therefore outside of its competence, with the exception of readmission agreements. This makes the ratification procedure easier by eliminating a veto-player. The decision rule in the Council depends on whether the policy being agreed on is specifically mentioned in the treaties. In case of operational cooperation with third countries that falls outside the treaties, member states must agree unanimously on any new measure. Such a decision rule inevitably makes the ratification procedure more difficult, by introducing 27 veto-players. Equally, at the domestic level of the member states, the ratification procedure depends on the national context and the type of policy. Some governments may (be obliged to) consult their parliaments or specific interest groups on all matters of EU policy. This would make the ratification procedure at EU level more difficult, by introducing a new veto-player for each member state using such a decision-making procedure. In other member states, civil servants in the ministry responsible for migration or EU policy may have relative autonomy in deciding to participate/not participate in the Mobility Partnerships. Overall then, it is difficult to outline precise expectations on the nature of the ratification procedure. It should be noted that the ratification procedure is considered also for negative cases (where the member state decided not participate in the Mobility Partnerships). Ratification, as conceptualised in this thesis, is the autonomy of the central decision-maker(s) to 
take a decision; that decision could also be negative, in other words the decision not to participate in the Mobility Partnerships.

The size of the win-sets can be represented graphically (Putnam, 1988). In figures 2.3 and 2.4, the continuum represents the space of all potential agreements. The size of the space between $\mathrm{EU}$ and $\mathrm{EU}_{1}$ represents the win-set for the $\mathrm{EU}$, and this depends on the cost of no agreement for the EU and the ratification procedure in the EU; the size of the space between MS and $\mathrm{MS}_{1}$ represents the win-set for a member state, and this depends on the cost of no agreement for the member state and the ratification procedure in the member state. Where these spaces overlap, between $\mathrm{EU}_{1}$ and $\mathrm{MS}_{1}$, lays the possibility for agreement - this is the space containing the agreements that are acceptable to both parties, indicating that there is some common ground (Collinson, 1999, p.216). Figure 2.3 depicts a situation where both the EU and the member states have a large win-set, for instance if the cost of no agreement is high and the ratification procedure is easy in both cases. In such a situation, both the EU and the member states desire and can commit to an agreement. Figure 2.4 depicts an example of a situation in which no agreement is possible: the cost of no agreement for the $\mathrm{EU}$ is high, but the ratification procedure in the EU is difficult. At the same time the cost of no agreement for the member states is small and the ratification procedures in the member states is difficult. Only one party is therefore striving for an agreement, and institutional rules are unfavourable to ratification: reaching agreement will not be possible.

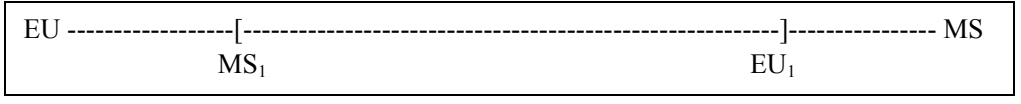

Figure 2.3: Agreement possible.

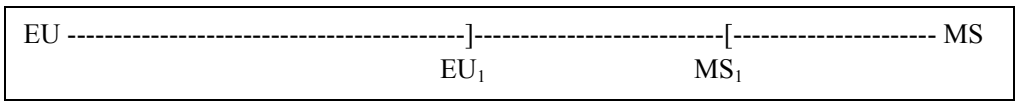

Figure 2.4: No agreement possible.

\subsubsection{EU-third country interaction: size of the win-set}

For the EU-third country interaction, the cost of no agreement again depends on the actor concerned. Sub-section 2.5.2 showed that there is recognition within the EU that cooperation with third countries on migration issues is necessary. For the EU, the cost of no agreement is therefore assumed to be high in all cases: without agreements with third countries, there is no EU external migration policy. For the third country, the cost of no agreement depends on one of two factors (see sub-section 2.5.1): whether the policy is expected to bring more benefits than costs; or whether the policy is considered appropriate. In case cooperation with the EU is expected to be beneficial or appropriate, the cost of no agreement will be high. But if the value or nature of the EU agreement is not certain, or there are preferable alternatives, the cost of no agreement for the third country is low. This is where the link between the member states and the third countries becomes important (see figure 2.1): if these bilateral relations offer a preferable alterna- 
tive to the one presented by the Commission, the win-set of the third country is small, making agreement with the EU impossible. In other words, bilateral migration agreements undermine the Commission's bargaining position.

The ratification procedure in the third country will depend on the national context (just as for the member states). If veto-players (such as the national parliament or other domestic groups) are involved in the decision-making procedure, the ratification procedure is difficult. The smaller the number of actors that must approve the cooperation with the EU, the easier is the ratification procedure. Just as for the member states, the ratification procedure is also considered for negative cases (cases where the third country decided not to sign a Mobility Partnership). In these cases, ratification refers to the process by which the decision not to sign was taken: where was the decision made? Did the decision need to be reached jointly with other institutions? Did the decision need approval from higher levels in the bureaucracy? Was the decision to participate/not participate confirmed by the parliament? The nature of the ratification procedure in the EU depends on the extent to which the Commission is constrained by the member states in the Council. Sub-section 2.3.2 showed that the Commission has cooperated closely with the member states in making EU external migration policy, but that the member states have exercised control over the Commission's actions. If this control of the Commission by the member states is tight, the ratification procedure is difficult because the Commission cannot act autonomously but must consider the preferences of the 27 member states. Examples of tight control might include a requirement for the Commission to report frequently to the Council; to include member states' experts in the negotiating team for migration agreements with third countries; or to gain member states' approval before finally concluding a migration agreement.

Figures 2.5 and 2.6 depict two possible situations for the EU-third country interaction. The continuum represents the space of all possible agreements. In figure 2.5, agreement is possible: the cost of no agreement for the EU is high, and the ratification procedure in the EU is easy. The cost of no agreement for the third country is also high, although the ratification procedure is difficult. Nevertheless, the two win-sets overlap, so agreement is possible. Figure 2.6 depicts an example of a situation in which no agreement is possible. The cost of no agreement for the EU remains high, but the ratification procedure is difficult. The cost of no agreement for the third country is low and the ratification procedure is difficult. Only one of the actors actually desires to reach agreement, and institutional rules are unfavourable to ratification. The win-sets do not overlap and there can be no agreement.

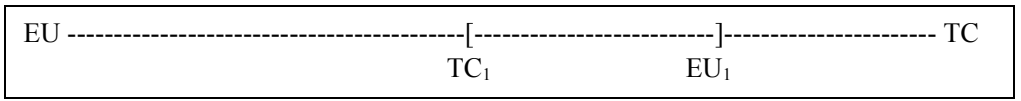

Figure 2.5: Agreement possible.

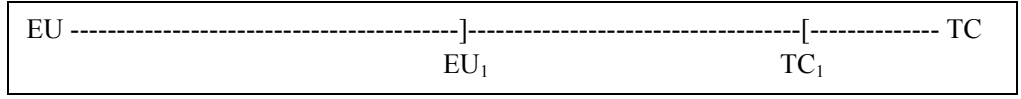

Figure 2.6: No agreement possible. 
Sub-section 2.2.2 argued that the two interactions in a three-level game are linked, because the policy that is decided upon in one interaction becomes the subject of negotiation in the second interaction. The member states and the EU institutions negotiate in the first interaction to determine the format and content of EU external migration policy, and this policy then becomes the subject of the negotiations between the EU and the third country. This is show in figure 2.7: the room for manoeuvre that the Commission has in the interaction with third country depends on what has been agreed in the first interaction with the member states.

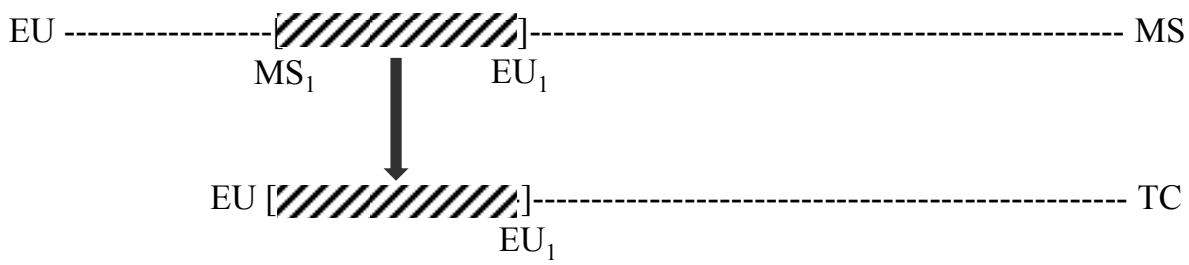

Figure 2.7: The link between the two interactions in a three-level game.

\subsection{Conclusion}

This chapter has outlined four sub-questions to be addressed in this research project:

- What was the role of the EU institutions and the member states in the negotiation of the Mobility Partnerships? (chapter 4)

- What implications does this have for the form of the partnerships? (chapter 4)

- Why do some member states chose to participate in the Mobility Partnerships while others do not? (chapter 5)

- Why do third countries choose to join a Mobility Partnership? (chapter 6)

Decision-making on EU external migration policy should be conceptualised as a threelevel game. The interactions between these three levels determine policy outcomes. The chapter outlined competing rationalist and constructivist explanations for member states' and third countries' preferences on EU external migration policy (see table 2.7). Finally, section 2.6 outlined some expectations about the conditions for win-sets to be large (which makes agreement possible). Figure 2.8 shows the complete model: the links between the three levels, the theoretical explanations for member states' and third countries' preferences, and the determinants of the size of the win-set for each actor.

Table 2.7: Rationalist and constructivist explanations for member states' and third countries' preferences

\begin{tabular}{lll}
\hline & Member states & Third countries \\
\hline Rationalist & Cost-benefit & Policy conditionality \\
Constructivist & National identity & Social learning \\
\hline
\end{tabular}




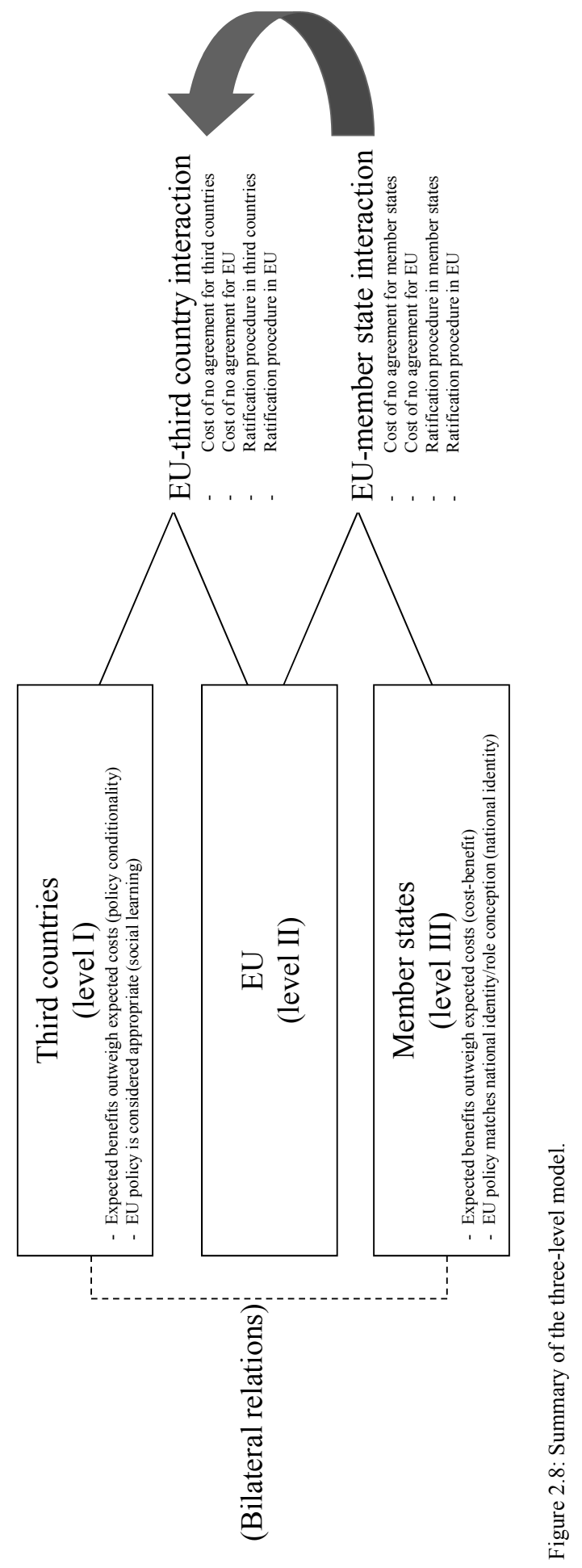


The empirical chapters follow the structure established in this chapter. Chapter 4 deals with the EU level (level II of the three-level game) and answers the first two subquestions. It explains the nature of EU-level governance in the particular case being examined in this thesis: the Mobility Partnerships. This chapter will show the central role played by member states on this policy instrument. This is a necessary part of empirical research: showing first 'what is happening', before explaining 'why it is happening' (Goldthorpe, 2001, p.11). In this case, the dynamics between the EU institutions and the member states must be established, before explaining why member states have certain preferences on EU external migration policy. These preferences (the third subquestion) are dealt with in chapter 5. It deals firstly with the member state level (level III of the three-level game) by explaining why member states chose to participate in the Mobility Partnerships. It also deals with the interaction between the EU institutions and the member states by discussing the size of the win-sets for both sets of actors, in order to account for the policy outcome. Chapter 6 answers the final sub-question and therefore deals with the international level (level I of the three level game) by explaining why third countries chose to agree/not agree a Mobility Partnership. It also deals with the negotiations between the EU and the third country by discussing the size of the winsets for both sets of actors. This accounts for the outcome of the negotiations. Chapter 6 shows the significance of the member states, which are informally present at all three levels of the game, even though formally it is the Commission that plays the game at the international level. 

Chapter 3

Methodology 


\subsection{Choosing for case studies}

This research applies a case study methodology in order to answer the research questions presented in chapters 1 and 2. Case studies have frequently been criticised, particularly by those favouring a large- $\mathrm{N}$ research strategy. The main criticisms of case studies are that case studies provide specific, rather than general, knowledge; case studies are not generalisable; case studies are only suitable for hypothesis-generating and not hypothesis-testing; case studies are not rigorous and therefore have an inherent verification bias; case studies are prone to selection bias because cases are selected when values on certain variables are already known; and that single case studies have no value for social scientific research because there is no variance on the values of the variables.

Such critiques overlook or downplay the inherent strengths of case studies, or misrepresent case study methodology. Case studies are, in a sense, intuitive (George and Bennett, 2005, p.5). They represent the very way in which humans learn: through concrete, context-dependent knowledge (Flyvbjerg, 2001, p.73). Context is everything, and it is the "detailed consideration of contextual factors" (George and Bennett, 2005, p.19) that is a hallmark of case study research. This lends such research high conceptual validity - something that is difficult for large-N research to achieve. As Collier et al. (2004, p.237) point out, "the size of the $\mathrm{N}$ is hardly the only source of inferential leverage". A case study researcher is intimately familiar with his or her cases, and case study research therefore provides a wealth of details. Indeed, a large- $\mathrm{N}$ researcher necessarily has some distance from his or her cases, but this distance "can lead to ritual academic blind alleys, where form becomes more important than content" (Flyvbjerg, 2001, p.72). Case studies allow researchers to go beyond a simple statement that "cause $\mathrm{X}$ and outcome Y are linked': case study research uncovers the causal mechanisms that explain how X and Y are linked (Gerring, 2007, p.45). Generalisation is not and should not be the only ideal of scientific research. Science and research are about accumulating knowledge: "formal generalisation is only one of many ways by which people create and accumulate knowledge. That knowledge cannot be formally generalised does not mean that it cannot enter into the collective process of knowledge accumulation in a given field or society" (Flyvbjerg, 2001, p.76). And yet case studies, even a single case study, can generate generalisable knowledge if the case is selected in a theoretically meaningful way: if, for instance, a most likely case does not display the theoretically predicted outcome, this has serious implications for the theory being examined. In order to select theoretically meaningful cases, case study researchers need to know the value of some variables before they embark on their research. This is not problematic, as quantitative researchers would hold. Rather it is a function of the familiarity of the researcher with the cases and should be embraced because it allows for more fruitful research to be conducted.

Ultimately both quantitative and case study methodologies have their merits and pitfalls. There is therefore "no virtue, and potentially great harm, in pursuing one approach to the exclusion of the other" (Gerring, 2007, p.63). However, these very differ- 
ent methods should be judged on their own terms, not those of the other method. They are, in a sense, two different cultures (Mahoney and Goertz, 2006). George and Bennett (2005, p.6) argue that "scholars' understanding of case studies is often distorted by critiques based on the assumptions of statistical methods". Such critiques universally neglect the fact that the logic of causation underpinning statistical methods and case studies is very different: statistical methods are probabilistic and correlational; they aim to uncover the average effect of a number of independent variables on an outcome ('effects-of-causes'). Case studies are interested in establishing the causes for a certain outcome ('causes-of-effects'); such causes are necessary and/or sufficient, and explanations are multivariate because causes act in conjunction to produce an effect (Mahoney and Goetz, 2006). As a result of these differences, "the case study has its own rigor, different to be sure, but no less strict than the rigor of quantitative methods" (Flyvbjerg, 2001, p.82). There is a clear trade-off between large-N and small-N research in terms of breadth versus depth: large-N research can incorporate many cases, but not in much depth. Small-N research provides rich empirical detail, but is limited in that this exacting level of detail cannot be established for more than a handful of cases (George and Bennett, 2005, p.31; Flyvbjerg, 2001, p.87).

The inherent strengths of case study methodology were the main reason for case studies to be selected for this research. However, case studies were also the only feasible and appropriate method for this particular research project. The theoretical explanations outlined in chapter 2 cannot be distilled into quantifiable variables. How would one quantify whether a third country took a decision on the Mobility Partnerships based on a cost-benefit analysis or because it was persuaded by the EU of the appropriateness of this policy? In order to understand why a certain decision was reached, it is necessary to trace the process, conducting interviews in order to understand policy-makers' interests and motivations. This is a very intensive research process and cannot be done for more than a few cases. For this reason, a case study methodology was selected. George and Bennett (2005, p.90) recommend that case study researchers are as transparent as possible regarding their methods, so that the results of their research are more convincing. ${ }^{23}$ This chapter therefore outlines which cases were selected and why, and how the cases were analysed.

\subsection{Research design}

The main research question of the Ph.D. project is: How does the interaction between EU institutions, member states and third countries shape the governance of the EU's external migration policy? The research focuses on explaining the cause(s) - the interaction between EU institutions, member states and third countries - leading to a particular outcome - the governance of the EU's external migration policy. The general

\footnotetext{
${ }^{23}$ Collier et al. (2004, p.239) point out that this applies also to quantitative researchers: given the practice of running several regression analyses in order to reach statistically significant results, quantitative researchers should be open about the number of tests run and the explanatory variables used.
} 
outcome is the Mobility Partnerships. At the EU level (level II), the outcome is an EU policy instrument: the Mobility Partnerships. At the member state and third country levels (levels III and I), the outcome is the decision to participate/not participate in the Mobility Partnerships. The cause for these outcomes is to be found in the process of decision-making at each level leading to the signature/no signature of these partnerships. It should be noted that 'governance' is a broad term and could subsume the entire policy-making process. This thesis is only interested in the negotiation of the Mobility Partnerships, which subsumes three stages of the policy-making process: agenda-setting (recognition that there is a problem that needs to be solved), policy formulation (the proposal of a solution), and decision-making (the choice of one solution over another) (Versluis et al., 2010; Howlett and Ramesh, 2003). The implementation and evaluation of the Mobility Partnerships are not dealt with in this research.

The aim of the research was thus to uncover the reasons why policy-makers made their decisions on Mobility Partnerships; nothing was known about this in advance of the study. In other words, the outcome of each case (Y) was known, but the cause (X) was not. The cases at both the member state and third country levels differ on the outcome displayed. At both levels, two different Xs are posited which can account for these outcomes; the research then establishes the causal process (the precise sequence of events) leading to the outcome to determine which $\mathrm{X}$ was the starting point. The Xs relate to the theoretical explanations developed for each level (see chapter 2). So for the member states, $\mathrm{X}_{1}$ is a cost-benefit analysis (cost-benefit explanation), and $\mathrm{X}_{2}$ is a concept of national identity/role conception (national identity explanation). For the third countries, $\mathrm{X}_{1}$ is a cost-benefit analysis (policy conditionality explanation), and $\mathrm{X}_{2}$ is a process of persuasion (social learning explanation). Each theoretical explanation posits its $\mathrm{X}$ as a necessary and sufficient condition: if $\mathrm{X}$, then $\mathrm{Y}^{24}$

A major strength of case studies is the combination of inquiries into causal effects as well as causal mechanisms: "causal inference via the analysis of causal effects falls short of offering a causal explanation of why an outcome occurs, that is, it remains unclear as to what the causal process and mechanism are that underlie the effect and tie the cause to the outcome" (Rohlfing, 2012, p.3). The aim of this research, as depicted in the research design in figure 3.1, is thus to uncover both causes and causal processes (the sequence of events linking causes to outcomes). It should be noted that the Xs in this research design are not causes in the sense of empirical events that triggered a series of other events leading to the outcome; rather the interest is in an anticipated process (pp.154-158). An explanation of outcomes in terms of an anticipated process "focuses on the considerations that actors make before coming to a decision and/or committing a specific action ... It follows that the empirically relevant process is the decision-making

\footnotetext{
${ }^{24}$ See Mahoney et al. (2009) on necessary and sufficient causes. Necessary and sufficient conditions are related to set-relational causation, as distinct from correlational causation. This distinction is neatly captured by the following example: there is a difference between arguing that high GDP per capita is a cause of low illiteracy (set-relational causation) and arguing that the higher GDP per capita is, the lower the illiteracy rate is (correlational causation) (Rohlfing, 2012, p.32). The choice for a set-relational approach in this research is made based on the set-relational views of the rationalist/constructivist theories being applied to member states' and third countries' decision-making processes.
} 
process that brings about the outcome" (ibid.). The decision/action in this case (the Y) is the decision to participate/not participate in a Mobility Partnership. The processtracing therefore collected pieces of evidence showing that the governments concerned weighed the two alternative courses of action, and determines which logic (rationalist or constructivist) informed these deliberations. Rationalism and constructivism can therefore be seen as the causal mechanisms at work in each of the case studies.

\begin{tabular}{|ccc|}
\hline $\begin{array}{c}\mathrm{X}_{1} \text { or } \mathrm{X}_{2} \\
\text { (cause to be identified) }\end{array}$ & $\rightarrow$ & $\mathrm{Y}$ \\
(causal process to be identified) & (absent or present) \\
\hline
\end{tabular}

Figure 3.1: Research design.

\subsection{Case selection}

Various, overlapping, typologies of case studies have been developed over the years (see Eckstein, 1975; Gerring, 2007; Levy, 2008; Lijphart, 1971). George and Bennett (2005, p.75) summarise the various proposed typologies as follows: atheoretical/configurative idiographic case studies are descriptive and not directly contributing to theory; disciplined-configurative case studies explain a particular event in terms of established theory; heuristic case studies aim at theory-building by studying 'deviant' or 'outlier' cases; theory-testing case studies assess the validity of a single or competing theories; plausibility probes are preliminary tests of new theories/hypotheses. Within these various typologies fits well-known 'case study language'. Most likely cases raise questions about theory: if a theory cannot account for a case when it really ought to be able to, then the validity of that theory is called into question. Least likely cases raise the status of a theory: if a theory can account for a case 'against all the odds', then the theory is strengthened. Typical cases are used in theory-generating or theory-building studies: if the aim is to develop a theory that says something general about a larger phenomenon, then the cases used to make the point should be somehow typical of that larger phenomenon. Crucial cases are studied for the purpose of theory modification: they expose serious flaws in established theory, and in-depth analysis can suggest new hypotheses or alterations to the theory, to be taken into account in future research.

Clearly having such a multitude of different terms to describe similar kinds of case studies is not helpful. There is a real danger of case study researchers simply talking past each other, rather than engaging in useful methodological debate. Indeed, Rohlfing (2012, p.11) argues that, regardless of the type of case study being conducted, the research process is much the same: first concepts are formulated, hypotheses are then formulated or modified (if the research aims to test a hypothesis), cases are selected, the empirical analysis is conducted, and conclusions are drawn regarding the hypothesis being proposed/tested/refined.

At the most basic level, types of cases and case selection is about the role of theory. The cases in this research project are neither atheoretical nor theory-testing. The empirical chapters specifically aim to discern whether rationalist or constructivist explanations 
can better account for member states' and third countries' preferences on the Mobility Partnerships. Theory therefore plays and important role. However, theory-testing is not at the centre of the research: the aim is not to discover flaws in rationalist or constructivist theory. Enough other scholars are already working on this. George and Bennett (2005, p.117) warn that, "if a phenomenon has not previously received wide study, a theory can only make a rather weak claim to being the 'best' explanation". To date, literature on EU external migration policy tends to under-theorise particularly member states' decisions to participate in such policy measures. The policy conditionality and social learning models are well-developed in the area of EU external governance in general, but less so for external migration policy in particular. The Mobility Partnerships specifically have not yet been the subject of in-depth comparative research on all three levels of actors. The results reached about which explanation can best account for member states' and third countries' decisions must therefore be treated with some caution.

Instead, the three-level game model is at the heart of this thesis. The thesis represents the first attempt to thoroughly conceptualise the three levels of EU external policy-making, the links between these levels, and the conditions for agreement to be reached. It applies this model to a recent policy instrument, the Mobility Partnerships. The research is in this sense rather exploratory, aiming to modify existing accounts of the three-level game model which have not been fully conceptualised. For such cases, Rohlfing (2012, pp.66-71) recommends selecting either typical or diverse cases. Typical cases "provide evidence for causal propositions of a broad reach" because they are representative of the phenomenon under study (Gerring, 2007, p.49). Diverse cases are selected based on the assumption that the results from two cases that display extreme values on either the cause or the outcome can be generalised to all the cases lying between these two points (Rohlfing, 2012, p.70). Broadly speaking, the phenomenon under study here is EU external migration policy, and member states' and third countries' decisions to participate in such policy measures: the overarching research question pertains to the governance of EU external migration policy, and how this is shaped by the interaction of the EU institutions, the member states and the third countries. The Mobility Partnerships are conceived as an instance of EU external migration policy. Within this population, there are many possible cases: every decision by a member state or a third country to participate/not participate in a Mobility Partnership is a case. As the explanations posited in chapter 2 for these decisions differ slightly, case selection needs to occur at two levels: at the member state level, and at the third country level.

There is general agreement among scholars that selecting cases randomly (which is the approach used for most statistical analysis) is not appropriate for the study of a small number of cases (Levy, 2008, p.8). Indeed, intentional selection of cases is the only way for researchers to select case studies (Rohlfing, 2012, p.96). However, King, Keohane and Verba (1994, p.128), while acknowledging this fact, nevertheless argue that abandoning randomness opens the door to bias - in particular, they warn against selection on the dependent variable. Case study researchers, they argue tend to select cases which display the outcome that they are interested in; however from a correlational point of 
view, "nothing whatsoever can be learned about the causes of the dependent variable without taking into account other instances when the dependent variable takes on other values" (p.129). Levy (2008, p.8) argues that case studies operating at the within-case level espouse a very different inferential logic to that of King, Keohane and Verba, which means that selecting cases which display the same outcome on the dependent variable is not problematic. ${ }^{25}$ Nevertheless, this Ph.D. includes 'negative cases', where either a member state or a partner country chose not to participate in a Mobility Partnership.

The following sub-section treats the two instances of case selection (at member state level and third country level) separately. However, before examining the case selection, one qualification should be made regarding the time-frame on which the case selection is based. The case selection was finalised in autumn 2009. Given that the Mobility Partnerships are a new policy instrument, it is rather like trying to pin down a moving target: the instrument is constantly changing and evolving, and new partnerships, involving different constellations of member states and different third countries, are being negotiated and signed throughout the duration of this Ph.D. project (20082013). By July 2013, Mobility Partnerships had been signed with Armenia (Council, 2011b) and Morocco (Council, 2013), while negotiations with Ghana appeared to have stalled. It could in the future be that the case selection is no longer valid: perhaps a Mobility Partnership will be signed but the French government will decide not to take part. Perhaps the Austrian government will reverse its policy and decide to take part after all. Or perhaps the negotiations with Senegal will be resumed and a Mobility Partnership will be signed. However, for the purposes of this research, a time frame for the case selection had to be established. This section therefore refers only to those Mobility Partnerships negotiated by the end of 2009. The empirical chapters refer to names of Commission DGs and member states' ministries as they were at the time that the decision on Mobility Partnerships was made, although it will be noted that in several cases DGs and ministries have since changed name and/or function.

\subsubsection{Case selection - member states}

One sub-question presented in the theoretical chapter was: Why do some member states chose to participate in the Mobility Partnerships while others do not? By the end of 2009, Mobility Partnerships had been signed with Moldova, Cape Verde and Georgia. Participation ranges from 5 member states participating in the partnership with Cape Verde, to 16 member states participating in the partnership with Georgia. Table 3.1 shows which member states participate in each of the Mobility Partnerships.

\footnotetext{
${ }^{25}$ Indeed, Collier and Mahoney (1996, p.73) argue that no-variance designs can play an invaluable role in investigating new phenomena.
} 
Table 3.1: Member states' participation in the Mobility Partnerships up to 2009 (Council 2008b; 2008c; 2009a).

\begin{tabular}{lll}
\hline Cape Verde (2008) & Moldova (2008) & Georgia (2009) \\
\hline France & Bulgaria & Belgium \\
Luxembourg & Cyprus & Bulgaria \\
Netherlands $^{26}$ & Czech Republic & Czech Republic \\
Portugal & France & Denmark \\
Spain & Germany & Estonia \\
& Greece & France \\
& Hungary & Germany \\
& Italy & Greece \\
& Lithuania & Italy \\
& Poland & Latvia \\
& Portugal & Lithuania \\
& Romania & Netherlands \\
& Slovakia & Poland \\
& Slovenia & Romania \\
& Sweden & Sweden \\
& & UK \\
\hline
\end{tabular}

Clearly, given the fact that the EU now counts 27 member states, it is not possible to conduct an in-depth case-study analysis of all member states' reasons for joining/not joining the Mobility Partnerships, and therefore a selection has to be made. The member states which will be studied are diverse cases. Diverse cases have maximum variance on the outcome - they are at either extreme of the values possible for Y (Rohlfing, 2012, p.71). Given that the outcome is either present or absent (a member state either participates or does not participate in Mobility Partnerships) it may seem counter-intuitive to argue that the selected cases have extreme values on Y. However, two of the cases are indeed extreme: one member state is selected which has participated in all the Mobility Partnerships to date - the extreme end of 'participation'. The choice of cases on this criterion is limited: France is the only member state that has chosen to participate in all the Mobility Partnerships to date. One member state is selected that has not participated in any Mobility Partnerships. Four member states (Austria, Finland, Ireland and Malta) do not participate in any Mobility Partnerships. This thesis will focus on Austria as an extreme case: the Austrian government was so opposed to the idea of the Mobility Partnerships that it directed a letter to the Commission stating that the intent of the partnerships is to undermine the competences of the member states in the area of labour migration (Interview 21). Given such fierce opposition, the case of Austria is located at the extreme end of 'no participation'. A major advantage of studying diverse cases is that the results can be generalised to all other cases that lie between these cases in terms of their value on Y: "the causal inferences are extended to all other cases because they are

\footnotetext{
${ }^{26}$ The Netherlands did not participate in the Mobility Partnership with Cape Verde from the outset and therefore did not sign the declaration, but joined later in 2008. This table is correct as of July 2013, although it does not include the Mobility Partnerships with Armenia or Morocco. However, as highlighted in the Council conclusions in June 2008, Mobility Partnerships are open to member states joining later (as the Netherlands did with Cape Verde). It is possible that this will also happen with the agreements with Moldova and Georgia.
} 
embraced by the diverse cases" (Rohlfing, 2012, p.201). Nevertheless, to complement the diverse cases of France and Austria, one 'ambivalent' member state is selected - in other words, a member state that has participated in some but not all of the three partnerships, so that the value on Y lies somewhere between the values for France and Austria. Although several countries have signed up to only one or two agreements, the Netherlands (which has only signed the agreements with Cape Verde and Georgia) is selected due to the fact that it did not favour the Mobility Partnerships from the outset. Rather, it joined the Mobility Partnership with Cape Verde later in the process, some months after the agreement had been signed. The process leading up to the Dutch decision to sign the Mobility Partnerships is therefore assumed to be clearly documented, as it entailed a specific change in policy preference. For an overview of the case selection for the member states, see table 3.2.

Table 3.2: Case selection (member states). ${ }^{27}$

\begin{tabular}{llll}
\hline & Participation & Ambivalent & No participation \\
\hline Member state & France & Netherlands & Austria \\
\hline
\end{tabular}

The three cases are similar in many respects. All three are 'old' EU member states, in other words part of the EU15 before the 2004 and 2007 enlargements. They are all members of the Schengen area, and none has an opt-out from the EU's area of freedom, security and justice, meaning that all EU legislation adopted in the area of migration applies to them and must be implemented. In both France and the Netherlands, far-right parties took less than $10 \%$ of the popular vote in the last election before $2007 .^{28}$ In the 2006 parliamentary elections in Austria, the two right-wing populist parties, the Austrian Freedom Party (FPÖ) and the Alliance for the Future of Austria (BZÖ), together took $14 \%$ of the popular vote. ${ }^{29}$ However, in none of the cases was a far-right party part of the government at the time of the decision being taken on the Mobility Partnership. In Austria, the government consisted of a 'grand coalition' between the SPÖ (Social Democratic Party of Austria) and the ÖVP (Austrian People's Party), with the minister of interior provided by the ÖVP. In France, the UMP (Union for a Popular Movement) formed the government. In the Netherlands, the government consisted of a coalition between the Christian Democrats, the labour party, and the Christian Union. In 2007, the ministers for foreign affairs, justice, and social affairs all came from the Christian Democrats. In other words, the ministries responsible for making the decision on Mobility Partnerships in each member state (see chapter 5) were all controlled by centre-right political parties. Types of immigration are also similar across the cases. European Mi-

\footnotetext{
${ }^{27}$ Although the Mobility Partnerships with Armenia and Morocco fall outside the time frame for the case selection for this thesis, it is interesting to note that France and the Netherlands both take part in these new partnerships, while Austria again has chosen not to participate (Council, 2011; Council, 2013). The assumptions about 'positive' and 'negative' cases among the member states therefore still hold.

${ }^{28} 2007$ is the reference point for this section because the member states' decisions on participating in Mobility Partnerships were made during 2007.

${ }^{29}$ Data from http://www.parties-and-elections.eu/ (retrieved 9 March 2012).
} 
gration Network data shows that, for all three countries, the single most important reason for first residence permits to be granted in 2007 was family reunification. ${ }^{30}$ There were differences between the cases in terms of the second- and third-most important reasons: France granted significantly more residence permits for study purposes than for employment; the Netherlands granted significantly more residence permits for employment than for study purposes; whilst Austria granted an equal number of residence permits for both study and employment.

There are, however, also some differences between the cases, which must be acknowledged. Firstly, the immigrant population (as a percentage of the total population) is higher in Austria than in France and the Netherlands. In Austria, non-EU citizens accounted for $6.5 \%$ of the total population in 2007. In France, they accounted for $3.7 \%$ and in the Netherlands $2.7 \%$. The percentage for Austria is thus higher than the EU27 average (4.2\%), whilst for both France and the Netherlands it is lower. Figure 3.2 shows that Austria had the third-highest number of non-EU nationals as a proportion of the total population in the EU in 2007. This might suggest that foreign nationals in Austria choose not to/are not eligible to naturalise, whereas France and the Netherlands have higher naturalisation rates.

Although all three member states received significant numbers of guest workers in the past, these migrants came from different countries of origin. These different migration histories mean that the immigrant populations in each case represent different countries of origin (see table 3.3). Immigration to Austria has been shaped by the permanent settlement of temporary workers recruited from Turkey and the Former Yugoslavia during the 1960s and 1970s (Jandl and Kraler, 2003). France has a long history of immigration, with migrants from the colonies in North Africa (particularly Algeria) arriving already at the end of the $19^{\text {th }}$ century (Currle et al., 2004). Between the 1940s and 1970 s, France recruited migrants to meet the labour needs involved in reconstructing the country. These migrants were mainly recruited from the Mahgreb (Algeria, Morocco and Tunisia) and the Iberian Peninsula, but also to a lesser extent from Turkey and subSaharan Africa (European Migration Network, 2009d, p.7). Starting in the 1960s, the Netherlands recruited unskilled workers from Turkey and Morocco, and since 1970 the Netherlands has seen substantial immigration from the Dutch overseas territories (Wal, 2007; Geddes, 2003). In each of these cases, immigration in the form of family reunification continued even after the guest worker schemes had ended.

\footnotetext{
${ }^{30}$ European Migration Network data for 2007 (http://emn.intrasoft-intl.com/Downloads/prepareShowFiles. do;jsessionid=0F1A2232A40FB70511DD49DB3A2EF52B?entryTitle $=00 \mathrm{~b} . \% 20$ Tables $\% 20$ of $\% 20$ Asylum $\% 2$ 0and\%20Migration\%20Statistics\%202007\%20and\%20earlier retrieved 8 March 2012)
} 


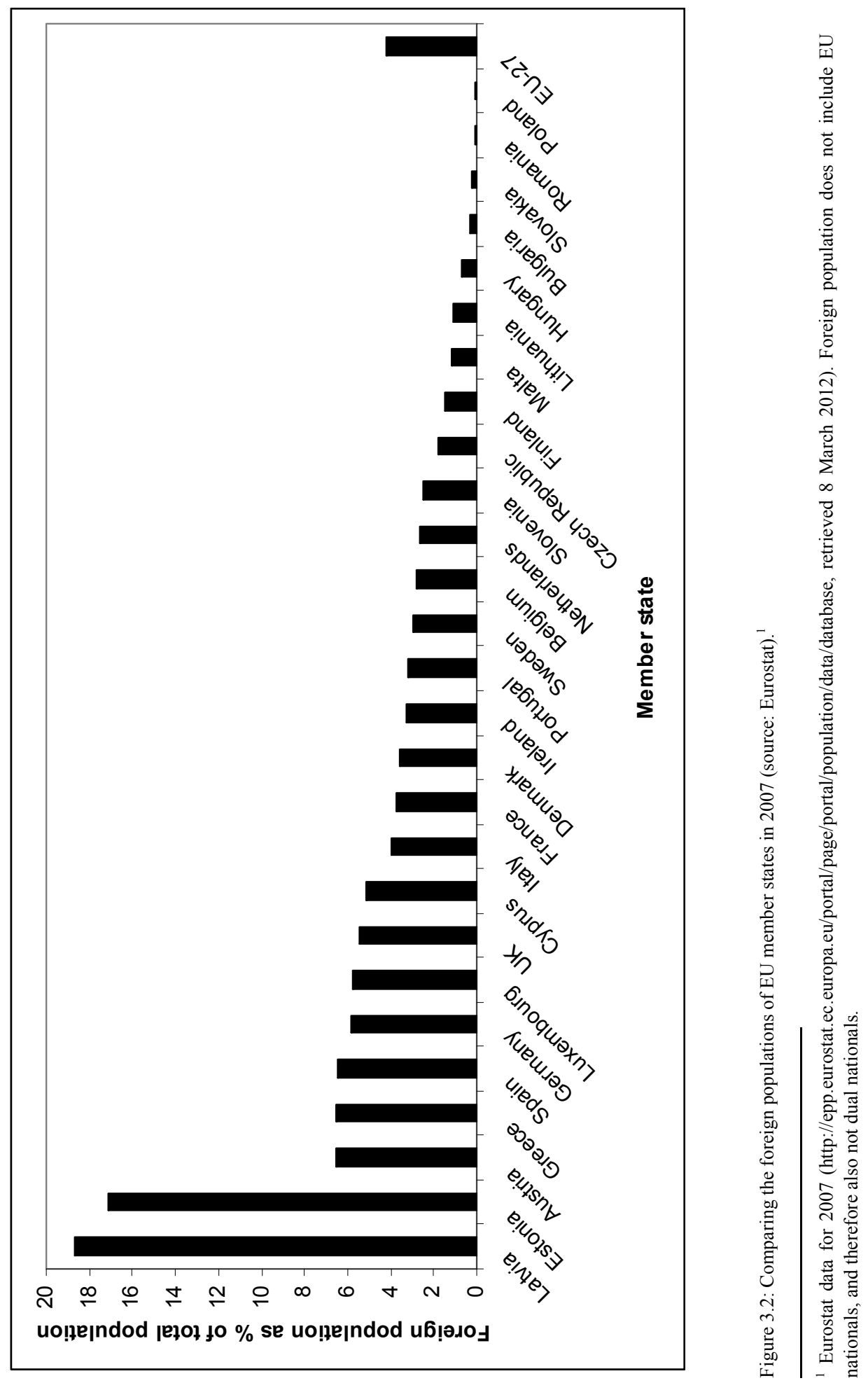


Table 3.3: Top 5 countries of origin of non-EU nationals present in 2007 (source: European Migration Network 2009a; 2009b; 2009c).

\begin{tabular}{lll}
\hline Austria & France & Netherlands \\
\hline Serbia and Montenegro & Algeria & Turkey \\
Turkey & Morocco & Morocco \\
Bosnia and Herzegovina & Turkey & China \\
Croatia & Tunisia & United States \\
Russia & China & Indonesia \\
\hline
\end{tabular}

Current rates of immigration are also slightly different between the three cases selected. Figure 3.3 shows the rate of immigration to the EU member states in 2007 per 1,000 of the total population. As with the immigrant population, the rate of immigration to Austria is higher than for France and the Netherlands. The rate of immigration to Austria (4.768) is slightly higher than the EU-27 average (4.087), whilst for both France and the Netherlands it is lower. France is the 'old' member state with the lowest rate of immigration in 2007.

Finally, Eurobarometer data shows a different salience of immigration as a public issue in the three countries, at least at the time that the decision on participation on the Mobility Partnerships was being made. The issue of immigration was more salient in Austria than in both France and the Netherlands. 26\% of Austrian respondents rated immigration as one of the most important issues facing their country, making it one of the three 'main problems' identified by Austrians. In contrast, 14\% of both French and Dutch respondents rated immigration one of the most important issues facing their country, just below the EU-27 average of $15 \%$. In neither country was immigration one of the main problems identified by respondents (Eurobarometer, 2008b, p.25). This implies a higher politicisation of migration in Austria than in France and the Netherlands. 

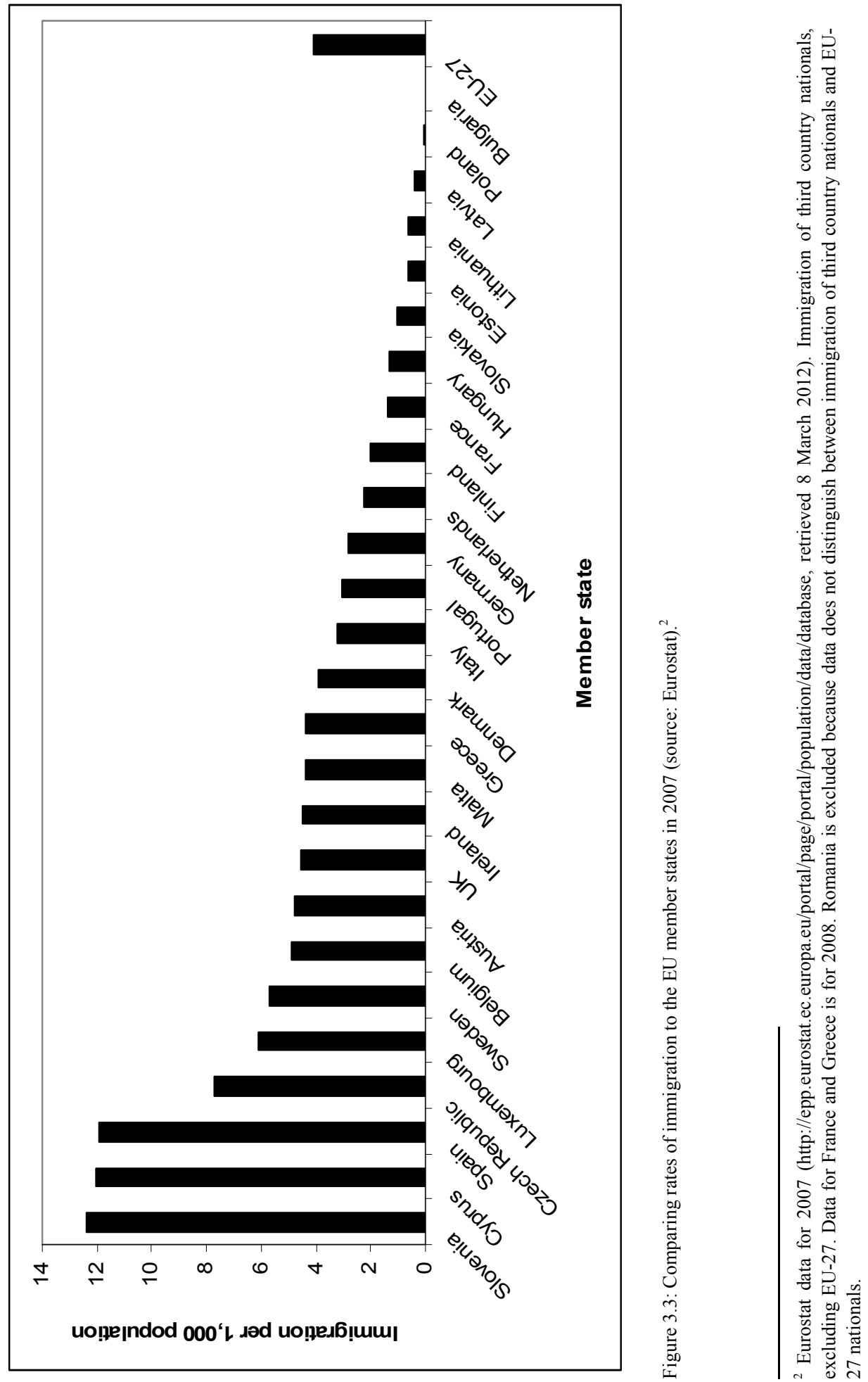
Chapter 5 explains member states' preferences on the Mobility Partnerships in terms of domestic politics: participation in the Mobility Partnerships is favoured if the partnerships match the national identity/role conception, or if the member state expects greater benefits than costs from participation. The differences between the cases are therefore not problematic; indeed, an appreciation of these differences is necessary to understand the "domestic sources of national negotiating positions" at the EU level (Bulmer, 1983, p.353). It is not fruitful to assume that member states are similar in important respects, partly because this does not stand up to empirical scrutiny (Gerring, 2003, p.21), and partly because it is the differences between member states that explain their different preferences on EU policies. Process-tracing (see section 3.4) can make up for the limitations of having cases that are not perfectly similar in all respects but one, because process-tracing establishes the causal mechanisms leading to an outcome. It can therefore establish whether different causal mechanisms in different cases have led to the same outcome (George and Bennett, 2005, pp.214-215). For the purposes of this research, both France and the Netherlands ultimately decided to join the Mobility Partnerships. Process-tracing can uncover whether the same causal mechanisms led to this decision in the two countries.

\subsubsection{Case selection - third countries}

Another sub-question presented in the theoretical chapter was: Why do third countries choose to join a Mobility Partnership? So far, Mobility Partnerships have been signed with countries in the south and in the east, reflecting the balance of the GAM (Commission, 2009d, p.3). These regions are considered important in terms of migration - in 2006, the Commission recognised that countries of Central and Eastern Europe and Northern Africa lack the infrastructure to effectively deal with migration, leading to illegal immigration to the EU (Commission, 2006b, p.4). In the same year, migrants from non-EU European countries and Africa together accounted for approximately 50\% of all immigration to the EU (Eurostat, 2008). West Africa in particular was designated in 2007 as a priority region for migration missions, due to the volume of illegal migrants travelling through this region (Council, 2007a, p.11). Table 3.4 shows the different partner countries for Mobility Partnerships.

Table 3.4: Partner countries for Mobility Partnerships. ${ }^{31}$

\begin{tabular}{|c|c|c|c|}
\hline Signed Mobility Partnership & Negotiations underway & Negotiations stalled & Negotiations still to open \\
\hline Moldova & Ghana & Senegal & Tunisia \\
\hline Cape Verde & & & Egypt \\
\hline \multicolumn{4}{|l|}{ Georgia } \\
\hline \multicolumn{4}{|l|}{ Armenia } \\
\hline Morocco & & & \\
\hline
\end{tabular}

By the end of 2009 (the time-frame for the case selection), Mobility Partnerships had been signed with Moldova, Cape Verde and Georgia, and negotiations with Senegal had

\footnotetext{
31 This table is correct as at July 2013.
} 
stalled. In Eastern Europe, two out of two proposed Mobility Partnerships had been signed. In order to compare a 'positive' case and a 'negative' case, whilst selecting broadly comparable cases, this thesis therefore studies the Mobility Partnerships with African countries. The cases are Cape Verde (the 'positive' case) and Senegal (the 'negative' case). These can be seen as typical cases. Typical cases are selected on two main criteria: "one should choose one case having the outcome present and one case having the outcome absent ... [and] the difference of the selected cases' score on the outcome should be large" (Rohlfing, 2012, p.68). As with the member states, the choice of third country cases is limited: the thesis covers all the negotiations on Mobility Partnerships initiated with African countries by the end of 2009. Given the focus of the Global Approach, it is reasonable to assume that Mobility Partnerships will be agreed with more African countries in the future. Indeed, in June 2013 a Mobility Partnership was signed with Morocco. Negotiations are pending with Tunisia, and are being considered with Libya, Egypt and Jordan (see chapter 1). Negotiations on a Mobility Partnership were initiated with another West African country, Ghana, although these have since stalled; however, these negotiations were initiated after the case selection for this research was made.

Table 3.5: Case selection (third countries).

\begin{tabular}{lll}
\hline & Mobility Partnership & No Mobility Partnership \\
\hline Third country & Cape Verde & Senegal \\
\hline
\end{tabular}

Africa has a different relationship with the EU than do Eastern European countries. This thesis acknowledges that there are therefore likely to be different dynamics and factors at play in Eastern European countries' decision-making processes on the Mobility Partnerships. The aim is not to make statements that are generalisable to the EU's partner countries to the east or south-east. The population that is of interest in this research is therefore migration relations between the EU and African countries; being an African country is a scope condition for the third countries being investigated (Rohlfing, 2012). One significant difference between Eastern European and African countries is that African countries do not have the prospect of membership of the EU. The only African country ever to apply for membership was Morocco in 1987, and this request was rejected on the basis that Morocco is not a European country (Haddadi, 2002, p.151). Nevertheless, the Commission has emphasised the importance of the relationship between the EU and Africa, for example in terms of trade and development but also the political, economic and cultural links existing between certain member states and African countries (Commission, 2005b, p.2). It is therefore vital for the EU to have a "comprehensive, integrated and long-term framework for its relations with the African continent" (ibid.), clearly indicating the importance of this region in the EU's external relations. This communication was followed by the Council's adoption of the EU Strategy for Africa, which recognises that "Europe has a strong interest in a peaceful, prosperous and democratic Africa" (Council, 2005d, p.8) and listed several measures to be achieved, including in the area of migration: addressing the root causes of migration; 
fostering links with development; and combating illegal migration (ibid.). Van Reisen (2007) argues that, due to Europe's colonial past, relations with Africa have played an important role in the EU ever since its inception - indeed, the Treaty of Rome established the principle of 'association' for overseas territories of member states and created the European Development Fund to share the burden of assistance to the colonies.

Relations between the EU and African countries, including both Senegal and Cape Verde, are regulated by the Cotonou agreement. Article 13 of the Cotonou Agreement deals with migration - in particular, article 13(5) stipulates an obligation to readmit own nationals. Under the agreement, five-year country strategy papers are drawn up, and migration is an important component of the 2008-2013 country strategy papers of both Cape Verde and Senegal. The country strategy paper for Cape Verde includes specific objectives on migration under the general objective of support for national security. The objectives focus on improved border control and management of migratory flows (Cape Verde-European Community, 2008, p.39). The country strategy paper for Senegal recalls that Senegal has traditionally been a country of destination for migrants, but it has increasingly become a country of departure. However, migration is not a priority area for cooperation between the EU and Senegal. The national indicative programme focuses on regional integration, sanitation, and budgetary support. Only 8\% of the funds available are allocated to non-priority areas (migration, civil society and culture) (Senegal-European Community, 2008). The migration profiles for both countries highlight the importance of remittances. Although the value of remittances to Cape Verde as a percentage of GDP has declined over the past decades, they are still estimated to make up between 10\% and 20\% of GDP (Cape Verde-European Community, 2008; Carling, 2008, p.23; World Bank, 2011). Remittances are also an important part of Senegal's economy: IOM estimates that remittances made up 12\% of Senegalese GDP in 2007 (IOM, 2009a), whilst the World Bank puts the figure at 9\% of GNI (gross national income) for 2010 (World Bank, 2011). In 2002, remittances to Senegal were estimated to be worth one and a half times the value of official development aid (IOM, 2009a).

There are, however, also important differences between Cape Verde and Senegal. Firstly, there is less emigration from Cape Verde than from Senegal. The net migration rate for Cape Verde of -0.66 per thousand in 2011 is considerably lower than in Senegal, where the rate is -1.9 (CIA World Factbook, 2011a; 2011b; IOM, 2009a). The 2008-2013 country strategy paper for Senegal indicates that a high level of unemployment contributes to illegal emigration (Senegal-European Community, 2008). Migration from Senegal and including Senegalese migrants became headline news in the mid2000s. In 2006, tens of thousands of migrants attempted to reach the Canary Islands, of which 50\% were estimated to be Senegalese. Over 1,000 migrants were confirmed drowned and thousands more were missing (Gerdes, 2007, p.6). Following pressure from Spain, Frontex missions were deployed in Senegalese waters starting in September 2006, in order to prevent further illegal migration from Senegal (van Criekinge, 2008, p.21). In comparison, the 'migration pressure' from Cape Verde is low. The migration profile shows that only 183,000 Cape Verdeans are estimated to live in the EU (Cape Verde-European Community, 2008). This is relatively insignificant compared to the 
numbers of migrants coming from some other African countries. In 2006, for instance, an estimated 481,000 Algerians were living in France alone (European Migration Network, 2009b). By comparison, official figures show that approximately 200,000 Senegalese citizens live in Europe; unofficial figures, however, are much higher, estimating the real number to be more than two million (Senegal-European Community, 2008, p.19). Generally, Cape Verdeans perceive migration as only temporary - most migrants have the intention to return (Carling and Åkesson, 2009; Carling, 2002). The migration profile in the country strategy paper also indicates that Cape Verde is increasingly becoming a country of destination or transit, particularly for ECOWAS citizens (Cape Verde-European Community, 2008).

A second difference between Cape Verde and Senegal is their different economic and governance status. Within the Cotonou Agreement, Cape Verde represents a special case. The country was removed from the list of least-developed countries by the UN, after having satisfied two of the three conditions: GDP and level of human development. For the third condition (degree of economic vulnerability) Cape Verde remains in a weak position (Cape Verde-European Community, 2008, p.18). Nevertheless, Cape Verde has achieved a "high level of governance" (Commission, 2007b, p.3). In comparison, the migration profile included in the 2008-2013 country strategy paper is critical of Senegal's governance of migration, stating that there is a lack of coordination between different actors and no clear leadership by the Senegalese authorities (SenegalEuropean Community, 2008, p.45). This is echoed by the 2009 migration profile by IOM: "Despite the size of regular and irregular migration flows, Senegal has neither a formal migration policy nor a structure dedicated to the migration issue for determining and implementing the national migration policy. Migration management is entrusted to various ministries" (IOM, 2009a, p.28; cf. Dia, 2009). The economic differences between Cape Verde and Senegal are clear from their GDP per capita for 2010: the GDP per capita for Cape Verde $(\$ 3,800)$ is twice that of Senegal $(\$ 1,900)$ (CIA World Factbook, 2011a; 2011b).

Finally, within the Cotonou Agreement, Cape Verde has achieved a special status. In 2007, the Commission issued a communication on the future of relations between the EU and Cape Verde, in which it proposed a 'Special Partnership' (Commission, 2007b). One month later, the Council endorsed this proposal (Council, 2007c). The Special Partnership is "intended to strengthen dialogue and policy convergence between the two parties, so enhancing the traditional donor-beneficiary relationship with a framework of mutual interests" (Commission, 2007b, p.2). This does not signal the end of Cape Verde's inclusion in the Cotonou Agreement - rather, the Special Partnership is to be compatible with the Cotonou Agreement (Cape Verde-European Community, 2008, p.21). It provides for a regular dialogue between the parties, centred around six pillars: good governance; security/stability; regional integration; technology and standards convergence; knowledge-based society; and poverty alleviation and development (Commission, 2007b). The 2008-2013 national indicative programme indicates that $€ 11.5$ million of Cape Verde's allocation ( $€ 51$ million) will be spent on the development of the Special Partnership (Cape Verde-European Community, 2008, p.32). Cape 
Verde is not the only African country in the Cotonou agreement to have a special status: other examples include the Strategic Partnership agreed between South Africa and the EU in 2007 (Council, 2007d) and the association agreements signed with Egypt, Morocco and Tunisia. ${ }^{32}$

The comparison of Senegal and Cape Verde is therefore not a perfect one as there are important differences between the two countries. However, this is the best comparison possible, given that the case selection is limited to those African countries that have so far negotiated a Mobility Partnership. As with the member states, it is not fruitful to assume that third countries are similar in all respects that are relevant to explaining their preferences; indeed, it is the differences in their domestic contexts that explain their different preferences. In the case of Senegal and Cape Verde, their different migration situations might, for example, cause them to have very different national migration policy objectives, which in turn will affect their decision to cooperate/not cooperate with the EU in a Mobility Partnership. Although Senegal and Cape Verde are not demographically, culturally, politically or historically identical to the other African countries (or to each other), they are both part of the Cotonou agreement and the overall structure of their relationship with the EU is therefore representative of the relationship between the EU and Africa.

Five cases are thus selected for this research: France, Austria and the Netherlands at the member-state level, and Senegal and Cape Verde at the third-country level. Rohlfing (2012, pp.24-26) argues that, since a case is usually defined as a bounded empirical phenomenon that is an instance of a population of similar empirical phenomena, the boundaries that delineate the case must be set out. Cases are bound in three main ways: spatially, substantially, and temporally. Spatially, each case in this study is a country. The focus is on policy-makers in the government, but the spatial limitation is the state. Substantively, the cases are instances of decision-making on the Mobility Partnerships. Decision-making is understood as being separate from policy implementation and evaluation: the interest is in how the decision to participate/not participate in a Mobility Partnership was made, not on how this decision, once taken, was put into practice. Temporally, the end point for the case selection has already been defined as autumn 2009. This end point captures member states that changed their policy from nonparticipation to participation, such as the Netherlands. By the end of 2009, the Mobility Partnership with Cape Verde was signed and the negotiations with Senegal were clearly stalled. The starting point for each case will be 2006, because this is the time when the Commission first began to mention the idea of Mobility Partnerships. This allows the case studies to capture member states' and third countries' position during the whole of the evolution of the policy instrument.

\footnotetext{
${ }^{32}$ Respectively OJ L 304, 30 September 2004, pp.39-208 ; OJ L 70, 18 March 2000, pp.2-204; OJ L 97, 30 March 1998, pp.2-183.
} 


\subsection{Process-tracing and causal process observations}

A within-case analysis in this thesis determines how the Mobility Partnerships were negotiated, and the role and preferences of the various actors (EU institutions, member states and third counties). Several authors have argued that case studies suffer from a 'small N many variables problem' (e.g. King, Keohane and Verba, 1994) - in other words, designs with only one or two cases are empirically underdetermined and crosscase comparisons therefore cannot be made. Case study researchers respond that, because there are many observable implications of a theory, there are no studies where $\mathrm{N}$ $=1 .^{33}$ George and Bennett $(2005$, p.151) nevertheless acknowledge that the control required for case study researchers to carry out a comparative analysis of a small number of cases is difficult to achieve, and therefore suggest alternative methods: withincase analyses; counterfactual analyses; and a before-after research design. As they point out, these approaches focus "not on the analysis of variables across cases, but on the causal path in a single case" (p.179). As this Ph.D. project attempts to establish the causal process linking causes to outcomes, the process-tracing method is used. Tarrow (1995, p.472; cited in George and Bennett, 2005, p.177) has pointed out that the goal of process-tracing is not to examine individual causal steps with a view to integrating them "into a larger number of data points but to connect the phases of the policy process and enable the investigator to identify the reasons for the emergence of a particular decision through the dynamic of events". Checkel (2005, p.14) argues that process-tracing can move social sciences away from correlational views of causation towards "theories that capture and explain the world as it really works".

George and Bennett (2005, p.206) define process-tracing as a method that "attempts to identify the intervening causal process - the causal chain and causal mechanism - between an independent variable and the outcome of the dependent variable". Rohlfing (2012, p.158) defines process-tracing as "a method for the collection of casual process observations in order to be able to reconstruct the process that leads to the outcome of interest". This definition specifies that process-tracing aims to collect a specific type of data: causal process observations. Collier et al. (2004) draw a distinction between data-set observations (which are observations in the sense of rows in a data set) and causal process observations which are insights that support the claim about causal effect. Causal process observations may not be directly comparable to each other within a case or across cases; rather, evaluating causal process observations is "similar to assembling a jigsaw puzzle; every piece is more or less different from every other piece, but when put together, they deliver a full picture of the phenomenon of interest" (Rohlfing, 2012, p.30). Process-tracing is based on causal process observations and is there-

\footnotetext{
${ }^{33}$ King, Keohane and Verba (1994, p.212) actually do acknowledge that, as case study researchers work at the level of processes, there are no studies with $\mathrm{N}=1$ because a case study always contains many observations. Collier et al. (2004, p.264) argue that "it is precisely the emphasis on standard quantitative tests that leads [King, Keohane and Verba] to make what we view as a major mistake: subordinating causal-process observations to a conventional quantitative framework". King, Keohane and Verba take as their point of departure an experimental model, which is incompatible with the observational data of qualitative research, acquired "through the unfolding of political and social processes" (p.230).
} 
fore "a style of causal inference focused on mechanisms and processes, rather than on covariation among variables" (Collier et al., 2004, p.260). However, "it is not as though observations . . . can be connected to each other however one pleases. Only certain connections can legitimately be drawn" (Trachtenberg, 2006, p.29). Process-tracing is closely related to theory: when tracing a process, "the researcher looks for a series of theoretically predicted intermediate steps" (Checkel, 2005, p.5). Theoretical explanations cannot be directly 'observed'. As Checkel (2001, p.557) points out, the issue of operationalisation is a difficult one: "How would I know persuasion when I saw it?" In order to evaluate the explanatory power of different theoretical approaches, the researcher should ask him- or herself 'what would I expect to observe if this theoretical explanation holds?' This step-wise procedure "essentially produces a series of minichecks, constantly pushing the researcher to think hard about the connection (or lack thereof) between theoretically expected patterns and what the data say" (Checkel, 2005, p.5). The process-tracing method used in this research is therefore not simply a detailed, atheoretical narrative - it is an analytic explanation based on theoretical expectations (on this distinction see George and Bennett, 2005, pp.201-211).

The theoretical chapter considered the preferences and roles of the actors involved in the decision-making process on Mobility Partnerships at three levels: the EU level (level II of the three-level game), the member state level (level III) and the third countries (level I). Different explanations can account for the preferences of each of these actors. At Level II, the EU institutions (particularly the European Commission) are assumed to always have an interest in creating EU policies because the existence of such policies creates a role for these institutions. If there is no EU policy, there will by default be no role for the EU institutions to play. However, the EU institutions are only able to play a role in the decision-making process in so far as the member states allow them to have an influence in a policy area which is crucial to national sovereignty concerns. Chapter 4 traces the process of decision-making within the EU to determine which actor played the decisive role in the creation of the Mobility Partnerships. Causal process observations which would be associated with a central role of an actor might be:

- Proposing the concept of Mobility Partnerships

- Issuing policy proposals

- Securing a legally binding status for Mobility Partnerships

- Deciding on partner countries

- Proposing projects for a Mobility Partnership

- Conducting negotiations with third countries

One common criticism of case studies is that they have a verification bias: case study researchers are said to impose their favoured hypothesis or explanation on their cases. Case study researchers can counter such criticism by considering alternative theoretical explanations: "The plausibility of an explanation is enhanced to the extent that alternative explanations are considered and found to be less consistent with the data" (George and Bennett, 2005, p.91; cf. Gerring, 2003, p.18 who refers to this as 'comparison of causal arguments'). At both levels I and III, rationalist and constructivist logics are juxtaposed in order to determine which is better able to account for policy- 
makers' decisions. At level III, two competing explanations could account for member states' decisions to participate in the Mobility Partnerships: participation is due either to a fit with a national role conception (national identity explanation) or to a calculation that the benefits of participation outweigh the costs (cost-benefit explanation). Table 3.6 shows the causal process observations that would confirm the explanatory power of each of these explanations (see e.g. Lewis, 2008).

Table 3.6: Causal process observations at level III.

\begin{tabular}{|c|c|c|}
\hline Explanation & National identity & Cost-benefit \\
\hline $\begin{array}{l}\text { Causal process } \\
\text { observations }\end{array}$ & $\begin{array}{l}\text { - policy-makers link Mobility Partner- } \\
\text { ships to a notion of 'appropriate' or } \\
\text { 'inappropriate' policy measures } \\
\text { - participation in Mobility Partnerships } \\
\text { is considered as the 'right' or 'wrong' } \\
\text { thing for the government to do } \\
\text { - Mobility Partnerships match or } \\
\text { contradict ideas about the role the } \\
\text { state 'ought to' play in the EU or in- } \\
\text { ternational affairs }\end{array}$ & $\begin{array}{l}\text { - government choice to participate or } \\
\text { not to participate in Mobility Partner- } \\
\text { ship is linked to an expected outcome } \\
\text { - policy-makers explicitly consider } \\
\text { both the costs and benefits of partici- } \\
\text { pation }\end{array}$ \\
\hline
\end{tabular}

At level I, third countries' decisions to cooperate with the EU in a Mobility Partnership are due either to a third country being persuaded of the appropriateness of a Mobility Partnership (social learning explanation), or to a decision by the government that the benefits of a Mobility Partnership outweigh the costs (policy conditionality explanation). Table 3.7 shows the causal process observations that would confirm the explanatory power of these explanations.

Table 3.7: Causal process observations at level I.

\begin{tabular}{lll}
\hline Explanation & Social learning & Policy conditionality \\
\hline $\begin{array}{l}\text { Causal process } \\
\text { observations }\end{array}$ & $\begin{array}{l}\text { there is interaction and dialogue } \\
\text { between the EU and the third country } \\
\text { on the Mobility Partnerships } \\
\text { the EU attempts to persuade the third } \\
\text { country that a Mobility Partnership is } \\
\text { an appropriate policy instrument }\end{array}$ & $\begin{array}{l}\text { policy-makers explicitly consider the } \\
\text { balance of costs and benefits of a } \\
\text { pobility Partnership } \\
\text { policy-makers consider the resonance } \\
\text { policy-makers in the third country see } \\
\text { tional policy objectives }\end{array}$ \\
& $\begin{array}{l}\text { Mobility Partnerships as an 'appro- } \\
\text { priate' or 'inappropriate' way to deal } \\
\text { with migration issues }\end{array}$ \\
\end{tabular}

\subsection{Sources}

The sources used to support the causal process observations are primary sources, secondary sources, and, crucially, interviews. This section discusses the use of primary and 
secondary sources. The following section is dedicated to reflection on the main source of data in this research, namely interviews.

\subsubsection{Primary sources}

The primary sources used for this project are mainly policy documents at the member state and partner country level, as well as those issued by the EU institutions. Primary sources are particularly useful for gaining an insight into the policy-making process. As George and Bennett (2005, p.98) point out, "when academic scholars attempt to reconstruct how and why important decision were made, they tend to assume an orderly and more rational policymaking process than is justified". Primary sources can therefore provide a more complete picture of the policy process. However, there are also several disadvantages of primary sources which should be acknowledged. Thies (2002, p.356) argues that "of all the primary sources that might be pertinent to your research question, you are automatically dealing with a smaller group" - in other words, there is already some inherent bias in the research. In order to overcome this problem, it is important to evaluate the sources used (ibid.) - George and Bennett (2005, p.100; emphasis in original) suggest that researchers should consider "who is speaking to whom, for what purpose and under what circumstances". This is particularly relevant for this project as it is presumed that the different actors involved (EU institutions, member states, and third countries) have different preferences on the Mobility Partnerships. A variety of types of primary sources should be consulted in order to maximise coverage of the event in question (Thies, 2002, p.357). Primary sources should not be chosen in a selective way to depict the event in question in a way consistent with the favoured theory or hypothesis (p.355). For the purpose of transparency of the research, all primary sources consulted are clearly referenced in the empirical chapters.

\subsubsection{Secondary sources}

The idea of Mobility Partnerships is relatively recent, and so there are few secondary sources dealing with this policy instrument (see also chapter 1). Instead, secondary sources can act as a cue-giver, for example leading to new policy documents which are important in the policy process. The problems of secondary sources should therefore be acknowledged, though they are not likely to cause a serious problem for the research. Lustick (1996; cited in Thies, 2002) warns against the selective use of historians' work to support the argument being made - to overcome this problem, Thies (2002, p.360) argues that research should always use more than one account of the event in question. Another problem with secondary sources is 'presentism' - "descriptions or analyses of the past based on the vantage point of the present" (ibid.). Here it is an advantage to be examining a relatively young policy instrument, so that secondary sources are temporally close to the events they describe. The secondary sources being used may also be biased and base analyses on only some primary sources (p.359). Chou and Gibert (2010), for instance, cite only one interview within the Senegalese administration. As

with primary sources, it is necessary to evaluate each source and to consult several different secondary sources. Trachtenberg (2006, p.64) highlights issues which make a 
secondary source dubious as evidence, such as the absence of references to primary sources and contradictions in the argument being made.

\subsection{Interviews as a data source}

There are not many primary or secondary sources dealing specifically with the Mobility Partnerships and the decision-making processes that are the focus of this study. At the EU level, the main Commission documents on the Mobility Partnerships are the communication proposing their establishment (Commission, 2007a) and the 2009 evaluation (Commission, 2009d). These do not explicitly explain how Mobility Partnerships came to take the form that they do, or why member states and third countries have made different decisions on participating. Various Council conclusions authorise the Commission to take forward negotiations on Mobility Partnerships, but do not reveal or explain the different preferences of the member states on this policy instrument. No government of the member states or third countries selected as case studies has produced any official document explaining their decision on participation in a Mobility Partnership. Given that Mobility Partnerships are a new policy instrument, the number of secondary sources related to the decision-making process is also fairly limited (see chapter 1).

Aberbach and Rockman argue that, in research, "interviews are not always necessary. Written records, for example, may be more than adequate" (2002, p.673). In the case of the Mobility Partnerships, official written records are far from adequate because they do not report on the process of decision-making, only on the decision that has been taken. In order to trace back the roles and preferences of the different actors involved in making these decisions, interviews were a necessary source of information. The interviews conducted were elite interviews, in the sense that interviewees were in decisionmaking roles and were therefore experts on the topic of the research (Leech, 2002a, p.663), in this case the decision-making procedure on the Mobility Partnerships. When conducting research based on interviews, a "sustained time period 'in country' is key to making connections and being able to set up interviews" (Goldstein, 2002, p.671). Table 3.8 gives an overview of the periods of fieldwork for this research project and table 3.9 outlines the number of interviews conducted. A complete, anonymised list of interviewess is provided in Annex I. George and Bennett (2005, p.94) recommend that case study researchers are open and honest in reflecting on the methodological challenges encountered during the process of data collection. This section therefore reflects on the methodological and practical issues associated with the interviews conducted. 
Table 3.8: Overview of fieldwork.

\begin{tabular}{lll}
\hline $\begin{array}{l}\text { Time } \\
\text { September-October 2009 }\end{array}$ & $\begin{array}{l}\text { Location } \\
\text { The Hague, } \\
\text { Netherlands }\end{array}$ & $\begin{array}{l}\text { Organisation } \\
\text { IOMistries of foreign affairs, justice, and social affairs; }\end{array}$ \\
$\begin{array}{l}\text { February 2009- } \\
\text { September 2010 }\end{array}$ & $\begin{array}{l}\text { Brussels, } \\
\text { Belgium }\end{array}$ & $\begin{array}{l}\text { Commission (DG Home Affairs, DG Development, } \\
\text { DG Relex); member states' Permanent Representa- } \\
\text { tions; ICMPD; IOM }\end{array}$ \\
June 2010 & Vienna, Austria & $\begin{array}{l}\text { Ministries of interior, foreign affairs, social affairs; } \\
\text { IOM }\end{array}$ \\
January 2011 & $\begin{array}{l}\text { Paris, } \\
\text { France }\end{array}$ & $\begin{array}{l}\text { Ministries of immigration, foreign affairs, European } \\
\text { coordination office; IOM }\end{array}$ \\
Danuary-February 2011 & Dakar, Senegal & $\begin{array}{l}\text { Ministries; member states' embassies; development } \\
\text { agencies; IOM; Commission delegation }\end{array}$ \\
& Praia, \\
Cape Verde & $\begin{array}{l}\text { ministries; member states' embassies; development } \\
\text { agencies; IOM; Commission delegation }\end{array}$ \\
\hline
\end{tabular}


Table 3.9: Number of interviews conducted

\begin{tabular}{|c|c|c|}
\hline Location & Organisation & Number of interviews \\
\hline Brussels & $\begin{array}{l}\text { European Commission (DG JLS) } \\
\text { European Commission (DG Development) } \\
\text { European Commission (DG Home Affairs) } \\
\text { European Parliament (DG Internal Policies) } \\
\text { Permanent Representation of Portugal } \\
\text { Permanent Representation of the Netherlands } \\
\text { Permanent Representation of France } \\
\text { Permanent Representation of Austria } \\
\text { Permanent Representation of the United Kingdom } \\
\text { IOM }\end{array}$ & $\begin{array}{l}5 \\
2 \\
1 \\
1 \\
1 \\
1 \\
1 \\
1 \\
1 \\
1\end{array}$ \\
\hline The Hague & $\begin{array}{l}\text { Ministry of Housing } \\
\text { Ministry of Justice } \\
\text { Ministry of Social Affairs } \\
\text { Ministry of Foreign Affairs } \\
\text { IOM }\end{array}$ & $\begin{array}{l}1 \\
3 \\
1 \\
3 \\
1\end{array}$ \\
\hline Vienna & $\begin{array}{l}\text { Ministry of Foreign Affairs } \\
\text { Ministry of Interior } \\
\text { Ministry of Labour }\end{array}$ & $\begin{array}{l}1 \\
1 \\
2\end{array}$ \\
\hline Paris & $\begin{array}{l}\text { Ministry of Foreign Affairs } \\
\text { Ministry of Interior } \\
\text { SGAE } \\
\text { IOM }\end{array}$ & $\begin{array}{l}1 \\
2 \\
1 \\
1\end{array}$ \\
\hline Dakar & $\begin{array}{l}\text { Ministry of Interior } \\
\text { Ministry of Senegalese Abroad } \\
\text { Ministry of Foreign Affairs } \\
\text { Ministry of Finance } \\
\text { Ministry of Public Service and Employment } \\
\text { Dutch embassy } \\
\text { French embassy } \\
\text { Spanish embassy } \\
\text { OFII } \\
\text { EU delegation }\end{array}$ & $\begin{array}{l}2 \\
1 \\
4 \\
1 \\
1 \\
2 \\
1 \\
1 \\
1 \\
1\end{array}$ \\
\hline Praia & $\begin{array}{l}\text { Ministry of Foreign Affairs } \\
\text { Ministry of Communities } \\
\text { Office of the Prime Minister } \\
\text { Former Minister of Foreign Affairs } \\
\text { Institute of Communities } \\
\text { National Institute for Employment and Vocational Training } \\
\text { Portuguese embassy } \\
\text { Luxembourg embassy } \\
\text { EU delegation } \\
\text { EU common visa centre } \\
\text { CAMPO } \\
\text { IOM }\end{array}$ & $\begin{array}{l}7 \\
1 \\
1 \\
1 \\
1 \\
1 \\
1 \\
1 \\
1 \\
1 \\
1 \\
1 \\
1\end{array}$ \\
\hline
\end{tabular}




\subsubsection{Criticism of interviews}

Interviews may provide insights into the 'informal' part of the policy process, particularly any aspects of decision-making which are undocumented. However, interviews are criticised as a data source, particularly in terms of reliability: are the results achieved from different interviews consistent? (Berry, 2002) This thesis is, however, interested precisely in the differences between interviewees. Chapter 2 argued against 'blackboxing' entities, such as 'the EU', 'the French government', 'the Commission', 'the Senegalese government'. Within each entity, different policy-makers played different roles and may have different preferences on the Mobility Partnerships. Differences between interviewees are an empirical fact and are highlighted in the empirical chapters. Of course it is important to recognise that interviewees tell, at best, a version of 'the truth':

Interviewers must keep in mind that it is not the obligation of a subject to be objective and tell us the truth. We have a purpose in requesting an interview but ignore the reality that subjects have a purpose in the interview too: they have something they want to say ... They're talking about their work and, as such, justifying what they do. That's no small matter (ibid., p.680).

Berry suggests three strategies for countering this tendency of interviewees to exaggerate certain details and leave others out. All these strategies were used in the interviews conducted for this research. Firstly, it is important to use multiple sources. The aim of the fieldwork for this Ph.D. was to interview at least two policy-makers in each department working on the Mobility Partnerships (although in some cases only one person in any given department had been involved in the Mobility Partnerships). Secondly, the interviewer can ask the subject to critique his or her own case. For instance, Commission documents on the external dimension of migration policy were used to take member states' policy-makers away from their own point of view to the more general politics of the Mobility Partnerships. Finally, an interviewer should ask about other participants in the policy-making process. This was the very aim of this research, and interviewees were always asked about the role of other departments in their own administration, and the other actors in the three-level game.

\subsubsection{Interviewees}

Once the choice had been made to conduct interviews, consideration had to be given to which interviews to select and how to find these people. Goldstein (2002) argues that sampling is not only a concern for quantitative researchers; researchers conducting elite interviews should also be concerned to identify a target population and draw a sample that is representative. This is not always straightforward. The limited number of public documents available on Mobility Partnerships was the main reason for choosing to conduct interviews, and yet it also made it difficult to identify the policy-makers that had been involved in the decision-making process. Interviewees were therefore sampled using a 'snowball' method (Weiss, 1994, p.25; Goldstein, 2002, p.671), based on two initial interviews in DG JLS of the European Commission. These two initial interviews 
made use of existing points of access (Goldstein, 2002, p.671), demonstrating that conducting interviews relies, unfortunately, on a bit of luck (Woliver, 2002, p.678). Yanow (2000, p.38) suggests asking at the end of each interview 'with whom else should I be speaking?' This approach was adopted during this research as well, and was very fruitful - interviewees in the Commission, for example, pointed to officials in member states' permanent representations in Brussels, and these in turn pointed to the relevant policy-makers in their capitals. Snowball sampling can overcome the problem that elite systems are not stable over time (Aberbach and Rockman, 2002, p.675) - policy-makers move to different positions within the bureaucracy. This was the case also for this research. For instance, in the Dutch ministry of foreign affairs, all policy-makers are rotated after a maximum of four years in one position. However, when using snowball sampling this is not problematic, because people remember who they worked with on a particular policy issue, even if that person has since moved to another function.

The aim was for the sampling frame to be equivalent to the target population (Goldstein, 2002, p.670). The Mobility Partnerships are one policy tool, and therefore presumably a limited number of policy-makers had been involved. It should therefore be possible to identify and interview them all. Ultimately, two obstacles prevented this: firstly, not all those approached in any given research project wish to be interviewed. They may be too busy (Aberbach and Rockman, 2002, p.673), or may simply not want to take part in the research. This happened in only one instance in this case: an official in DG Development did not feel qualified to answer questions on the Mobility Partnerships. In such a case, one can be "politely persistent", and follow up an email with a phone call to attempt to arrange the interview (ibid.). If this fails, however, the best that the researcher can do is take into consideration how different those interviewed are from those who refused to be interviewed (Golstein, 2002, p.670). The official who refused to be interviewed was working in DG Development on the Mobility Partnerships from a thematic point of view, rather than his two colleagues who were working from a geographical point of view. As Goldstein (p.672) points out, "unlike those doing survey research of the mass public, researchers using elite interviews actually know quite a bit about those who remain uninterviewed". In this case, something is known about the views of DG Development in general about migration issues (Boswell, 2008; 2003).

The second obstacle to interviewing the entire target population is a practical one: namely the limits (time and money) on field research. This was a particular problem in this research for the case studies of France, Austria, Senegal and Cape Verde. Visiting these countries again for follow-up interviews would be difficult to arrange within the time-span of the project. One French official was unavailable during the field research in Paris, so a follow-up interview was conducted by email. One Austrian official was unavailable during the field research in Vienna, so a follow-up interview was conducted by telephone. Despite intense efforts (also by the student assistant in Praia), an official of the Cape Verdean ministry of interior could not be contacted during the field research there. 


\subsubsection{Preparing the interviews}

All interviewees were approached first and foremost by email. ${ }^{34}$ The email outlined briefly the nature of the research, stated who had provided the interviewee's contact details, made the request for input, and suggested a possible date for the interview. The email mentioned Maastricht University and made use of the official university email signature (cf. Goldstein, 2002, p.671 on using official stationary). Sending an email in this way allowed interviewees to read the information in their own time, rather than being caught off-guard and at a busy moment with a phone call. If there was no response, the email was followed up 2-3 weeks later with another email, and after that with a phone call.

Approaching interviewees must be done carefully: they must not be misled as to the nature of the research, but it is also not possible to give precise details of research questions and hypotheses because this may affect the answers they give (Woliver, 2002). Fortunately the policy instrument which formed the case study for this research - the Mobility Partnerships - is specific enough that simply mentioning this as the topic of the interview in the email sent was sufficient. No interviewee requested details on the exact aims of the research.

Leech (2002b, p.666) stresses that it is important to put interviewees at their ease. It can, for instance, make interviewees nervous if a researcher wants to 'interview them'. 'Talking with them' is much less threatening. The emails sent to interviewees in this research requested "a meeting" to gain "input" for the Ph.D. research. It is also important to consider the ethical issue of confidentiality (Kvale, 2007, pp.27-28). Interviewees were told at the beginning of the interview that their responses were confidential, in the sense that arguments or quotations would not be linked to their name, and that the information gathered would only be used for academic purposes. Gaining good rapport with interviewees is essential to snowball sampling - interviewees will only open doors to other potential interviewees if they feel comfortable with the researcher (Goldstein, 2002, p.671).

Another aspect of putting interviewees at ease which played a role was an issue of language. Interviewees in France, Senegal and Cape Verde were approach in their native languages (interviewees in the EU institutions, Austria and the Netherlands were all competent in, and happy to conduct the interview in English). This necessitated the hiring of student assistants in France, Senegal and Cape Verde to assist with translation of emails to interviewees and interpretation during the interviews. ${ }^{35}$

\subsubsection{Conducting the interviews}

Researchers must choose between three main types of interviews: ethnographic style, unstructured interviews; structured interviews with close-ended questions; and semi-

\footnotetext{
${ }^{34}$ An exception is the fieldwork in Senegal. Senegalese ministries insisted that requests for interviews be submitted by regular mail, after which the secretary of the person concerned would get in touch. However, the text of the letter was the same as that usually sent by email.

${ }^{35}$ Coincidentally, two of these student assistants were migrants themselves: the student assistant in Senegal was from Benin, and the student assistant in Cape Verde was from Guinea-Bissau.
} 
structured interviews. Both unstructured and structured interviews were inappropriate for this research project. Unstructured interviews are useful for gaining insights into the interviewee's world, but not for exploring hypotheses. Structured interviews are useful if a researcher already has a lot of knowledge about a topic, but close-ended questions can backfire if the researcher asks the wrong questions or omits a response option. Semi-structured interviews with open-ended questions are the middle ground: they can "provide detail, depth, and an insider's perspective, while at the same time allowing hypothesis testing" (Leech, 2002b, p.665). Semi-structured interviews are appropriate when interviewing elites, because these people do not appreciate "being put in a straightjacket of close-ended questions" Aberbach and Rockman, 2002, p.674). Instead, "open-ended questions have the virtue of allowing the subjects to tell the interviewer what's relevant and what's important rather than being restricted by the researcher's preconceived notions about what is important" (Berry, 2002, p.681).

How the researcher presents him- or herself during the interview is important. Leech (2002b, p.665) recommends presenting oneself as knowledgeable on the general political context and decision-making procedures, whilst having no idea about what happened in the particular instance that is the subject of the research. This is the approach adopted in this research: I presented myself as knowledgeable on EU decisionmaking procedures and external migration policy in general, but with little idea about how the Mobility Partnerships were decided upon. Leech (2002b, p.665) warns against "playing dumb" with interviewees, because they will feel that they are wasting their time; however, cultural factors should be taken into account. Senegalese interviewees (who were, almost without exception, middle-aged men) seemed to enjoy lecturing to the 'young white woman', and allowing them to do this made them more open later to more sensitive questions.

It is advisable to begin the interview with a 'grand tour' question, which requires the interviewee to give an outline of something they know well, in order to get them talking (Leech, 2002b, p.667). As "people find talking about themselves about as fascinating as any subject they know" (Aberbach and Rockman, 2002, p.675), this helps to put interviewees at ease. Interviewees for this research project were always asked first to outline their own involvement in the Mobility Partnerships. From then on, the next questions depended on the answer to this first question and on the placement of the interviewee (in the European Commission, in a member state's ministry, or in a third country's ministry). As Leech $(2002 b, p .668)$ points out, the first grand tour question may actually render some planned later questions redundant, because the interviewee already answers them.

Woliver (2002, p.678) recommends ending the interview by asking a question like "“Is there anything you would like to tell me about which I haven't thought to ask you?' ... Interviewers cannot anticipate everything and you need to give the respondents openings to tell you about an event, connection, or insight that you didn't think to ask them about". This approach was also adopted in this research to ensure that vital information was not missed. 
Interviews were tape-recorded. Aberbach and Rockman (2002, p.675) argue that this helps to "facilitate the use of a conversational style and to minimise information loss". Tape-recording ensures accuracy and provides a record in case the interviewee later disputes the way in which the results of the interview are reported. Indeed, deciding which question to ask next whilst also listening to the current answer and taking notes, is a difficult task (Berry, 2002, p.682). The only interviewees who refused to be taperecorded were the officials in the Senegalese ministry of foreign affairs, one official in the Cape Verdean ministry of foreign affairs, and one official in DG JLS of the Commission. The wishes of these interviewees were respected.

\subsubsection{Analysing the interviews}

Having been tape-recorded, all interviews were transcribed according to a denaturalised approach: grammar was corrected and interview noise removed (Oliver et al., 2005). As the research did not aim to apply quantitative techniques to analyse the data collected, no systematic coding procedure was used (Aberbach and Rockman, 2002; Aberbach et al., 1975); rather, interviews were analysed through a close reading, matching interviewees' responses with the causal process observations expected according to the competing theoretical explanations (see sections 2.4.1 and 2.5.1).

\subsection{Conclusion}

This chapter has set out the case study methodology applied in this research project. Case selection occurred at two levels: the member state level, and the third country level. The member states selected are France, Austria and the Netherlands; these are diverse cases in terms of their score on the outcome (participation in the Mobility Partnerships). The third countries selected are Senegal and Cape Verde; these are typical cases. The following chapter deals with the EU level (level II of the three-level game). It examines the role of the EU institutions and the member states in the negotiation of the Mobility Partnerships, and the impact this had on the form of the partnerships. 


\section{Chapter 4 The EU level}

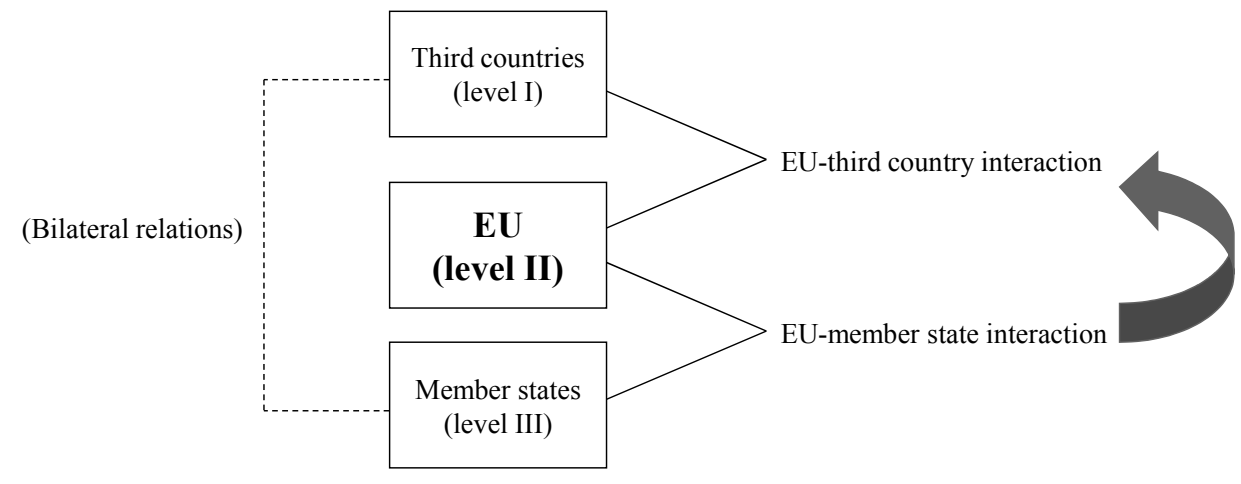




\subsection{Introduction}

This chapter deals with the EU level (level II of the three-level game). It maps the governance at the EU level of the particular case of external migration policy being examined in this research: the Mobility Partnerships. It answers the first two sub-questions of the project as presented in chapter 2: what was the role of the EU institutions and the member states in the negotiation of the Mobility Partnerships? And what implications does this have for the form of the partnerships? This chapter thus specifies the politics of EU external migration policy and the nature of negotiations between the EU institutions and member states on policy content.

The member states therefore form (one of) the subjects for both chapters 4 and 5 . This chapter concerns decision-making at the EU level, of which the member states are an inevitable part. The chapter shows that member states sought to maintain control over the policy-making process at the EU level on the Mobility Partnerships: their national external migration policies indirectly influenced the Commission proposal on Mobility Partnerships; the member states in the Council mandated the Commission to negotiate Mobility Partnerships; member states determined the legal form and specific content of the Mobility Partnerships; and member states controlled the selection of third countries with which partnerships should be negotiated. This chapter thus deals with the general role of the member states in the policy-making process. It does not answer the question of why individual member states chose to participate in the Mobility Partnerships; it is chapter 5 which opens up the 'black box' and examines the cases selected for this study (France, Austria and the Netherlands). This chapter refers to the general concerns expressed by member states over the Mobility Partnership instrument; chapter 5 examines the specific domestic considerations for the cases selected in order to explain why these member states decided to participate or not.

This chapter begins with a brief section concerning policy-making in the EU, before accounting for the role of the various EU institutions in the decision-making process on the Mobility Partnerships. Decision-making on the Mobility Partnerships actually encompassed two separate, but overlapping, elements: first the Commission communication was published setting out the purpose and principles of this policy instrument (this is dealt with in section 4.4); then once this general outline of the Mobility Partnerships had been agreed, specific individual Mobility Partnerships were signed with third countries (section 4.5). ${ }^{36}$ Figure 4.1 summarises the decision-making process in the form of a timeline of the Mobility Partnerships.

\footnotetext{
${ }^{36}$ As outlined in chapter 3, the time-frame for the case-selection was 2006-2009. The Mobility Partnerships with Armenia and Morocco fall outside of this time frame, having been signed in 2011 and 2013 respectively. This thesis will therefore refer mainly to the partnerships with Moldova, Cape Verde and Georgia, and the failed negotiations with Senegal.
} 


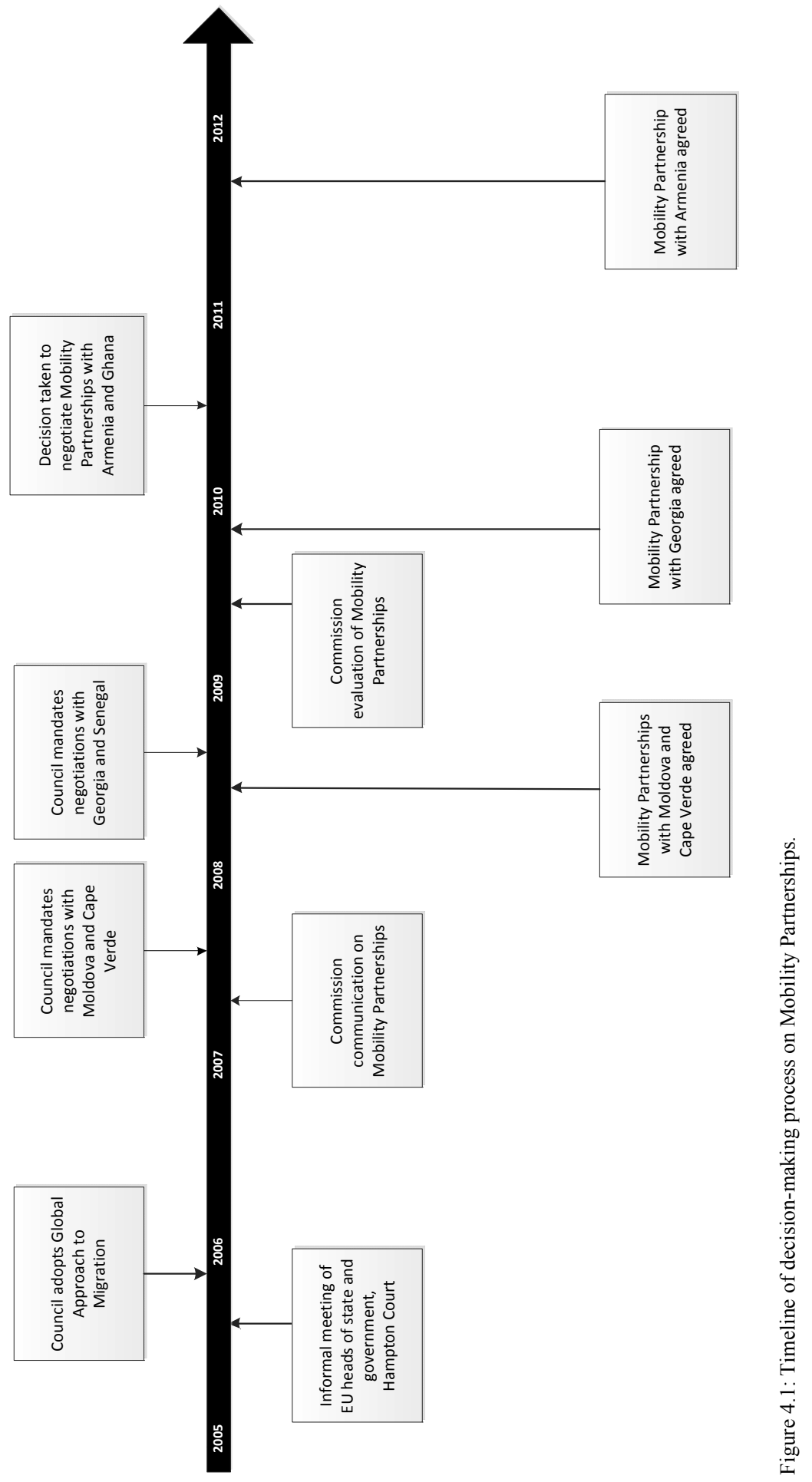




\subsection{Policy-making in the EU}

In the classic 'community method' of policy-making, EU policies are proposed by the Commission and decided on by the Council, with some degree of involvement of the European Parliament. The resulting legislation is subject to the jurisdiction of the European Court of Justice (Nugent, 2010, p.294). This thesis, however, is dealing with a policy instrument that does not envisage the adoption of EU legislation. Several scholars point out that there is no single version of the EU policy-making process; rather, the role of the various institutions depends on the policy area concerned (Nugent, 2010; Wallace, 2005a). Both JHA and foreign policy-making are better described by 'intensive transgovernmentalism', where the member states (in the European Council and the Council) dominate the process, with only a limited role for the Commission and European Parliament (Wallace, 2005a, p.87; see also chapter 2). Indeed, international agreements such as the Mobility Partnerships exemplify a three-level game, where both the member states and the third countries also make a decision on whether or not to participate. Even when EU legislation is being proposed, the story is not as simple as 'the Commission initiates'. The Commission may be at the centre of policy formulation, but due to the consensus oriented nature of the EU system it must still ensure support for its policy proposals if agreement is eventually to be reached with the Council and the European Parliament (Versluis et al., 2010, pp. 133-134). It is also misleading to speak of 'the' Commission, 'the' Council or 'the' European Parliament as unitary actors. Within the Commission, it is officials in the DGs that undertake practical policy work; in the Council, important 'pre-cooking' of policy decisions is done by working groups consisting of national experts or representatives from the member states' Permanent Representations; and in the European Parliament the parliamentary committee and rapporteur responsible for a particular policy proposal play an important role in formulating the final parliament position (pp.33-38). Within each institution, different bodies may have different interests or compete for influence. In the drafting of the EU's Strategy for the External Dimension of JHA, for instance, DG JLS of the Commission marginalised other DGs (Pawlak, 2009, p.33). This chapter takes account of this nuanced picture by referring to the specific bodies involved at all stages of the policy-making process on the Mobility Partnerships.

The remainder of this chapter is structured according to the stages of the policymaking process (Versluis et al., 2010). It starts by outlining the agenda-setting behind the Mobility Partnerships: how did the idea of a partnership on migration issues with third countries become an issue deserving serious consideration within the EU? This section also highlights the type of policy tools being employed by the EU before the Mobility Partnerships were developed. The chapter then goes on to look at the process of policy formulation: how did the policy proposal for Mobility Partnerships emerge? What were the main features of the Commission's communication? Finally, the chapter looks at the process of decision-making on the Mobility Partnerships: how was the pol- 
icy proposal decided upon? What form do the signed Mobility Partnerships take ${ }^{37}$ Each section outlines the role of the various EU institutions (Commission, member states in the Council, European Parliament and other EU institutions) in the Mobility Partnerships.

\subsection{Agenda-setting: the policy background to the Mobility Partnerships}

Two trends are evident in EU policy documents since 2000: firstly, an awareness of increased and continuing international migration flows; and secondly, a resulting need for the EU to cooperate with third countries on migration issues. ${ }^{38}$ These trends have been emphasised both by the Commission and by the member states in the Council.

In its communication on a community immigration policy in 2000, the Commission noted that "large numbers of third country nationals have entered the Union in recent years and these migratory pressures are continuing with an accompanying increase in illegal immigration, smuggling and trafficking" (Commission, 2000, p.3). This increased immigration to the EU can be explained by the imbalances between wealthy European countries with ageing populations on the one hand, and poorer third countries with young and fast growing populations on the other (Commission, 2006b, p.3). There are also specific push factors at play in developing countries, such as "failing economies, impoverishment of the population, human rights violations, environment degradation . . . civil war, wars for control of natural resources, political persecutions, political instability, corruption and dictatorships" (European Parliament, 2006b, p.3). The increased immigration to the EU is characterised by "a rise in the absolute number of migrants, including in the number of women, the multiplication of the types of migration, the increase in trafficking in human beings, the growth of diasporas, the integration challenges for the migrants and the host countries . . . the diversification of destinations and origins, and the multiplication of migration routes" (Commission, 2006b, p.4). Particularly the human cost of illegal migration has often been emphasised, for example in 2005 when several migrants lost their lives trying to enter the Spanish enclaves of Ceuta and Melilla (see chapter 1). This led to an informal meeting of EU heads of state and government at Hampton Court in October 2005, where it was agreed that more needs to be done to prevent illegal migration (Bosch and Haddad, 2007, p.7). In response to the meeting at Hampton Court, the Commission issued a communication stating the EU's commitment to respond to the challenges of illegal migration in order to avoid the "human tragedy that is a frequent consequence" (Commission, 2005c, p.3).

\footnotetext{
${ }^{37}$ In reality, it is very difficult to draw a clear distinction between the different stages of the policy-making process (Versluis et al., 2010, p.133). They are separated here for heuristic reasons, but there is clearly overlap in particular between agenda-setting and the first stages of policy formulation. The policy-making process contains two further stages: implementation and evaluation. These are, however, not relevant to the research questions of this thesis and are therefore not considered.

${ }^{38}$ These trends have continued to be emphasised in policy documents up to the present (e.g. Commission, 2011h; Council, 2009b), but this section concerns the policy context leading up to the launch of the concept of Mobility Partnerships, and therefore examines only policy documents up to 2007.
} 
The need to cooperate with third countries is considered essential if the EU is to regulate immigration (e.g. Commission, 2000, p.22). Third countries should be involved in "helping to manage the migration flows, stem illegal immigration and set up effective information campaigns on the conditions in the recipient countries of the EU including the criteria for obtaining asylum" (European Parliament, 2006b, p.3). Several policy documents emphasise that this cooperation should be differentiated according to the type of country of origin, making a distinction between applicant countries for EU membership, countries that are party to a regional programme funded by the EU, and other third countries (Commission, 2002b, p.46). In a 2001 communication, the Commission made suggestions as to how migration should be integrated into the EU's external relations: taking account of migration when planning development cooperation; enhancing the positive impacts of migration, such as remittances from migrants abroad, whilst reducing the negative impacts, such as brain drain; encouraging migrants resident in the EU to maintain links with their countries of origin; discouraging illegal migration, amongst others by ensuring that a framework for legal migration exists; supporting third countries' efforts to manage migration; and supporting the reintegration of returning migrants in their country of origin (Commission, 2001b, pp.10-11). Cooperation is particularly important on illegal migration (Commission, 2006a, p.3; Council, 2002a, p.10), specifically on issues of return and readmission: "third countries must readmit their own nationals unlawfully present in a Member State, and, under the same conditions, nationals of other countries who can be shown to have passed through their territories before arriving in the EU" (Commission, 2002a, p.9; cf. Council, 2002a, p.11).

As an indication of the importance of cooperation with third countries on migration issues, specific budget headings have been created to finance such actions. Cooperation with third countries was financed from 2001 to 2003 from the budget heading B7-667. This heading was created in the general budget of the EU as a preparatory action, in order to assess the appropriateness and effectiveness of funding in this area. The budget heading belonged to JHA, and so DG JLS of the Commission controlled the selection of projects to be implemented (Coleman, 2009, pp.122-123). Budget heading B7-667 was replaced in 2004 by the AENEAS programme to assist third countries to manage migratory flows, and AENEAS was replaced in 2007 by the thematic programme for cooperation with third countries in the areas of migration and asylum (Commission, 2006b). DG JLS also controlled the AENEAS programme (Coleman, 2009, p.125), however the thematic programme is part of the EU's DCI, and is thus controlled by DG Development.

Cooperation with third countries on migration issues has been central to the EU's multi-annual programmes on JHA. The Tampere programme called for a common EU asylum and migration policy to be based on four elements: a common European asylum system; fair treatment of third country nationals; management of migration flows; and partnership with countries of origin (Council, 1999a). The Hague programme acknowledged that "asylum and migration are by their very nature international issues. EU policy should aim at assisting third countries . . . in their efforts to improve their capacity for migration management" (Council, 2004b, p.20). The external dimension of asylum 
and migration is therefore one of the specific orientations of the programme, including partnership with countries and regions of origin and an effective return and readmission policy.

Against this background, the Council, under the UK presidency, adopted the Global Approach to Migration in December 2005 (Council, 2005a). The GAM builds on the Commission's follow-up to the Hampton Court meeting (Commission, 2005c), but also on the Strategy for the External Dimension of JHA (Council, 2005c). The Strategy emphasised again that issues such as terrorism, organised crime, corruption, drug smuggling and migration cannot be dealt with by the EU alone. It is therefore necessary to work in partnership with third countries, based on certain principles: incentivising cooperation on JHA for third countries; adopting a differentiated approach to third countries; ensuring coherence between the EU's internal and external policies; ensuring coordination between EU and member state actions; and monitoring and evaluating actions properly (p.5). The GAM incorporates cooperation with third countries across three dimensions: legal migration, illegal migration, and migration and development (Council, 2008f, p.4).

How has this perceived need to cooperate with third countries on migration issues been implemented in practice? The GAM sets out certain actions to be taken with regard to African and Mediterranean countries: increasing operational cooperation between member states, for instance through the work of Frontex or by establishing regional networks of Immigration Liaison Officers; implementing a dialogue on migration with Africa through various fora including the EU-Africa ministerial troika discussions, the EU-Africa ministerial conference, ECOWAS, the Cotonou Agreement, and the United Nations High Commissioner for Refugees (UNHCR); and working with neighbouring countries, for instance on a Mediterranean Coastal Patrols Network, and particularly with Morocco, Algeria and Libya (Council, 2005a). In 2007 the GAM was extended to countries to the east and south-east of the EU, particularly the Western Balkans, Turkey, countries in the ENP, and Russia (Council, 2007e). At this occasion, the Council also suggested further possible actions to be taken under the Global Approach, including: establishing common visa application centres; organising joint return flights through Frontex; establishing migration cooperation platforms with third countries; strengthening cooperation on migration through Ministerial Conferences; promoting networks of companies and academic institutions in third countries and EU member states; providing information to migrants about the costs of sending remittances; carrying out information campaigns to raise awareness of the danger of trafficking in human beings; and supporting third countries to effectively implement EU readmission agreements (ibid.).

The Commission's 2002 communication on integrating migration in the EU's external relations includes an overview of the projects related to migration programmed for third countries in the period 2000-2006 (both from the community budget and from the European Development Fund). It shows that projects were programmed under the following headings: refugees and displaced populations (21 projects); migration management (24 projects); voluntary return (23 projects); fighting illegal immigration (8 projects); border management (19 projects); JHA (5 projects); and development (2 pro- 
jects) (Commission, 2002b). Examples of types of projects include: information campaigns; capacity-building of the civil service of the third country concerned (e.g. to implement a migration and asylum policy); technical assistance (e.g. with border control systems); material assistance (e.g. with constructing a migrant reception centre); action plans on migration; and support to diaspora in developing projects in their country of origin (ibid.).

The two main tools in the cooperation with third countries on migration issues have been readmission and visa facilitation agreements (see also chapter 1). These agreements have been combined in the EU's external relations: in order to encourage countries to accept the onerous conditions attached to readmission agreements, visa facilitation agreements are used as a 'carrot'. As a former official of DG JLS phrased it: "it's no use trying to sell to a third country the idea of a readmission agreement if you don't have anything to offer" (Interview 20). Readmission agreements are in principle reciprocal, obligating EU member states to also take back their own or third-country nationals illegally present on the territory of the other signatory state. However, this reciprocity is unlikely to be utilised, as "the countries with which [the EU concludes readmission agreements] would not in theory have any problem with expulsions to the Community" (Council, 2002c, p.2). Starting in 2004 the member states in the Council therefore began to accept the linking of readmission agreements to visa facilitation agreements (Coleman, 2009), although the Council has stressed that the signature of a readmission agreement will not automatically lead to the opening of negotiations on a visa facilitation agreement (Council, 2005b). As of February 2011, there were 18 countries with which negotiations on readmission agreements were foreseen, ongoing, or concluded. ${ }^{39}$ 10 of these 18 proposed or concluded readmission agreements have been linked to visa facilitation agreements (Commission, 2011i). ${ }^{40}$

In addition to a thematic focus on the external dimension of migration policy at the EU level, migration appears as a topic in several geographic policy instruments. The most important for these in terms of the Mobility Partnerships are the ENP, the PCAs, and the Cotonou Agreement.

Firstly, a 2007 communication by the Commission emphasised that the promotion of mobility should be an important element of the ENP. Increased mobility "will go hand in hand with the commitment of our partners to increase security and justice and fight illegal migration" (Commission, 2007c, p.5). ENP Action Plans cover cooperation on migration issues under the titles on cooperation in JHA. Measures that could be taken include "support for the creation and training of corps of professional, non-military border guards and measures to make travel documents more secure" (Commission, 2004a, p.17). Second, cooperation on prevention of illegal migration is a topic in the

\footnotetext{
${ }^{39}$ Readmission agreements were in force with Hong Kong, Macao, Sri Lanka, Albania, Russia, Ukraine, Macedonia, Bosnia and Herzegovina, Montenegro, Serbia, Moldova and Pakistan. A readmission agreement had been signed with Georgia. Negotiations with Morocco, Turkey, Cape Verde, China and Algeria were ongoing.

${ }^{40}$ This is the case for Albania, Russia, Ukraine, Macedonia, Bosnia and Herzegovina, Montenegro, Serbia, Moldova, Georgia, and Cape Verde.
} 
PCAs with Armenia, Azerbaijan, Georgia, Russia, Uzbekistan and Tajikistan (Commission, 2010c). Generally, however, this cooperation is operationalised in the texts only as a commitment by the PCA country to readmit its own nationals if they are illegally present in the EU, to provide its nationals with the necessary identity documents for readmission, and to conclude bilateral agreements with member states on readmission (including the readmission of third-country nationals). Third, article 13 of the Cotonou Agreement deals with migration issues. Article 13(4) concerns the relationship between migration and development and emphasises that development strategies should take account of migratory flows. Article 13(5) is a readmission clause establishing that each party shall readmit their nationals if they are illegally present on the territory of the other. At the request of any party, negotiations shall be opened on bilateral readmission agreements to extend this cooperation to third country nationals and stateless persons.

By 2007, the agenda for Mobility Partnerships had been set. Cooperation with third countries on migration issues had been highlighted by both Council and Commission documents as essential to the EU's migration policy. The main concept of the Mobility Partnerships - increased legal migration opportunities in exchange for cooperation on illegal migration - had been established through the linking of readmission and visa facilitation agreements. Although there is no discernible difference between the Commission and the member states in the Council on the need to cooperate with third countries, the form of the cooperation has been contested: the Commission acknowledges the need to compensate third countries for their cooperation, whilst member states have been reluctant to grant automatic visa facilitation to third countries in return for readmission agreements. A geographic focus had also taken shape, with ENP countries, PCA countries, and ACP countries being specifically targeted for cooperation on migration. The stage was set for the formulation of the new Mobility Partnership instrument.

\subsection{Policy formulation: the Commission communication on Mobility Partnerships}

This section traces the process leading up to the publication of the Commission communication on Mobility Partnerships in May 2007. It shows that, despite the communication being a Commission document, the Commission "does not invent policy proposals in a vacuum" (Wallace, 2005b, p.29). In the case of the Mobility Partnerships, the Commission's communication was guided by member states' preferences and their existing national policy solutions to migration issues.

\subsubsection{The role of the Commission}

The notion of Mobility Partnerships first appeared in 2006, in a speech by thenCommissioner Franco Frattini, and in a communication by the Commission evaluating the GAM. At the very outset, the concept of Mobility Partnerships was framed in two ways: as part of the migration and development agenda, whereby migration policy and development policy should be better linked and more coherent; and as one of the measures need to develop the legal migration aspect of the GAM. 
Franco Frattini, at that time the Commissioner for JLS, first mentioned the notion of Mobility Partnerships in a speech to the EU-Africa Ministerial Conference on Migration and Development in Tripoli on 22 November 2006 (Frattini, 2006). In his speech Frattini outlined the EU's priorities in migration policy with Africa. These include a focus on issues such as the rights of children, asylum and return and readmission; the establishment of migration profiles to analyse the measures needed within migration and development; the establishment of cooperation platforms to bring together African states and EU member states to manage migration more effectively; and the establishment of Migration Support Teams consisting of experts from EU member states to provide assistance to African states. In addition, Frattini stated that "once certain conditions have been met, such as cooperation on illegal migration and effective mechanisms for the readmission of illegal migrants, Mobility Packages could be agreed upon between the EU and interested African states, which would make for easier movement of people and give them better access to the EU labour market" (ibid.; emphasis added). He is thus echoing the concern in previous EU policy documents (both by the Council and the Commission) that cooperation with third countries on illegal migration is necessary (e.g. Commission, 2006a; 2002a; Council, 2002a).

A few days after the speech by Frattini, the Commission published an evaluation of the GAM (Commission, 2006c). The evaluation listed the achievements so far and suggested recommendations for the further development of the Global Approach, which the Commission argued should focus on five priorities: strengthening dialogue and cooperation with African countries, including promoting the migration and development agenda; legal migration; integration and intercultural dialogue; fighting illegal migration and trafficking in human beings; and asylum and refugee protection. In terms of legal migration, the Commission highlighted that "the further development of a common European policy on labour immigration is an important component of the Global Approach" (p.6). One of the five objectives to be achieved in the area of legal migration was the conclusion of 'mobility packages' with third countries. The wording of the communication is very similar to that used by Frattini in his speech: "Once certain conditions have been met, such as cooperation on illegal migration and effective mechanisms for readmission, the objective could be to agree Mobility Packages with a number of interested third countries which would enable their citizens to have better access to the EU" (p.7; emphasis added).

In May 2007, the Commission published its communication on Mobility Partnerships and circular migration (Commission, 2007a). This had been discussed and adopted at the meeting of the Commissioners on 16 May 2007 (Commission, 2007d). Whenever an initiative is prepared within the Commission, "the department responsible for preparing an initiative shall ensure . . . that there is effective coordination between all the departments with a legitimate interest in the initiative". The communication on Mobility Partnerships was drafted by DG JLS, ${ }^{42}$ although both DG Relex and DG Development

\footnotetext{
${ }^{41}$ Commission decision of 15 November 2005 amending its rules of procedure (2005/960/EC, Euratom)

${ }^{42}$ DG JLS (Justice, Freedom and Security) was created in October 1999. Prior to this, the Commission had had only a small task-force dedicated to justice and home affairs matters (Lavenex, 2009b, p.259). In July
} 
were consulted, already in advance of the usual inter-service consultation (Interview 20). ${ }^{43}$ These three DGs have the institutional competence for the issues covered in the Mobility Partnership communication: migration, development, and relations with third countries. It has often been argued that, on migration issues, DGs Relex and Development have rather different preferences than DG JLS. They have, for instance, disagreed on how funding should be spent: Boswell (2003, p.626) argues that DGs Relex and Development are keen to prevent development funding from being used for migration purposes. DG Relex tried (but failed) to insert a human rights clause into EU readmission agreements (Coleman, 2009, p.149). It is not surprising that the DGs have different preferences on migration issues given their different missions statements and mandates. DG Development is committed to "defending the interests of the most disadvantaged developing countries and the poorest sections of the population in economically more advanced developing countries" (Commission, 1999, p.1). DG Relex has a broad mission statement (cf. Moyer, 1993), namely to contribute "to the formulation of an effective and coherent external relations policy for the European Union" (Commission, n.d., p.3). In contrast, the objectives of DG JLS are more inward-looking, namely to ensure that the EU is an area of freedom, security and justice (Commission, 2008d). Nevertheless, cooperation between the DGs is necessarily frequent. DG Development, for instance, is responsible for the thematic programme for cooperation with third countries in the areas of migration and asylum, because this is financed from the DCI. The thematic programme, however, is clearly relevant to the work of DG JLS. DG Relex is also somewhat constrained by its broad mandate (cf. Moyer, 1993) - it is not possible for it to specialise in all thematic areas. DG JLS, on the other hand, can specialise in a specific aspect of external relations, namely migration cooperation with third countries. DG JLS has benefited from an increased budget over the past few years. In 2006, the budget of the Commission for the area of freedom, security and justice was just under $€ 580$ million; ${ }^{44}$ by 2010 , this had increased to over $€ 1$ billion. ${ }^{45}$ An increased budget implies that a DG will be able to expand its policy role due to having more resources available to it.

2010, DG JLS was split to create DG Home Affairs and DG Justice. Since 2010, therefore, migration issues have been dealt with by DG Home Affairs. The Mobility Partnerships are currently the remit of unit 2 of DG Home Affairs, which is responsible specifically for International Affairs (Commission, 2011j) and reports directly to the director general of the DG (Interview 30). This thesis refers to DG JLS throughout because this was the way that the Commission was organised during the time-frame concerned (up to 2009).

${ }^{43}$ With the creation of the European External Action Service (EEAS) in 2010, DG Relex ceased to exist because much of its mandate was transferred to the EEAS. Today, the Commissioner for International Cooperation, Humanitarian Aid and Crisis Response heads DG ECHO (Humanitarian Aid and Civil Protection). DG Development and DG Aidco were merged in 2011 to form DG Devco, headed by the Commissioner for Development. This thesis refers to DGs Relex and Development as they existed during the time-frame concerned (up to 2009).

${ }^{44}$ Final adoption of the general budget of the European Union for the financial year 2007, OJ L 77 volume 50. Retrieved 8 February 2012 from http://eur-lex.europa.eu/JOHtml.do?uri=OJ:L:2007:077:SOM:EN:HTML

${ }^{45}$ Definitive adoption of the European Union's general budget for the financial year 2010. OJ L 64 volume 53. Retrieved 8 February 2012 from http://eur-lex.europa.eu/JOHtml.do?uri=OJ:L:2010:064:SOM:EN:HTML 
The 2007 communication refers to the 'mobility packages' mentioned in the 2006 evaluation of the Global Approach, but states that these packages "should in the Commission's view be called 'mobility partnerships" (Commission, 2007, p.3). Officials in DG JLS state that this change was made for linguistic purposes: there was a feeling that 'mobility packages' would not translate well from English to other languages (Interview 20). Mobility Partnerships was therefore preferred as the term for this new policy instrument. Lavenex and Stucky $(2011$, p.126) claim that the shift to using the term 'partnership' was made to imply an element of shared responsibility and ownership of this new policy instrument with third countries. Mobility 'packages', on the other hand, would have implied a policy tool with a "bargaining character".

The aim of the communication on Mobility Partnerships is to "identify novel approaches to improve the management of legal movements of people between the EU and third countries" (Commission, 2007, p.2). Just as both Frattini's speech and the 2006 evaluation of the Global Approach, the communication indicates that Mobility Partnerships will be negotiated "with third countries that have committed themselves to cooperating actively with the EU on management of migration flows, including by fighting against illegal migration, and that are interested in securing better access to EU territory for their citizens" (p.3). In other words, legal migration opportunities will be offered to countries in return for their cooperation in preventing illegal migration. The communication does, however, identify obstacles to such facilitated movement: firstly, any measures relating to legal migration must be based on the labour needs of the member states; secondly, the principle of Community preference for EU citizens must be respected; finally, other EU agreements already in place should also be taken into account, for example the Association Agreement with Turkey, under which EU member states give priority to Turkish workers.

The communication highlights that Mobility Partnerships will be tailored to suit each partner country. There is therefore no 'standard' format for a partnership; rather contents of a partnership will depend on: the state of the EU's relations with that country; the specifics of that country (the migration situation in the country and the legal framework in place); and the level of the country's commitment in terms of action against illegal migration and the facilitation of return migration. Nevertheless, the communication lists possible commitments which might be expected from third countries, and possible commitments which could be made by the EU and its member states. These are summarised in table 4.1 . 
Table 4.1: Possible commitments to be made in a Mobility Partnership (Commission, 2007a).

Commitments by third countries

A commitment to readmit their own nationals

A commitment to readmit stateless persons who enter the EU from their territory

Initiatives to discourage illegal migration

Efforts to improve border control, supported by member states and/or Frontex

Cooperating and exchanging information with member states to improve border management

Measures to combat human trafficking

Commitments to improve the domestic economic and social conditions (to reduce incentives for emigration)

Commitments by the EU/member states

Improved opportunities for legal migration for nationals of the third country

Assistance to help third countries develop their capacity to manage migration

Measures to address the risk of brain drain and promote circular migration

\section{For employment \\ For studies/training}

Providing information on the labour market needs of member states and the conditions for migrating to the EU

Facilitating mobility of students, young professionals, researchers and volunteers

Providing pre-departure linguistic/technical training for those with a job offer in a member state

Matching of job offers in EU member states with jobseekers in the third country

Facilitating the economic and social reintegration of migrants returning to the third country

Facilitating the transfer of migrants' remittances

Exclude migration from sectors which are under strain in the third country

Incentives for migrants to return to the third country

Mechanisms to foster circular migration

Mechanisms to allow migrants to divide their life between the host country and the country of origin

Support from the EU for the third country to create attractive job opportunities locally

Longer opening hours at member states' embassies

Consular cooperation between member states

Flexibility in issuing visas (for instance to bona fide persons needing to travel to the EU frequently)

Establishment of a common visa application centre

Conclusion of a visa facilitation agreement

\subsubsection{The influence of the member states}

Despite the fact that the Commission was responsible for the policy proposal on Mobility Partnerships, the proposal was nevertheless influenced by the member states (Interview 2). That Commission proposals are influenced by member states is not surprising: Commission officials are aware that member states' agreement on its proposals will eventually be required. It must take into account the different positions of the member states if its proposals are to be effective (Edwards, 2006, p.10). The Commission therefore "pools ideas and proposals but is not always the original author of them" (Diedrichs and Wessels, 2006, p.223). In the case of the Mobility Partnerships, the influence 
by member states was not direct, in the sense that member states were not actively pushing for a certain formulation of the policy proposal. Rather, the Commission was aware of member states' existing national policy solutions to migration issues and therefore knew which type of policy instrument would be acceptable to member states.

In a 2006 communication the Commission referred to member states' bilateral approach to concluding readmission agreements: "Member States are increasingly offering also other forms of support and assistance to third countries to facilitate the conclusion of such agreements, and the possibilities of applying this wider approach at EU level should be explored" (Commission, 2006c, p.9). The concept of offering incentives for the conclusion of readmission agreements is therefore not one unique to the EU level, but was already being utilised by the member states.

The origins of the Mobility Partnerships can be traced to a Franco-German proposal for a 'new European migration policy', presented by the then interior ministers Wolfgang Schäuble and Nicolas Sarkozy to a meeting of the $\mathrm{G6}^{46}$ interior ministers on 26 October 2006 (Angenendt, 2007; Carrera and Hernández i Sagrera, 2009). This proposal was supported by the other members of the G6 (Deutscher Gewerkschaftsbund Bundesvorstand, 2008, p.8). The initiative set out the idea of using circular migration schemes to reduce illegal migration to the EU (Carrera and Hernández i Sagrera, 2009, p.11): "Wir wünschen keine ungesteuerte Zuwanderung in unsere Arbeitsmärkte und unsere Sozialsysteme. Im Hinblick auf mögliche Maßnahmen zur Förderung der zirkulären Migration sollten Quoten der Arbeitsmigration für bestimmte Berufe festgelegt werden" (Schäuble and Sarkozy, 2006, p.3). Quotas for labour immigration are to be reported by the member states to the Commission, so that the Commission can use these as leverage in negotiations on readmission agreements (p.4). The initiative calls for partnership with countries of origin of migrants and for the signature of bilateral partnerships between member states and third countries: "Die Summe aller Partnerschaften ergibt eine europäische Partnerschaft mit einer Vielzahl von Herkunftsländern" (ibid.). Circular migration had appeared in previous Commission communications in the context of fostering the development of third countries (Commission, 2005a, pp.7-8), but the link between offering legal migration opportunities and preventing illegal migration was first made at the EU level in the concept of the Mobility Partnerships. However, the Franco-German proposal demonstrates that member states' interior ministers were already discussing such a linkage before the Commission proposal on Mobility Partnerships.

In addition to the Franco-German proposal, which concerned specifically the form that European migration cooperation with third countries should take, existing national policy practices also influenced the creation of the Mobility Partnerships (Interview 10; 16). Particularly the French bilateral migration agreements (the accord de gestion concertée des flux migratoires) had been discussed previously at the EU level in brainstorming sessions organised by the French government and attended by other member states' officials (Interview 16). These agreements link cooperation on legal migration,

${ }^{46}$ Germany, France, the UK, Italy, Spain and Poland. 
illegal migration, and migration and development (Assemblée Nationale, 2009; see also chapter 5). Significantly, they facilitate access to certain sectors of the French labour market for migrants from the third country concerned (European Migration Network, 2009d, p.16). The concept is thus similar to the idea contained in the Mobility Partnerships of facilitating movement to the EU for citizens of countries that are prepared to cooperate on preventing illegal migration. The first French bilateral agreement, with Senegal, was signed in September 2006 (French Ministry of Interior and OFII, n.d.) - in other words, before the publication of the Commission communication on Mobility Partnerships.

Spanish bilateral migration agreements are also cited as a source of inspiration for the Mobility Partnerships (Interview 10). The Spanish agreements are of two types: agreements on migratory flows concern only the management of immigration to Spain of workers required on the Spanish labour market, whereas Framework Agreements include cooperation both on readmission and labour migration (European Migration Network, 2009e, p.65), just as the Mobility Partnerships do. The Spanish government considers that "legal immigration may represent a very important indirect aspect of the fight against illegal immigration" (ibid.). The labour migration dimension of these agreements may involve notification of job offers in Spain, agreements on rights and social and working conditions, or provision for temporary migration (European Migration Network, 2010b, pp.41-42). By the end of 2007, an agreement had been signed with, among others, Cape Verde, and the Spanish and Senegalese governments had signed a declaration stating their intent to conclude an agreement.

The communication on Mobility Partnerships mentions at several points that they will be signed by "interested Member States" (Commission, 2007a, p.3) and that commitments will be made by "Member States participating" (p.5). The implication is that participation in a Mobility Partnership will be voluntary. The Stockholm programme emphasises that the development of the Mobility Partnership instrument should respect their voluntary nature (Council, 2009b, p.61). Making the Mobility Partnerships voluntary for member states to join was a strategy adopted by the Commission in order to prevent member states from blocking this policy tool altogether (Interview 17). Indeed, some member states were initially hesitant about the concept of Mobility Partnerships, particularly because elements of legal migration policy are included (Interview 17; see also sub-section 4.5.2). The UK government was one of those stressing that the partnerships should not be overly focussed on legal migration, as this is only one aspect of the GAM (Interview 18). Indeed, the UK is one of the fiercest opponents of EU competence in the area of legal migration (Poli, 2012, p.57). The Commission's 2009 evaluation of the Mobility Partnerships is positive about the voluntary framework, stating that this should in principle ensure that the partnerships "will be supported by motivated signatories" (Commission, 2009d, p.4). Caviedes (2004, p.290) argues that the Commission has been very calculating when introducing new measures in migration policy: it is "aware of the parameters that states will insist upon in drafting immigration policy [and has therefore] eschewed attempting to assume direct legislative authority for fear of their veto power". It is not possible to introduce new measures without some degree of sup- 
port from member states, and it is therefore not fruitful for the Commission to suggest a policy instrument that member states will object to. In the past, the Commission has emphasised that EU policy measures can only be effective if backed up by political determination of the member states (Commission, 2004b, p.5). In 2002, the Commission identified a lack of political and diplomatic support by member states as a reason for slow progress on the negotiation of readmission agreements (Commission, 2002a, p.24). It is therefore important to have this political support of the member states for new policy instruments. Indeed, member state officials point out that, if the Commission had attempted to impose the Mobility Partnership instrument on member states, "it would never have succeeded" (Interview 32). Instead, the Commission took a flexible approach and yielded to member states' preferences.

The member states' preferences and national policy solutions, as well as an understanding of what type of policy instrument would be acceptable to them, therefore played an implicit role in the policy formulation of the Mobility Partnerships. The Commission was very well aware of what the member states could accept, and what they would reject. This influence of the member states on the policy formulation stage is acknowledged by the Commission. The communication on Mobility Partnerships emphasises the mandate of the member states in the Council and European Council. Firstly, the communication is a response to a request by the European Council in December 2006 which asked the Commission "to present detailed proposals on how to better organise and inform about the various forms of legal movement between the EU and third countries by June 2007" (Council, 2006, p.9). Secondly, the communication emphasises that "negotiation of any mobility partnership would need to be based on clear political guidelines from the Council, on the basis of a recommendation from the Commission" (Commission, 2007a, p.3).

\subsection{Decision-making: deciding on the Mobility Partnerships}

Once the general concept of the Mobility Partnership instrument had been formulated in the Commission communication, the exact shape of the instrument needed to be decided and partnerships needed to be signed. This section examines the process within the EU, after the publication of the Commission communication, which led to the first Mobility Partnerships being signed (summarised in figure 4.2). It focuses on the role of the Commission and the member states, and accounts for the exclusion of the European Parliament and other EU institutions from the policy-making process. 


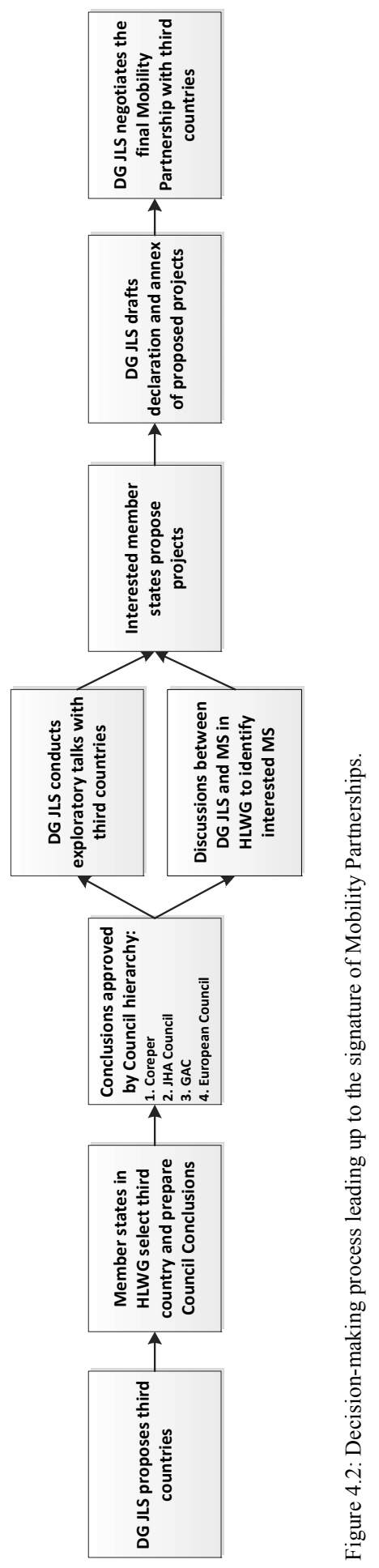


Following the publication of the communication on Mobility Partnerships, the first partnerships with Moldova and Cape Verde were signed in 2008. A partnership was signed with Georgia in 2009. These partnerships all take the same form: they consist first of a preamble concerning the intention of the EU, the participating member states, and the third country concerned to cooperate on migration issues in general; this is followed by a political declaration outlining more specific objectives in a number of categories; finally there is an annex of specific projects that are proposed (see Council, 2008a; 2008b; 2009a). ${ }^{47}$

The preambles of the Mobility Partnerships have the same structure. They begin by listing the participants in the partnership: the third country, the participating member states, and the European Community/Union. They then outline the existing frameworks for cooperation between the EU and the third country concerned, which varies for each of the countries (see table 4.2). All Mobility Partnerships then note the "benefits and opportunities that a well managed migration can bring to migrants and to the Signatories alike" (ibid.) and confirm the commitment of the signatories to facilitate the movement of persons from the third country to the EU, whilst working to prevent illegal migration. The preambles recall the context for the Mobility Partnership, namely the GAM and the Commission's communication on Mobility Partnerships, and, for Cape Verde, the EUAfrica Partnership on Migration, Mobility and Employment. All preambles, except the Mobility Partnership with Cape Verde, reaffirm the commitment of the signatories to conclude and implement visa facilitation and readmission agreements. The preambles recognise the existing bilateral migration agreements in place between the third country and EU member states. Finally, the preambles outline briefly the main purposes and objectives of the Mobility Partnership, which are identical for all partnerships: facilitating and better managing legal migration; cooperating on migration and development; preventing illegal migration; and promoting an effective readmission and return policy.

\footnotetext{
${ }^{47}$ The format of the Mobility Partnerships with Armenia and Morocco, signed in 2011 and 2013, is the same as these first partnerships (Council, 2011b; Council, 2013).
} 
Table 4.2: Existing frameworks for cooperation between the EU and the third country concerned.

\begin{tabular}{ll}
\hline Country & Frameworks \\
\hline Moldova & European Neighbourhood Policy \\
& Partnership and Cooperation Agreement \\
Cape Verde & Cotonou Agreement \\
& Special Partnership \\
Georgia & European Neighbourhood Policy \\
& Partnership and Cooperation Agreement \\
& Prague Eastern Partnership Summit \\
Armenia & European Neighbourhood Policy \\
& Partnership and Cooperation Agreement \\
& Prague Eastern Partnership Summit \\
Morocco & Euro-Mediterranean Association Agreement \\
& European Neighbourhood Policy \\
& Regional processes e.g. Rabat Process \\
\hline
\end{tabular}

The political declarations of the Mobility Partnerships are divided into cooperation in four categories: mobility, legal migration and integration; migration and development; border management, identity and travel documents, fight against illegal migration and trafficking in human beings; and, in the partnership with Georgia, asylum and international protection. Table 4.3 shows the objectives covered in each category of cooperation. The final section of the declaration concerns implementation of the Mobility Partnership, which will happen through the initiatives listed in the annex. EU agencies, such as Frontex and the European Training Foundation, may also be involved. The signatories intend to meet at least twice a year, and will conduct an evaluation of the Mobility Partnership if considered appropriate. Finally, each declaration ends with a statement that the provisions contained in it "are not designed to create legal rights or obligations under international law" (ibid.).

The annexes to each Mobility Partnership list the projects which are intended to be carried out, and are specific to the partnership concerned. The project proposals state which party has proposed the project and the overall objective to be achieved. Projects are proposed by the participating member states, the Commission or an EU agency, or the third country concerned. An example of a project proposed by a member state is the proposal by Romania to offer scholarships to Moldovan students (Council, 2008a, p.14). An example of a project proposed by the Commission is the proposal to sign a visa facilitation agreement with Cape Verde (Council, 2008b, p.10). An example of a project proposed by a third country is the proposal by Moldova to strengthen the information centres for Moldovan migrants in its embassies (Council, 2008a, p.13). Tables containing all the projects proposed under the first Mobility Partnerships can be found in Annex II. ${ }^{48}$

${ }^{48}$ This annex includes the projects proposed in the Mobility Partnership with Armenia. 
Table 4.3: Objectives of the Mobility Partnerships.

\begin{tabular}{lll}
\hline Legal migration & - & promote a better framework for legal mobility \\
& - & inform potential migrants on ways of legal migration to the EU \\
& - & strengthen the capacity of the third country to manage migration \\
Migration and & - & ensure the social protection of legal migrants \\
development & - & deepen dialogue on visa issues \\
Illegal migration & - & implement pre-departure training for migrants \\
& - & prevent brain drain and brain waste \\
& - & improve data collection on migration \\
& - & fight illegal migration and strengthen border management \\
Asylum & - & promote operational cooperation between third country and Frontex \\
& - & improve security of travel and identity documents \\
& - & develop dialogue on readmission \\
& - & carry out information campaigns on the risks of illegal migration \\
& only use regularisation of illegal migrants on a case-by-case basis \\
& - & build capacity of the third country to implement asylum policy \\
& - & facilitate the reception of asylum seekers in third country \\
\hline
\end{tabular}

\subsubsection{The role of the Commission}

In the process leading to the signature of the Mobility Partnerships, DG JLS of the Commission played a central, coordinating role (Lavenex and Stucky, 2011, p.128; Interview 13; 14). This DG conducted negotiations with third countries and was responsible for ensuring "the overall coordination and consistency of the combined EC offer based on the individual proposals and political priorities expressed by each participating member state" (Carrera and Hernández i Sagrera, 2009, p.28).

As a first step, DG JLS suggested potential partner countries for Mobility Partnerships by preparing fiches on the migration situation in some third countries (Interview $21 ; 30)$. When proposing potential partner countries, officials in DG JLS took into consideration several criteria: in order to begin testing the concept of Mobility Partnerships, countries should be selected with which cooperation is generally smooth so that negotiations could be quickly concluded; the third countries concerned should have a functioning administration so that the implementation of a Mobility Partnership would be possible; and there should be immigration to the EU from the third countries concerned (Interview 1; 13; 21). Both Moldova and Cape Verde were suggested by the Commission to the member states because they were seen as small countries with which negotiations could be quickly and successfully concluded (Interview 21). The Moldovan government also proactively indicated its interest in becoming a partner country for a Mobility Partnership by submitting three non-papers (Carrera and Hernández i Sagrera, 2009, pp.22-23). ${ }^{49}$ An early version of these non-papers highlighted circular migration

\footnotetext{
${ }^{49}$ For an explanation of how Cape Verde and Senegal were selected by the EU for a Mobility Partnership, see chapter 6; for more on how Georgia was selected, see sub-section 4.5.2.
} 
as a possible topic for cooperation (Carrera and Hernández i Sagrera, 2011, p.103). DG JLS was responsible for conducting exploratory talks with the third countries concerned, in order to judge the interest of the authorities in taking part in a Mobility Partnership (Interview 13; 17). Officials in DG JLS relied on officials in DG Relex and DG Development for information on the third countries concerned (Interview 21) - DG Development being responsible for countries falling under the Cotonou Agreement, and DG Relex being responsible for relations with all other third countries (Interview 12).

Once a third country had been selected, DG JLS gauged the interest of the member states in participating in the Mobility Partnership. Interested member states were invited to meetings to discuss their input to the partnership, and thereby allow DG JLS to coordinate the various proposals being made (Interview 1). Indeed, "until the date of formal adoption of the MPs, the Commission 'campaigned' for the involvement of as many Member States as possible in the partnerships" (Carrera and Hernández i Sagrera, 2011, p.103). To do this, the Commission adopted an approach of 'soft bargaining', by making several proposals for member states to choose from. DG JLS officials would, for instance, offer member states' officials examples of different types of projects that would be suitable for a Mobility Partnership, in order to encourage their participation (Interview 21).

DG JLS was responsible for the discussions with officials of the third country that ultimately led to each Mobility Partnership being signed: "no direct meetings between Member States and partner countries have taken place; it is the Commission - acting like a 'broker' or 'mediator' - which holds discussions with each of the parties to determine how far the different interests could be matched" (Lavenex and Stucky, 2011, p.131). At first sight, this seems to put DG JLS in a central role as the main negotiator. The member state holding the presidency of the Council was, however, included in meetings with the third countries (Commission, 2009d, p.4), and the member states maintained control of the Mobility Partnership instrument in other ways (see subsection 4.5.2). This significantly limited the room for manoeuvre that DG JLS had in the negotiations (see also chapter 6). Discussions were led by the head of the DG JLS directorate on immigration, asylum and borders (Interview 13). Based on member states' proposals, officials in DG JLS drafted the joint declarations and annexes which ultimately form the Mobility Partnerships (Lavenex and Stucky, 2011, p.132).

Besides its role in the conclusion of specific Mobility Partnerships, the Commission has continued to shape this policy tool past the policy formulation stage by promoting it as "an overall framework for migration management with third countries" (Commission, 2008e, p.4). In 2008, the Commission suggested that Mobility Partnerships could be the key element in 'Mobility and Security Pacts' to be offered to countries under the Eastern Partnership dimension of the ENP (Commission, 2008b, p.6). The 2009 evaluation by the Commission states that the "mobility partnerships constitute the most innovative and sophisticated tool to date of the Global Approach to Migration and contribute significantly to its operationalisation" (Commission, 2009d, p.4). They therefore "merit being further developed, improved and replicated" (p.8). In 2011 the Commission argued that the Mobility Partnership tool "should be upgraded and promoted as 
the principal framework for cooperation in the area of migration and mobility between the EU and its partners" (Commission, 2011b, p.10).

\subsubsection{The role of the member states}

Despite the Commission's apparently central role in coordinating and promoting the Mobility Partnership instrument, it is the member states (in the Council) that have ultimately controlled the shape and progress of this instrument. Any steps taken on negotiating new Mobility Partnerships have always been mandated by the Council; member states' reluctance to commit to legally binding agreements determined the legal form of the Mobility Partnerships; member states determine the specific content of each Mobility Partnership through the projects they propose; and member states have controlled the selection of third countries with which partnerships should be negotiated. The High Level Working Group on Asylum and Migration (HLWG) has been the main Council body following the Mobility Partnerships and the main forum for political and strategic discussions on the partnerships (Interview 2; 30). This sub-section outlines the role of the member states in general in the decision-making process on the Mobility Partnerships; chapter 5 will 'open up the black box' and deal with the preferences of Austria, France and the Netherlands in particular.

Shortly after its publication, the Commission communication on Mobility Partnerships was the subject of discussion in the Council structures. At the highest level, Council conclusions on the communication were discussed in both the JHA and GAERC Councils, having been broadly agreed to in Coreper and the HLWG (Council, 2007e). These Council conclusions welcome the Commission communication "as a basis for further discussions" on how to incorporate legal migration into the EU's external policies (p.5). Mobility Partnerships could include measures to enhance the links between migration and development; capacity-building measures in migration management; measures to promote the reintegration of returning migrants; visa facilitation; protection of human rights in the fight against illegal immigration; and protection of refugees (p.6). Finally, the Council authorises the Commission to take this policy instrument forward:

The Council believes that the concept of mobility partnerships between the European Union, Member States and third countries could be tested by way of a limited number of pilot partnerships. The Council therefore invites the Commission to consult Member States on the further development of this concept . . . with a view to exploratory talks with interested third countries on pilot partnerships in close cooperation with the Presidency and interested Member States. The Commission is invited to report back to the Council on the outcome of these consultations in order to enable the Council to decide by the end of 2007 whether to invite the Commission to launch pilot partnerships (ibid.).

These conclusions were endorsed by the European Council one week later (Council, 2007f). In December 2007, the General Affairs and External Relations Council agreed conclusions mandating "the Commission, in close liaison with Member States and/or the Presidency, in order to ensure a close involvement of the Council, to open 
dialogue with Cape Verde and Moldova, with a view to launching pilot mobility partnerships" (Council, 2007g, p.25). These conclusions are based on "preliminary discussions held between the Commission and Member States on the added value, possible content and structures of mobility partnerships" (ibid.). A few days later, the European Council endorsed these conclusions and welcomed the decision to open negotiations with Cape Verde and Moldova (Council, 2008e, p.4). In June 2008, the Council authorised the Commission "in close liaison with Member States and the Presidency, to take forward exploratory talks with Georgia and Senegal and to open dialogue with these countries, with a view to launching additional pilot Mobility Partnerships" (Council, 2008f, p.7). ${ }^{50}$ It also requested the Commission to carry out an evaluation of the pilot Mobility Partnerships and to report on the results by June 2009 (p.6). The European Council endorsed the conclusions later in June (Council, 2008g). It is clear, therefore, that steps taken by the Commission to negotiate new Mobility Partnerships have always been mandated by the member states in the Council and European Council. The member states (in the Council and European Council) have also been active in promoting the use of Mobility Partnerships. The Stockholm programme, for instance, states that these partnerships should be the "main strategic, comprehensive and long-term cooperation framework for migration management with third countries" (Council, 2009b, p.61).

Sub-section 4.4.2 showed that member states' concerns determined that Mobility Partnerships would be voluntary, rather than obligatory. Member states also determined another important aspect of the form of the Mobility Partnerships, namely their nonlegally binding nature. In general, member states are concerned with ensuring that Commission "proposals (and even impending proposals or 'gleams in the Commission's eye') do not establish precedents leading to an increase in the Commission's power or the spill-over of responsibility from an exclusively national arena to the sphere of Community competence" (Usher, 2006, p.105). This was certainly the case with the Mobility Partnerships.

The original Commission communication on Mobility Partnerships does not clearly specify the legal nature that the partnerships will take. It only states that

mobility partnerships will necessarily have a complex legal nature, as they will involve a series of components, some of which fall in the Community's remit and others in the Member States'. The EU needs to ensure that a coherent partnership can be put together in the most expeditious manner, while respecting the division of powers between the EC and Member States (Commission, 2007a, p.3).

The legal nature of the Mobility Partnerships was first stated explicitly in Council conclusions adopted in December 2007: the partnerships should "represent an overall political framework ... [and] will need to strictly respect the division of competences between the EU and the Member States" (Council, 2007g, p.25; emphasis added). The Commission's 2009 evaluation of the Mobility Partnerships is positive about the nonbinding nature of the political declarations which are the basis of the partnerships:

\footnotetext{
${ }^{50}$ Similarly, the member states invited the Commission to launch negotiations with Armenia on a Mobility Partnership in May 2009 (Commission, 2010a, p.17).
} 
"While guaranteeing the expeditious establishment of the current mobility partnerships, these arrangements also ensure that mobility partnerships are flexible tools, which can be adapted according to current needs" (Commission, 2009d, p.4). Officials in DG JLS maintain that a formal agreement would have been too static and unable to adapt to changing circumstances - a 'living document' is therefore preferable (Interview 17). A political statement allows implementation of the Mobility Partnerships to begin as soon as possible, in contrast to a formal international agreement under article 218 TFEU, which would require a full ratification process involving the European Parliament (Interview 2). Nevertheless, Commission officials would have preferred to have a legally binding basis for the Mobility Partnerships (Interview 1). A non-legally binding basis means that there are no guarantees that member states will carry out the initiatives they propose - the Commission can only encourage them to do so but has no sanctioning mechanism (Carrera and Hernández i Sagrera, 2011, p.106; Lavenex and Stucky, 2011, p.133). However, when the notion of legally-binding Mobility Partnerships was discussed in meetings with member states, member states were very opposed (Interview 13). Commission officials therefore adopted a conciliatory, pragmatic approach and yielded to member states' preferences on the legal form of the partnerships. It was more important to be able to launch this new policy tool than to insist on legally-binding Mobility Partnerships in the face of opposition from member states. Indeed, Commission officials acknowledge that "a legally binding agreement is not necessarily a panacea" as there may be problems with ratification or implementation (Interview 20).

In addition to determining the form of the Mobility Partnerships, member states determine the content of the partnerships through the projects that they propose. This control over the content of Mobility Partnerships is apparent in four ways: the fragmented nature of the package of proposals in each partnership; the tendency by member states to rephrase existing initiatives rather than propose new projects; the dominance of bilateral initiatives despite the Commission's preference for multilateral initiatives; and the absence of projects offering opportunities for legal migration to the EU. These different elements of the member states' control over the content of the Mobility Partnerships are explained below.

Member state control of the content of the Mobility Partnerships makes it difficult for the Commission to ensure that each partnership is an "effective and coordinated offer bringing added value to existing cooperation" (Commission, 2009d, p.5). Rather than such a coherent package, Mobility Partnerships are a "package of fragmented cooperation measures including a shopping list of different proposals" (Carrera and Hernández i Sagrera, 2011, p.106). Indeed, in some of the Mobility Partnerships two separate proposals appear to overlap although they are not linked. Both Spain and Portugal, for instance, separately propose to provide support to the Cape Verdean national health system (Council, 2008b). Officials in DG JLS acknowledge that Mobility Partnerships are more a collection of projects than a coherent framework, and that there is not much the Commission can do to force a change in this situation (Interview 21).

Member states have tended to rephrase existing initiatives as part of the Mobility Partnership, rather than proposing new initiatives (Interview 7; 30). In the Mobility 
Partnership with Cape Verde, for instance, the government of Luxembourg simply transferred all their planned or ongoing bilateral projects to the 'umbrella' of the Mobility Partnership (Interview 53). Member states also in some cases repeated initiatives from the Mobility Partnership with Moldova in the Mobility Partnership with Georgia (Interview 21). In both these Mobility Partnerships, Germany proposed to allow migrants from Moldova/Georgia extended stays away from Germany without losing their German residence rights; Bulgaria proposed to sign a bilateral agreement on social security with both countries; and several member states proposed to provide information on the possibilities for legal migration to the EU (Council, 2008a; 2009a). Officials in DG JLS acknowledge that ideally the Mobility Partnerships should be based on new projects (Interview 30), and the 2009 evaluation emphasises that the partnerships should bring "added value to existing cooperation" (Commission, 2009d, p.5). However, given the non-legally binding nature of the partnerships, the Commission cannot force member states to propose new projects. It finds itself in a weak bargaining position, with little choice of strategy as it is simply not in a position to demand change.

The Commission can, however, encourage the proposal of a certain type of projects by the member states through its control of funding. For the Mobility Partnerships, officials in DG JLS had envisaged cooperation between the member states, with projects being proposed jointly by three or four member states (Interview 13). The 2009 call for proposals for funding under the thematic programme for cooperation with third countries in the areas of migration and asylum contains a lot dedicated to the development of the Mobility Partnership instrument. The funding available for 2009 and 2010 together was $€ 4$ million (Commission, 2009g). The call for proposals gives priority to projects undertaken by "a partnership among a number of organisations" (p.10), underlining that "the lack of a partner will have to be justified" (ibid.). However, this leverage has failed at bringing about a significant number of multilateral initiatives. Table 4.4 gives an overview of the project proposals in the Mobility Partnerships to date, according to the actors that proposed them (Council, 2008a; 2008b; 2009a). Bilateral initiatives clearly dominate each Mobility Partnership. ${ }^{51}$

\footnotetext{
${ }^{51}$ In the Mobility Partnership with Armenia, this tendency has been repeated: 11 of 21 proposed projects are proposed by only one member state (Council, 2011b).
} 
Table 4.4: Project proposals in the Mobility Partnerships to date.

\begin{tabular}{lccc}
\hline Actors proposing & MP with Moldova & MP with Cape Verde & MP with Georgia \\
\hline One member state & 40 & 20 & 11 \\
Two or more member states & 12 & 1 & 5 \\
The Commission/EU agency & 5 & 2 & 0 \\
Partner country & 3 & 0 & 0 \\
$\begin{array}{l}\text { Member state(s) and the Commis- } \\
\text { sion/EU agency }\end{array}$ & 2 & 1 & 2 \\
Member state(s) and partner country & 0 & 2 & 0 \\
$\begin{array}{l}\text { Partner country and the Commis- } \\
\text { sion/EU agency }\end{array}$ & 1 & 2 & 0 \\
$\begin{array}{l}\text { Member state(s), partner country and } \\
\text { the Commission/EU agency }\end{array}$ & 1 & 3 & 0 \\
Total no. of projects & 64 & 31 & 18 \\
\hline
\end{tabular}

One final way in which member states' control over the content of the Mobility Partnerships is apparent is the absence of projects offering new opportunities for legal migration to the EU (Reslow, 2010, pp.15-16). An examination of the projects proposed in each Mobility Partnership shows that the projects proposed under the heading of 'legal migration' tend to relate to informing potential migrants about the possibilities for legal migration to the EU (not creating new opportunities); information campaigns to highlight the danger of illegal migration; projects to inform migrants about voluntary return; pre-departure training for migrants planning to migrate to the EU; and bilateral agreements on social security provisions (ibid.). Very few projects seek to create new opportunities for legal migration. The exceptions are a proposal by Romania and the Veneto region to support labour migration and development for Moldova; a proposal by the Czech Republic and Cyprus to offer circular migration opportunities for Moldovans; a proposal by Poland to offer Moldovans admission to the Polish labour market for temporary work without a work permit; a proposal by Portugal to sign a protocol with Cape Verde to promote temporary and circular migration; a proposal by France to open up certain professions for Cape Verdean migrants; a proposal by Luxembourg to consider a circular migration scheme for Cape Verdeans; a proposal by France and Poland to facilitate access for Georgians to their national labour markets; and a proposal by France to encourage circular mobility of young Georgian professionals. This means that a total of 8 of the 113 projects proposed across the three Mobility Partnerships seek to create new opportunities for legal migration to the EU. ${ }^{52}$

The absence of projects on legal migration contradicts the central notion behind the Mobility Partnerships, namely to offer increased legal migration opportunities to the EU in return for third countries' cooperation on preventing illegal migration (Commission, 2007a). The reason for this contradiction is member states' concern to maintain national

\footnotetext{
${ }^{52}$ If the Mobility Partnership with Armenia is included, the number of projects creating new legal migration opportunities to the EU is 9 of 134 in total. In the Mobility Partnership with Armenia, France proposed to encourage circular mobility of young Armenian professionals (Council, 2011b).
} 
control over the admission of migrants to their territories, and particularly to their labour markets (Interview 21;30). Several member state officials indicate their government's opposition to including legal migration in the Mobility Partnerships. An official of the Dutch ministry of social affairs and employment stated that the Netherlands will not be offering legal migration opportunities in the Mobility Partnerships (Interview 6). The UK government was concerned that the Mobility Partnerships were too focused on legal migration, whereas this is only one aspect of the GAM (Interview 18). A French government official emphasised that legal migration is a matter of national competence (Interview 16). The inclusion of legal migration was the main reason for Austrian opposition to the Mobility Partnerships (see chapter 5).

The member states as a group have thus adopted a negotiating strategy of contending as regards the issue of legal migration: they have stood firm in their assertions that they will not include legal migration in the Mobility Partnerships. In an expert meeting of member state representatives and the Commission in 2008, the Commission noted that the concept of 'mobility' was falling by the wayside in the partnership with Moldova, and that more should be done to emphasise mobility in future Mobility Partnerships. This was, however, merely met with confirmation from several member states (the Netherlands, Germany and the Czech Republic) that no legal migration opportunities will be offered (Dutch Ministry of Foreign Affairs, 2008a).

The issue of national competence over labour migration was already emphasised in the Franco-German proposal for a 'new European migration policy': "Die Steuerung der Arbeitsmigration muss jedoch weiterhin in nationaler Verantwortung der Mitgliedsstaaten verbleiben" (Schäuble and Sarkozy, 2006, p.3). The Council's June 2007 conclusions highlighted that any legal migration opportunities in the Mobility Partnerships should be adapted "to the specific Member States' labour market needs, while fully respecting the competences of the Member States" (Council, 2007e, p.5). The Commission has previously acknowledged the sensitivity of immigration policy for the member states, noting in 2005 that there is not enough support among member states for "a horizontal framework covering conditions of admission for all third-country nationals seeking entry into the labour markets of the Member States" (Commission, 2005d, p.5). The 2011 report on policy coherence for development acknowledges that it has been difficult for member states to offer legal migration opportunities in the Mobility Partnerships due to the financial and economic crisis in Europe (Commission, 2011k, p.81). Nevertheless, officials in DG JLS were keen to see the inclusion of legal migration opportunities in the Mobility Partnerships: "anything on legal migration, even one action, that is really a moment when we can say the EU has placed its foot in the member states' stronghold" (Interview 21). Already in his speech on 'mobility packages', Franco Frattini recognised the sensitivity of the issue of division of competences between the EU and the member states, stating that "quotas will continue to be set at national level in Member States of the European Union. But I hope it will be possible for the EU Commission to know exactly the working needs on a State by State basis, to use them as an instrument to get political packages and agreements with African countries" (Frattini, 2006). Member states' control over legal migration opportunities weakened the Commission's 
position in negotiations with third countries on Mobility Partnerships: it limited the room for manoeuvre that Commission officials had and closed off certain negotiation strategies. Commission officials were, for instance, unable to guarantee that the project proposals would include access to member states' labour markets, as that would depend on what member states were willing to offer (Interview 1). Given that legal migration opportunities are to be offered in return for third countries' cooperation on illegal migration, this is problematic: "third states need to get something to be interested [but ... ] most of the things they are interested in are still in the hands of our member states" (Interview 13). It is therefore highly significant for the EU-third country interaction that member states determine the content of Mobility Partnerships (see chapter 6).

Finally, member states have controlled the choice of partner countries for Mobility Partnerships. Based on the proposals made by the Commission, member states in the HLWG have selected the countries with which partnerships should be signed (Interview 30). However, the Commission was not entirely free in its proposals of third countries: member states insisted on an east-south balance; other political considerations affected member states' preferences; and member states' control of the content of Mobility Partnerships limited the type of partner countries that the Commission felt it could propose. Officials in DG JLS favoured the selection of countries for Mobility Partnerships for which migration flows to the EU were significant (Interview 21). As the Mobility Partnerships are a tool of the GAM, the countries selected should also be one of the priority countries under the approach. When the European Council first adopted the Global Approach in 2005, the focus was on 'Africa and the Mediterranean' in very broad terms. The conclusions mention several different cooperation frameworks, such as the African Union, ECOWAS, the Euromed countries, the Cotonou Agreement countries, and individual countries such as Tanzania, Morocco, Algeria and Libya (Council, 2005a). The implication seems to be that the whole of Africa will be the focus of the Global Approach. In 2007, the GAM was extended to the countries to the east and south-east of the EU: Turkey, the Western Balkans (Albania, Bosnia and Herzegovina, Croatia, Macedonia, Montenegro and Serbia), ENP countries in Eastern Europe (Ukraine, Moldova and Belarus) and the Southern Caucasus (Armenia, Azerbaijan and Georgia), and Russia (Commission, 2007e, p.3). Figures 4.3 and 4.4 show the top 10 countries of the GAM contributing legal and illegal migration flows to the EU, plus the Mobility Partnership countries up to 2009 (Moldova, Cape Verde, Georgia and Senegal). ${ }^{53}$

\footnotetext{
${ }^{53}$ The data for legal migration is the number of immigrants from the third country (based on citizenship) entering the EU 27 in 2007, based on Eurostat data (http://epp.eurostat.ec.europa.eu/portal/page/portal/ population/data/database, retrieved 17 February 2012). Notes: data for Ireland is for 2008; data for France is for 1999; data for the UK is for 2005; no data is available for Portugal or Romania; data from Belgium is not available for Montenegro, Serbia, Moldova, Botswana, Burkina Faso, Cape Verde, Central African Republic, Chad, Comoros, Djibouti, Equatorial Guinea, Eritrea, Gabon, Gambia, Guinea-Bissau, Kenya, Lesotho, Liberia, Libya, Madagascar, Malawi, Mali, Mozambique, Namibia, São Tomé and Príncipe, Seychelles, Sudan, Swaziland, Tanzania, Uganda, Zambia or Zimbabwe; data for France is not available for Montenegro or Serbia; 2008 data from Austria is used for Montenegro; 2008 data from Denmark is used for Botswana, Central African Republic, Djibouti, Equatorial Guinea, Guinea-Bissau, Lesotho, Mauritania, Namibia, São Tomé and Prìncipe and Swaziland; 2001 data from UK is used for Cape Verde, Comoros, Equatorial Guinea, and São Tomé and Prìncipe; 2008 data from the Netherlands is used for Chad and Mauritania; 2006 data from
} 


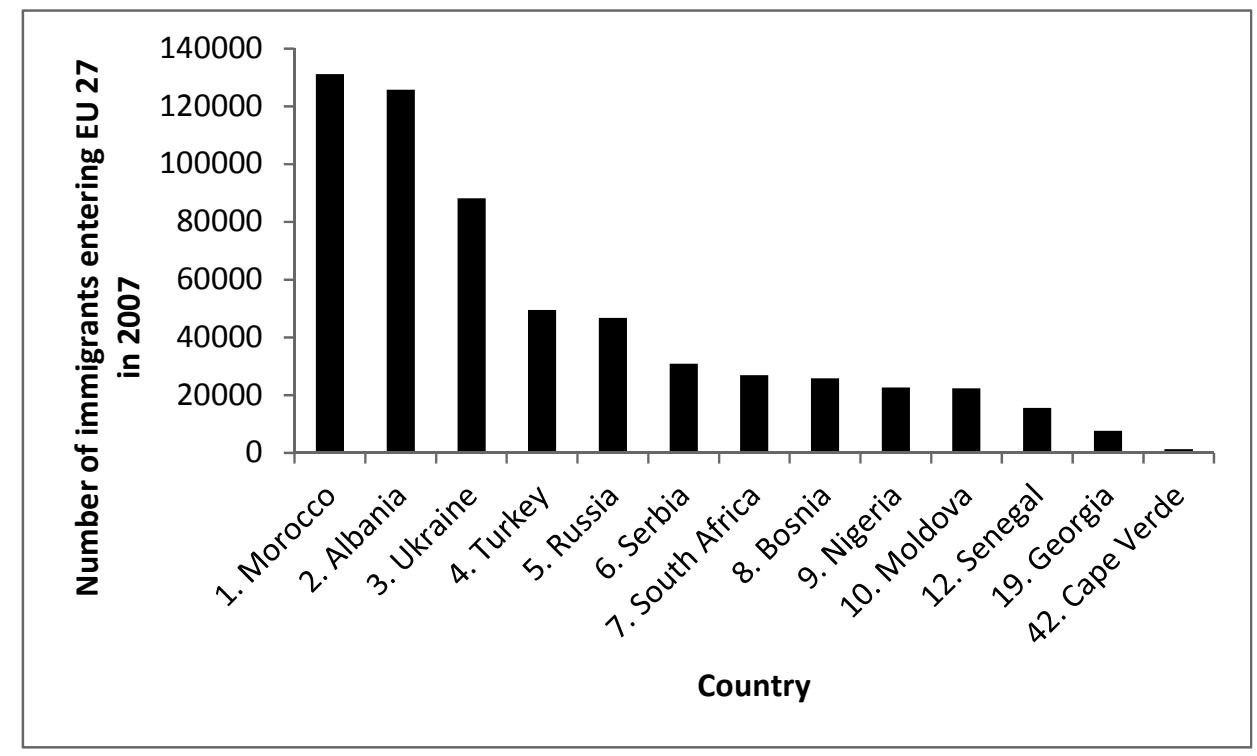

Figure 4.3: Legal immigration flows to the EU 27 in 2007 (source: Eurostat).

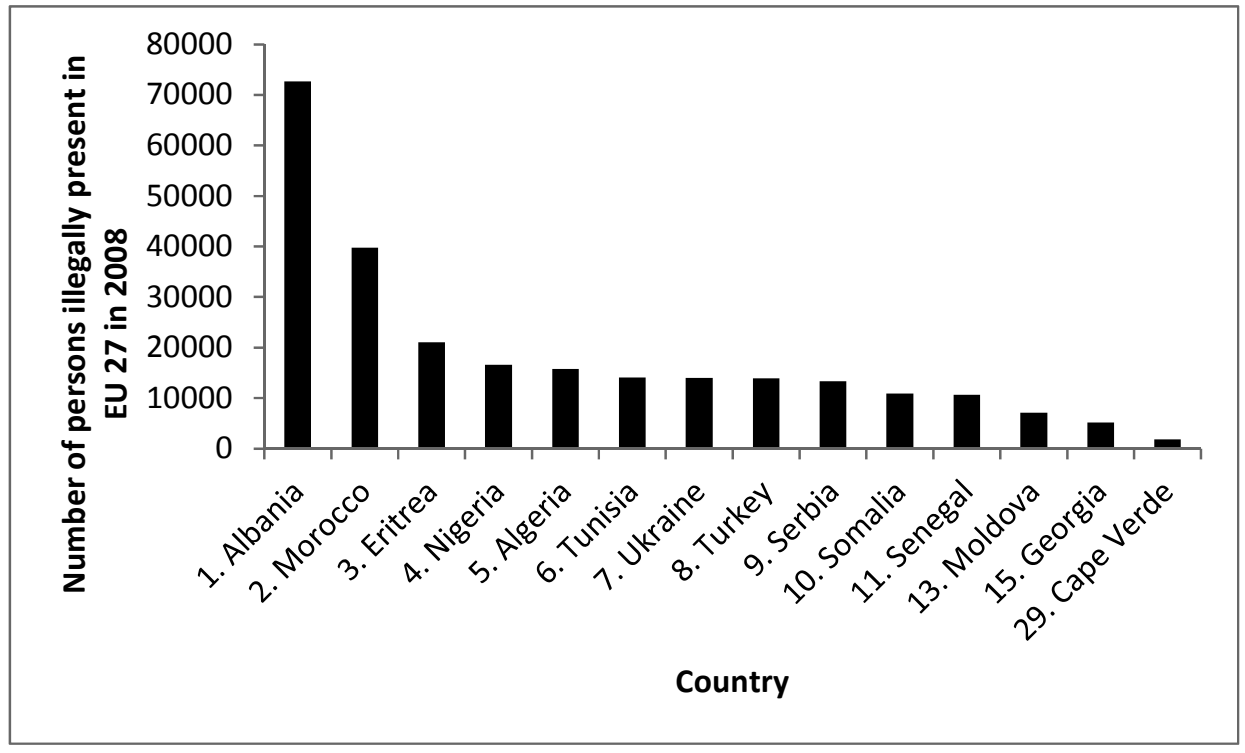

Figure 4.4: Illegal immigration flows to the EU 27 in 2008 (source: Eurostat).

the Netherlands is used for Swaziland; 2005 data from France is used for Namibia. The data for illegal migration is the number of migrants with the citizenship of the third country found to be illegally present in the EU 27 in 2008, based on Eurostat data (http://epp.eurostat.ec.europa.eu/portal/page/portal/population/data/ database, retrieved 17 February 2012). Data for Luxembourg is for 2009. For full data tables see Annex III. A total of 68 countries are covered by the Global Approach to Migration. 
The figures show that the five most significant countries contributing to legal immigration flows to the EU are Morocco, Albania, Ukraine, Turkey and Russia. The five most significant countries contributing to illegal immigration flows to the EU are Albania, Morocco, Eritrea, Nigeria and Algeria. Apart from Morocco, the Mobility Partnership countries only barely make it to the top 10, and Cape Verde in particular is a country of low migration pressure for the EU. However, countries were not chosen for Mobility Partnerships in the first instance according to their contribution to migration flows. Although the presence of some level of migration from the third country to the EU was a criterion for selecting the first countries for Mobility Partnerships (Interview 13), other factors played a more important role. In particular, member states insisted on an 'east-south' balance (Interview 11; 13; 20). This east-south axis divides member states and determines their preferences for the geographical focus of the EU's external policies (Interview 21). The Spanish government, for instance, opposed a visa facilitation agreement with Georgia on the grounds that something similar should then be offered to a country to the south of the EU (Interview 21). In one expert meeting of member state representatives and the Commission, the east-south tension was clear in the remarks of the Spanish and Polish representatives: Spain opposed a possible Mobility Partnership with Ukraine on the grounds that a PCA already exists with Ukraine and EU funding is therefore available for migration-related projects; Poland countered that African countries have received enough attention in migration-related matters (Dutch Ministry of Foreign Affairs, 2008a). Parkes (2009a, p.343) has also observed this tendency with regards to the ENP: "The EU Member States wrangle with one another to ensure that third countries are favoured with which they enjoy a special relationship. In general, one can talk of an 'East-South' divide in ENP. If an eastern neighbour is favoured, a bloc of EU Member States will demand a 'compensatory' focus on a southern state, and vice versa". This preference by the member states explains the initial pair-wise selection of third countries for Mobility Partnerships: Moldova-Cape Verde, Georgia-Senegal, and later Armenia-Ghana. Broader political considerations also played into the selection of partner countries, particularly in the case of Georgia. There was general sympathy among the member states with Georgia in the aftermath of the war with Russia in 2008 (Interview 1). On 1 September 2008, an extraordinary meeting of the European Council committed the EU to "step[ping] up its relations with Georgia" including in the area of visas (Council, 2008h, p.4). Member states' control of the issue of legal migration also constricted the Commission in its suggestions for third countries: DG JLS officials were aware that third countries with significant migration flows to the EU would be likely to demand greater access to the EU labour market as the price for their cooperation on illegal migration. As access to the labour market remains under member state control, selecting such third countries would have resulted in negotiations on a Mobility Partnership dragging on (Interview 1).

Ultimately, without adequate member state support there would be no Mobility Partnership, because member states propose the projects that form the content of the partnerships. The level of interest of member states was therefore the most important consideration in the selection of third countries for Mobility Partnerships (Interview 
13). The example of Ghana demonstrates this: the Commission proposed Ghana for the first African Mobility Partnership, but member states did not display significant interest (Interview 20). Later, however, member states' preferences had changed, and Ghana was selected for negotiations. The "interest of a critical mass of EU member states" is also recognised as the first criterion for the selection of third countries for a migration mission (Council, 2012a, p.4).

This sub-section has outlined the 'tug-of-war' between the Commission and member states in the decision-making process leading to the signature of Mobility Partnerships. On the surface, the Commission appears to have played a central, coordinating role: it proposed third countries for Mobility Partnerships; coordinated between interested member states; conducted negotiations with the third countries selected; and has been active in promoting the Mobility Partnership tool. However, the member states in the Council mandated the Commission's actions at each step; determined the legal form of the Mobility Partnership tool; determined the content of each specific Mobility Partnership; and controlled the choice of third countries for Mobility Partnerships. This has limited the Commission to yielding and flexibility, negotiation strategies associated with 'soft bargaining'. The control by member states has also put the Commission in a weak bargaining position when negotiating Mobility Partnerships with third countries because it is not able to offer unilateral concessions that member states have not approved.

\subsubsection{The European Parliament and other EU institutions}

This sub-section shows that the Commission and the Council have been the only EU institutions to play a role in the decision-making process on the Mobility Partnerships. Indeed, the European Parliament has been noticeably silent on the partnerships. Carrera and Hernández i Sagrera (2009, p.30) label this a "clear democratic deficit": "It is striking to see that the European Parliament was completely absent in the process leading to the conclusion of the mobility partnerships with Moldova and Cape Verde". This absence is due to the legal form of the Mobility Partnerships: because the partnerships are signed as political declarations, rather than international agreements based on article 218 TFEU, there is no formal role for the European Parliament as there is no legislative procedure. Although the member states insisted on this legal form in order to maintain control over the policy instrument, the process-tracing uncovered no evidence that keeping the European Parliament completely outside the policy-making process was a specific aim of the member states.

Following the adoption by the Commission of the communication on Mobility Partnerships on 16 May 2007, the communication was officially transmitted to both the Council and the European Parliament on 21 May 2007. However, at no point have the partnerships been the specific subject of debate in the Parliament, and mentions of them are few and far between. Indeed, the policy rhetoric of Parliament resolutions is somewhat different to the notion underlying the Mobility Partnerships. The Parliament has on several occasions noted that legal and illegal migration are linked, because the availability of channels for legal migration will reduce the extent of illegal migration (European 
Parliament, 2007; 2005). However, legal migration is not conceived of as a bargaining tool for obtaining third countries' cooperation on illegal migration. The Parliament even warns against making technical and financial assistance to third countries dependent on their performance on readmission (European Parliament, 2006a, p.11).

The 2007 resolution by the European Parliament on illegal immigration lists as one of the reference documents the Commission's communication on Mobility Partnerships. However, the resolution does not specifically refer to a European Parliament position on the partnerships. Rather the resolution notes in general terms that "the cooperation of the EU and its Member States with the third countries of origin and transit is vital, and an effective and practical policy of co-development must be put in place with a view to addressing at an early stage in third countries the root causes of immigration" (European Parliament, 2007). The Parliament further calls on the member states and the Commission to ensure that adequate resources are in place for the implementation of the GAM.

In a resolution adopted in January 2008 on EU policy towards the South Caucasus, the European Parliament calls for the signature of a Mobility Partnership with Georgia (European Parliament, 2008a). In the resolution, the Parliament "stresses the importance of cooperation in the area of freedom of movement across the borders of the EU and its neighbours; calls on the Commission and the Council . . . to take the necessary steps for the launch of negotiations on readmission and visa facilitation agreements between the EU and Georgia and for the signature of a mobility partnership agreement with the EU'. This is earlier than the Council conclusions which mandated the Commission to begin negotiations with Georgia (June 2008). However subsequent Commission and Council documents do not refer to this resolution, therefore it is not possible to conclude a causal impact of the opinion of the Parliament on the choice of Georgia as a partner country for a Mobility Partnership. In September 2008, the Belgian MEP Frank Vanhecke addressed a written question to the Commission, enquiring about the "reports" that "the European Union set up a pilot project with the African island state of Cape Verde to allow migrants from that state to travel easily back and forth between Cape Verde and the EU" and the meaning of such a project in practice (European Parliament, 2008b). The answer provided by the Commission outlines the idea of Mobility Partnerships (based on the 2007 Commission communication) and confirms that Spain, France, Luxembourg, Portugal and the Commission have signed such a partnership with Cape Verde. The answer also points out that projects within the Mobility Partnership address legal migration, illegal migration, and migration and development (European Parliament, 2008c).

In February 2009, the Parliament's Policy Department commissioned a briefing paper on circular migration and Mobility Partnerships for the Civil Liberties, Justice and Home Affairs Committee, in response to the 2007 Commission communication (Interview 29). However, the briefing paper deals solely with the concept of temporary labour migration, covering aspects such as incentives for migrants to return and integration requirements in European countries (Wiesbrock and Schneider, 2009). The paper concludes that "from a development perspective, rather than focusing on temporariness, migrant workers should be encouraged to stay in the host country for a longer time in 
order to enable them to accumulate sufficient resources to make return worthwhile" (p.12). While it is true that schemes for circular migration might be incorporated into a Mobility Partnership, this has so far not been the case in practice (see sub-section 4.5.2). The briefing paper, once completed, was sent to all MEPs but it was not followed up with a specific debate in a plenary session on either Mobility Partnerships or circular migration (Interview 29).

A 2010 report commissioned by the European Parliament on the EU's readmission policy also refers to the Mobility Partnerships (Cassarino, 2010). The report concerns the legal basis for readmission agreements and the balance between costs and benefits for third countries to sign such agreements. The link to Mobility Partnerships is made because readmission is one of the commitments required from third countries wishing to sign a partnership: "mobility partnerships stem from the consolidation of a new compromise encompassing a large array of issues ranging from development aid, to temporary entry visa facilitation, circular migration schemes and the fight against illegal migration including readmission" (p.34). However, the section of the report dealing with Mobility Partnerships does not mention the European Parliament or its position on the partnerships, and the policy recommendations of the report which address actions to be taken by the Parliament on readmission do not mention the Mobility Partnerships. No plenary debate was held in Parliament specifically on the basis of this report, although at the same time as the report was finalised MEPs were debating the ratification of the readmission agreement between the EU and Pakistan (European Parliament, 2010). This was the first readmission agreement to require ratification by the Parliament, due to the entry into force of the Lisbon Treaty. MEPs were divided: the EPP group generally emphasised the importance of a repatriation policy if EU migration policy is to be credible, whilst the S\&D group raised concerns over human rights, given that Pakistan has not signed the Geneva Convention. Ultimately, however, Parliament ratified the agreement.

In an opinion on EU labour immigration policy and relations with third countries adopted in June 2008, the Committee of the Regions refers to the Mobility Partnerships (Committee of the Regions, 2008). The opinion deals not only with the Commission communication on Mobility Partnerships, but also a communication on sanctions against employers of illegal migrants and two Commission proposals for Council directives: one on the conditions of entry to the EU for migrants for the purposes of highly qualified employment, and one on a single permit for third country nationals to reside and work in the EU. The overarching conclusion of the Committee of the Regions is that the EU "must equip itself as soon as possible with a genuine European immigration policy, respecting the powers of the different levels of government" (p.2). In this context, the Committee "applauds the mobility partnerships with third countries . . . [and] notes the importance of concluding readmission agreements with third countries as part of their commitments" (p.5). However, the opinion "regrets that the role of the Committee of the Regions is not mentioned in any of the reference documents, and voices its concerns at the lack of attention to the territorial dimension" (p.3). The opinion is 
adopted under article $307 \mathrm{TFEU},{ }^{54}$ however it is an 'optional referral' meaning that there is no legal requirement for the Commission to refer the documents concerned to the Committee of the Regions. Indeed, no later documents by either the Council or the Commission refer to this opinion by the Committee of the Regions. The opinion calls for a stronger role for "towns and regions of origin and destination of migration flows in the mobility partnerships, since they can facilitate mobility for immigrants and exert a positive influence on the social integration of immigrants" (p.6).

The European Economic and Social Committee dealt with the Mobility Partnerships in an own-initiative opinion on EU immigration and cooperation policy with countries of origin (European Economic and Social Committee, 2007). The opinion concerns particularly the contribution that cooperation with third countries can make to their development, and discusses the benefits of remittances, the role of diaspora networks in development, and return migration as a way of recovering human capital. In this context, "the Committee supports the proposal to establish mobility partnerships" (p.19) but it makes several suggestions: Mobility Partnerships should be flexibly adapted to suit the situation of third countries; the Mobility Partnerships should contain an EU offer of quotas to match European job markets; funding available for Mobility Partnerships under the thematic programme should be increased; the Commission delegations and member states' embassies should cooperate more intensively; and immigration legislation should be more flexible to facilitate circular migration. However, as with the European Parliament and the Committee of the Regions, there is no evidence that this opinion of the European Economic and Social Committee was taken into consideration in further Council or Commission documents relating to the Mobility Partnerships.

This chapter does not deal with the role of the ECJ because the court is not involved in decision-making processes, but rather judges the application of EU legislation. However, commentators have noted that the non-legally binding form of the Mobility Partnerships makes it doubtful that "these partnerships can be subject to any judicial control exercised by the ECJ" (Carrera and Hernández i Sagrera, 2009, p.30).

\subsection{Conclusion}

This chapter has mapped the governance at the EU level of the Mobility Partnerships. It set out to answer the first two sub-questions of the research project: what was the role of the EU institutions and the member states in the negotiation of the Mobility Partnerships? And what implications does this have for the form of the partnerships? Chapter 2 took as a theoretical starting point the governance approach to understanding EU policymaking. Scholars adopting a governance approach are not concerned with the process of European integration as such; rather, they share an interest in the day-to-day functioning of EU institutions and EU decision-making - in other words, in the EU as a political system. These scholars do not aim to develop an explanation of decision-making that will hold across all policy areas; rather they acknowledge that patterns of governance

${ }^{54}$ As renumbered by the Treaty of Lisbon; ex article 265. 
vary between policy areas. This chapter has followed such an approach by aiming to depict the pattern of governance of the Mobility Partnerships, and explain why this pattern of governance has emerged.

The pattern of governance that we see for the Mobility Partnerships is a classic example of 'intensive transgovernmentalism' (see chapter 2, and Lavenex, 2009b). Many aspects of EU migration policy are now governed by the Community method: the Commission has the exclusive right to initiate policy, legislation is passed by the Council and the European Parliament together, and this legislation is subject to adjudication by the ECJ. In contrast, the European Parliament and ECJ have been excluded from the policy process on the Mobility Partnerships. Decision-making at the EU level has instead been characterised by a 'tug-of-war' between the Commission and the member states. On the surface, the Commission appeared to have played the central role: in the policy formulation stage, the Commission published the communication on the Mobility Partnerships. In the decision-making stage, DG JLS suggested potential partner countries, gauged the interest of the member states in taking part, conducted discussions with officials of the third countries, and continually promoted the Mobility Partnerships as a policy tool in the EU's relations with third countries. However, behind the scenes member states were maintaining control over the content, direction and form of the Mobility Partnerships. The member states influenced the policy formulation stage through their own policy initiatives, such as the French and Spanish bilateral migration agreements. In the decision-making stage, the member states have mandated every step taken by the Commission through Council conclusions, and controlled the selection of third countries for Mobility Partnerships. The influence of the member states on the decisionmaking process has manifested itself in the form of the partnerships: Mobility Partnerships are signed as political declarations (rather than legally binding international agreements); participation is voluntary for member states; and member states control the content of the partnerships through the projects they propose. This control by member states placed the Commission in a weak bargaining position, both in its interactions with the member states, but also crucially in its negotiations with third countries on Mobility Partnerships.

Why do we see contestation between the Commission and the member states in the decision-making process? Chapter 2 argued that EU institutions will seek to maximise their competences by expanding the role of the EU in existing and new policy areas. Quite simply, if there is no EU policy there is no role for the EU institutions. The Commission thus had a clear interest in the creation and control the Mobility Partnership instrument. However, external migration policy is at the crossroads of migration policy and foreign policy. These are two policy areas that are sensitive for the member states. They will therefore likely resist the transfer of too many competences to the EU institutions, preferring to maintain control of the policy-making process.

The combination of a Commission that seeks to expand EU external migration policy with member states that are reluctant to hand over control of a policy area that intersects both foreign policy and migration policy sets the stage for a complex decision-making process, as demonstrated in the case of the Mobility Partnerships. The 
chapter has not dealt with the interest of individual member states in participating in the Mobility Partnerships; this will be dealt with in the following chapter, where the case studies of France, Austria and the Netherlands will be set out. 


\section{Chapter 5}

\section{The EU-member state}

\section{interaction}

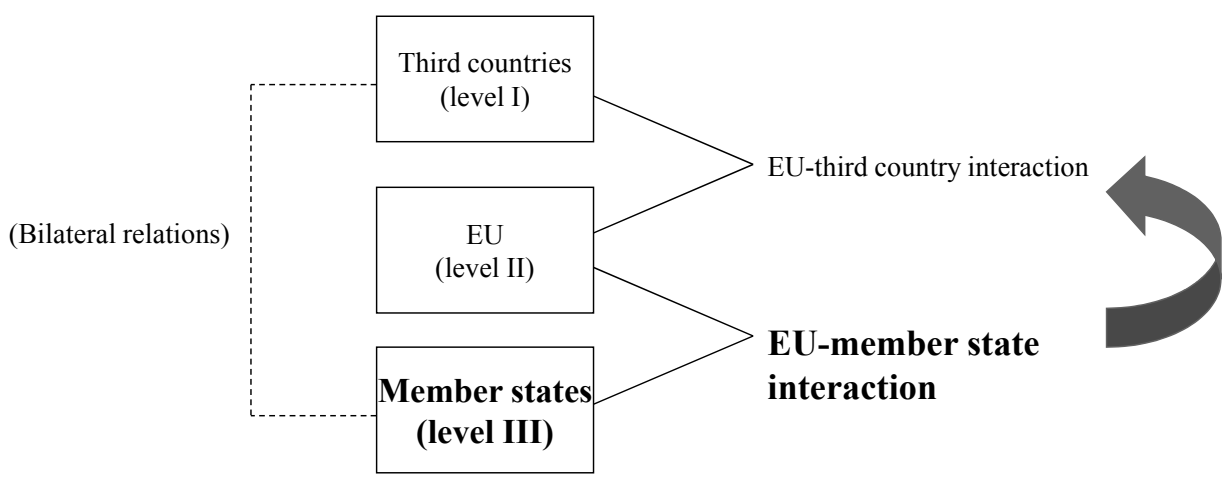




\subsection{Introduction}

This chapter deals with the member-state level (level III of the three-level game), as well as the interaction between the EU and the member states. At the member-state level, a domestic preference on participation in EU external migration policy emerges. These domestic preferences then feed into the interaction with the EU institutions, leading to agreement on the shape of the EU policy instrument. Chapter 4 outlined the central role played by the member states during the policy-making process on the Mobility Partnerships, both in terms of policy formulation and in terms of decision-making. The control exercised by member states had important implications for the legal form of the Mobility Partnership instrument in general and the content of the individual partnerships specifically. This chapter will now answer the third sub-question of the research project as presented in chapter 2: why do some member states chose to participate in the Mobility Partnerships while others do not? In order to address this question, the focus in this chapter will be on three case studies: France, Austria and the Netherlands (see chapter 3 ). These three member states reached very different decisions on participation in the Mobility Partnerships. France and Austria represent complete opposites in this respect: the French government decided early on in the discussions on this policy instrument to participate in all future Mobility Partnerships. The Austrian government decided that it was completely opposed to this policy instrument, regardless of the partner country concerned in any specific instance. The Dutch government took an intermediate position: having been rather ambivalent at the outset and not joining either of the first two Mobility Partnerships (with Moldova and Cape Verde), it later reversed its position and joined first the partnership with Cape Verde and then the partnership with Georgia. This chapter accounts for these different domestic preferences. It therefore specifies the domestic politics of external migration policy for the member states and offers explanations for governments' preferences on the issue.

The chapter starts by setting out the external migration policies of each of the member states. All three cases have some policies or measures in place that either resemble Mobility Partnerships or would be compatible with participation in a Mobility Partnership. The existence of such a policy in itself therefore cannot account for their different preferences on this EU policy instrument. Section 5.3 outlines how decisions relating both to the EU and to migration policy are taken in each member state. Section 5.4 shows that the national identity explanation accounts for the decision by France to participate in all Mobility Partnerships, but that the same notion of 'appropriateness' is not the best explanation for Austrian and Dutch preferences on the partnerships. Instead, in these two cases a rationalist cost-benefit analysis led the two governments to formulate very different preferences (section 5.5). Section 5.6 outlines the size of the win-set for the EU and the member states. 


\subsection{External migration policy in France, Austria and the Netherlands}

All three member states have an external migration policy in place or are implementing projects related to migration in third countries. The bilateral agreements on the management of migratory flows that France signs with some third countries most closely resemble the concept of Mobility Partnerships.

\subsubsection{France}

The French government emphasises the importance of cooperation with third countries on migration issues: "migration is about third countries, people coming from third countries, so we cannot imagine having a national policy disconnected from what is happening outside" (Interview 32). The aim is to establish a "detailed dialogue with immigration countries of origin" (European Migration Network, 2009d, p.24). Such cooperation is seen as essential to achieve the government objective of preventing illegal migration (European Migration Network, 2010e, p.3; 2010f, p.3). Examples of French measures in cooperation with third countries include: provision for circulation visas in bilateral agreements; readmission clauses; police cooperation; placement of immigration liaison officers in third countries to exchange information and best practices; exchange of experiences between the French border police and third countries' services; contribution to training programmes organised by Frontex; and participation in the Conference of the Ministers of Interior of the Western Mediterranean (together with Malta, Italy, Spain, Portugal, Morocco, Algeria, Tunisia, Libya and Mauritania) (European Migration Network, 2010f, pp.18-20). In addition to the EU readmission agreements, France has signed more than 40 bilateral readmission agreements (p.41). France implements programmes that could fall under the existing Mobility Partnerships, for instance a programme on voluntary assisted return of migrants to Moldova (European Migration Network, 2009d, p.20). The French Agency for Immigration and Integration (OFII) also provides assisted resettlement to migrants wanting to undertake business ventures in their country of origin (European Migration Network, 2010f, p.44), including in all the countries that have signed Mobility Partnerships.

The concept of 'co-development' has long been important in the French external migration policy (Magoni, 2004). The French Ministry of Interior defines the concept of co-development in the following way: "c'est toute action à laquelle participent des migrants pour aider au développement de leur pays d'origine" (French Ministry of Interior, n.d.; see also European Migration Network, 2009d, p.8). The overall objective is to reduce poverty in regions of emigration, and thereby contribute to a better management of migratory flows. Three main types of actions are envisaged: financial support for initiatives by migrant associations in their country of origin; support for migrants in setting up businesses in their country of origin; and measures to mobilise the expertise of highly-qualified migrants to contribute to the development of their country of origin. Until 2007, the policy of co-development focussed mainly on Senegal and Mali. In Senegal, primary and secondary schools and health centres have been constructed. In Mali, a project for the management of surface water was implemented in the region of 
Djombougou. For the period 2009-2011, €100 million was earmarked for codevelopment policy (ibid.). The concept of involving the diaspora in the development of their home country is also part of the general objectives of the Mobility Partnerships. The partnership with Moldova, for instance, states that the parties intend to "create the conditions for boosting the diaspora's investment in their home country through twinning projects, loan and transfer facilitation and targeted remittance schemes enhancing the development impact of migrant workers' money transfers" (Council, 2008b, p.4).

The main framework for French cooperation with third countries on migration issues is a bilateral accord de gestion concertée des flux migratoires et de développement solidaire (agreement on the concerted management of migratory flows and cooperative development) (French Ministry of Interior, n.d.). This instrument is based on the EU's Global Approach to Migration and the European Pact on Immigration and Asylum (ibid.). As of March 2012, accords had been signed with fourteen countries: Benin, Burkina Faso, Cape Verde, Congo, Gabon, Mauritius, Russia, Senegal, Tunisia, Cameroon, Lebanon, Macedonia, Montenegro and Serbia. Of these, the first nine had been ratified (République Française, n.d.). The French government describes these accords as a "global partnership on migration" (European Migration Network, 2010f, p.41), encompassing legal migration, visas, readmission, police cooperation, reintegration, and development projects (p.45). These agreements set out certain sectors of the labour market for which nationals from the partner country can be employed without proof that there is no French or EU citizen to perform the task (European Migration Network, 2009d, p.18). They also aim to encourage the movement of highly qualified migrants, and they allow students to supplement their studies in France with a first professional experience before they return to their country of origin (European Migration Network, 2010f, pp.28-29). ${ }^{55}$ Circular migration is already envisaged in French migration policy: short-stay circulation visas, for instance, are issued to "foreign nationals who manifestly contribute to the development of the [French] economy or bilateral relations". These visas are valid for multiple trips in several years (European Migration Network, 2009d, p.9). However, the Ministry of Interior also underlines that permanent labour immigration to France must respond to French business needs and must be consistent with French reception capacity (p.8).

\subsubsection{Austria}

Austria does not have a history of pursuing the type of agreements that the French government is signing with third countries. However, the Gastarbeiter agreements signed with third countries in the 1960 s are an instance of external migration policy in that they drew third countries into cooperation with the Austrian government on migration issues. In the 1960s, the post-war economic boom coupled with a domestic labour force short-

\footnotetext{
${ }^{55}$ Like the EU Mobility Partnerships, the French accords are differentiated according to the third country concerned, so different conditions apply in the different agreements (European Migration Network, 2009h, p.39), for instance regarding the duration of the residence permit issued to students after their studies in France. Students from Benin, Burkina Faso, Mauritius and Tunisia receive a 6-month residence permit, whilst students from Cape Verde, Congo, Cameroon and Gabon receive a 9-month residence permit (European Migration Network, 2010f, p.29).
} 
age led the government to follow the lead of Germany and Switzerland and sign bilateral agreements with southern and south-eastern European countries on the recruitment of temporary labour migrants (Jandl and Kraler, 2003; European Migration Network, 2010c). Agreements with Spain and Italy were not successful - Austrian employers had difficulty attracting workers from these countries in the face of competition from France, Germany, Switzerland and the Benelux countries (Gächter, 2008, p.4). Agreements were signed with Turkey in 1964 and Yugoslavia in 1966, and these were more successful: by 1973 there were 178,000 Yugoslavians and 27,000 Turks in Austria (Jandl and Kraler, 2003). Migration under these agreements was conceptualised as temporary in nature: migrants would come to Austria, work according to Austrian economic need, and then return to their countries of origin (European Migration Network, 2010c, p.29). With the onset of the oil crisis and recession in the early 1970s, these programmes were terminated and the access of foreigners to the Austrian labour market was restricted in the 1975 Aliens Employment Act (Jandl and Kraler, 2003). Nevertheless, immigration to Austria continued in the form of family reunification so that the experience with the Gastarbeiter programmes has had a lasting effect on the make-up of Austrian society: in 2008, 53\% of all non-EU nationals living in Austria came from the two main recruitments regions of the Gastarbeiter programmes - the former Yugoslavia and Turkey (European Migration Network, 2010c, p.38).

Although the Gastarbeiter programmes have long since ended, the Austrian government actively pursues different kinds of measures on migration in or with non-EU countries (European Migration Network, 2010d, p.34). The 2007-2010 coalition programme emphasised the importance of international cooperation to prevent illegal migration, and suggested measures such as cross-border cooperation between national labour market services (Bundeskanzleramt Österreich, 2007, p.51). The most important countries for cooperation are those to the east and south-east of the EU; the Austrian government has, for instance, signed social security agreements with several countries to the south-east of the EU, including Bosnia and Herzegovina, Serbia and Turkey (Österreichische Sozialversicherung, 2012). The Austrian Ministry of Interior, in cooperation with IOM and NGOs, operates assisted voluntary return programmes and reintegration support to migrants from certain regions including Moldova (European Migration Network, 2010c, p.72; European Migration Network, 2011a). The Ministry of Interior also operates information campaigns in third countries on the consequences of illegal migration to Austria (European Migration Network, 2010c, p.78). In 1998, the Austrian presidency of the Council drafted a strategy paper on EU migration policy. In it, agreements with countries of origin of migrants on prevention of illegal migration and repatriation are identified as one of the pillars of an EU migration policy. The strategy paper also suggests linking facilitated border crossings with guarantees by third countries on readmission (Council, 1998a).

\subsubsection{The Netherlands}

Like Austria, the Netherlands also has a history of guestworker agreements with third countries. In the 1960s, agreements were signed with Greece, Italy, Morocco, Portugal, 
Spain, Tunisia, Turkey and Yugoslavia (Geddes, 2003, p.105). As in Austria, the need for such guestworker agreements resulted from strong economic growth in the post-war years and a domestic shortage of low-skilled workers. The concept behind these agreements was that migrants could work for a while in the Netherlands, and then return with their earnings to their home country to make a living there; migration was thus seen as temporary (European Migration Network, 2012a, p.26). With the onset of economic recession in 1973, guestworker agreements were terminated, although immigration to the Netherlands continued in the form of family reunification, just as in the Austrian case.

To this day, the Dutch government pursues an external migration policy. Since the 1990s, the government has acknowledged the importance of cooperation with third countries on migration issues, for instance in securing the repatriation of illegal migrants (Bonjour, 2005; European Migration Network, 2005a, p.26). A number of projects have been implemented in or with the cooperation of third countries. The Dutch Immigration and Naturalisation Service (IND), for instance, has posted immigration liaison officers to a number of third countries, including Syria, China, South Africa and Kenya. The aim of such postings is to improve the border control capacities of these third countries (European Migration Network, 2010h, p.19). Dutch external migration policy includes projects targeting more than one third country at a time: in 2009 the government signed an agreement according to which Liberian border guards would be trained in Ghana (p.20). IOM in the Netherlands has been an important implementing partner for Dutch external migration policy (Interview 15). The two most important projects implemented by IOM for the Dutch government in third countries have been MIDA Ghana (Migration for Development in Africa) and Temporary Return of Qualified Nationals (TRQN). MIDA Ghana has been running since 2005, and aims to contribute to the development of the Ghanaian healthcare sector. Ghanaians living in the Netherlands may return to Ghana for assignments lasting between two weeks and three months, during which they provide training to local healthcare professionals. Alternatively, healthcare professionals in Ghana may travel to Europe to receive training. Travel costs are covered by funding from the Dutch government (IOM, 2010a). In 2009, there were 35 assignments (IOM, 2009b). TRQN has been implemented since 2006. The project aims to contribute to the reconstruction and development of Afghanistan, Bosnia and Herzegovina, Ethiopia, Georgia, Sierra Leone and Sudan. Highly-educated migrants from these countries carry out assignments lasting from a couple of weeks to a maximum of three months in their country of origin, much like MIDA Ghana. The assignments are based on the needs formulated by the institutions in the country of origin. In the first two years of the project (2006-2008), 160 assignments were completed (IOM, 2010b). Already in the policy memorandum on Dutch development cooperation 2007-2011, the government emphasised the link between migration policy and development cooperation (Dutch Ministry of Foreign Affairs, 2007), and in 2008 a policy memorandum setting out Dutch migration and development policy was published (see section 5.5). 


\subsection{The coordination of EU and migration-policy making in France, Austria and the Netherlands}

This section identifies the main governmental actors in each member state that could be involved in making the national decision on participation in the Mobility Partnerships. As external migration policy sits at the crossroads between migration policy and foreign policy, it is not only the ministry (or ministries) responsible for migration issues that are likely to be responsible for decision-making on the Mobility Partnership instrument, but also the ministry of foreign affairs. Coordination of national EU policy in general is also an inherently complex task (see Kassim et al., 2000). The EU "blurs the traditional distinction between foreign and domestic policy, and covers a range of different policy types" (p.7). Governments must decide whether to establish a central ministry for European affairs, responsible for taking national policy to Brussels, or whether to leave responsibility for EU policy in each policy area to the ministry responsible for that policy, or whether to establish some coordinating structure along with an EU unit in each ministry. The role of the Permanent Representations also varies between member states and between policy areas (van Keulen, 2006). This section shows that the three cases organise their EU and migration-policy making in rather different ways.

\subsubsection{France}

French coordination of EU policy is marked by a strong role for the Secretariat General for European Affairs (SGAE) ${ }^{56}$ and the Ministry of Foreign Affairs, and a weak role for the French parliament. The SGAE has always had a central role in the coordination of French positions within the EU. It is a service under the authority of the prime minister and is responsible for coordinating all aspects of French European policy-making (Szukala, 2003, p.228). The SGAE hosts interministerial coordination meetings to arrive at the French position on matters of EU policy, and communicates instructions for discussions in the Council to the Permanent Representation in Brussels (Menon, 2000). The French Ministry of Foreign Affairs has retained an important role in French EU policy through its control of the French Permanent Representation to the EU. The permanent representative and the deputy permanent representative of France to the EU always come from this ministry (Menon, 2001, p.76), and officials in the Permanent Representation play a significant role in the formulation of the instructions by the SGAE which constitute the French position on EU policies (p.83).

In 1973, the Senate created a Delegation for European Affairs, and in 1979 the National Assembly followed suit. These committees have traditionally been considered ineffectual and have been overlooked by French governments (Szukala, 2003, p.223; Ambler and Reichert, 2001, p.35; Menon, 2000, p.90). However, their position was significantly strengthened following a 1992 ruling of the Constitutional Council on the conformity of

\footnotetext{
${ }^{56}$ In French: Secrétariat Général des Affaires Européennes. The SGAE replaced the Secretariat General of the Interministerial Committee for Questions of European Economic Cooperation (in French: Secrétariat Général du Comité Interministériel pour les question de coopération économique européenne; SGCI) in 2005. The SGCI was created already in 1948 (SGAE, n.d.).
} 
the Maastricht Treaty with the French constitution. The Constitutional Council called into question certain treaty provisions, including those on a common EU visa policy, because they affected "the essential conditions for the exercise of national sovereignty" (Szukala, 2003, p.223). ${ }^{57}$ As a result of this ruling, a new article 88(4) was included in the French constitution, which gives parliament the constitutional right to be informed about EU legislative proposals (p.224). However, it is not always clear which EU policy proposals constitute "matters for statute" - this has been a particularly contentious issue in the area of JHA (p.225). As Szukala (ibid., p.225) points out, "important EC decisions may not touch the legislative domain at all while being incendiary in political terms".

\section{French EU policy}

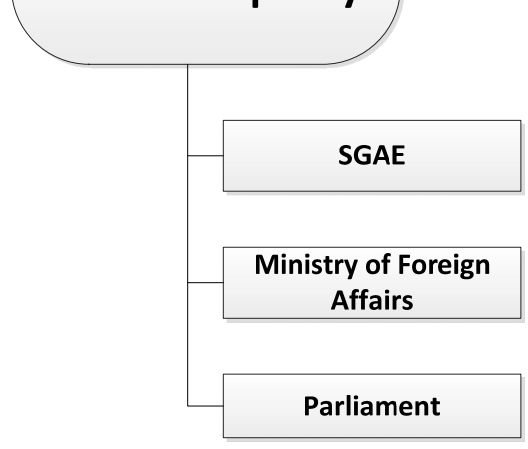

Figure 5.1: Decision-making on French EU policy.

On migration policy, the most important governmental actors in France are the Ministry for Immigration and the comité interministériel de contrôle de l'immigration (CICI). In 2007, the Ministry for Immigration, Integration, National Identity and Co-development was created and charged with managing policies on immigration, integration, and codevelopment with countries of origin of migrants (European Migration Network, 2009d, p.3). ${ }^{58}$ The creation of this ministry had been an important manifesto pledge by the incoming president Nicolas Sarkozy, and should be understood in the context of a general politicisation of the issue of immigration in French politics, particularly since 2002 (Marthaler, 2008). In 2002, the far-right Front National won 18\% of the vote in the first round of the presidential election, before being defeated by Jacques Chirac in the second round. The success of the far-right had an important impact on Chirac's second term in

\footnotetext{
${ }^{57}$ The Constitutional Council reached the same conclusion regarding the Amsterdam Treaty, partly due to the extension of qualified majority voting to the issue of asylum (Szukala, 2003, p.239).

${ }^{58}$ In 2010, the competence for migration policy was transferred to the Ministry of Interior. Within this ministry, a General Secretariat for Immigration and Integration was created (European Migration Network, 2011b, pp.5-6). This chapter refers to the Ministry of Immigration as this was still in existence during the time-frame concerned (up to 2009).
} 
office: "The outcome of the 2002 presidential election indicated that the immigration policy of both the centre-left and centre-right was perceived by key sections of the electorate as being too lax, and addressing this issue became a major focus of Chirac's second presidency" (p.387). In this context, Sarkozy was appointed minister of interior, and he presided over a rightward shift in policy and discourse on immigration by the French government (ibid.).

Other ministries also play a role in migration policy. The Ministry of Interior retained competence over border control and the enforcement of removal measures for illegal migrants (European Migration Network, 2010f, p.5). The Ministry of Labour must approve the issuance of residence permits (European Migration Network, 2011c). Until 2007, the French Office for the Protection of Refugees and Stateless Persons was under the control of the Ministry of Foreign Affairs (European Migration Network, 2009h, p.8). However, the Ministry of Immigration has played the leading role in the area of migration and development, often at the expense of the Ministry of Foreign Affairs (Assemblée Nationale, 2009, p.33). The two ministries share the responsibility for representing France in the EU's HLWG (Interview 32; 33), but on the issue of Mobility Partnerships the Ministry of Immigration took the lead and represented the French position (Interview 32).

These other ministries are represented in the CICI, which was created in 2005. The CICI is responsible for setting the overall direction of government policy on migration and asylum (European Migration Network, 2011b, p.5). The CICI is chaired by the prime minister, and includes (representatives of) the ministers of immigration, interior, social affairs, defence, justice, foreign affairs, education, economics and finance, and overseas France. ${ }^{59}$

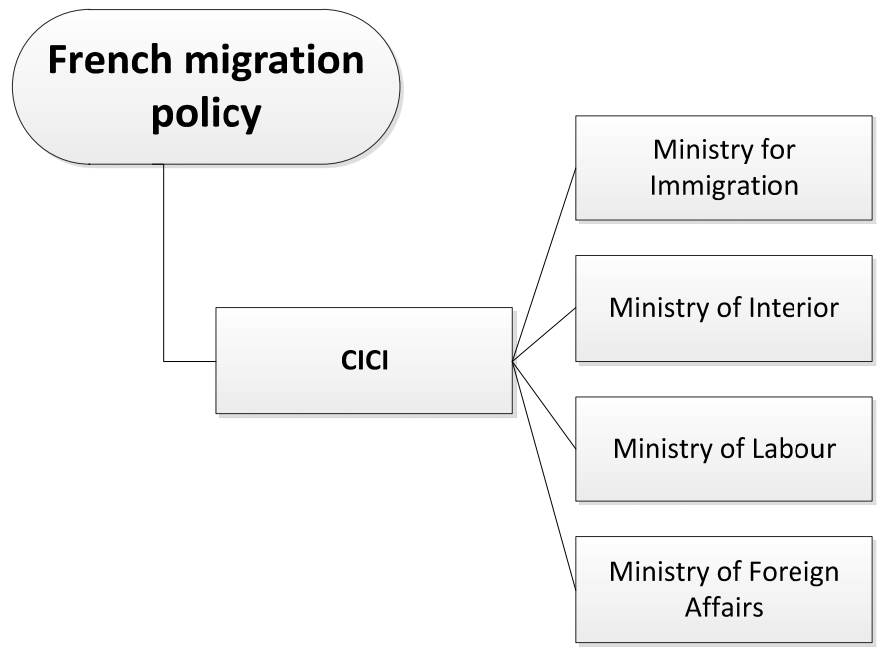

Figure 5.2: Decision-making on French migration policy.

\footnotetext{
${ }^{59}$ Décret n²005-544 du 26 mai 2005 instituant un comité interministériel de contrôle de l'immigration.
} 


\subsubsection{Austria}

Austria is traditionally thought of as a corporatist state, with the main interest groups having an important influence on policy-making (European Migration Network, 2010c). The Austrian model is based on "a pact between parties, chambers, employers and trade unions called the "social partnership" (Höll et al., 2003, p.337). This social partnership consists of the Federal Chamber of Labour, the Austrian Federation of Trade Unions, the Presidential Conference of Chambers of Agriculture, the Austrian Chamber of Business, and interest groups (Falkner, 2001; Gächter, 2008; Höll et al., 2003). ${ }^{60}$ The social partners and the state together shape public policies; indeed, draft legislation is often negotiated between the social partners and the relevant ministry, and merely rubberstamped by the Austrian Parliament (Falkner, 2001). The social partners have also traditionally been influential in the formulation and implementation of Austrian migration policy specifically (Gächter, 2008, p.3).

EU membership has, however, caused some significant changes in the Austrian political landscape (Falkner et al., 1999; Müller, 2000). Leading ministries have gained influence in the policy-making process, at the expense of interest groups, the Parliament, and the Länder. EU membership has therefore made a great difference in terms of "who formally decides what Austria wants" (Falkner et al., 1999, p.499). Proposals for domestic legislation must be approved by all cabinet ministers unanimously, must gain majority support in Parliament, and must be presented to the interest groups that have chamber status. In contrast, "position-taking in EU bodies is left to individual cabinet members or civil servants accountable to them" (ibid.). The responsible ministry on an issue usually coordinates with officials of other affected ministries before taking a decision on the Austrian position in the Council, but the powers of ministers and ministries in policy-making have nevertheless been greatly increased by EU membership (Luif, 1998). One reason for this shift has been the time pressure involved when taking a position on EU matters: the "traditional, sometimes sluggish consultations among the 'social partnership' institutions" are not conducive to allowing efficient Austrian participation in EU policy-making (Höll et al., 2003, p.340). The time pressure also makes it difficult for the individual groups in the policy-making process, for instance the Länder, "to articulate a joint position [on EU matters] in time" (Falkner et al., 1999, p.502). The Austrian constitution gives the Parliament, in theory, an important role in EU policymaking (Falkner, 2001; Müller, 2000). Positions of the Main Committee, for instance, are binding on the government. However, in practice the Parliament is not able to deal with the inordinate amount of information coming from Brussels, and does not have the resources to verify this second-hand information (Höll et al., 2003, p.343).

\footnotetext{
${ }^{60}$ In German: Bundesarbeitskammer; Österreichischer Gewerkschaftsbund; Präsidentenkonferenz der Landwirtschaftskammern; and Wirtschaftskammer Österreich.
} 


\section{Austrian EU policy}

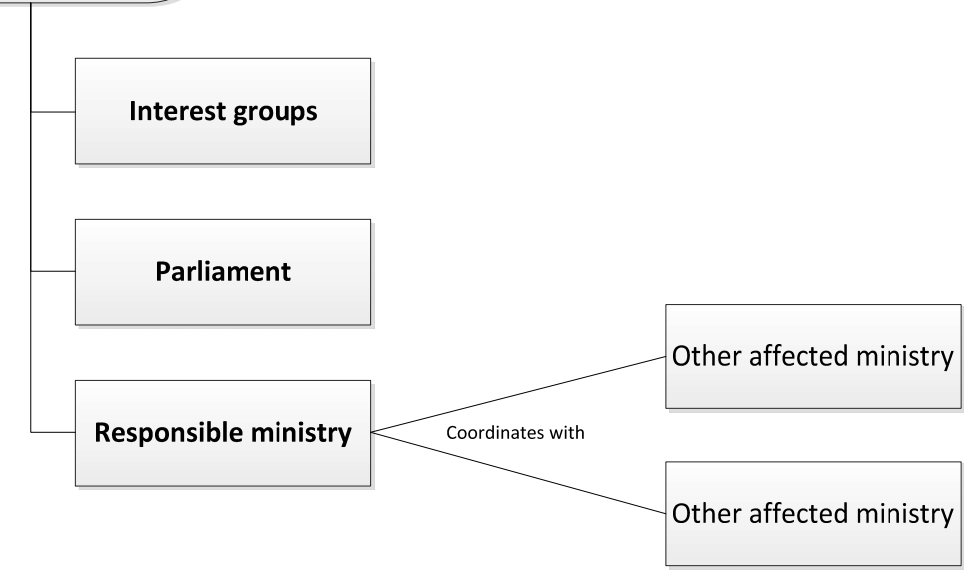

Figure 5.3: Decision-making on Austrian EU policy.

In terms of migration policy, responsibility is shared between the Austrian ministries of Interior; Labour, Social Affairs and Consumer Protection; and Foreign Affairs (European Migration Network, 2010g). The Ministry of Interior has overall competence on migration policy, including on border control, visas and illegal migration. The Ministry of Foreign Affairs ${ }^{61}$ is involved in external migration policy due to its competence on development policy and relations with third countries. These two ministries share responsibility for representing Austria in the EU's HLWG (Interview 24; 25). The Ministry of Labour, Social Affairs and Consumer Protection regulates access to the labour market. ${ }^{62}$ The Ministry of Interior therefore normally liaises with the Ministry of Foreign Affairs and the Ministry of Labour, Social Affairs and Consumer Protection on migration issues (Interview 25; 27).

\footnotetext{
${ }^{61}$ The Federal Ministry for European and International Affairs.

${ }^{62}$ Previously, access to the labour market was regulated by the Ministry for Economics and Labour. This competence was passed to the Ministry of Social Affairs and Consumer Protection in 2009, after which the ministry became known as the Ministry of Labour, Social Affairs and Consumer Protection (European Migration Network, 2009f, p.14).
} 


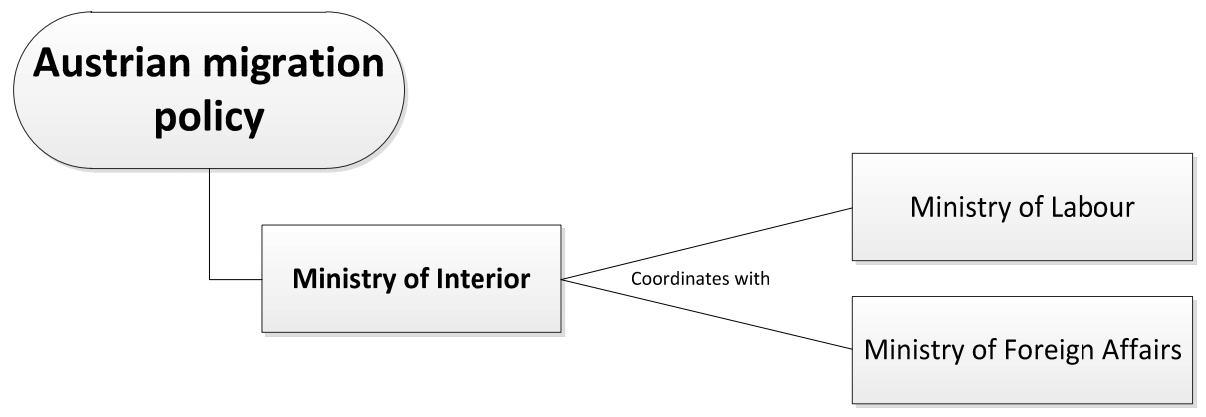

Figure 5.4: Decision-making on Austrian migration policy.

\subsubsection{The Netherlands}

Dutch EU policy is coordinated in the Hague; officials at the Permanent Representation in Brussels "act on instructions that are formulated domestically", although they are not "passive recipients of these instructions" (Soetendorp and Andeweg, 2001, p.219). The Ministry of Foreign Affairs has overall responsibility for ensuring a coherent Dutch national position on EU issues, although the sectoral ministries most concerned with an issue at hand are responsible for preparing the Dutch negotiating position (Soetendorp and Hanf, 1998, p.37). A central role is played by the working group Beoordeling Nieuwe Commissievoorstellen (BNC), an interministerial group established in 1989 and chaired by the Ministry of Foreign Affairs, which examines legislative proposals put forward by the Commission (Soetendorp and Andeweg, 2001, p.220; Hoetjes, 2003, p.320). The BNC also decides which should be the lead ministry on any particular EU issue. In the case of migration policy, this is mostly the Ministry of Justice, except in cases where visa policy is concerned, as this falls under the competence of the Ministry of Foreign Affairs (Interview 8). The official Dutch negotiating position is approved by the cabinet, based on discussions in the Coordination Committee for European Integration and Association Issues (Co-Co) (Soetendorp and Andeweg, 2001, p.222; Hoetjes, 2003, p.322). The Dutch Parliament has traditionally had a rather limited role in Dutch EU policy. A standing committee for EC affairs was created in 1986, however the Parliament cannot determine the Dutch negotiating position in the EU, which is fixed by the cabinet (Soetendorp and Hanf, 1998, pp.42-43). 


\section{Dutch EU policy}

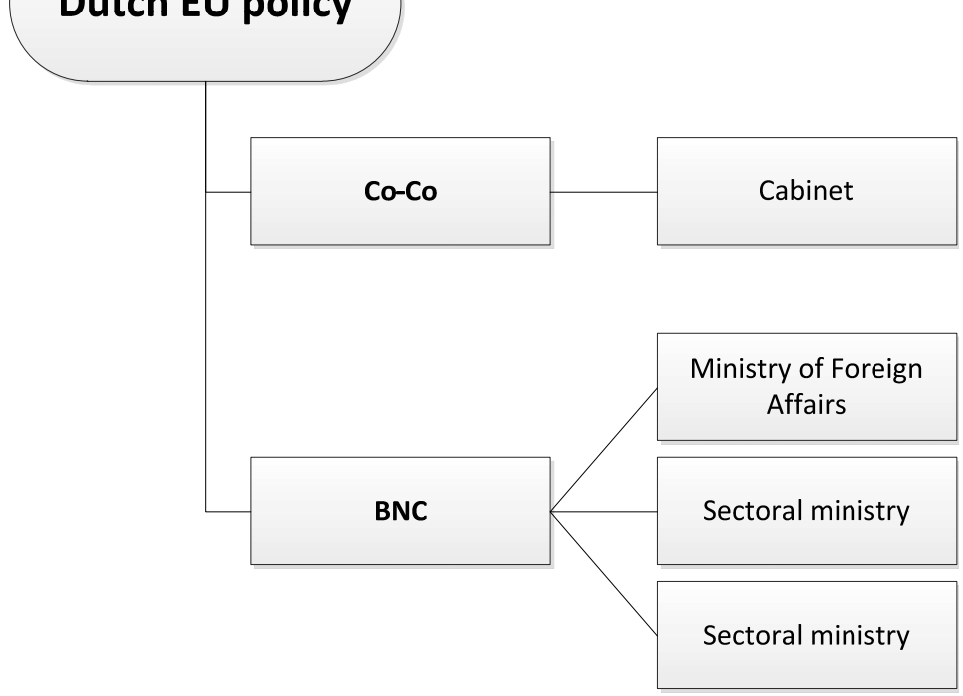

Figure 5.5: Decision-making on Dutch EU policy.

In the Netherlands, responsibility for migration policy was, at the time of the decisionmaking on the Mobility Partnerships, shared between the Ministry of Justice, the Ministry of Foreign Affairs, and the Ministry of Social Affairs and Employment. ${ }^{63}$ Until 2011, the Ministry of Justice had overall responsibility for migration and asylum policy, including citizenship and border control. The Ministry of Foreign Affairs is responsible for visa policy and migration and development policy, and the ministry's migration department represents the Netherlands in the EU's HLWG (Interview 8). The Ministry of Social Affairs and Employment regulates the access of foreign nationals to the Dutch labour market (European Migration Network, 2009i, p.14). The IND and the Repatriation and Departure Service (DT\&V) fall under the Ministry of Justice (p.17), also after 2011 when responsibility for migration policy was transferred to the Ministry of Interior. Occasionally, other ministries may also play a role in migration policy: the Ministry of Economic Affairs, for instance, determines whether an essential Dutch economic interest is served by the admission of migrants taking up self-employment in the Netherlands (European Migration Network, 2009j, p.33). The Royal Constabulary, which carries out border controls, falls under the Ministry of Defence. Since 2007, the Ministry of Housing, Spatial Planning and the Environment has been responsible for integration policy (European Migration Network, 2009k, p.10). The Aliens Police, which ensures compliance with residence procedures and decides on applications for residence permits, belongs to the Ministry of the Interior (p.13).

\footnotetext{
${ }^{63}$ In 2011 the responsibilities for migration policy previously held by the Ministry of Justice were transferred to the Ministry of Interior and Kingdom Relations (European Migration Network, 2012b).
} 


\section{Dutch migration policy}

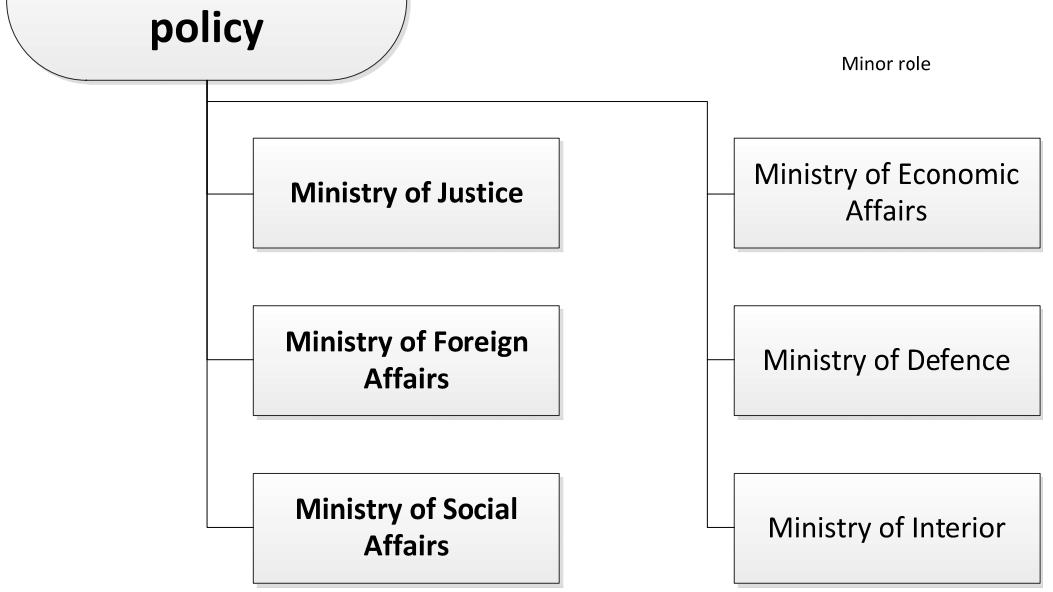

Figure 5.6: Decision-making on Dutch migration policy.

This section has demonstrated that the three cases organise both their EU and migrationpolicy making structures rather differently. France is the only of the cases that had (at the time that the decisions on the Mobility Partnerships were made) an independent ministry responsible solely for immigration; in both Austria and the Netherlands, responsibility for migration is shared between the ministries of interior/justice, foreign affairs, and social affairs. In both France and the Netherlands, the ministry of foreign affairs and a coordinating structure play an important role in EU policy; in France, the coordinating structure is the SGAE, whereas in the Netherlands the BNC working group and Co-Co discuss EU policy. In Austria, by contrast, EU policy is largely left to the sectoral ministry or ministries mainly responsible for the policy under discussion. In the area of EU external migration policy, the smoothest decision-making process can be expected in Austria: the ministry of interior has overall responsibility for migration policy, and is therefore the sectoral ministry responsible for the Austrian position on EU migration policy. In France and the Netherlands, some tension could be expected between the ministry of foreign affairs (which have competence on EU policy) and the ministries involved in setting national migration policy (particularly ministries of interior). 


\subsection{The member state level: Mobility Partnerships matching with national identity?}

Chapter 2 outlined two possible explanations for member states' decisions to participate in EU external migration policy. The first was a constructivist explanation: member states will participate in EU external migration policy if this matches with a notion of 'national identity' and the conception of the role that the member state ought to play in the world. In other words, participation is considered 'appropriate', but is not related to a rational calculation of means and ends. This section argues that such a national identity explanation best accounts for the decision by the French government to participate in all Mobility Partnerships. The Austrian and Dutch governments share similar beliefs about an appropriate division of competences between the EU and its member states on migration, and yet reached different decisions on the Mobility Partnerships. The rationalist cost-benefit explanation is therefore better able to account for the domestic preferences in these two cases.

Historically, France has had a national role conception of itself as a 'leader' in the EU (van Keulen, 2006). Along with the Commission (as the institution initiating EU policies), the 'Franco-German tandem' has often been ascribed a pivotal role in EU policymaking (e.g. Metcalfe, 1998, p.414; Ambler and Reichert, 2001, p.54). During the 1990 s, defending this status as a significant player in the EU was one of the central preferences of the French government (Szukala, 2003). Suzkala argues that there is a European rhetoric being espoused by the French political elite that "emphasises the growing importance of a genuine French contribution to the European project" (p.220). The issue of the EU is a "major part of the national political game" (p.221) and there is agreement amongst the political elite that France should aim to preserve its "rank and influence among its European partners" (ibid.).

In the area of external migration policy, the French government sees a role for France as a pioneer in new policy solutions (Interview 16). The government states that "France has without a doubt been one of the host countries that has most 'systematised' the concrete application of the global approach [to migration] within the framework of bilateral agreements concluded with countries of origin" (European Migration Network, 2010f, p.48). The French National Contact Point for the European Migration Network describes the French bilateral agreements on the concerted management of migratory flows as not only an instrument of French migration policy, but "an international benchmark" (European Migration Network, 2009d, p.8). The French Parliament has in the past pointed out that France has pioneered certain policy tools for migrants' remittances, at a time when countries such as Germany, the UK and Spain were still only exploring how to reduce the cost of sending remittances (Assemblée Nationale, 2009, p.20). French bilateral migration agreements can be seen as paving the way for the EU Mobility Partnerships (Interview 34; see also section 5.5).

In the context of the Mobility Partnerships, the fact that France was to hold the rotating presidency of the Council in the second half of 2008 was significant. The rotat- 
ing Council presidency is "without doubt an important arrangement in the governance of the European Union ... [The presidency] performs several noteworthy functions" such as administrative tasks in preparation for Council meetings, setting political priorities, mediating between other member states, and representing the Council externally (Thomson, 2008, pp.593-594). Despite the fact that academic contributions have been generally pessimistic about the influence wielded by the president of the Council, Tallberg finds that the role "provides each occupant with certain agenda-setting instruments, beyond what is available to 'normal' member states" (2003, p.6). Metcalfe (1998, p.414) concurs: "on a day-to-day basis, [the presidency] plays a major leadership role in EU policy making and holds a position of special prominence in the context of Council negotiations". The presidency has important political responsibility for the smooth running of the policy-making process in the Council (p.416). Member states clearly perceive the role of the president as being important, as evidenced by the debate surrounding the reform of this institutional arrangement during the constitutional convention (Thomson, 2008, p.595). It is also considered important that a member state has "something to show" for their time holding the presidency (Interview 22), for instance Council conclusions on a favoured national initiative or policy area.

Migration was certainly a focal point of the French presidency in 2008. In particular, the European Pact on Immigration and Asylum was concluded during this period and the JAIEX Council working group was created. The European Pact on Immigration and Asylum builds on the GAM and aims to "give a new impetus to the definition of a common immigration and asylum policy that will take account of both the collective interest of the European Union and the specific needs of each Member State" (Council, 20081, p.4). The pact is based on five main commitments: to organise legal immigration according to the priorities and needs of the member states and encourage integration; to control illegal immigration through return measures; to improve the effectiveness of border controls; to construct a Europe of asylum; and to encourage the synergy between migration policy and development policy through a partnership with countries of origin and transit (ibid.). The French Ministry of Interior makes clear that the pact was a French initiative (French Ministry of Interior, n.d.) and the French government sees the conclusion of the Pact as an "undeniable success" of the French presidency of the EU (European Migration Network, 2009h, p.40). The French presidency also presided over the creation of the JAIEX Council working group. In September 2008, the French government proposed the creation of a 'Friends of the Presidency Group' to discuss the linkages between external relations and JHA issues (Council, 2008i). Three meetings were held during the time of the French Presidency, which were attended by all member states, as well as the Commission, Frontex, Eurojust and Europol (Council, 2008j). One of the results of the group's deliberations was the proposal to create an Ad Hoc Support Group concerning the external dimension of JHA questions, which would "facilitate the exchange of information and contribute towards more strategic and horizontal reflections in that area" (Council, 2008k, p.2). Although the term of office of JAIEX (as the ad hoc group came to be known) was originally intended to end in 2009 , this working party was made permanent by a decision of Coreper (Council, 2009c). 
At the time that the decision was to be made on the Mobility Partnerships, therefore, three notions of French leadership came together: the general idea that it is appropriate for France to play an important role within the EU, a role conception for France as a pioneer in the area of external migration policy, and the specific instance of the upcoming French leadership through holding the presidency of the Council. As one interviewee put it, in the case of the Mobility Partnerships there was simply "no question of participating or not" (Interview 32). Supporting this new policy instrument was an automatic decision because of the upcoming presidency (Interview 16;32;33), not a result of a decision about the means required to reach pre-defined ends.

Participation in the Mobility Partnerships with Moldova and Cape Verde, which were being negotiated during the run-up to the presidency, was therefore unrelated to achieving certain objectives, and simply an appropriate action for the French government. The choice of whether or not to participate was so constrained by ideas about the French role in the EU and in external migration policy that is was scarcely a choice at all (cf. Fearon and Wendt, 2002, p.60). Indeed, Moldova and Cape Verde are not priority countries for French foreign or migration policy. In terms of migration cooperation, the French government aims to establish migration agreements with countries in Africa, the Caribbean, South America and Asia (République Française, 2007); in other words, Eastern and South-Eastern Europe are not priority regions. There was no strategic interest in participating in the Mobility Partnership with Moldova (Interview 35); the French government, at a loss of projects to propose for the text of the agreement, decided at the last minute to simply support the work of a French NGO which assists victims of trafficking with reintegration in their country of origin (Interview 32). In terms of foreign policy more generally, Cape Verde is not the focal point for France in West Africa: Senegal and Mali are more important partners. Whereas Senegal receives around $€ 100$ million in French development aid each year, Cape Verde receives only $€ 8$ million (Interview 31). Table 5.1 shows the number of migrants present in France in 2005 from the top 5 countries of origin and, for comparison, the numbers of Moldovan, Cape Verdean and Georgian migrants present in the same year. These first three Mobility Partnership countries are clearly not major sources of immigration in France. 
Table 5.1: Number of migrants present in France in 2005 (source: Eurostat) ${ }^{64}$

\begin{tabular}{ll}
\hline Country of origin & Number of migrants \\
\hline Algeria & 477,495 \\
Morocco & 461,465 \\
Turkey & 220,750 \\
Tunisia & 146,514 \\
China & 64,211 \\
Cape Verde & 13,246 \\
Georgia & 4,607 \\
Moldova & 3,139 \\
\hline
\end{tabular}

In contrast to the case of France, the 'appropriateness' or 'inappropriateness' of the Mobility Partnership instrument is not the most suitable explanation of the Austrian or Dutch governments' decisions on participation. Certainly both governments see it as inappropriate for the EU to control the admission of migrants to their territories. Both were satisfied that the Mobility Partnerships would not overstep the bounds of an appropriate division of competences between the EU and its member states: the Austrian government allowed the Mobility Partnership instrument to be established and used because participation by member states would be voluntary. The Dutch government judged that the Mobility Partnerships would not adversely affect the ability of member states to determine their labour market policy. These two governments therefore shared some perceptions about the appropriateness of the Mobility Partnerships, but nevertheless made different decisions on participation. These different decisions are better explained by a cost-benefit analysis. The Austrian government believes that it is generally inappropriate for the EU to act on immigration and labour market policy, and saw specific costs associated with the Mobility Partnership instrument. The Dutch government eventually decided that the benefits of joining the Mobility Partnerships outweighed the costs. The remainder of this section outlines briefly the hesitations of these two countries concerning the issue of EU competence; section 5.5 then explores the cost-benefit analysis made by the two governments.

The Austrian government has frequently emphasised that immigration should remain a matter of national competence - it is not seen as appropriate for the EU to act in this policy area. The Austrian public is less supportive than the EU-27 average of a common EU immigration policy: only $68 \%$ of Austrian respondents favour a common policy, compared with an EU-27 average of 74\% (Eurobarometer, 2008b, p.132). ${ }^{65}$ In 2000, the Chancellor Wolfgang Schüssel voiced his opposition to the use of qualified majority voting at the EU level for matters of migration and asylum, stating that these were is-

\footnotetext{
${ }^{64}$ Eurostat data for 2005 (http://epp.eurostat.ec.europa.eu/portal/page/portal/population/data/database, retrieved 2 May 2012). Data for 2005 is the most recent available.

${ }^{65}$ The same Eurobaromter poll shows that $74 \%$ of French respondents and $83 \%$ of Dutch respondents favour a common EU immigration policy.
} 
sues to be determined by member states (Pollak and Puntscher-Riekmann, 2002, p.77). In the negotiations on EU directives on intra-corporate transferees and seasonal workers, for instance, the Austrian government has voiced general reservations related to the principle of subsidiarity (Council, 2011d; 2011e). There is a suspicion amongst some Austrian government officials that the European Commission is continuously attempting to expand its powers in the area of migration at the expense of member states' competences (Interview 26). Indeed, the Austrian government sent a letter to DG JLS accusing the Commission of wanting to use the Mobility Partnerships to undermine member state competence over labour migration policy (Interview 21). This position has also been expressed by the standing subcommittee of the Austrian Parliament on EU matters, for instance in terms of the Commission's proposals to approximate rights of third country nationals in the EU to those of EU citizens: "Einen Eingriff in national Kompetenzen sehen die Abgeordneten auch in den Überlegungen der Kommission, einen einheitlichen Rechtsstatus für illegale Einwanderer zu schaffen, der vergleichbar mit jenem der EUBürgerInnen ist" (Austrian Parliament, 2009, p.3). The Austrian strategy paper on EU migration policy drafted in 1998 therefore emphasised that participation in EU measures on migration should remain voluntary for member states (Council, 1998a). In the internal EU discussions on the concept of Mobility Partnerships, Austria emphasised that participation by member states in these partnerships should be on a voluntary basis (Interview 25). In its 2007 report on security, the Austrian Ministry of Interior expressed satisfaction with the internal EU negotiations on Mobility Partnerships because the voluntary basis had been guaranteed: "Im Laufe der Verhandlungen konnte Österreich seine Vorstellungen erfolgreich einbringen, dass eine Teilnahme an Mobilitätspartnerschaften auf freiwilliger Teilnahme beruht, nationale Kompetenzen und die Beachtung der Gemeinschaftspräferenz gewährt bleiben sowie die Bekämpfung illegaler Migration als Verpflichtung der Partnerländer festgeschrieben wird" (Austrian Ministry of Interior, 2007, p.395). This voluntary basis explains the acceptance by the Austrian government to allow the Mobility Partnership instrument to be established and used. However, Austrian officials have since complained about the proposal of visa facilitation and readmission agreements within the framework of Mobility Partnerships, because these EU-wide agreements are binding also on Austria despite its nonparticipation in the partnerships (Interview 22; 25; Dutch Ministry of Foreign Affairs, 2008e).

The Dutch government also argues that member states should remain responsible for deciding which migrants are admitted to their territory (Interview 3), but is more nuanced in its view than the Austrian government: the fiche prepared by the BNC working group on the Mobility Partnerships acknowledges that the EU has competences in immigration policy, but emphasises that labour market policy, and thus labour migration, is a member state competence (BNC, 2007). Officials in the Ministry of Foreign Affairs determined that the name 'Mobility Partnerships' is actually misleading because member states are free to decide whether or not to offer legal migration opportunities to partnership countries (Dutch Ministry of Foreign Affairs, 2008d). Indeed, the Commis- 
sion communication on Mobility Partnerships clearly states that "mechanisms to facilitate economic migration should be based on the labour needs of interested Member States, as assessed by them" (Commission, 2007a, p.5). In December 2007, the secretary of state for justice defended to the parliamentary committees for justice and interior the view of the government that Mobility Partnerships will not affect member states' ability to determine their labour market policy (Tweede Kamer, 2008a, p.7).

Table 5.2 summarises this section and shows which elements of the Mobility Partnerships were considered appropriate or inappropriate by each of the member states. This does not, however, tell the whole story of domestic preference formation on the partnerships, particularly for the Austrian and Dutch preferences: both had concerns about EU competence, and both ultimately judged that the Mobility Partnerships did not overstep the boundaries of an appropriate division of competences between the EU and its member states. Nevertheless, they reached different domestic preferences. The following section explains these different preferences in terms of a cost-benefit analysis.

Table 5.2: Application of the national identity explanation to the case studies.

\begin{tabular}{|c|c|c|}
\hline Member state & Appropriate & Inappropriate \\
\hline France & $\begin{array}{l}\text { Opportunity for France to play leadership } \\
\text { role (holding Presidency) } \\
\text { Mobility Partnerships modelled on French } \\
\text { bilateral migration agreements }\end{array}$ & \\
\hline Austria & Voluntary basis & EU competence on immigration \\
\hline The Netherlands & $\begin{array}{l}\text { Member states maintain competence on } \\
\text { labour market }\end{array}$ & EU competence on labour migration \\
\hline
\end{tabular}

\subsection{The member state level: costs and benefits of participation in the Mobility Partnerships}

The second explanation for member states' decisions to participate in EU external migration policy is a rationalist one: member states assess participation in terms of the expected costs and benefits. If the benefits outweigh the costs, the member state will choose participation. This explanation is therefore very much of a 'means-end' type. Whilst such an explanation could plausibly account for the French decision-making on the Mobility Partnerships, this section argues that the national identity explanation is the 'prior' one for the French case. However, the cost-benefit explanation can better account for the preferences of the Austrian and Dutch governments than the national identity explanation.

The French decision to participate in the Mobility Partnerships could be accounted for by a desire to reproduce at the EU level policy solutions that the government implements at the national level, and therefore achieve a 'politics of scale' in terms of na- 
tional migration policy objectives. French policy emphasises the importance of cooperation with third countries on migration issues (Interview 32; 35). The French bilateral migration agreements "aspire to compatibility with EU migration policy" (Panizzon, 2012, p.107). The Mobility Partnerships are similar to these bilateral agreements (Interview 35). The French government "would like to share this vision with other countries and organisations active in the 'development and migration' field" (European Migration Network, 2010f, p.48). Indeed, in 2007 the government stated the aim of generalising these types of agreements (République Française, 2007). Participation in EU Mobility Partnerships contributed to this aim, by providing "on a platter" new bilateral migration agreements (Interview 32). The partnerships offer the opportunity for France to strengthen existing cooperation with traditional partner countries or establish new cooperation with countries that are not traditional partners for France. ${ }^{66}$ In the case of Georgia, the French President Nicolas Sarkozy was playing an important role during the 2008 conflict between Georgia and Russia, which occurred during the French presidency. It could therefore be beneficial for France to show political support for the Georgian government in any way possible, including by participating in a Mobility Partnership. There is an important Armenian diaspora in France, and a desire to involve this group in development efforts in their country of origin could explain French participation in that Mobility Partnership. Ambler and Reichert (2001) argue that French governments have consistently proven themselves willing to "use the European project to achieve goals in the domestic arena" (p.54). In the area of foreign policy, for example, the French government has viewed EU action as "a necessary extension of French policy, not a constraint upon its sovereign decisions" (Balme and Woll, 2005, p.105).

The French government sees the Mobility Partnerships as being inspired by French bilateral migration agreements (Interview 16;35). ${ }^{67}$ Indeed, the French agreements cover the same elements - legal migration, illegal migration, and development - as the EU's GAM. The first of these agreements was signed with Senegal in 2006 (European Migration Network, 2009d, p.8) - in other words, during the same time that the Commission was formulating its proposal for EU Mobility Partnerships (Interview 35). Chapter 4 also outlined the significance of the Franco-German proposal for a 'new European migration policy' as a source of inspiration for the concept of Mobility Partnerships (Angenendt, 2007; Carrera and Hernández i Sagrera, 2009). This proposal set out the idea of using circular migration schemes to reduce illegal immigration to the EU and the importance of signing cooperation agreements with third countries on migration issues (Schäuble and Sarkozy, 2006). In advance of the French presidency of the EU in 2008, the government announced its intention to consult with the Commission and other member states on migration and development issues, so that the French approach would not 'remain isolated in Europe' (République Française, 2007). Participating in EU Mobility Partnerships would therefore allow the French government to achieve a 'politics

\footnotetext{
${ }^{66}$ Personal communication, official of Ministry of Foreign Affairs of France, 15 February 2011

${ }^{67}$ There is, however, an important difference between Mobility Partnerships and the French bilateral migration agreements, namely that the French agreements are legal agreements, whereas the Mobility Partnerships are political declarations (Interview 35).
} 
of scale' in terms of its own migration policy objectives because it could take part in agreements at the EU level that mirrored its own bilateral migration agreements.

In reality, however, a political decision was made early in the discussions on Mobility Partnerships that France would participate in every partnership in the future, regardless of the partner country (Interview 32). Participation in a Mobility Partnership is therefore not considered by the French government in terms of the costs or benefits involved in the specific case; rather, participation is a foregone conclusion, based on a decision made in the context of the French Council presidency in 2008. Indeed, the French government was not convinced that a Mobility Partnership should be offered to Senegal, knowing that negotiations would likely be difficult. Nevertheless, had the partnership been successfully concluded, France would have taken part (Interview 32; 33).

In contrast to the French government, the Austrian and Dutch governments based their decisions on the Mobility Partnerships on an assessment of the consequences of participation - in other words, on means-end logic. The Austrian decision not to participate in the Mobility Partnerships is in several respects quite surprising. On the surface, it does not appear that there would be significant costs to the Austrian government of participation. The Mobility Partnerships are quite compatible with national migration policy objectives and practice. Section 5.2 outlined the Austrian external migration policy, which includes projects that could very well be integrated into a Mobility Partnership. The Austrian government has, for instance, implemented assisted voluntary return programmes in Moldova. Such voluntary return and reintegration schemes have also been included in the Mobility Partnership with Moldova (Council, 2008b, p.12). The information campaigns on the dangers of illegal migration to Austria operated by the Ministry of Interior could easily be included in a Mobility Partnership (Commission, 2007a, p.4). The strategy paper drawn up by the Austrian government in 1998 on EU migration policy links facilitated border crossings with guarantees by third countries on readmission, in much the same way as the Mobility Partnerships link legal migration opportunities to cooperation by third countries on illegal migration.

Despite its conviction that migration policy is a member state competence, conducting some aspects of migration policy at the EU level has been emphasised by the Austrian government as a key national objective. The 2008 report on internal security by the Ministry of Interior points out that Austria is one of the most engaged member states in operational cooperation within the framework of Frontex (Austrian Ministry of Interior, 2008, p.230). The 2008-2013 coalition agreement expresses support for the negotiation of further EU readmission agreements (Republik Österreich, 2008, p.111; European Migration Network, 2009f, p.13). In some cases, the Austrian government believes that an EU-wide readmission agreement can "exercise pressure more efficiently than bilateral agreements" (Council, 1999b, p.5). The 1998 strategy paper by the Austrian presidency emphasised the importance of developing a common EU migration policy (Council, 1998a). 
Finally, potential partner countries for Mobility Partnerships would come from regions that are also important to Austria in terms of migration. In 2007, the Austrian Ministry of Interior expressed satisfaction that the EU's GAM had been extended to incorporate regions to the east and south-east of the EU: "Damit wurde dem Umstand Rechnung getragen, dass illegale Migration nach Europa in erheblichem Maß über östliche und südöstliche Schleusungsrouten stattfindet” (Austrian Ministry of Interior, 2007, p.395). The Austrian Ministry of Interior emphasises the value for Austrian internal security of cooperation at the EU level on JHA when this cooperation is aimed at third countries that are also important for Austria (Austrian Ministry of Interior, n.d.). In 2007, Moldovan citizens were one of the main groups of migrants apprehended for being illegally present in Austria (European Migration Network, 2009g, p.20). Given that cooperation on illegal migration is a central component of a Mobility Partnership (Commission, 2007a), Austria would seem to have an interest in participating in a Mobility Partnership with Moldova.

Despite the Mobility Partnerships seemingly being an opportunity for Austria to pursue and strengthen its national policy solutions at the EU level, the Austrian government decided not to participate in the partnerships, regardless of the partner country concerned. The central reason for this decision was a contradiction between the Mobility Partnerships and national policy. In particular, the Mobility Partnerships were seen as a repeat of the Austrian experience with Gastarbeiter programmes, which led to significant and permanent immigration to Austria. The potential costs, in terms of increased immigration to Austria, associated with participation in the Mobility Partnerships were therefore considered too high by the government.

Austria has a long history of immigration: already in 1934, as a result of migration from east to west that had taken place within the Habsburg Empire, 12\% of the population of Austria was born in another country (Gächter, 2008, p.1). However, it is particularly the experience with the Gastarbeiter programmes that are fresh in the minds of Austrian policy-makers. The migration which was supposed, in the 1960 s, to be temporary, turned out to be very much of a permanent nature due to continued family reunification.

In the Mobility Partnerships, the Austrian government saw a potential repeat of the Gastarbeiter programmes: increased mobility, intended to be circular, would lead to permanent immigration (Interview 22; 25; 26). The Commission communication on Mobility Partnerships clearly states as an objective that "Mobility partnerships will facilitate the migration of nationals of the third country to interested EU Member States" (Commission, 2007a, p.5). Schemes for circular migration could be included in a Mobility Partnership in order to "help mitigate brain drain" (p.7). It was particularly the connection to circular migration which was problematic (Interview 22; 25) because this is in direct opposition to the stated migration policy of the Austrian government, namely that it does not operate programmes for circular migration (European Migration Network, 2010d, p.23). ${ }^{68}$ The government feared that permanent immigration would

\footnotetext{
${ }^{68}$ Jandl and Kraler (2003) argue that the refusal of Austrian policy-makers to acknowledge that Austria is a country of immigration has led to conflicting policies on migration: labour migration and family reunification
} 
result from such circular migration schemes: in 2009, the interior minister Maria Fekter likened the Mobility Partnerships to an "Einbahnstraße für die Zuwanderung nach Europa" (Austrian Parliament, 2009, p.3). There is a direct contradiction between this view of the Mobility Partnerships and Austrian migration policy which essentially aims to limit the numbers of migrants moving permanently to Austria. The Austrian priorities on EU migration policy are preventing illegal migration, promoting integration of existing immigrants rather than encouraging new immigration, and allowing legal migration only in so far as it is necessary and acceptable from a labour market and internal security perspective (Austrian Ministry of Interior, 2007, p.396). Officials felt that there was not enough emphasis in the concept of Mobility Partnerships on preventing illegal migration (Interview 25).

In 1991, Austria became the first European country to base its immigration policy on a quota system, according to which foreign workers could constitute a maximum of $8 \%$ of the workforce. This quota for work permits is still in place. In addition, work permits for migrants are subject to a labour market test: a work permit will only be issued if there is no suitable unemployed Austrian citizen to fill the vacancy (European Migration Network, 2010c, p.63). The 1993 Residence Act also established a cap on the number of residence permits which could be issued in any one year (p.31; Currle et al., 2004, p.239). By 2007, the quota for first residence permits was set by the Ministry of Interior at 6,500 persons (European Migration Network, 2010c, p.50). Instead of encouraging new immigration, the Austrian priority has, since the passing of the Aliens Act in 1997, been the integration of those migrants already present in Austria; in other words, 'integration before immigration' (Jandl and Kraler, 2003; European Migration Network, 2007). The 2007-2010 coalition programme stated this objective clearly: "Primär gilt Integration der in Österreich lebenden Fremden; ungeregelte Zuwanderung ist zu stoppen . . . Integration steht ganz klar vor Neuzuzug" (Bundeskanzleramt, 2007, pp.138-139). Interior minister Maria Fekter reiterated this policy again to the Austrian Parliament in 2009: "Integration hat Vorrang vor Neuzuzug" (Austrian Parliament, 2009, p.3). The aim of Mobility Partnerships to increase mobility of third country nationals to participating EU member states did not fit with these national policy objectives. The Ministry of Labour, Social Affairs and Consumer Protection, for instance, was concerned that a Mobility Partnership would force Austria to abandon its system of labour market testing for work permits (Interview 26).

Immigration has also become a highly politicised issue in Austria and is one of the most debated topics in Austrian media (European Migration Network, 2010d, p.8; Interview 24; 26). This is exemplified by the electoral success of the far-right Freedom Party (FPÖ), which, at the height of its success, became the second biggest political

programmes have been limited, whilst at the same large numbers of temporary seasonal workers have been admitted. Indeed, in 1993 a new programme similar to the Gastarbeiter programmes of the 1960s was introduced. It set a quota for the number of seasonal workers permitted entry to Austria during the summer and winter seasons, which, since 2003, has resulted in approximately 8,000 seasonal permits being issued each year (Gächter, 2008, p.12). In 2002 amendments were made to this law which further facilitated temporary migration by allowing allowed seasonal employment in sectors other than agriculture and tourism (European Migration Network, 2010c, p.33; Currle et al., 2004, p.269). 
party in the 1999 elections. This electoral success has resulted in more restrictive immigration policies being adopted in Austria (Zaslove, 2004). Immigration is one of the three issues that concerns Austrians the most, with $26 \%$ citing it as the most important issue facing Austria (Eurobarometer, 2008b, p.25) ${ }^{69}$ This is much higher than the average for respondents across the EU27, which was $15 \%$. Only $14 \%$ of French respondents and $15 \%$ of Dutch respondents rated immigration as one of the most important issues facing their country in 2007. In the 2008 parliamentary elections, both the SPÖ and the ÖVP lost vote share to the right-wing parties, the FPÖ and the BZÖ (European Migration Network, 2009f, p.10). The public discourse surrounding migration is primarily concerned with illegal immigration to Austria and unjustified asylum claims being submitted (European Migration Network, 2005b, p.49). Increased immigration resulting from a Mobility Partnership would therefore be 'difficult to sell' to the public, particularly given the increased immigration likely to result from opening the borders to the new EU member states (Interview 27). Indeed, even before the end of the transition periods for free movement for nationals from the new member states, the number of migrants from these countries present in Austria has increased significantly (see figure 5.7).

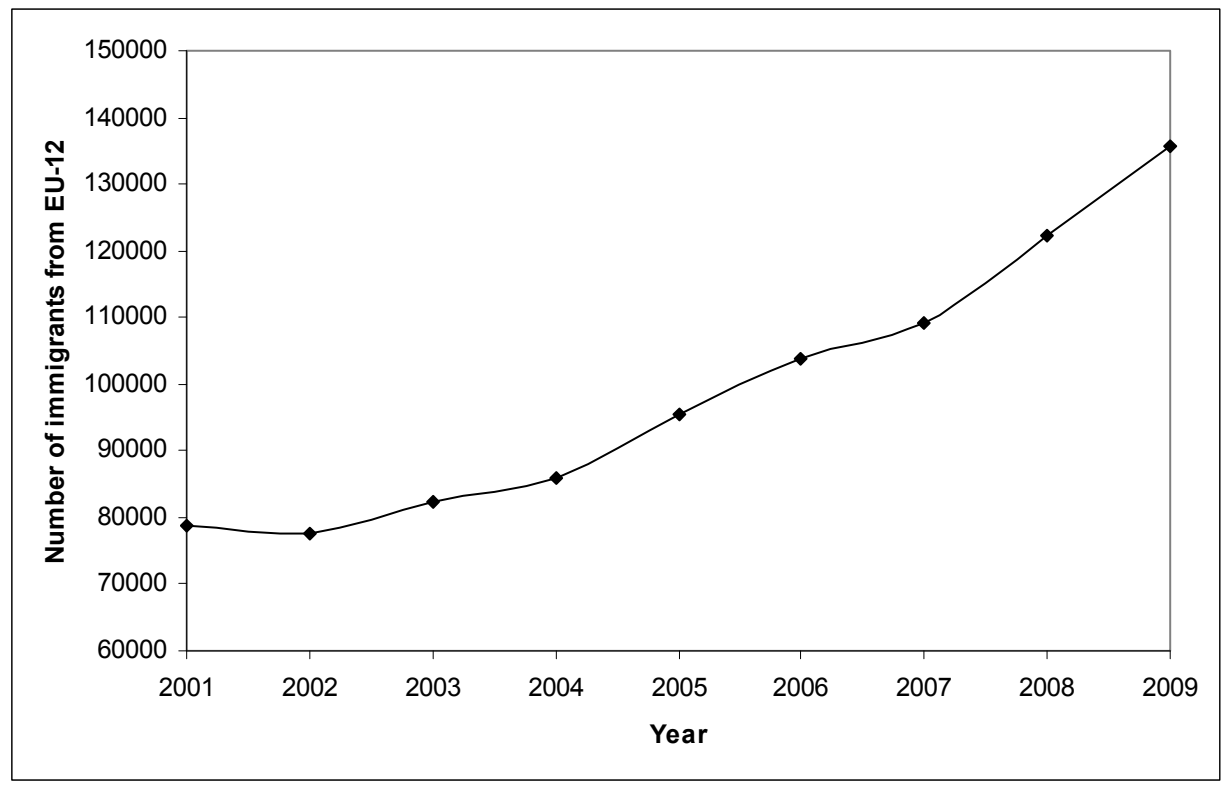

Figure 5.7: Immigrants from the new member states in Austria (source: Eurostat). ${ }^{70}$

\footnotetext{
${ }^{69}$ Data is from autumn 2007. This Eurobarometer report has been selected because member states were making their decisions on whether or not to participate in Mobility Partnerships at this time.

70 Eurostat data (http://epp.eurostat.ec.europa.eu/portal/page/portal/population/data/database, retrieved 27 April 2012) for immigrants from Bulgaria, Cyprus, Czech Republic, Estonia, Hungary, Latvia, Lithuania, Malta, Poland, Romania, Slovakia and Slovenia
} 
The case of the Netherlands is an interesting one, entailing as it does a specific change in preferences. The Dutch government was rather ambivalent about the Mobility Partnerships at the outset because it was not certain about the costs or benefits that could be expected from this instrument. The fiche on the Mobility Partnerships prepared by the BNC working group in September 2007 emphasised that the form and content of these partnerships is not yet clear. These issues must first be defined before it would be possible to determine if the partnerships will bring any added value (BNC, 2007, p.3) - in other words, before the potential benefits of participation could be determined. Significantly, despite this ambivalence, the fiche does not propose any opposition to the Mobility Partnership instrument. The government later decided that the benefits of participation did indeed outweigh the costs, and joined the Mobility Partnerships with Cape Verde and Georgia.

At the time that Mobility Partnerships were being discussed at the EU level, a discussion on linking migration policy and development policy was still ongoing at the Dutch national level. The Dutch government did not want to commit to participating in the Mobility Partnership instrument before the national policy on migration and development had been clarified (Interview 3). Only once the national policy had been clarified would it be clear what the costs and benefits of participating in the Mobility Partnership instrument would be. However, despite the fact that the national policy on migration and development was still being developed, the Dutch government (like the Austrian) was implementing measures which would be perfectly compatible with the EU-level approach of cooperating with third countries on migration issues. These measures include capacity-building projects to train third countries' border guards, and temporary return programmes (see section 5.2.3).

Despite the uncertainty over the national migration and development policy, the Dutch government already saw potential costs associated with the Mobility Partnership instrument. In particular, the government was concerned about the emphasis on legal migration in the Mobility Partnerships. Dutch government policy aims at preventing large-scale immigration of low-skilled migrants (European Migration Network, 2010i, p.6). In general, foreign nationals are only granted a work permit in the Netherlands "if there is insufficient supply from workers from the Netherlands and the EEA countries" (p.29). Since the publication of a policy memorandum in 2006 entitled 'Towards a Modern Migration Policy', the focus of Dutch labour migration policy has been to ensure that migrants that are needed in the Netherlands are admitted quickly (Dutch Ministry of Justice, 2006). In particular, this implies an emphasis on attracting highlyskilled migrants to the Netherlands. The new government, elected during 2007, undertook measures in support of this aim, such as increasing the length of time that foreign students may remain in the Netherlands after finishing their studies to look for work (European Migration Network, 2009i, p.32). In 2008, the government established a new scheme for highly-educated migrants, which would allow for 500 permits a year to be issued to give these migrants the opportunity to find highly-qualified employment or start a business in the Netherlands (European Migration Network, 2009j, p.32). 
Nevertheless, migration remains an 'explosive' political subject (Interview 19). Since the 1990s, immigration, asylum and integration have been highly politicised issues in the public and media discourses in the Netherlands (Wal, 2007). In 2007 (the time that the initial decision on participation in the Mobility Partnerships was made), there was particular media attention for the views of the right-wing populist party, the Partij voor de Vrijheid (Freedom Party; PVV). The PVV seeks to limit immigration to the Netherlands of non-Western foreigners, and emphasises cultural assimilation of those foreigners already present in the Netherlands (European Migration Network, 2009i, p.21). Due to this political climate, the government needs to 'show results' in the area of migration control (Interview 5). Dutch immigration policy therefore remains rather restrictive. Although the immigration of highly-skilled migrants should be facilitated, employers will still have to prove a labour shortage before recruiting middle- or low-skilled migrants from outside of the EU (Dutch Ministry of Justice, 2006, p.7). The government emphasises migration control (Interview 6;11), and "attaches great importance to maintaining a selective and restrictive admissions policy, based on an effective control and return policy" (Dutch Ministry of Foreign Affairs and Ministry of Justice, 2008, p.4). Indeed, only countries that cooperate on return issues should be considered for migration and development measures (p.44). An effective return policy was emphasised in the 2007 coalition agreement (Rijksoverheid, 2007). For these reasons, the government was very clear that legal migration opportunities could not be offered as part of the Mobility Partnerships. The fiche by the BNC emphasised that the Netherlands should continue to follow its policy on admitting qualified migrants, as laid down in the 2006 policy memorandum 'Towards a Modern Migration Policy' (BNC, 2007, p.3). The Mobility Partnerships clearly do not aim to facilitate the mobility only of highly-skilled migrants; rather, the focus is on matching job-seekers in the third countries concerned to vacancies in the EU, and preventing brain drain by excluding from the partnerships sectors of the labour market that are under pressure in the third country (Commission, 2007a). Given the focus of the Dutch government on highly-skilled immigration, there was a potential contradiction between national and EU policy objectives in this case.

However, in late 2008 there was a change of policy. The Dutch government issued a note verbale on 12 November, indicating its desire to join the Mobility Partnership with Cape Verde that had been agreed in May 2008 (Dutch Ministry of Foreign Affairs, 2008b). When the Mobility Partnership with Georgia was agreed in 2009, the Netherlands was one of the signatories. This change in policy preference can be explained by a shifting perception of the costs and benefits associated with the Mobility Partnership instrument. Due to the clarification of the national policy on migration and development, the establishment of a national circular migration pilot scheme, and a desire to play a role in defining this new EU policy instrument, the government decided that the benefits of participation outweighed the costs. There were specific benefits in terms of national migration and foreign policy objectives of joining the partnerships with Cape Verde and Georgia (see below), while the partnership with Moldova was not seen as being relevant to Dutch national policy objectives. 
The Dutch policy on migration and development was established in July 2008 when the policy memorandum entitled 'International Migration and Development' was presented to Parliament (European Migration Network, 2010h, p.45). The policy on migration and development is based on six pillars: attention for the linkages between migration policy and development policy; capacity-building of third countries in the area of migration management; encouraging circular migration and brain gain; increased involvement of migrant organisations; strengthening the developmental effect of remittances; and support for sustainable return and reintegration (Dutch Ministry of Foreign Affairs and Ministry of Justice, 2008). A budget of $€ 5$ million per year would be made available from the development cooperation budget of the Ministry of Foreign Affairs for the newly defined migration and development priorities (p.12). Cooperation with third countries is seen as being crucial for a policy on migration and development (p.14) and the policy will focus on the 40 priority countries for Dutch development cooperation, ${ }^{71}$ plus three countries selected specifically due to their migration situation. ${ }^{72}$ The three latter countries were added at the request of the Ministry of Justice (Interview 9). This list of 43 countries contains all the countries that had, by the end of 2009, signed Mobility Partnerships (Moldova, Cape Verde and Georgia), as well as the countries that signed Mobility Partnerships in 2011 and 2013 (Armenia and Morocco). Dutch government officials recognise that the national policy on migration and development is, to a large extent, complementary to the EU's GAM (Interview 5).

One aspect of the new policy on migration and development was the introduction of a circular migration pilot scheme, in order to promote brain gain (Dutch Ministry of Foreign Affairs and Ministry of Justice, 2008). Just as Austria, the Netherlands has a history of immigration of guest workers which was intended to be temporary in nature but turned out to be permanent (European Migration Network, 2010i, p.6; Interview 3). However, whereas a fear of renewed permanent immigration has led the Austrian government to reject circular migration schemes, the Dutch government decided to introduce a pilot project on circular migration in order to test the ability of the concept to contribute to brain gain in practice. Under the scheme, 80 migrants per year could come from Indonesia and South Africa to work and learn in the Netherlands for a maximum period of two years. In this way these migrants would develop new competences, and in the long term the circular migration scheme would therefore contribute to building capacity of third countries and preventing brain drain (European Migration Network, 2010h, p.46). Indonesia and South Africa were selected as the pilot countries because of the possibility to contribute to development goals, the good labour supply of these countries, the English language skills of their populations, and their good records on return and reintegration initiatives. Historical reasons naturally also played a role: Indonesia

\footnotetext{
${ }^{71}$ Afghanistan, Albania, Armenia, Bangladesh, Benin, Bolivia, Bosnia and Herzegovina, Burkina Faso, Burundi, Cape Verde, Colombia, Democratic Republic of Congo, Egypt, Eritrea, Ethiopia, Macedonia, Ghana, Georgia, Guatemala, Indonesia, Kenya, Kosovo, Mali, Moldova, Mongolia, Mozambique, Nicaragua, Pakistan, Palestinian Territories, Rwanda, Senegal, South Africa, Sri Lanka, Sudan, Suriname, Tanzania, Uganda, Vietnam, Yemen, Zambia.

${ }^{72}$ Angola, Morocco, Sierra Leone.
} 
and South Africa were selected also because Dutch enterprises are active in these countries and the Dutch NGO carrying out the project had networks and experience in these countries (Siegel and van der Vorst, 2012, p.30). The government saw a possibility for the pilot circular migration scheme to be incorporated into a Mobility Partnership (Interview 3).

Another benefit from participating would be the ability to influence the development of the Mobility Partnership instrument (Interview 6; 7). The decision to participate in the Mobility Partnerships was made in the Ministry of Foreign Affairs, where the head of the migration unit in particular did not want to be confronted at a later point with a well-developed EU policy instrument that could no longer be changed (Interview 7). The Netherlands has often been a central actor in EU migration initiatives (Geddes, 2003, p.123). Indeed, the creation of the HLWG followed a Dutch proposal for a 'crosspillar' approach to migration (van Selm, 2002). The Dutch government in 1998 proposed that the EU should create a 'Task Force' on asylum and migration. The task force should be responsible for preparing a country-specific approach to the main countries of origin of migrants arriving in the EU. Such a country-specific approach should contribute to the overall aim of curbing the inflow to the EU of "persons abusing asylum procedures and of illegal migrants" (Council, 1998b, p.5). This task force later became established as the HLWG.

The Netherlands is the only of the three cases studied in this thesis which has not made a blanket decision to participate/not to participate in the Mobility Partnership instrument as a whole; rather, the Dutch government evaluates participation in each specific Mobility Partnership based on the expected costs and benefits in terms of Dutch national policy objectives. Moldova, for instance, was not considered relevant for Dutch policy preferences, and there were therefore no benefits expected from participation in this Mobility Partnership (Interview 11; Dutch Ministry of Foreign Affairs, 2008d). There were no perceived benefits from participating in the Mobility Partnership with Cape Verde in terms of migration policy objectives (Interview $5 ; 14):^{73}$ the Cape Verdean diaspora in the Netherlands, although sizeable from a Cape Verdean point of view, does not belong to one of the largest immigrant groups in the Netherlands (see chapter 3). There is also no significant immigration from Cape Verde to the Netherlands: in 2007, only 110 Cape Verdeans immigrated to the Netherlands. ${ }^{74}$ However, there were foreign policy reasons to favour participation in a Mobility Partnership with Cape Verde: officials at the Ministry of Foreign Affairs saw the partnership as a way to reassure the Cape Verdean government that the Netherlands remains committed to the bilat-

\footnotetext{
${ }^{73}$ Despite there not being a substantial migration interest for the Dutch government in Cape Verde, the Netherlands participated in a project entitled 'DIAS de Cabo Verde', funded by the EU and implemented by IOM. The project began already in 2007, before the Dutch decision on participation in the Mobility Partnership. The project aimed at facilitating the engagement of the Cape Verdean diaspora in the development of their country of origin. Cape Verdeans living in Portugal, Italy or the Netherlands could carry out a temporary project in Cape Verde, such as a training programme for a Cape Verdean organisation (European Migration Network, 2010g, p.26; Interview 57).

${ }^{74}$ Eurostat data for 2007 (http://epp.eurostat.ec.europa.eu/portal/page/portal/population/data/database, retrieved 4 April 2012)
} 
eral relationship between the two countries (Interview 7). In 2007 the Dutch government decided to dismantle the development cooperation relationship with Cape Verde, based on the results achieved by the country (Dutch Ministry of Foreign Affairs, 2009a; 2007). ${ }^{75}$ There was therefore a need to find new topics of cooperation with Cape Verde in order to broaden the scope of the bilateral relationship (Interview 11). The Mobility Partnership could be used as a new framework for cooperation with Cape Verde. In the case of the Mobility Partnership with Georgia, the situation was reversed: there was no substantial interest by the Ministry of Foreign Affairs in participating, despite Georgia being on the list of development partner countries. However, the Ministry of Justice was interested in cooperating with Georgia on issues of return and reintegration (Interview 14). Although actual migration flows from Georgia to the Netherlands are limited, Georgia is a transit country for migrants heading to the EU, and the Ministry of Justice therefore saw benefits from participating in the Mobility Partnership (Interview 9).

Table 5.3 summarises the cost-benefit analyses for each of the three cases. This section has argued that the national identity explanation is the 'prior' one for the case of France: decision-making within the French government was not means-end in nature, but rather concerned the appropriateness of French leadership and the notion of France as a pioneer in external migration policy. The French government viewed particularly the choice of Senegal for a Mobility Partnership as wrong, knowing that the negotiations would be difficult, but would nevertheless have participated in such a partnership because of its a priori commitment to participate in all partnerships. The Austrian government implements an external migration policy in countries with which Mobility Partnerships could be foreseen, implying potential benefits to participation in such partnerships. However, the Austrian government did not perceive such benefits, and focused instead on the significant potential costs of participation in the Mobility Partnerships. These costs explain the decision not to participate. The Dutch government was ambivalent in the beginning, and concerned about the emphasis on legal migration in the Mobility Partnerships. However, once the national policy on migration and development had been determined, it was clear that this was compatible with participation in the partnerships. The choice of Cape Verde and Georgia as partner countries was relevant for national foreign policy and migration policy objectives.

\footnotetext{
${ }^{75}$ In order to ease the transition for the Cape Verdean government, Dutch development aid was phased out gradually during the period 2007-2011 (Dutch Ministry of Foreign Affairs, 2008c).
} 
Table 5.3: Application of the cost-benefit explanation to the case studies.

\begin{tabular}{lll}
\hline Member state & Costs & Benefits \\
\hline France & Choice of partner countries & Achieve 'politics' of scale \\
Austria & $\begin{array}{l}\text { Potential for permanent immigration } \\
\text { (repeat of Gastarbeiter experience) }\end{array}$ & \\
& $\begin{array}{l}\text { Difficult to 'sell' Mobility Partnerships } \\
\text { to the public }\end{array}$ & \\
The Netherlands & $\begin{array}{l}\text { Over-emphasis on legal migration in the } \\
\text { Mobility Partnerships }\end{array}$ & $\begin{array}{l}\text { Possibility to incorporate national circular } \\
\text { migration scheme into Mobility Partnership } \\
\end{array}$ \\
& & $\begin{array}{l}\text { Ability to influence development of Mobil- } \\
\text { ity Partnership instrument } \\
\text { Cape Verde: foreign policy objectives } \\
\end{array}$ \\
& & Georgia: return and reintegration \\
\hline
\end{tabular}

\subsection{EU-member state interaction: size of the win-sets}

Sections 5.4 and 5.5 accounted for the French, Austrian and Dutch preferences on the Mobility Partnership. This section explains the dynamics of the game between the Commission and the member states by examining the size of the win-set for each actor. It shows that the Commission had to be willing to compromise in order to secure agreement on the Mobility Partnership instrument as such. The cost of no agreement for all the member states was low, but was relatively lower for Austria which was opposed to the concept of the partnerships. The Commission was therefore in a weaker position in the decision-making process than the member states, because the member states would not have been negatively affected if no agreement had been reached. This weaker position is reflected in the flexible, 'soft' bargaining strategies adopted by Commission officials.

\subsubsection{Cost of no agreement for the EU}

Chapter 2 argued that the cost of no agreement for the EU is high, because if there is no agreement on EU external migration policy then there is by default no role for the EU. In this case, 'the EU' is the Commission because chapter 4 showed that other EU institutions were side-lined in the policy-making process on the Mobility Partnerships. For the Commission, it was more important to get some kind of policy in place than to ensure a specific format of the Mobility Partnerships. Without member state involvement, there would be no Mobility Partnerships. Commission officials therefore adopted a flexible negotiating strategy and yielded to member states on issues such as the legal nature of the partnerships, in order to secure agreement on the policy instrument as such. The lengths that Commission officials were willing to go to clearly demonstrate the high cost of no agreement in this case. Officials in DG JLS would, for instance, have preferred to have legally binding Mobility Partnership (Interview 1), but adopted a pragmatic approach when it became clear that member states were opposed to this suggestion (Interview 13). 
The Commission had a great deal invested in the Mobility Partnership instrument, which also makes the cost of no agreement high. These partnerships are seen by Commission officials as necessary because immigration to the EU will continue, and therefore needs to be managed (Interview 17). In addition, there are specific advantages to the partnerships, such as the chance to discuss sensitive issues, particularly labour migration, with the member states (Interview 21). The partnerships can also form an important source of 'leverage' in the Commission's often difficult negotiations on readmission with third countries (Interview 2; 13). Later Commission documents have continued to emphasise the importance of the Mobility Partnership instrument for the EU. The 2009 evaluation, for instance, describes the partnerships as

promising, innovative and comprehensive tools [that] may represent a valuable framework for increasing transparency, enhancing synergies, triggering cooperation and ensuring more cost-efficient operations between partners, between the Commission and Member States, and inside them, between various ministries and departments involved (Commission, 2009d, p.8).

The 2011 communication on the GAMM argues that Mobility Partnerships should be "the principal framework for cooperation in the area of migration and mobility between the EU and its partners" (Commission, 2011b, p.10).

\subsubsection{Cost of no agreement for the member states}

Despite their different preferences on participation in the Mobility Partnerships, the cost of no agreement for all the member states studied can be considered low. However, the cost of no agreement is lower for Austria than for France and the Netherlands. The Austrian government, whilst willing to allow the Mobility Partnerships to go ahead on a strictly voluntary basis, was very opposed to the instrument and would have been pleased if the whole idea had been shelved. The French and Dutch governments do participate in the Mobility Partnerships but would not have been really disadvantaged if no agreement had been possible at the EU level: the French government has its bilateral migration agreements available to it as an alternative, and the Dutch government created a policy and budget for migration and development and could therefore carry out actions independently. Indeed, all the governments, no matter whether they favoured or opposed participation in the Mobility Partnerships, emphasised that legal migration remains a national competence. It is therefore not costly if the EU fails to agree a policy instrument that potentially incorporates elements of legal migration.

Section 5.4 showed that the French government did not consider participation in the Mobility Partnerships in a 'means-end' way; rather, participating in this new instrument was simply considered appropriate because it matched a national role conception of France as a leader both in the EU and also in the area of external migration policy. However, in case there would have been no agreement at the EU level on the Mobility Partnerships, the French government would be able to resort to its own bilateral migration agreements (the accord de gestion concertée des flux migratoires et de développement solidaire). Indeed, the French government prioritises these bilateral 
agreements: it was reluctant when the Commission suggested Senegal as a partner country for a Mobility Partnership because it already has a bilateral agreement with Senegal and this is "enough" (Interview 16). In cases where a bilateral agreement is being negotiated, intervention by the EU is even seen as "interference" which can obstruct the conclusion of the more important bilateral agreement (ibid). The French government also asserts national competence over which migrants to admit to French territory (French Ministry of Interior, n.d.), and government officials were concerned that a Mobility Partnership would lead partner countries to make unrealistic requests of participating member states, such as a quota for their citizens to migrate to the EU (Interview 16). Therefore, even though the Mobility Partnerships matched a French national role conception, the cost of no agreement was still low.

Given the contradiction between Austrian national policy objectives and the Mobility Partnerships, the cost of no agreement for Austria was low; indeed, the cost of the wrong kind of agreement (legally-binding Mobility Partnerships with circular migration schemes in which Austria would be forced to participate) would have been very high. The Ministry of Interior made very clear in negotiations at the EU level that Austria was opposed to the concept of Mobility Partnerships, and Austrian officials in EU settings (such as the HLWG) emphasised that participation in the Mobility Partnerships should be voluntary (Interview 22; 25). The Austrian government was willing to let the Mobility Partnership instrument go ahead provided that participation by member states would be voluntary, but if no agreement would have been possible at the EU level then this would actually have been a positive outcome: it would have removed any possibility that Austria might find itself forced to accept measures that it opposed. Indeed, having emphasised the voluntary nature of the Mobility Partnerships, Austrian government officials were furious when the Commission requested mandates for readmission and visa facilitation agreements for the Mobility Partnership countries, because these agreements are binding on all member states - including Austria (Interview 22; 25). Ultimately, however, the government was outvoted in the Council and therefore forced to accept the conclusion of such agreements.

Section 5.5 showed the change in preferences of the Dutch government: having been unsure of the costs and benefits of the Mobility Partnership instrument at the outset, the government later decided that the benefits would outweigh the costs and therefore decided to join. However, the cost of no agreement on the Mobility Partnerships was still low. The Dutch government had developed its own policy and budget on migration and development, and could therefore implement measures independently. There would be no major disadvantage if the Mobility Partnership instrument did not exist, because it is possible to "have a good migration discussion with a country without having a Mobility Partnership" (Interview 11). The Dutch government also emphasises that it will not offer legal migration opportunities as part of a Mobility Partnership (Interview $4 ; 6$ ). Failure to reach agreement on the Mobility Partnership instrument would not be costly because it would remove any possibility of the Dutch government being forced to accept legal migration measures as part of such a partnership. 


\subsubsection{Ratification procedure within the EU}

Ratification concerns the autonomy of the central decision-maker(s) to take a decision. In terms of the number of institutional players involved within the EU in decisionmaking on Mobility Partnerships, the ratification procedure could be described as easy: only the Commission and the member states (in the Council structures) were involved in the policy-making process. Chapter 4 showed that other EU institutions, and particularly the European Parliament, were side-lined and did not play any role at all. Between the member states and the Commission there was something of a struggle for control over the policy instrument. Ultimately, member states retained control over several features of the Mobility Partnerships: the legal form (a political declaration rather than a legally binding international agreement); the voluntary nature of participation; the selection of partner countries; and the specific content of each Mobility Partnership. This is a type of 'ongoing' or 'continuous' ratification: member states have ensured that they must approve each step in the process towards Mobility Partnerships being signed. The Commission adopted a flexible and pragmatic approach, allowing member states this degree of control because it made the ratification procedure easy: it prevented member states from vetoing this new policy instrument altogether. The Austrian government, for instance, was very opposed to the notion of increasing legal migration opportunities, but allowed the Mobility Partnership instrument to proceed on the basis that participation by member states would be voluntary. The Dutch government was ambivalent about the Mobility Partnerships at the outset; however the BNC fiche makes no mention of opposing this policy instrument (BNC, 2007). It notes that labour market policy is a member state competence where the EU must not act, but it acknowledges that the EU has competence on immigration. Allowing such a degree of member state control over the policy has come at a cost: the Commission is not free to make proposals or concessions to third countries, because ultimately member states shape the Mobility Partnerships through their participation and the projects they propose.

\subsubsection{Ratification procedure within the member states}

For all three of the member states studied in this chapter, the domestic ratification procedure on the Mobility Partnerships was easy in the sense that the central decisionmaker(s) could act relatively autonomously: in each case, the decision was taken in one or two ministries, without involvement of other ministries, the national parliaments, or societal actors. This may be explained by the lack of politicisation of the Mobility Partnerships: this is not a policy instrument that has been brought to public attention. When EU issues do not attract much attention, they are generally dealt with at the administrative level of each member state (van Keulen, 2006). In France, the Ministry of Immigration was the decision-maker; in Austria it was the Ministry of Interior; and in the Netherlands the decision on the Mobility Partnerships was made jointly by the Ministry of Foreign Affairs and the Ministry of Justice.

As outlined in section 5.3, several French ministries have a stake in immigration policy and are therefore represented in the CICI. However, in the case of the Mobility Partnerships, these ministries were largely by-passed. The decision that France would 
participate in Mobility Partnerships was taken by the then secretary-general of the Ministry of Immigration, on the basis of advice from officials in the European Affairs section (Interview 32). The Ministry of Immigration was the main one concerned with the substance of the Mobility Partnerships, and was therefore the site of the French decision to participate. The Ministry of Foreign Affairs was naturally also concerned by the Mobility Partnerships because of its competence over diplomatic relations (Interview 32), and representation of France in the HLWG is shared between the Ministry of Immigration and the Ministry of Foreign Affairs. However, in this instance the Ministry of Foreign Affairs was rather 'being informed' about the French position than determining it (Interview 33). The decision was taken by the Ministry of Immigration (Interview 35). Given the interministerial rivalries within the French administration and between 'Paris' and the Permanent Representation in Brussels (Menon, 2000), the ratification procedure on the Mobility Partnerships can be characterised as easy - the decision was made at the bureaucratic level within the Ministry of Immigration, in coordination with the SGAE in Paris.

Despite the Austrian corporatist tradition and the involvement of three ministries in setting migration policy, the decision not to participate was taken by the Ministry of Interior as the main government institution responsible for migration policy (European Migration Network, 2010c; Interview 25). The Ministry of Interior thus acted autonomously: other ministries and the social partners were bypassed. It is important to note that a different ratification procedure within Austria involving these other groups might have led to a different outcome, as they have taken a rather different view of Mobility Partnerships. The Federation of Austrian Industry, for instance, has criticised the restrictive and security-oriented approach of the government to immigration, and argued that Austria needs to be more open to immigrants entering the country (Der Standard, 2009; European Migration Network, 2007; Interview 24). In the Austrian Permanent Representation, there was a feeling that participation, especially in the Mobility Partnership with Moldova, would be perfectly compatible with Austrian policy objectives, particularly given the Moldovan concern with promoting return migration of its own citizens (Interview 22). The Austrian visa application office in Chisinau has brochures about the opportunities and risks of migration, and this information is also made available to diaspora communities in Austria (European Migration Network, 2010d, p.25). Such a project could fall under a Mobility Partnership. However, within the Austrian system for EU coordination, the chain of command runs from the ministry in Vienna to the departments of the Permanent Representation (Müller, 2001, p.235). In other words, the ministries in Vienna determine the Austrian position, to be defended by the Austrian Permanent Representation. Officials at the Ministry of Foreign Affairs also believed that, given that Mobility Partnerships are largely made up of technical cooperation programmes, participation would be perfectly compatible with Austrian national policy: "we always had and we always will have technical cooperation programmes" (Interview 24). The Ministry of Foreign Affairs therefore favours rethinking the Austrian position on Mobility Partnerships (Interview 22). However, on the issue of Mobility Partnerships the Ministry of Interior is the lead ministry, and in case Austrian government depart- 
ments disagree on an EU matter it is the lead ministry that makes the decision (Müller, 2000, p.206).

The Ministry of Interior was not, however, alone in its negative assessment of the concept of Mobility Partnerships. A parliamentary subcommittee on EU affairs echoed the government's concern over the concept of circular migration being proposed at the EU level, because this would increase possibilities for immigration to the EU: "Das Konzept der Kommission zur zirkulären Migration, das heißt zu einer befristeten Zulassung für einige Jahre mit obligatorischer Rückkehr und ohne Integration, wird strikt abgelehnt. Jedenfalls dürfe es zu keiner Erweiterung der Zulassungsmöglichkeiten von Drittstaatsangehörigen zum Arbeitsmarkt durch die EU geben" (Austrian Parliament, 2009, p.3). The Ministry of Labour, Social Affairs and Consumer Protection is also extremely cautious about admitting new 'waves' of immigration to Austria, arguing that the integration of those migrants already in Austria should take priority (Austrian Integration Fund, 2008). In a position paper published in August 2007, the Federal Chamber of Labour declared itself to be officially opposed to Austrian participation in the Mobility Partnerships and the introduction of a circular migration model at the EU level, questioning whether the EU has the competence to introduce such policies (Austrian Federal Chamber of Labour, 2007). It is therefore not certain that including other groups in the ratification procedure would have resulted in a different Austrian position on the Mobility Partnerships, but it would likely have made the ratification procedure difficult.

Dutch decision-making on the Mobility Partnerships officially fell to the Ministry of Justice, in close coordination with the Ministry of Foreign Affairs and the Ministry of Social Affairs and Employment (BNC, 2007). However, informally decision-making was shared between the Ministry of Foreign Affairs and the Ministry of Justice (Interview $4 ; 5)$, and both ministries were involved in drawing up an overview document about the Mobility Partnerships for the BNC working group (Interview 3; 8). The Ministry of Foreign Affairs focuses on migration and development broadly, whilst the Ministry of Justice focuses on return (Interview 4; 9; 11). Siegel and van der Vorst (2012, p.23) found that these differing interests and aims were also present in the Dutch circular migration project: the Ministry of Foreign Affairs was concerned with securing a 'triple win' scenario for migrants, sending and receiving countries, whereas the Ministry of Justice was concerned with ensuring return migration. So whereas the Ministry of Foreign Affairs might evaluate a project on voluntary return of migrants according to whether the migrants find work once they return, the Ministry of Justice will focus on whether all migrants participating in the project actually returned (Interview 6; 15). These different priorities are reflected in the budgets available: the Ministry of Foreign Affairs provides the budget for migration and development measures, whilst the Ministry of Justice only has (limited) financing available for return actions (Dutch Ministry of Foreign Affairs and Ministry of Justice, 2008, p.16). On the issue of Mobility Partnerships, the Ministry of Justice was hesitant to make commitments that it might not be possible to keep. Officials were aware that projects involving exchange of knowledge on migration management with third countries would rely on the expertise and experience of staff in the Ministry of Justice or its services (Interview 5; 9). The Ministry of 
Social Affairs and Employment was opposed to the concept of a Mobility Partnership; in principle, it does not support the conclusion of labour migration agreements with third countries (Interview 6). The Ministry was particularly unhappy with the Dutch circular migration pilot project, which it vigorously opposed on the basis that there is no need for labour migration from outside the EEA region (Siegel and van der Vorst, 2012, p.23). However, ultimately the ministry's view was outvoted in the cabinet and it had to accept the pilot project (Interview 3; 6), which is officially a joint project of the Ministries of Foreign Affairs, Justice, and Social Affairs and Employment (European Migration Network, 2010i, p.16). All three ministries have seats in the steering committee (Siegel and van der Vorst, 2012, p.11).

Mobility Partnerships have not been the specific subject of parliamentary debate in the Netherlands, but they have been considered during discussion of events at the EU level more generally. These discussions have, however, consisted of ministers/secretaries of state outlining the Dutch position on Mobility Partnerships; Parliament was not involved in taking the decision, but was informed ex post facto of the Dutch position. Parliament was informed of the Dutch position on Mobility Partnerships in a letter from the minister for development and the state secretary for justice in September 2007: Mobility Partnerships are one of the developments at the EU level, and the Netherlands is reported to be cautiously positive about such partnerships, providing that member state competence over the labour market is retained (Tweede Kamer, 2007, p.4). During a meeting with the parliamentary committees for justice, interior, and European affairs in June 2008, the secretary of state for justice assured members of parliament that decisions on Mobility Partnerships will be made based on the Dutch interest to cooperate with the country concerned. The Dutch interest is return and readmission, border control, and the prevention of human trafficking. As negotiations were ongoing for a Benelux readmission agreement with Georgia, and as Georgia is an important transit country of migration for the Netherlands, the decision was made to join this Mobility Partnership (Tweede Kamer, 2008b, p.9).

\subsection{Conclusion}

This chapter has accounted for the different preferences of the French, Austrian and Dutch governments on the Mobility Partnerships and, together with chapter 4, for the outcome of their interaction with the Commission. The chapter gives a somewhat mixed view of the explanatory powers of the rationalist and constructivist theories. Overall, a rationalist cost-benefit calculation is the more powerful theoretical explanation for member states' preference formation. Certainly both the Austrian and Dutch governments clearly considered the opportunities and constrictions offered by cooperating at the EU level on the Mobility Partnerships. The Austrian government decided that, due to the significant contradiction between national and EU policy objectives, the cost of participating would be too high. The Dutch government hesitated: initially, it was reluctant to decide to participate because the national policy on migration and development 
had not yet been established. The potential costs and benefits of EU level cooperation were therefore not yet clear. However, once the national policy was formulated, it was determined that the benefits of participation in the Mobility Partnerships outweighed the costs. Tracing the process in these two cases showed that the decision on participation was made in a means-end way, by weighing potential costs against potential benefits. However, the constructivist explanation cannot be entirely discarded. The Austrian government, for instance, sees EU competence in immigration policy as inappropriate; this is something that is and should be the domain of the member states. The Dutch government had similar concerns in terms of labour market policy, which in combination with the cost-benefit calculation accounts for the initial Dutch ambivalence: the Dutch government was concerned that legal migration was over-emphasised in the Mobility Partnerships, which is inappropriate because this is not an EU competence. Section 5.4 nevertheless argued that the national identity explanation could not fully enough explain the outcome in these two cases: despite similar concepts of what an appropriate division of competences between the EU and its member states should be, the two governments made different decisions on the Mobility Partnerships. The costbenefit explanation is thus the more convincing one.

The case of France might also be explained according to rationalist logic: section 5.4 showed how the French preference for participation in the Mobility Partnerships could be justified in terms of the benefits expected from participation. However, the process-tracing conducted showed that the 'prior' explanation is the one relating to the French national role conception. Participation in the Mobility Partnerships was considered 'appropriate' because it matched with a concept of France as a leader, both within the EU and in the domain of external migration policy more broadly. This has locked the French government into a path of participation in every Mobility Partnership decided to date and also those that will be decided in the future.

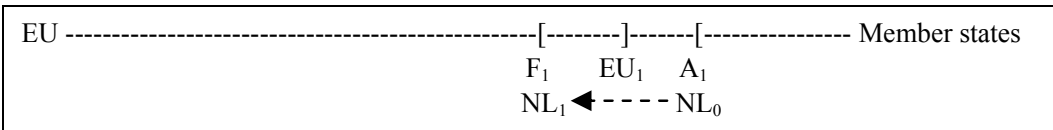

Figure 5.8: EU-member state interaction (including the change in Dutch preference).

Figure 5.8 illustrates the size of the win-sets in the interaction between the member states and the EU. It shows that the win-set for the Commission was large: the cost of no agreement was high, and the ratification procedure within the EU was easy. This limited the Commission to a 'soft bargaining' negotiating style in its interaction with the member states: Commission officials were forced to compromise on the details of the Mobility Partnership instrument in order to get member states' agreement to move ahead (see chapter 4). At the same time, being flexible and willing to compromise in this way made the ratification procedure easy because it prevented member states from vetoing the Mobility Partnership instrument altogether. In contrast, the win-sets for the member states were small. In all cases, the ratification procedure was easy but the cost of no agreement was low. Not even France and the Netherlands, which do both participate in Mobility Partnerships, would have been seriously disadvantaged if no agreement 
had been possible. However, the cost of no agreement was relatively lower for Austria because the government was opposed to the concept of Mobility Partnerships. 



\section{Chapter 6}

\section{The EU-third country}

\section{interaction}

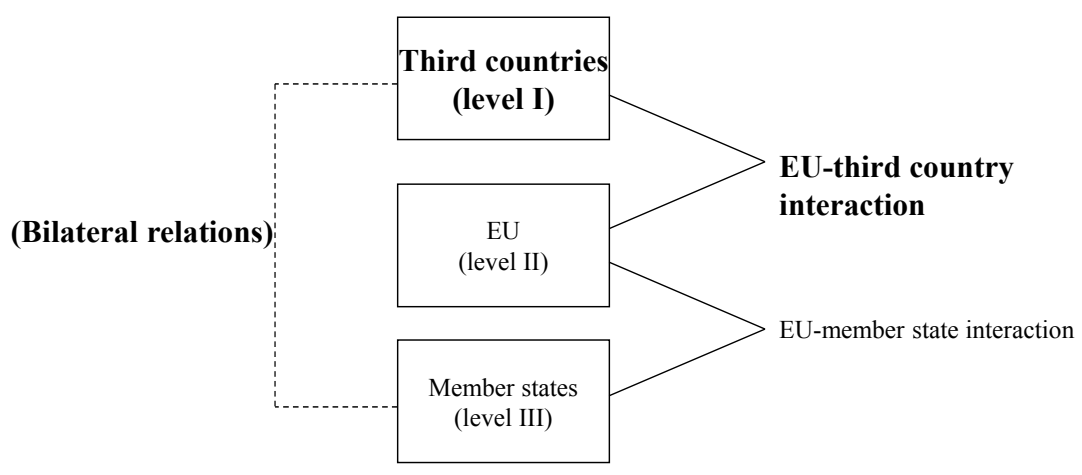




\subsection{Introduction}

This chapter deals with the international level (level I of the three-level game), as well as the interaction between the EU and the third countries. It answers the final subquestion of the research as presented in chapter 2: why do third countries choose to join a Mobility Partnership? This chapter thus specifies both the nature of the international negotiating environment between the EU and these third countries, and also the domestic politics of international cooperation on migration for the third countries. The cases selected were Senegal and Cape Verde. Section 6.2 outlines briefly the existing external migration policy of the EU towards Senegal and Cape Verde. Section 6.3 concerns the process of negotiations between the EU and Cape Verde and Senegal on the Mobility Partnerships. When Mobility Partnerships are negotiated, the substance of the negotiations is the preamble and the political declaration which form the main part of each Mobility Partnership text. The annex of proposed projects is not specifically negotiated; rather it is created on the basis of the actions that the member states, EU institutions, and/or third countries propose to carry out in the framework of the Mobility Partnership. Thus, the negotiations between the EU and Cape Verde concerned the content of the preamble and political declaration. In the case of Senegal, the Commission sent a proposed draft Mobility Partnership text to the Senegalese government, as a basis for negotiations.

Chapter 2 argued that the domestic preferences of third countries explain their decisions on whether to cooperate with the EU on migration issues. This process of domestic preference formation can be accounted for by two possible explanations: a social learning approach, and a policy conditionality approach. Section 6.4 shows that two of the conditions of the social learning model were the same across the Senegalese and Cape Verdean cases: neither case study uncovered evidence of a process of persuasion or dialogue being applied by the EU; and both governments consider EU readmission requirements to be inappropriate. The social learning model is therefore not convincing as an explanation for the success or failure of these Mobility Partnerships, because, despite these similarities, Cape Verde chose to sign the partnership while Senegal decided not to. Section 6.5 argues that the policy conditionality approach is best able to account for how these two countries developed different domestic preferences. Section 6.6 outlines the size of the win-sets in the EU-third country interaction. ${ }^{76}$

\subsection{EU external migration policy in Senegal and Cape Verde}

Senegal and Cape Verde are part of the Cotonou Agreement between the EU and ACP countries (see chapter 3). Independently of the Mobility Partnership instrument, the EU was therefore already implementing projects related to migration in both Senegal and Cape Verde, financed by the Thematic Programme on Cooperation with Third Countries

\footnotetext{
${ }^{76}$ For an analysis of the motivations of the Moldovan and Georgian governments to join Mobility Partnerships see Lavenex and Stucky (2011) and Carrera and Hernández i Sagrera (2011).
} 
in the Areas of Migration and Asylum. In the period 2007-2008, immediately before the negotiations on Mobility Partnerships, seven projects were financed in Senegal and three in Cape Verde (see table 6.1). The majority of projects implemented related to the prevention of illegal migration or the promotion of the link between migration and development. Member states were the lead implementers in most cases, although on average across all the projects represented in table $6.1,79.7 \%$ of funding came from the EU's Thematic Programme.

\subsection{Negotiations on the Mobility Partnerships}

The Mobility Partnership with Cape Verde was one of the first two pilot partnerships to be agreed in May 2008. ${ }^{77}$ Following the publication of the Commission communication on Mobility Partnerships in May 2007, the concept of Mobility Partnerships was discussed in the Council in June 2007 (see chapter 4). The Council invited the Commission to hold consultations with both member states and third countries during the course of 2007, so that the Council could decide by the end of 2007 whether to authorise the launch of Mobility Partnerships (Council, 2007e). At this time, the Cape Verdean government became aware, through the ambassador in Brussels, that the EU was looking to test the concept of Mobility Partnerships with a country from the ACP grouping. The Cape Verdean ambassador in Lisbon approached the Portuguese authorities to discuss the issue, as Portugal held the rotating presidency of the EU at the time. As Luxembourg is another traditional European partner country for Cape Verde, the Cape Verdean ambassador in Brussels discussed a potential Mobility Partnership with the Permanent Representation of Luxembourg (Interview 56; 65). However, the Cape Verdean government did not submit a formal written expression of interest in the Mobility Partnership to the Commission or Council (Commission, 2009d, p.3). In contrast, the Moldovan government submitted three non-papers indicating its interest in, and ideas about, a Mobility Partnership (ibid.; Carrera and Hernández i Sagrera, 2011). In December 2007, the Council authorised the Commission, "in close liaison with Member States and/or the Presidency ... to open dialogue with Cape Verde and Moldova, with a view to launching pilot mobility partnerships" (Council, 2007b, p.5). Following this, the Commission approached the Cape Verdean government with the formal proposal for a Mobility Partnership (Interview 13). The Cape Verdean government "quickly confirmed [its] interest and engaged in the process" (Commission, 2009d, p.3). Meetings were held both in Brussels and Praia, and the text of the Mobility Partnership agreed by May 2008. The Mobility Partnership was formally signed in September 2008 (Council, 2008c).

\footnotetext{
${ }^{77}$ The Mobility Partnership with Cape Verde was agreed at the same time as the Mobility Partnership with Moldova.
} 


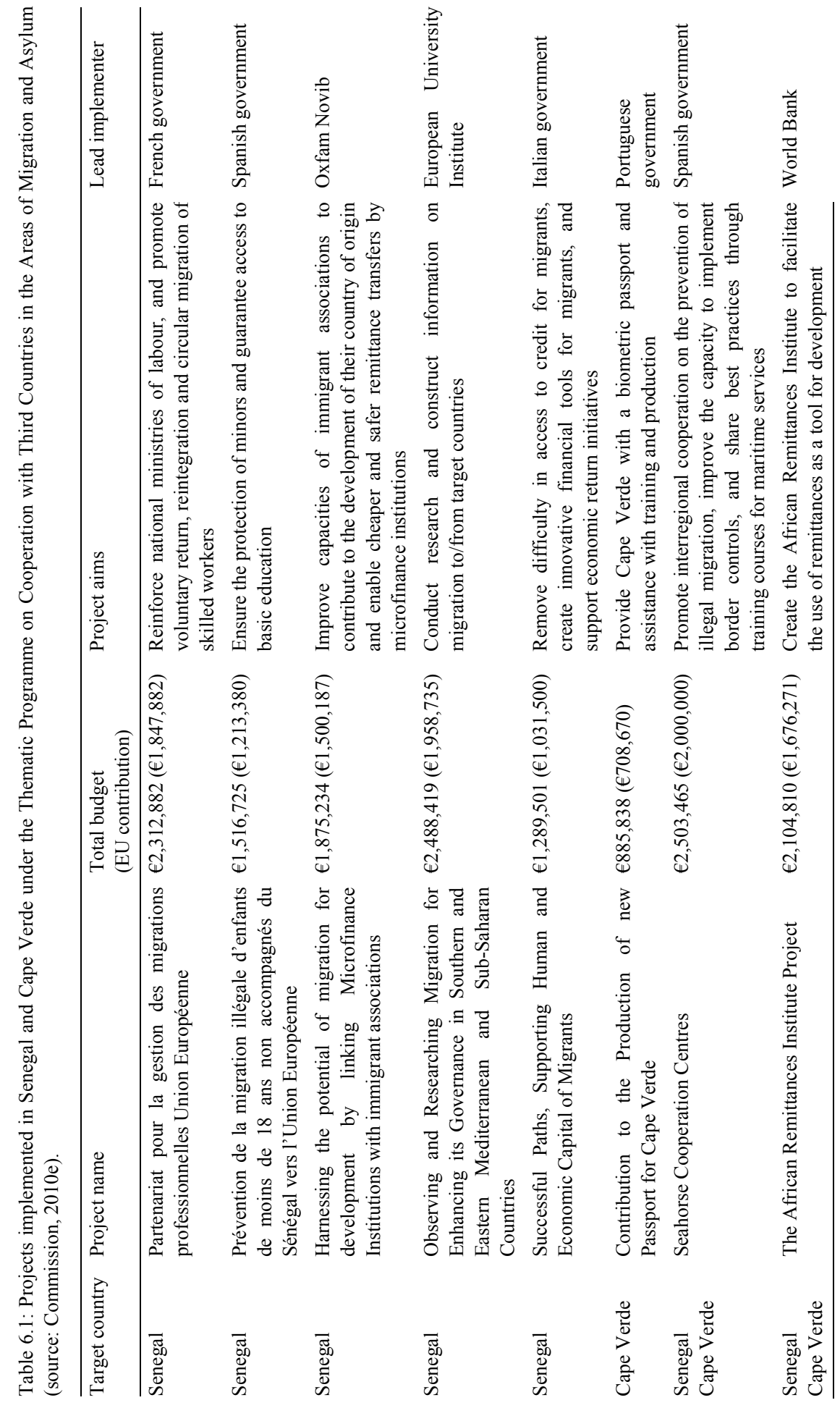


Already at the same time as the signature of the Mobility Partnership with Cape Verde, in May 2008, the HLWG reached agreement on inviting the Commission, "in close liaison with Member States and the Presidency, to take forward exploratory talks with Georgia and Senegal and to open dialogue with these countries, with a view to launching additional pilot mobility partnerships" (Council, 2008m, p.7). The Senegalese authorities had, at this point, not been consulted (Interview 17); rather the eligibility of Senegal for a Mobility Partnership had been discussed within the EU and decided by the Council (Commission, 2009d, p.3). Following the formal decision at EU level, a first meeting was held in Dakar in July 2008, in which the Senegalese government indicated that it was very interested in the idea (Interview 13). The Mobility Partnership was to be based largely on existing projects carried out by the French, Spanish and Italian governments - these member states had signalled that they would participate in the Mobility Partnership (Chou and Gibert, 2012, p.418). The Commission sent the draft declaration of the Mobility Partnership to the Senegalese government, but never received any reply. Despite bringing the issue up in bilateral meetings (for instance in the follow-up meetings of the Rabat process), and assurances by the Senegalese government that it was very interested, still the Commission received no reply (Interview 13). A European Parliament delegation visiting Senegal later in 2008 once again forwarded the request regarding the Mobility Partnership, and the Commissioner for development cooperation (Louis Michel) sent a letter to Senegalese President Wade (Interview 23). By September 2009, it was clear that negotiations were not progressing and the Commission had abandoned the idea for a Mobility Partnership with Senegal (Commission, 2009d, p.3). The Commission's 2009 report on policy coherence for development, which contains a section on Mobility Partnerships, makes no mention of negotiations with Senegal (Commission, 2009f, p.121). In contrast, the Mobility Partnership with Georgia, which had been initiated at the same time as the proposal was made to Senegal, was signed in November 2009 (Council, 2009a).

\subsection{The international level: a process of persuasion and dialogue?}

One explanation for third countries' decisions to cooperate with the EU on migration issues is social learning: third countries will cooperate with the EU if they are persuaded that the EU policy is appropriate. The most important condition according to this explanation is an attempt by the EU to engage the third country in a dialogue to persuade the government of the value of cooperation. However, negotiations on a Mobility Partnership with both Senegal and Cape Verde display a complete absence of such an approach by the EU. Instead, the negotiations were very much of a 'take it or leave it' character, leaving little room for either country to be persuaded of the appropriateness of the policy instrument. Mobility Partnerships require a commitment from the third country concerned to cooperate with the EU on readmission, including by signing an EU-wide readmission agreement (see chapter 4). Both the Senegalese and Cape Verdean government see these readmission requirements as inappropriate because they should not have 
to be responsible for failed EU border controls. For Cape Verde, however, the legitimacy of EU policies is enhanced due to its identification with the EU community. This section applies the social learning model first to the negotiations with Cape Verde and then to the negotiations with Senegal.

The Commission's 2009 evaluation of the Mobility Partnerships states that the Cape Verdean government had clear views on the main aspects it wanted to be reflected in its partnership, namely security and mobility (Commission, 2009d, p.3). However, tracing the actual process of negotiations shows that there was little room in the negotiations with the EU for the Cape Verdean government to influence the content of the Mobility Partnership. Interviewees in the Cape Verdean government point out that that this partnership "started as an experimental project of the EU . . That's why the beginning of the project was mostly a project from the EU than a project of bilateral genesis" (Interview 51), indicating the inability of Cape Verde to influence the content of the partnership. The text of the Mobility Partnership with Cape Verde is very similar to the text of the Mobility Partnership with Moldova (Interview 56), implying no attempt by the EU to persuade the Cape Verdean government that this instrument is appropriate specifically for the Cape Verdean case. ${ }^{78}$ There was a clear feeling within the Cape Verdean government that it had had a limited impact on the negotiations of the Mobility Partnership: "you can say that the partners are equal, that things have been discussed, this is politically correct, but the reality is not that" (Interview 56). From the text of the Mobility Partnership (Council, 2008c) it seems that the Cape Verdean desire for mobility to be incorporated has not been met (see Annex II). Many of the projects proposed under the heading of facilitating legal migration concern only informing potential migrants about possibilities for migration or establishing cooperation between European and Cape Verdean institutions. The projects are not aimed at increasing overall mobility from Cape Verde to the EU (see also chapter 4).

The requirements that the EU places on third countries in the area of readmission are seen by the Cape Verdean government as being inappropriate. Cape Verdean officials state that the government has no problem with readmitting its own citizens; indeed, it has agreements on readmission with some European countries, for instance France, Spain and Portugal. However, it has hesitated over the EU readmission agreement due to the inclusion of the clause on third country nationals. As one interviewee put it, if a migrant is found to be illegally present in the EU then it means that EU border controls have failed, so why should Cape Verde then have to take this person back? (Interview 66) The government does not, as such, object to readmitting third country nationals who are legally and long-term resident in Cape Verde. Interviewees indicate that the real objection is to the readmission of third country nationals who have only transited through Cape Verde: "we won't accept anybody, just because he has a piece of paper proving that he bought gas here in Praia, that he should therefore be sent back to Cape Verde" (Interview 65; cf. Coleman, 2009 on Ukraine, Turkey and Morocco).

\footnotetext{
${ }^{78}$ This tendency by the EU to use a 'template' agreement for different negotiation processes has also been noted by Cassarino (2012, p.193).
} 
On the other hand, the legitimacy of the EU's policies and approaches is enhanced by the identification within Cape Verdean society with Europe and the European Union. Both the government of Cape Verde and the European Commission see Cape Verde as a bridge between Europe and Africa (Interview 12; 49; Commission, 2007b). Interviewees point to several affinities between Europe and Cape Verde in terms of culture, religion, norms and values, the legal system, the organisation of the state, and respect for human rights (Interview 49; 56; 65). In its communication on the future of relations between the EU and Cape Verde, the Commission also indicates that the EU and Cape Verde share "close human and cultural links, the common experience of major events and strong, shared socio-political values" (Commission, 2007b, p.2). As one interviewee pointed out, "the references [in Cape Verde] are in the north, not in the west coast of Africa" (Interview 56; cf. Economist Intelligence Unit, 2008). This can be attributed to the interaction between Cape Verdeans and the diaspora, which is mainly found in the United States and Europe (ibid.).

The process of negotiation on the Mobility Partnership with Senegal was much the same as with Cape Verde. Following the formal decision at EU level to select Senegal as a partner for a Mobility Partnership, the Commission sent the completed draft text of the declaration of a Mobility Partnership to the Senegalese government for signature (Interview 41). This proposed text was largely identical to the Mobility Partnership with Cape Verde, with only minor changes made due to differences in Senegalese population and migratory flows (Chou and Gibert, 2012). Just as with Cape Verde, therefore, there is no evidence of an attempt by the EU to persuade Senegal of the appropriateness of this policy instrument for the Senegalese case in particular. The Senegalese government sees the unilateral actions of the EU and lack of deliberation with third countries as inappropriate, unacceptable and ineffective. Interviewees point out that EU projects on migration cannot be implemented without the cooperation of third countries, and yet the EU takes decisions unilaterally and then afterwards approaches third countries concerning the implementation. The Senegalese government believes that third countries should instead be invited to discuss and debate the contents of the policies which they are expected to help to implement (Interview 41). The government insists that it will not accept decisions on migration cooperation being imposed on it (Interview 47). There was particular anger among interviewees that such a unilateral approach was also employed by the EU in signing the European Pact on Immigration and Asylum (Council, 20081). The pact relies on third countries for implementation, but third countries were not consulted in the process leading up to the signature of the document (Interview 48). This finding confirms previous research by Chou and Gibert, who also noted the "tendency by European officials to present a 'joint cooperation' document in the state of near finality to non-EU partners", as in the case of the Mobility Partnership with Senegal (2010, p.8). Such a unilateral approach is in stark contrast to the stated principle by the EU to base its cooperation with Senegal on partnership, a dialogue between the two parties and support for the sectoral strategies identified by the Senegalese government (SenegalEuropean Community, 2008, p.31). Partnership has also been identified as a cornerstone 
of EU migration missions (Council, 2007a, p.8), although the fact that the terms of references for such missions are "shared" with third countries (p.4) leaves open to debate how much influence these countries actually have on the content.

Just as for the Cape Verdean government, EU readmission requirements are seen by the Senegalese government to be illegitimate. In fact, the position of the Senegalese government on readmission is more uncompromising than that of the Cape Verdean government. Senegalese interviewees insist that Senegal will not accept the return of non-Senegalese migrants (Interview 46), but readmission of its own nationals has also been a stumbling block in bilateral relations with EU member states (see sub-section 6.5.3). Senegalese government officials complain that the EU is overly focussed on the issue of return, without adequate attention for other migration issues, such as the integration of migrants in the country of destination (Interview 41). This implies that an appropriate migration policy would be more balanced and nuanced than the approach currently adopted by the EU.

Overall, it is clear that a social learning approach is unable to account for the different outcomes of the Mobility Partnership negotiations with Cape Verde and Senegal. Both countries' governments view EU readmission requirements as inappropriate, particularly as regards the clause on third-country nationals. In neither case was there evidence of a process of dialogue or persuasion: the EU approach was rather to present the Senegalese and Cape Verdean governments with a draft Mobility Partnership document, apparently assuming that the benefits of the cooperation would be obvious to both partners. The following section shows that this was not the case: the Senegalese and Cape Verdean governments saw very different costs and benefits to a Mobility Partnership (although they were being presented with essentially the same text), and therefore developed very different domestic preferences.

\subsection{The international level: policy conditionality and domestic preference formation}

The policy conditionality approach predicts that third countries will cooperate with the EU when the expected benefits of cooperation outweigh the expected costs. Chapter 2 argued that the cost-benefit calculation made by third countries will depend on three factors: (i) the resonance of the EU policy with national policy objectives; (ii) the administrative capacity of the target state; and (iii) the domestic costs of adopting the EU policy. This section looks at the process of domestic preference formation regarding the Mobility Partnership in Cape Verde and Senegal. It shows that, for Cape Verde, the expected benefits of the Mobility Partnership outweighed the expected costs, which led the government to agree to the partnership. Senegal refused to sign a Mobility Partnership because the benefits on offer could not outweigh the anticipated costs. 


\subsubsection{Resonance of EU policy with national policy objectives}

A central difference between the case of Cape Verde and the case of Senegal is the resonance of the Mobility Partnership with national policy objectives. Whereas the proposed partnership resonated well with Cape Verdean national migration policy objectives, there was a complete contradiction between the Mobility Partnership and the Senegalese government's approach to migration policy.

The Cape Verdean government perceived a resonance of the Mobility Partnership with national migration policy. In particular, the government believed the Mobility Partnership would strengthen its efforts to deal with illegal migration, whilst encouraging enhanced relations with the Cape Verdean diaspora. Migration is an important aspect of Cape Verdean history, culture and society, and shapes Cape Verdeans' views of themselves (Carling and Åkesson, 2009; Carling and Batalha, 2008; IOM, 2009c). Cape Verde has a rich and diverse history of emigration (Cape Verde-European Community, 2008). In the early twentieth century, the main destinations were the United States, Senegal, and Argentina. Cape Verdean emigrants to the United States mainly departed on board American whalers, and took up residence in New England. The capital of Senegal, Dakar, was a place of refuge for many Cape Verdean emigrants hoping to avoid forced migration to other Portuguese colonies. Cape Verdeans also joined the many Europeans migrating to Argentina. In the middle of the twentieth century, emigration to Europe picked up. The most important destination was Portugal, where there was a demand for labour due to the emigration of Portuguese workers. The successful shipping industry in the Netherlands attracted many Cape Verdean men to emigrate and settle, mainly in Rotterdam. At the same time, Cape Verdean women were moving to Italy to find domestic work. Many of the Cape Verdeans who had migrated to Dakar moved to France when Senegal gained its independence (Carling and Åkesson, 2009). Figure 6.1 shows the spread of the Cape Verdean emigration tradition in dark grey.

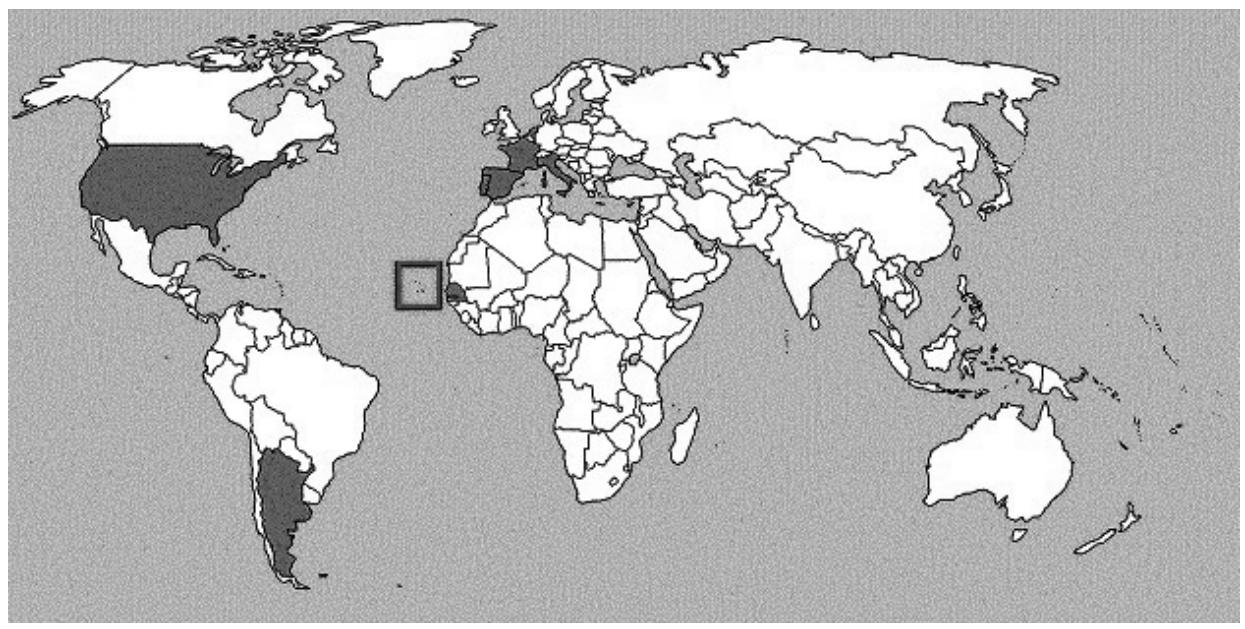

Figure 6.1: Countries of emigration for Cape Verdeans. 
As a result of this emigration tradition, there is a significant Cape Verdean emigrant population, particularly considering that the population of the islands themselves is only 516,000 (in 2011; CIA World Factbook 2011a). However, there are no exact figures on the size of this emigrant community. It is often stated that there are twice as many Cape Verdeans abroad as in Cape Verde itself (Interview 60), but there is no evidence for this claim (Carling, 2008). The World Bank puts the figure at 192,500 (World Bank, 2011). IOM estimates the emigrant community to be 700,000 (IOM, 2011). Carling (2008) agrees with IOM that the emigrant community is probably larger than the population of Cape Verde. A significant proportion of the Cape Verdean emigrant community lives in the EU. Eurostat data shows that there were around 75,000 Cape Verdeans (legally registered) in the $27 \mathrm{EU}$ member states in 2010. Table 6.2 shows the most important emigrant communities in EU member states.

Table 6.2: Cape Verdeans legally resident in selected EU member states in 2010 (source: Eurostat). ${ }^{79}$

\begin{tabular}{ll}
\hline EU member state & No. of Cape Verdean migrants \\
\hline Portugal & 49,434 \\
France & 13,246 \\
Italy & 4,624 \\
Spain & 3,345 \\
Luxembourg & 1,660 \\
Netherlands & 1,492 \\
\hline
\end{tabular}

Encouraging the Cape Verdean diaspora to participate in the economic, social, political and cultural development of Cape Verde is one of the key pillars of Cape Verdean migration policy (IOM, 2009c; Interview 55). There is a Cape Verdean saying that "the $11^{\text {th }}$ island of Cape Verde is abroad" (Interview 58), and the government is keen to incentivise the integration of the emigrant community in Cape Verdean life. Indeed, emigrants have electoral rights and can therefore contribute decisively to the outcome of elections (Interview 49). The Mobility Partnership has as one aim to "foster cooperation with Cape Verdean communities abroad", including by facilitating investment by the diaspora in Cape Verde, facilitating remittances, and supporting the voluntary return and reintegration of migrants in Cape Verde (Council, 2008c, p.4). Participation in this partnership was therefore seen by the Cape Verdean government as a chance to develop

\footnotetext{
${ }^{79}$ http://epp.eurostat.ec.europa.eu/portal/page/portal/population/data/database (retrieved 21 November 2011). Data for France is from 2005; data for Luxembourg is from 2001 (most recent available). Data based on citizenship is used because the dataset is more complete. However, a different picture emerges if data based on country of birth is selected. The number of Cape Verdeans in the Netherlands dramatically increases, from 1,492 to 11,708 in 2010 . This perhaps implies that many Cape Verdeans in the Netherlands naturalise. The number for France increases from 13,246 to 18,294. For Spain and Portugal, the increase in numbers of Cape Verdeans by measuring according to country of birth is not so dramatic.
} 
projects in cooperation with the diaspora.

Despite its history as a country of emigration, Cape Verde is increasingly becoming a country of immigration and transit migration (Interview 12; 38; 56; Dutch Ministry of Foreign Affairs, 2009b). In 2010, Cape Verde had a net migration rate of -0.66 per thousand, but this is much lower than for other countries in the region - Mali, for instance, had an emigration rate of -5.23 per thousand (CIA World Factbook, 2011c). The World Bank estimates that there were 12,100 immigrants in Cape Verde in 2010, making up $2 \%$ of the population. The main countries of origin of these migrants were São Tomé and Principe, Angola, Guinea-Bissau, Portugal, Senegal, Italy, the United States, France, Nigeria, and Brazil (World Bank, 2011). Cape Verde is a particularly attractive destination for migrants from other West African countries, either as a transit country for onward migration to Europe, or as a country of destination. The economic growth, political stability, and higher salaries in Cape Verde make it attractive for migrants (Cape Verde-European Community, 2008). Table 6.3 compares Cape Verde to the other ECOWAS countries to show why it is that Cape Verde is increasingly a country of immigration. It is clear that Cape Verde is the richest, most well-developed country in ECOWAS, and also the country where civil liberties are best protected.

Table 6.3: Cape Verde compared to other ECOWAS countries (sources: CIA World Factbook, 2011a; UNDP, 2011; Freedom House, 2011).

\begin{tabular}{lllll}
\hline Country & $\begin{array}{l}\text { GDP per } \\
\text { capita }\end{array}$ & $\begin{array}{l}\text { Human } \\
\text { development index }\end{array}$ & $\begin{array}{l}\text { \% of population below } \\
\text { poverty line }\end{array}$ & $\begin{array}{l}\text { Civil liberties } \\
\text { score }\end{array}$ \\
\hline Benin & $\$ 1,500$ & 167 & $37 \%$ & 2 \\
Burkina Faso & $\$ 1,200$ & 181 & $46 \%$ & 3 \\
Cape Verde & $\$ \mathbf{3 , 8 0 0}$ & $\mathbf{1 3 3}$ & $30 \%$ & $\mathbf{1}$ \\
Côte d'Ivoire & $\$ 1,800$ & 170 & $42 \%$ & 6 \\
Gambia & $\$ 1,900$ & 168 & Not available & 5 \\
Ghana & $\$ 2,500$ & 135 & $\mathbf{2 8 \%}$ & 2 \\
Guinea & $\$ 1,000$ & 178 & $47 \%$ & 5 \\
Guinea-Bissau & $\$ 1,100$ & 176 & Not available & 4 \\
Liberia & $\$ 500$ & 182 & $80 \%$ & 4 \\
Mali & $\$ 1,200$ & 175 & $36 \%$ & 3 \\
Niger & $\$ 700$ & 186 & $63 \%$ & 4 \\
Nigeria & $\$ 2,500$ & 156 & $70 \%$ & 4 \\
Senegal & $\$ 1,900$ & 155 & $54 \%$ & 3 \\
Sierra Leone & $\$ 900$ & 180 & $70 \%$ & 3 \\
Togo & $\$ 900$ & 162 & $32 \%$ & 4 \\
\hline
\end{tabular}

As a result of these regional differences, there has been a wave of immigration to Cape Verde from other ECOWAS countries. ECOWAS citizens have the right of free movement to Cape Verde for a stay of 90 days, but there are two problems with such immigration: firstly, the government is concerned that the Cape Verdean labour market is not 
big enough to absorb all those arriving (Interview 58); and secondly, ECOWAS citizens (mainly from Ghana, Mali and Senegal) use Cape Verde merely as a transit destination in their attempts to reach Europe. There have been several incidents of boats with migrants bound for the Canary Islands departing from Cape Verde, but the vast majority of migrants leaving aboard these boats are not Cape Verdeans (Carling, 2008, p.10; Carling, 2002, p.28). The Cape Verdean government is trying to deal with the new issues related to illegal immigration. Each year, Cape Verde returns approximately 800 citizens of ECOWAS countries who are illegally resident in Cape Verde. Returning these citizens is expensive, but the government is keen to convey an image of Cape Verde as a "serious country", where migrants who are illegally present will be returned (Interview 49). The increase in immigration also led to the creation of an inter-ministerial committee on migration, whose objective was to elaborate a national migration policy (Interview 50). This policy was presented to parliament in February 2011. The government emphasises that Cape Verde has no interest in being a country of transit for migrants heading to Europe. Instead, it favours well-organised legal migration (Interview 49 ; 60). For instance, one objective of the national institute for employment and vocational training (IEFP) is to prepare Cape Verdeans to migrate, by providing training courses or by matching skills of Cape Verdeans with skills needed in the European labour market (Interview 62). The Mobility Partnership instrument is designed to combine cooperation on legal and illegal migration. A stated objective of the partnership with Cape Verde is to "promote a better framework for legal mobility", for instance through visa facilitation (Council, 2008c, p.3). At the same time, one pillar of the partnership deals with border management, identity and travel documents, combating illegal migration and trafficking in human beings (p.5). This combination of cooperation on legal and illegal migration resonated with the Cape Verdean government's central concerns in migration policy. It should be noted that it was this overall concept behind the Mobility Partnerships that resonated well with Cape Verdean national policy objectives; the Cape Verdean government did not make its decision to sign the partnership based on the specific projects proposed by the member states (see Annex II for an overview of the projects in the Mobility Partnership with Cape Verde).

In contrast to the Cape Verdean government, the Senegalese government reached the conclusion that there was a contradiction between national migration policy objectives and the proposed Mobility Partnership. Senegal has traditionally been a country of destination in West Africa (IOM, 2009a) and there is therefore a significant immigrant community. The World Bank estimates that in 2010 there were 210,100 immigrants living in Senegal, mainly from Guinea, Mauritania, Guinea-Bissau, Mali, France, Cape Verde, Gambia, Morocco, Syria, and the United States (World Bank, 2011). ${ }^{80}$

Having long been a country of destination, Senegal is increasingly becoming a country of emigration. Since the mid-2000s emigration from Senegal has become headline news, as many of the migrants on boats bound for Europe have turned out to be

\footnotetext{
${ }^{80}$ Dia (2009; cf. Wagbou, 2008, p.151) warns that the scale of immigration to and emigration from Senegal is probably underestimated due to the lack of reliable statistics.
} 
Senegalese (Poeze, 2010, p.33). In 2011, Senegal had a net migration rate of -1.9 per thousand (CIA World Factbook, 2011b) and an emigrant community estimated at 636,200 (World Bank, 2011). The main countries of destination for Senegalese emigrants are Gambia, France, Italy, Germany, Mauritania, Spain, Côte d'Ivoire, Gabon, Ghana, the United States, Mali and Guinea-Bissau (IOM, 2009a; World Bank, 2011). Eurostat data shows that there were around 200,000 Senegalese (legally registered) in the 27 EU member states in 2010. Figure 6.2 shows the spread of Senegalese emigration, and table 6.4 shows the most important emigrant communities in EU member states.

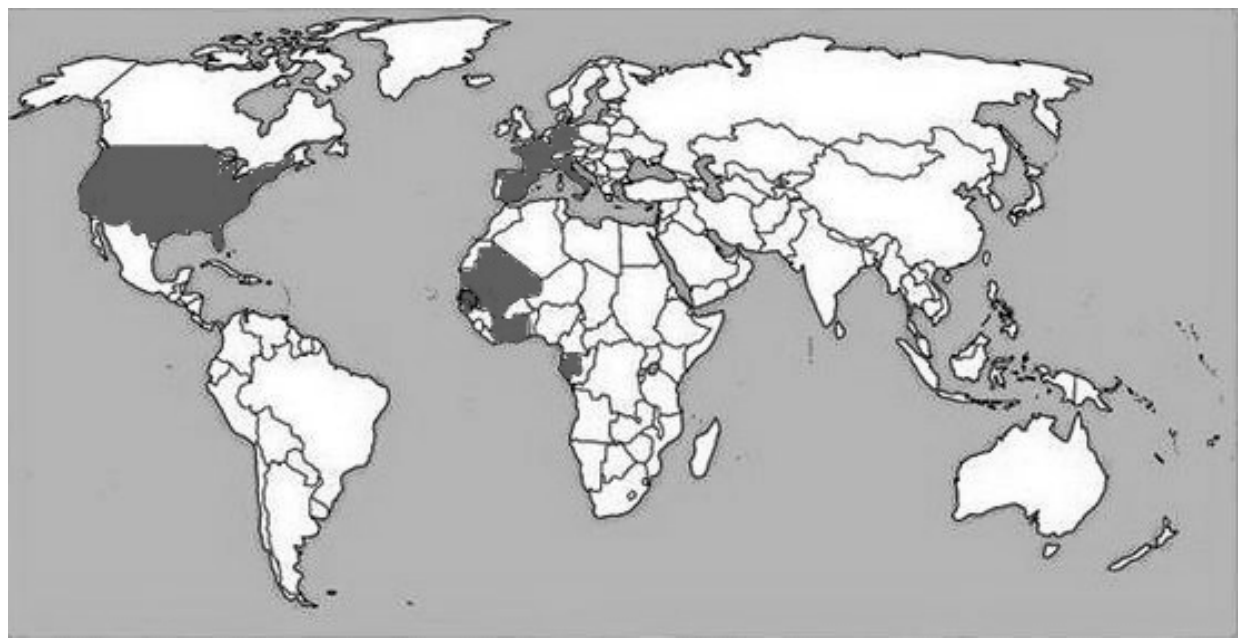

Figure 6.2: Countries of emigration for Senegalese.

Table 6.4: Senegalese legally resident in selected EU member states in 2010 (source: Eurostat). ${ }^{81}$

\begin{tabular}{ll}
\hline EU member state & No. of Senegalese migrants \\
\hline Italy & 72,618 \\
Spain & 60,895 \\
France & 48,178 \\
Germany & 2,383 \\
Portugal & 1,782 \\
Belgium & 1,414 \\
\hline
\end{tabular}

The Senegalese government views both immigration and emigration generally positively. In fact, in a 2003 study of 22 Poverty Reduction Strategy Papers by African countries, the paper by Senegal was one of only six to draw positive conclusions about

81 http://epp.eurostat.ec.europa.eu/portal/page/portal/population/data/database (retrieved 11 January 2012). Data for France is from 2005 (most recent available). Data based on citizenship is used. 
the impact of migration on poverty reduction (Bakewell, 2008, p.1348). The government is concerned about the departure of young Senegalese (Chou and Gibert, 2012, p.416), but simultaneously supports legal emigration as an important factor for development (Ndione and Broekhuis, 2006, p.9). Senegalese immigration policy is not particularly restrictive regarding residence permits for immigrants (Gerdes, 2007, p.3; Ndione and Broekhuis, 2006, p.9). Illegal immigrants, if discovered in Senegal, are not automatically deported (Interview 46). In September 2010, a meeting was held between the various ministries involved in migration matters, in order to establish an integrated national migration policy. The resulting document shows that illegal migration is not a priority; rather, the focus is on improving data on migration flows, promoting the contribution of the diaspora to the development of the country, protecting the rights of the diaspora, and reinforcing the capacities of the actors involved in migration (Interview 44). Remittances from emigrants are an important part of Senegal's economy (Agence Française de Développement, n.d.). IOM estimates that remittances made up $12 \%$ of Senegalese GDP in 2007 (IOM, 2009a), whilst the World Bank puts the figure at 9\% of GNI for 2010 (World Bank, 2011). Senegalese living abroad have been active, for instance, in financing infrastructure development in Senegal and establishing joint ventures with Senegalese associations (Panizzon, 2008, p.5). International migration, however, has only relatively recently become a topic of importance for the government: the government's 2002 policy on population focussed largely on internal migration (Senegalese Ministry of Economics and Finance, 2002). Senegal has played an active role in the Euro-African Partnership for Migration and Development (the Rabat process), for instance by organising preparatory meetings in Dakar in advance of the meeting in Rabat in $2006^{82}$ and hosting the 2011 meeting of the process in Dakar.

Interviewees in the Senegalese government indicate a significant contradiction between Senegalese and European migration policies. Senegalese government officials are critical of the EU's policies on both legal and illegal migration. Selective immigration policies of EU countries (which officials see reflected in the Mobility Partnership) cause developing countries like Senegal to lose talented and qualified citizens, whilst not making adequate provision for return or circular migration (Interview 45; 46; Dia, 2009 , p.24). The EU common approach to migration is seen as nothing more than a cynical approach to extend border control further away from the EU by giving competences to third countries (Interview 46). This common approach is seen as ineffective: interviewees expressed the opinion that, if the EU wishes to prevent migration, a more effective strategy would be to create more wealth in African countries. If the aim is to prevent illegal migration in particular, the EU should create more channels for legal migration (Interview 48). However, Senegal is open to cooperation with the EU on migration issues, as long as this reflects Senegalese policy objectives such as legal migration opportunities for its citizens (Interview 46; van Criekinge, 2010, p.9).

\footnotetext{
${ }^{82}$ Text of the Rabat declaration retrieved 12 January 2012 from http://www.realinstitutoelcano.org/ materiales/docs/RabatDeclaration_ActionPlan.pdf
} 


\subsubsection{Administrative capacity of the target state}

Low administrative capacity, in terms of staffing levels and the absence of internal coordination structures, will increase the costs to a third country of cooperating with the EU (see chapter 2). Both Senegal and Cape Verde have limited administrative capacity on migration matters, but this section argues that this administrative capacity did not affect the domestic preference formation on the Mobility Partnerships. Low staffing levels within the Cape Verdean administration, and the lack of experience of staff, was noted during the negotiation of the Mobility Partnership. The Cape Verdean government also lacks a coordination structure to deal with migration issues. However, this limited administrative capacity was not a factor in the government's preference formation on the partnership. The Senegalese government also lacks a coordination structure to deal with migration issues, but this alone cannot account for the Senegalese government's preferences on the Mobility Partnership: despite such limited administrative capacity, the government has succeeded in negotiating bilateral migration agreements with European countries.

Within the Cape Verdean administration, responsibility for migration is fragmented between several ministries, and there is a lack of reliable statistical data on migration and remittance flows (Carling, 2008). Figure 6.3 shows how responsibility for migration policy is allocated (IOM, 2009c). For the Mobility Partnership with the EU, the Cape Verdean ambassador in Brussels was responsible for the negotiations (Interview 56), while talks were conducted on behalf of the Commission by DG JLS, with the involvement of others, such as Development, Relex, and Aidco (Interview 13). The Cape Verdean ambassador faced two main problems during the negotiations: firstly, the Cape Verdean delegation had more limited resources, both in terms of experience and size of the team, than the delegation of the Commission (Interview 66). For instance, the ambassador had not realised that the negotiations on the Mobility Partnership would overlap with matters relating to mode four of the General Agreement on Trade in Services (GATS), ${ }^{83}$ as the Cape Verdean government does not have an expert on WTO matters (Interview 56). This lack of expertise affected the role that Cape Verde was able to play in the negotiations: "When you [negotiate an agreement] you might be pleased that you've done something good for your country, but you have the frustration of knowing that if you had specialists in other sectors you might have done better" (Interview 56). Kruse (2006, p.125) notes that the Albanian government had a similar problem when negotiating a readmission agreement with the EU: "Representatives of the Albanian government described their EU counterparts in negotiations as very skilful and specialised because they have a lot of negotiation experience. At the same time, they reported about their own weaknesses due to a lack of familiarity with issues concerning illegal migration".

\footnotetext{
${ }^{83}$ Mode four of the General Agreement on Trade in Services concerns the temporary movement of natural persons. This mode refers to "the supply of a service . . . by a service supplier of one Member, through presence of natural persons of a Member in the territory of another Member" (Ward, 2011).
} 
The second problem was one of coordination between the various Cape Verdean ministries. For the purposes of the negotiations of the Mobility Partnership, the Cape Verdean foreign minister at the time created a working group incorporating also representatives from the ministries of labour and interior (Interview 54). However, the ambassador in Brussels was getting only limited input from the ministry of interior and no input from the ministry of labour. These limitations of administrative capacity did not, however, affect the domestic preference formation, which was in favour of signing the Mobility Partnership.

Some EU officials speculate that the lack of response by the Senegalese authorities to the offer of a Mobility Partnership might signal a problem with coordination between the Senegalese ministries involved in migration matters (Interview 13; 23). Certainly the Commission struggled to identify the appropriate interlocutor for the Mobility Partnership negotiations (Chou and Gibert, 2012, p.416). Senegalese interviewees acknowledge that competence for migration is "sprinkled" across several ministries and that these ministries very much work separately as no independent coordination structure exists (Interview 36; 41). Figure 6.4 shows how competence for the various aspects of migration policy is allocated within the Senegalese government (Interview 40; 45; 47; Ministry of Senegalese Abroad, n.d. a; Senegalese Ministry of Economics and Finance, 2002; IOM, 2009a; CIGEM, 2009). There are, however, occasional deviations from this structure. The Ministry of Foreign Affairs is responsible for bilateral migration agreements, but some agreements may be dealt with by technical ministries if there is a need for the dossier to move quickly. The Ministry of Senegalese Abroad is responsible for assisting the diaspora with their investment projects in Senegal, but PLASEPRI (a joint Italian-Senegalese project to encourage the Senegalese diaspora in Italy to invest in Senegal), is managed for Senegal by the Ministry of Microfinance. To compound matters, the office of the President sometimes takes control of migration issues, for instance of the projects developed under the accord de gestion concertée des flux migratoires with France (Interview 40). Ministries frequently change name, and therefore remit: the Ministry of Senegalese Abroad started as an independent ministry, was then incorporated into the Ministry of Foreign Affairs, before being made independent again in 2003; and the Ministry of Microfinance used to be part of the Ministry of Family (Diatta and Mbow, 1999, p.249; Interview 42). Interviewees particularly stress that there is rivalry between the ministries of Foreign Affairs and Interior (Interview 16; 20; 44). The Ministry of Foreign Affairs guards its competence in external relations jealously; however the Ministry of Interior was tasked with conducting the negotiations with France on the accord de gestion concertée des flux migratoires (Interview 48). The accord was therefore signed by the Ministry of Interior, although the steering committee overseeing the implementation of the accord has been chaired by the secretary-general of the Ministry of Foreign Affairs (Interview 37). 


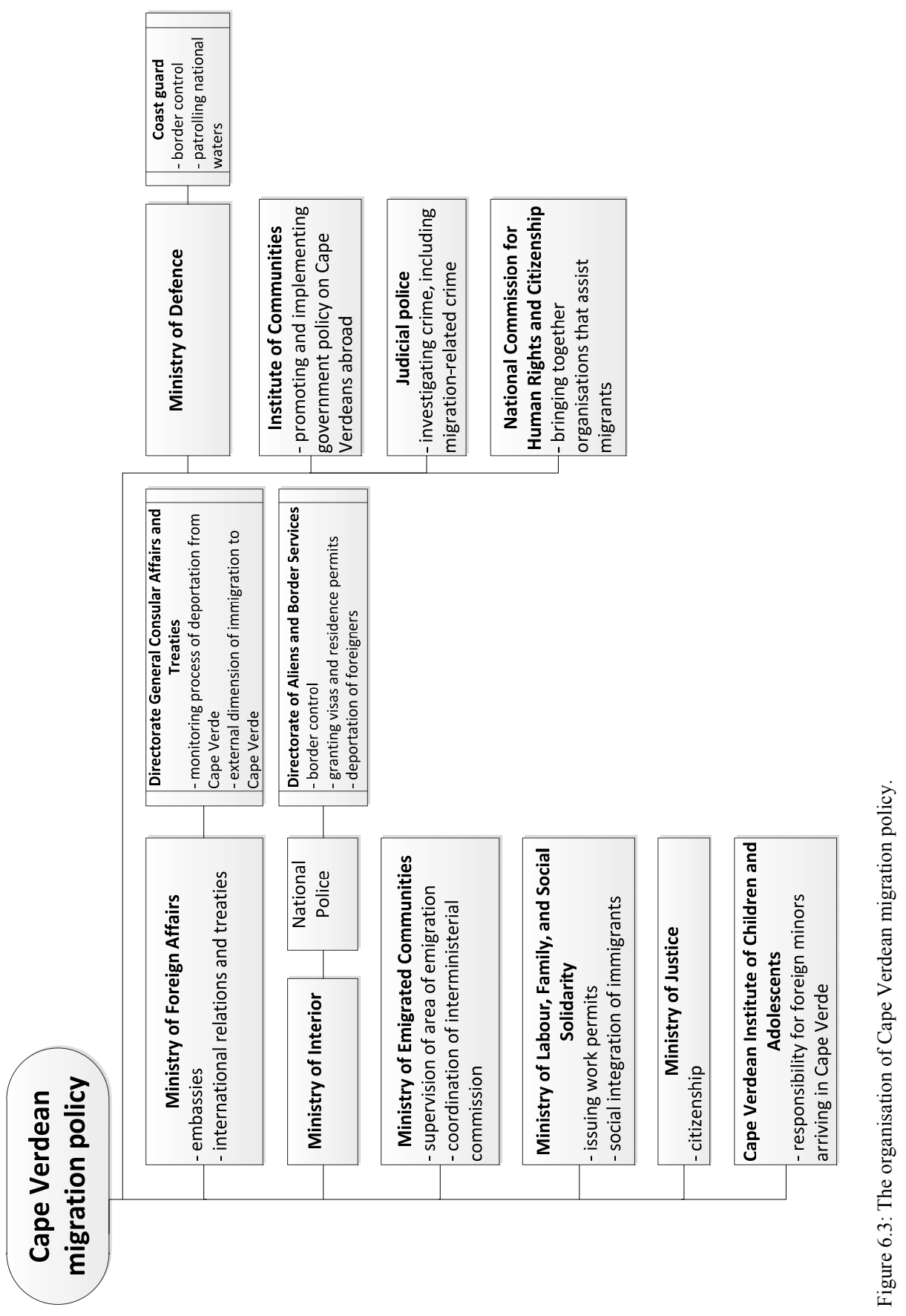




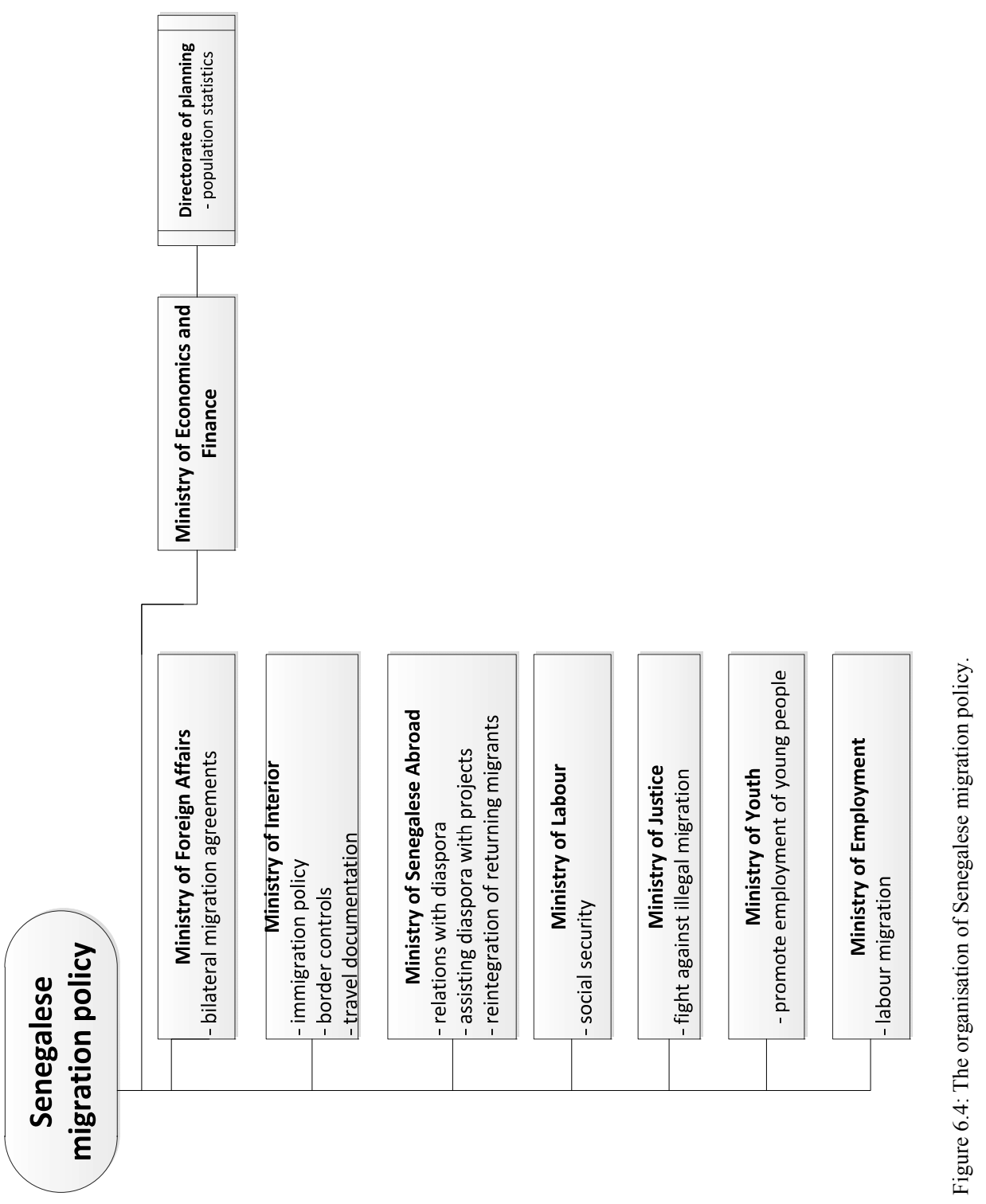


On the Mobility Partnership, interviewees in the Ministry of Foreign Affairs imply that coordination problems may have played a role in the domestic preference formation: the Ministry of Foreign Affairs forwarded the offer of a Mobility Partnership to other ministries with a request for proposals for projects. No reply was received (Interview 42). Despite this lack of coordination among the Senegalese ministries concerning migration, interviewees in the Commission acknowledge that the stalled negotiations on the Mobility Partnership cannot be explained only by this limited administrative capacity (Interview $17 ; 20$ ). There may be no overall vision of or strategy on migration policy within the Senegalese government (Dia, 2009, p.14), but action on migration issues is still possible. Senegal has signed migration agreements with France, Spain and Italy, has implemented five programmes to promote the employment of women and young people, and has implemented three programmes to utilise the skills of Senegalese emigrants for the country's development (IOM, 2009a, pp.28-29; cf. Panizzon, 2008). In 2007, the Senegalese government and the EU signed a joint declaration stating their intention to cooperate on the management of migratory flows (Agence de Presse Sénégalaise, 2007). The limited administrative capacity of the Senegalese government has not stood in the way of any of these agreements and therefore cannot on its own explain the failure of the Mobility Partnership. Chou and Gibert (2012, p.417) reach the same conclusion: they argue that President Wade's decision not to appoint one of his special advisors to deal with the Mobility Partnership "can be read as a covert strategy to stall the negotiations indefinitely".

\subsubsection{Domestic costs of adopting the EU policy}

For both Senegal and Cape Verde, the main cost involved with signing a Mobility Partnership was the prospect of a readmission agreement with the EU. The Cape Verdean government hesitated for a long time regarding this agreement, but ultimately decided that the costs would be outweighed by the benefits of the visa facilitation agreement on offer. The Senegalese government perceived further problems with the structure of the Mobility Partnership which meant that the benefits being offered could not outweigh the substantial cost associated with a readmission agreement.

The preamble of the Mobility Partnership with Cape Verde is the only Mobility Partnership not to include a commitment of the signatories to conclude and implement visa facilitation and readmission agreements (see chapter 4). However, the annex of proposed projects includes a proposal by the Commission to request a negotiating mandate from the Council for a readmission agreement (Council, 2008c, p.13). Indeed, it has been clear ever since the Commission proposed the concept of Mobility Partnerships that this instrument would only be offered to countries willing to cooperate on illegal migration, including by signing a readmission agreement covering third country nationals (Commission, 2007a, p.4). A readmission agreement has therefore been a prospect in the Mobility Partnership with Cape Verde since the beginning, and in February 2009 the Council authorised the Commission to open negotiations with Cape Verde (Council, 2009d). However, this comes with significant costs for the Cape Verdean government, 
and the more the Commission and member states insisted on this point, the more the government became concerned that "the readmission issue is at the heart of the Mobility Partnership; everything else is just window dressing" (Interview 66). Cape Verde is still a relatively poor country and is starting to have its own problems with immigration; the government therefore does not want to accept responsibility for the return of thirdcountry nationals (Interview 54), which is a requirement of an EU readmission agreement.

Such a readmission agreement is therefore clearly costly for the Cape Verdean government. At the outset, the government accepted this cost because it perceived the Mobility Partnership to be about more than only the readmission agreement. Indeed, the government sees many advantages of the partnership: access to resources to improve border management; the opportunity to work with the Cape Verdean diaspora; and a permanent dialogue with the EU on migration issues (Interview 49; 59). Significantly, the government sees the Mobility Partnership as providing opportunities for mobility, which is important given that European immigration policies have become increasingly restrictive over the past years (Interview 58; Ákesson, 2008). There is strong mobility from Cape Verde to the EU, with the government estimating that $45 \%$ of the Cape Verdean diaspora live in the EU (Interview 49).

The idea of the Mobility Partnership instrument is that countries that cooperate with the EU on illegal migration will be offered "better access to EU territory for their citizens" in return (Commission, 2007a, p.3). This might include facilitated access to the EU labour market and improvement of the procedures for issuing short-stay visas, including the possibility of a visa facilitation agreement (p.8). In Cape Verde, the EU visa procedure is seen as overly complicated (Interview 54; cf. Trauner and Kruse, 2008b, p.6). Achieving visa-free travel for all its citizens to the EU is therefore a stated goal of the Cape Verdean government (Interview 7; 51). The government believes that a visa liberalisation agreement would therefore be a fair deal in return for signing the readmission agreement (Interview 66). In the first draft of the text of the Mobility Partnership, visa liberalisation was mentioned. However, by the time of the second draft, the EU had replaced this offer of visa liberalisation with one of visa facilitation (Interview 49), which is in line with the Commission proposal on the Mobility Partnership instrument. The Cape Verdean government accepts that this indicates that visa liberalisation is simply not possible at this time, and this is confirmed by an official of the EU delegation (Interview 52).

In February 2009, the Council authorised the Commission to open negotiations with Cape Verde on a visa facilitation agreement (Council, 2009e). The Cape Verdean government is happy to accept a visa facilitation agreement as a step-by-step approach towards visa liberalisation, because, as one interviewee put it, if the government cannot solve the EU visa problem for all Cape Verdean citizens, it can at least solve it for some citizens (Interview 65). The Cape Verdean government displays understanding of how the EU functions. Officials understand that, on issues such as visa liberalisation, it is not only 'Brussels' taking the decision, but rather the member states (Interview 56). They are also aware that immigration policy remains a member state competence (Interview 
59), but equally that EU governance is in flux and the situation may change as a result of the Lisbon treaty (Interview 51).

There has been considerable anger within the government, and particularly within the Ministry of Foreign Affairs, about the pressure from the EU to sign the readmission agreement. In order to secure the conclusion of the readmission agreement, the Commission and member states have from the beginning made it clear that this is a precondition for a visa facilitation agreement to be signed. This bundling of the agreements, combined with the Cape Verdean government's desire to ease the visa process for its citizens travelling to the EU, led to the agreements being signed together on 24 April 2012 (Commission, 2012d; 2012e). The Cape Verdean government was not able to prevent the inclusion of third country nationals and stateless persons in the readmission agreement. However, a joint declaration is attached to the agreement stating that "the parties will endeavour to return any third-country national . . . to his or her country of origin" (Commission, 2012d, p.33). Such a declaration is not found in the readmission agreements signed with the other Mobility Partnership countries. ${ }^{84}$

The 2011 Commission communication on the Global Approach indicates that, where a readmission agreement and visa facilitation agreement are in place and are properly implemented, the EU could consider taking steps towards visa liberalisation for individual partner countries, "taking into account the overall relationship with the partner country concerned" (Commission, 2011b, p.11). Given the existence of both a Mobility Partnership and a Special Partnership, Cape Verde might be a test case of this commitment.

The Senegalese government is wary of making international agreements on readmission. Emigration can be a 'safety valve' for the many unemployed Senegalese (Fall et al., 2010, p.10): the unemployment rate was estimated to be $48 \%$ in 2007 (CIA World Factbook, 2011b). Government officials view the return of illegal migrants who have 'failed' in their migration attempts as a security risk (Dia, 2009, p.35). A readmission agreement would therefore have a "negative impact on the relationship between the state and society" (Cassarino, 2010, p.23). Given also the financial contribution made by the diaspora through remittances, it is clear that there would be significant costs associated with the acceptance of a readmission agreement.

Readmission has already proven to be an obstacle in bilateral agreements and almost caused the failure of the negotiations on the accord de gestion concertée des flux migratoires between Senegal and France (Assemblée Nationale, 2009, p.29). The agreement is one of the only bilateral agreements signed between France and a third country that does not contain a clause on the readmission of third country nationals, presumably due to Senegalese opposition and leverage as an important country of origin of immigrants to the EU (Panizzon, 2012, p.122). The final text of the agreement contains a readmission clause, which states: “La France et le Sénégal s'engagent à accepter

\footnotetext{
${ }^{84}$ The declaration is not included in the readmission agreements signed with Moldova and Georgia. As of July 20213, the readmission agreement with Armenia has been initialled but the text is not yet publicly available. The readmission agreement with Morocco has not yet been concluded.
} 
... le retour sur leur territoire de leurs ressortissants se trouvant en situation irrégulière sur le territoire de l'autre Partie". ${ }^{85}$ The article goes on to establish which documents are acceptable as proof of nationality in readmission cases. This is the key to readmission agreements, because "states do not usually outright reject readmitting their nationals, but they can obstruct or delay the process by refusing to issue documents or identifying their nationals" (Klavert and van Seters, 2012, p.2). French officials complain that, since the signature of the agreement, the Senegalese embassy in Paris has actually become less willing to provide illegal Senegalese migrants with the travel documents needed for their repatriation, despite the inclusion of the readmission clause (Interview 37). Senegalese officials respond that the government does not see the clause as an obligation to readmit, but rather a commitment to discuss the issue of readmission at a later stage (Interview 41). ${ }^{86}$ Senegal also refused to sign a bilateral readmission agreement covering third country nationals proposed by Spain: "The agreement would be accompanied by a substantial offer of cooperation aid (15m euros over five years) and moreover greater open legal migration channels for Senegalese ... Yet in the estimation of the Senegalese, the migration benefits for nationals would not offset the significant return costs for non-nationals" (Roig and Huddleston, 2007, p.378).

In the case of the Mobility Partnerships, the Senegalese government considered it unlikely that the nature of the partnership would provide the benefits necessary to compensate for the costs of the readmission agreement (Interview 42; 48). The financial benefits for Senegal of signing a Mobility Partnership were unclear - Commission and member state officials had not discussed this issue in depth, and no firm conclusions had been reached in this regard (Chou and Gibert, 2012, p.418). Participation in the Mobility Partnership would be voluntary for the EU member states. This would mean that not all member states would have to contribute to or finance the Mobility Partnership, but any member state could still hold Senegal to a readmission agreement signed in the framework of the partnership because such agreements are EU-wide (Interview 46). ${ }^{87}$ The Senegalese government was also aware that signing a Mobility Partnership would not automatically result in measures for increased mobility, such as a visa facilitation agreement (Interview 1). Of the 18 readmission agreements in force, signed, or

\footnotetext{
85 Décret no. 2009-1073 du 26 août 2009 portant publication de l'accord entre le Gouvernement de la République française et le Gouvernement de la République du Sénégal relatif à la gestion concertée des flux migratoires (ensemble trois annexes et une déclaration), signé à Dakar le 23 septembre 2006, et avenant à cet accord (ensemble deux annexes), signé à Dakar le 25 février 2008. Retrieved 16 January 2012 from http://www.journal-officiel.gouv.fr/

${ }^{86}$ This is similar to article 13(5) of the Cotonou Agreement, which states that "at the request of a Party, negotiations shall be initiated with ACP States aiming at concluding . . . bilateral agreements governing specific obligations for the readmission and return of their nationals. These agreements shall also cover, if deemed necessary by any of the Parties arrangements for the readmission of third country nationals and stateless persons". However, the Commission views this as a legal obligation to conclude readmission agreements, and therefore considers it unnecessary to offer further financial incentives to ACP countries (Commission, 2003, p.14).

${ }^{87}$ EU readmission agreements do not apply to Denmark due to its opt-out from the area of freedom, security and justice. Readmission agreements only apply to the UK and Ireland if they decide to opt in to them (Coleman, 2009).
} 
being negotiated as of February 2011, only 10 were coupled with a visa facilitation agreement (Commission, 2011i). Visa facilitation agreements are an important incentive for the negotiation of readmission agreements (Council, 2011f), but "the existence of a readmission agreement, or the willingness of a third-country to negotiate one, does not automatically nor routinely lead to the opening of negotiations on a visa facilitation agreement" (Council, 2005b, p.3). Cape Verde is the only African country to date to be offered a visa facilitation agreement; agreements have instead been negotiated with countries in eastern and south-eastern Europe, although the Commission suggested in 2011 to offer agreements to southern Mediterranean countries (Commission, 2011e).

\subsection{EU-third country interaction: size of the win-sets}

Section 6.5 accounted for the domestic preference formation on the Mobility Partnership in Cape Verde and Senegal. The Cape Verdean government judged that the expected benefits of the partnership would outweigh the expected costs, whereas the Senegalese government reached the opposite conclusion. Ultimately a partnership was signed with Cape Verde whilst negotiations with Senegal stalled and were then abandoned. This section explains the dynamics of the game between the EU and Cape Verde/Senegal by examining the size of the win-set for each actor. This can account for the outcome of the negotiations. The section shows that the EU's member states are very much present in this game, through the influence of their bilateral migration agreements, and through their control of the Commission's power to negotiate an agreement.

\subsubsection{Cost of no agreement for the $E U$}

Chapter 2 outlined that the cost of no agreement for the EU is assumed to be high. This is because both the Commission and Council have repeatedly outlined the importance of cooperation with third countries on migration issues. Senegal and Cape Verde were selected for Mobility Partnerships for very different reasons, but the cost of no agreement for the EU was still high in both cases: Cape Verde was one of the first two countries to be offered a Mobility Partnership, so failure of the negotiations would have been embarrassing for the EU; and Senegal was seen as the first real test for the Mobility Partnership concept.

Cape Verde was selected for a Mobility Partnership not so much because of its importance in terms of migration flows to the EU, but rather due to its image as an "easy" country with which to cooperate. Failure of one of the first two Mobility Partnerships to be negotiated would have been embarrassing, and so a 'safe' choice of partner country was made. There is an informal understanding between the Commission and the member states that there will be a "balance between east and south" in the GAM (Interview $5 ; 13 ; 20 ; 21 ; 22 ; 28 ; 32$ ), and there was therefore a need to find an African country with which the concept of Mobility Partnerships could be tested. Cape Verde was considered an ideal candidate because it has been willing to cooperate on security is- 
sues, which are normally seen as being sensitive and therefore a difficult area for cooperation between the EU and third countries (Interview 12). The 'migration pressure' from a country with only 500,000 inhabitants can also be considered limited (Interview 56).

In contrast, Commission officials were aware that Senegal would be the first real test for the concept of Mobility Partnerships because there is and has been significant migration from Senegal to the EU (Interview 1; Chou and Gibert, 2010; van Criekinge, 2010 , p.7). This implies that the cost of no agreement was high because this was seen as a true test of the policy instrument. Indeed, the failure of the partnership with Senegal led the Commission to conclude in its evaluation that "the pre-selection process should . . . benefit from a more strategic reflection and approach . . . and more clarity in relation to the objectives that the EU interested Member States and the Commission want to achieve" (Commission, 2009d, p.3).

The two countries were also selected in very different ways: Cape Verde played an active role in becoming a candidate country for a pilot Mobility Partnership, by requesting member states to propose Cape Verde to the Commission (Interview 65). ${ }^{88}$ Among the member states, Spain and Portugal in particular supported the idea, and were active in suggesting Cape Verde as a partner country for a Mobility Partnership in informal discussions between the Commission and member states (Interview 52). The process of selecting Cape Verde was therefore a reciprocal one between the Cape Verdean government on the one hand, and the member states and the Commission on the other. Senegal, in contrast, was approached by the EU (Interview 11) and therefore selected in a more one-sided way. Interviewees were divided over how Senegal was selected as a partner country. Some indicated that the Commission initiated the process, seeing advantages to a Mobility Partnership with Senegal (Interview 17). Others assign importance to member states' preferences (Interview 13), with Spain particularly favouring a Mobility Partnership with Senegal (Interview 16; 20). Regardless of whether the member states or the Commission initiated the process leading to Senegal being selected, Council conclusions were adopted in June 2008 authorising the Commission to open negotiations with Senegal before the Senegalese authorities were consulted (Interview 17). The risk of 'no agreement' being the outcome of the negotiations was therefore much more present than for the 'easier' case of Cape Verde.

\subsubsection{Cost of no agreement for the third countries}

The Senegalese and Cape Verdean governments perceived the cost of no agreement on the Mobility Partnerships very differently. For the Cape Verdean government, achieving closer relations with the EU is a cornerstone of its foreign policy (Interview 7). Membership of ECOWAS is not seen as satisfactory for the country's political ambitions due to the corruption and unbalanced development in West Africa, and the fact that Cape Verde's main trading partners are in Europe (Interview 56). In 2011, the three most important countries for Cape Verdean exports were Spain, Portugal and Morocco, and

\footnotetext{
${ }^{88}$ Although Cape Verde did not submit a formal written proposal to the Commission until after the Commission and member states had agreed to select Cape Verde for a Mobility Partnership (Commission, 2009, p.3).
} 
the three most important countries for imports to Cape Verde were Portugal, the Netherlands and Spain (CIA World Factbook, 2011a). The 2008-2013 country strategy paper also notes Cape Verde's lack of involvement in ECOWAS - for instance, Cape Verde is not much involved in the decision-making process of ECOWAS and does not contribute to its financial mechanisms (Cape Verde-European Community, 2008). Cape Verde is one of the most stable democracies in Africa (CIA World Factbook, 2011a), and the government therefore believes that cooperation with Cape Verde can be interesting for the EU as an example that democracy in Africa can be successful (Interview 56; Cape Verde-European Community, 2008, p.6). The EU delegation in Praia agrees, noting that Cape Verde lacks many of the problems (such as corruption) that other ACP countries grapple with (Interview 52).

The Mobility Partnership with Cape Verde should also be understood within the framework of the Special Partnership between the EU and Cape Verde (Interview 20). The Special Partnership has important symbolic value for the Cape Verdean government because it provides for a permanent, structured dialogue with the EU, despite the fact that it does not incorporate a financial envelope (Interview 51; 56). The Cape Verdean government saw the Mobility Partnership as a chance to further develop the Special Partnership (Interview 56). Indeed, since its signature the Mobility Partnership has frequently been referred to as "the most dynamic aspect of the Special Partnership" (Interview 13; 38; 61). A starting point for the Special Partnership was the pillar on security. The Commission communication states that this pillar covers cooperation on

transnational organized crime (cooperation on counter-terrorism, human trafficking and the smuggling of immigrants, illegal trafficking in drugs, arms, moneylaundering), whilst promoting respect for human rights; effective management of migration, including improving the contribution of the Cape Verdean diaspora to the development of the country (remittances) and action to tackle illegal migration; maritime safety (Commission, 2007b, p.5).

These issues are also highlighted in the national indicative programme for Cape Verde, where the "improved management of migratory flows" is one objective to be achieved in support of national security (Cape Verde-European Community, 2008, p.39). It is particularly the issue of drugs that concerns the Cape Verdean government. In 2005, Cape Verde requested the assistance of the United Nations Office on Drugs and Crime, and the CAVE INTECRIN programme (Cape Verde Integrated Crime and Narcotic Programme on strengthening the rule of law) was launched, with funds contributed by the Commission, Italy, Luxembourg and the Netherlands (UNODC, 2005). The Cape Verdean government sees that the EU has an interest in cooperating with Cape Verde on drug trafficking, as the drugs that pass through Cape Verde are headed for the European market (Interview 49; 51; 56). For the government, the issue of drugs is also related to migration - those in the diaspora who have criminal records have generally been involved with drugs in some way (Interview 56). Sometimes these people are then deported back to Cape Verde, creating further problems with reintegration (Interview 55). 
Given the immense symbolic value for the Cape Verdean government of the relationship with the EU, the cost of no agreement on the Mobility Partnership was very high. For the Senegalese government, on the other hand, the cost of no agreement was low due to the existence of bilateral alternatives. The existence of bilateral alternatives is not specific to Senegal: Cape Verde also had bilateral cooperation programmes on migration with some EU countries. However, the two countries evaluated these bilateral agreements differently: the Cape Verdean government saw benefits to the Mobility Partnership, and these benefits were not negatively affected by the existence of bilateral cooperation. The Senegalese government, on the other hand, is aware of the fact that EU migration policy is limited by the structure of decision-making - member states must collectively agree on measures to be taken (Interview 48). Given such "negative perceptions of the EU's capabilities in migration management", the government prefers to deal bilaterally with the member states whose agendas are often much more appropriate for Senegal's own preferences (van Criekinge, 2010, p.12; Chou and Gibert, 2012). The availability of such bilateral alternatives makes the cost of no agreement on EU proposals low. Indeed, due to their competence over labour migration policy, member states can make offers to third countries which the EU is not capable of competing with. In its bilateral migration agreements, for instance, France offers students of the third countries concerned a 6- or 9-month permit to remain in France for a first professional experience after they complete their studies (European Migration Network, 2010f, p.29). Such bilateral initiatives are weakening the Commission's bargaining position with third countries. The competition between member states to offer the most attractive agreement has built the confidence of the Senegalese government to make demands of bilateral partners and say 'no' to the EU when it feels the agreement being offered is not satisfactory, such as with the Mobility Partnership (Panizzon, 2008; Interview 1; 28). The most important bilateral partners in terms of migration are France, Spain and Italy. These are also the member states implementing migration projects in Senegal using funding from the EU's Thematic Programme (see table 6.1).

France and Senegal have a long history of cooperating on migration, and France has also implemented several programmes in Senegal with EU co-financing. One example is the partenariat pour la gestion des migrations professionnelles (in cooperation with the Belgian and Italian authorities and IOM) which aims to promote circular labour migration and capacity-building in Benin, Cameroon, Mali and Senegal (Commission, 2010e). At the bilateral level, an agreement entered into force already in 1980 offering professional training to Senegalese living in France, in preparation for their return to Senegal. A co-development convention was signed between France and Senegal in 2000 , with the aim of directing the diaspora's resources towards the development of Senegal (Panizzon, 2008). In 2006, Senegal signed the first agreement on the joint management of migratory flows with France (accord de gestion concertée des flux migratoires). The agreement covers cooperation on visas, residence permits, border control, return of illegal migrants, and migration and development. The central programme being implemented under the agreement is PAISD (Programme d'Appui aux Initiatives de Solidarité pour le Développement), which aims to help Senegalese living 
in France to contribute to the development of Senegal through investments, projects, or expertise (Interview 37; Ministry of Senegalese Abroad, n.d. b). Significantly, the agreement with France was signed in two rounds, the first being concluded in 2006 and the second in 2008. The reason for the renegotiation was dissatisfaction on the Senegalese side with the first agreement, which did not offer more in terms of migration opportunities than the existing French immigration law. French visas target highly-skilled migrants, and the Senegalese government was therefore concerned about a possible brain drain (Panizzon, 2008, p.2). The second agreement signed in 2008 extends the clause on return of illegal migrants, but in return lists over 100 professions which are opened up to Senegalese. This means that a French employer in one of these professions may hire a Senegalese without having to prove that no other suitable candidate can be found in the French or European labour market (Interview 37; 43). Professions covered by the agreement include tourism, security, agriculture, transport, ICT, and health. ${ }^{89}$ Such legal migration opportunities are precisely what the Senegalese government seeks in agreements with Europe (Gerdes, 2007, p.4; Interview 35) and the government is therefore satisfied with the agreement, describing it as a "good deal" (Interview 41; 48).

Spain has seen an enormous increase in the number of West African migrants arriving on its territory since 2004-2005, and has therefore launched a major policy towards the region, including the opening of new embassies (Interview 39). In its 2009-2012 Africa Plan, the Spanish government lists as one of the six main objectives the consolidation of the partnership with Africa on migration (Spanish Ministry of Foreign Affairs, 2009). In Senegal, Spain has "signed a Basic Development Cooperation Agreement . . . cancelled $€ 65.5$ million from Senegal's external debt, and started preparations for establishing a Fund for Concession of Microcredit" (Fall et al., 2010, p.15). In 2006, in response to the rising number of West African migrants making the journey to Europe, Spain and Senegal signed a memorandum of understanding. The agreement is a transparent trade-off between labour migration and illegal migration: Senegal received work permits for 4,000 Senegalese to work temporarily in Spain and funding for job training in Senegal, and in return had to accept Frontex patrols in its territorial waters and the return of 4,000 illegal Senegalese migrants by Spain (Panizzon, 2008). In 2007, Spain and Senegal signed a more comprehensive agreement on migration matters which included provision for 2700 Senegalese workers (in agriculture and fisheries) to go to Spain (ibid.). Like France, Spain has implemented projects with EU financing, such as the Seahorse project on border controls and interregional cooperation between Cape Verde, Gambia, Guinea-Bissau, Mauritania, Morocco and Senegal (Commission, 2010e).

Panizzon (2008, p.34) argues that a central difference between the French and Spanish approaches to bilateral cooperation on migration with Senegal is that Spain has

\footnotetext{
${ }^{89}$ Décret no. 2009-1073 du 26 août 2009 portant publication de l'accord entre le Gouvernement de la République française et le Gouvernement de la République du Sénégal relatif à la gestion concertée des flux migratoires (ensemble trois annexes et une déclaration), signé à Dakar le 23 septembre 2006, et avenant à cet accord (ensemble deux annexes), signé à Dakar le 25 février 2008. Retrieved 16 January 2012 from http://www.journal-officiel.gouv.fr/
} 
been "quicker than France in opening its labour market on a quota-basis to Senegalese migrant workers and more pragmatic in the sense that it will offer pre-departure orientation, linguistic and pre-employment training to the low-skilled or even unemployed workers in Senegal". This willingness to open channels for labour migration explains why the cooperation is positively viewed by the Senegalese government - interviewees feel that this is an effective way to respond to the problem of illegal migration, as opposed to the French immigration policy which is selective and favours the highly-skilled (Interview 45). The 2008 renegotiation of the French agreement with Senegal (which facilitated access to the French labour market for around 100 professions) was a response by France to the Spanish cooperation with Senegal (Panizzon, 2008, p.2). This demonstrates that the competition between EU member states strengthens the Senegalese negotiating position on migration matters: the possibility for cooperation with several different bilateral partners reduces the cost of no agreement of any single instance of cooperation. Senegal can also benefit from different types of funding because the partners may be duplicating their efforts (Interview 23). This seems to be the case with the general observatory on migratory flows created under the French-Senegalese migration agreement, and the observatory on emigration envisaged under Spain's framework agreement with West African countries (Panizzon, 2008, p.13).

After France introduced a visa requirement for Senegalese citizens in 1985, Italy became the most important country of destination for Senegalese migrants (Gerdes, 2007, p.3). Senegal is the main recipient of Italian development aid in West Africa, and Italy has also carried out projects with co-financing from the EU. One example is the COOPI project which ran in the period 2004-2006 and aimed to support developmentrelated initiatives by the Senegalese diaspora (Fall et al., 2010, p.16). The project MIDA (Migration for Development in Africa) is the result of cooperation between the Italian government and IOM. MIDA aims to improve knowledge transfer from the diaspora in order to stimulate development (Ndione and Broekhuis, 2006, p.22). Senegal has also benefited from an annual quota of work permits for Italy. In 2008, this was fixed at 1,000, although the decision is taken unilaterally by Italy (Dia, 2009, p.29).

It is important to note that Cape Verde, like Senegal, also cooperates bilaterally with EU member states on migration issues, mainly with Portugal, Spain and France. However, the symbolic importance of the relationship with the EU meant that the cost of no agreement for the Cape Verdean government on the Mobility Partnership was not reduced by the existence of these bilateral alternatives for cooperation. Spain has helped to patrol Cape Verdean waters (Carling, 2008, p.11). Labour migration agreements have been concluded with both Spain and France. However, despite the fact that both agreements are signed and ratified by both parties, no Cape Verdeans have yet migrated under these schemes due to the economic crisis in Europe (Interview 49; 62). A bilateral labour migration agreement with Portugal has been in place since 1997, allowing Cape Verdeans to work in Portugal for up to three years, subject to having an employment contract. However, this scheme has not been much used, partly due to the difficulty of finding employment contracts and partly due to a lack of information about the scheme (Carling, 2002, p.28). The labour migration scheme with France falls under the agree- 
ment on the joint management of migratory flows (accord de gestion concertée des flux migratoires) signed between France and Cape Verde. This agreement incorporates facilitated access to the French labour market for 40 selected professions; readmission and police cooperation; reinsertion of migrants returning to Cape Verde; and codevelopment with the diaspora in France (Interview 35).

\subsubsection{Ratification procedure within the EU}

Chapter 4 demonstrated that the number of institutional veto-players within the EU on the issue of Mobility Partnerships is small. Due to the fact that the partnerships are nonlegally binding political declarations, neither the European Parliament nor the other EU institutions play any role in the negotiations. The decision-making process is therefore the domain of the Commission and the member states (in the Council).

In terms of the EU-third country interaction, the control exercised by the member states over the Mobility Partnerships made the ratification procedure difficult: the Commission does not have the autonomy to make proposals or concessions to third countries, because ultimately member states shape the content of the Mobility Partnerships through the projects they propose. On the surface, the Commission appears to play the central role in the negotiations with third countries on Mobility Partnerships: after a partner country has been selected, in agreement with the member states, the Commission negotiates the partnership on behalf of the EU. However, member states are very much present in the interaction between the EU and third countries, because of their control of the content of the proposed partnership. The Commission is therefore constrained in the negotiation strategies it can adopt with third countries, in that it can only offer that which member states are prepared to give (Interview 1). It cannot yield to third countries' preferences for certain types of projects because it does not have the power to elicit offers from member states for specific projects. In the case of the partnership with Cape Verde, for instance, the government of Luxembourg simply transferred all their planned or ongoing bilateral projects to the 'umbrella' of the Mobility Partnership (Interview 53), despite the fact that Commission officials hoped for proposals for new projects that would not otherwise have been implemented (Interview 30). The Commission is also not in a position to use 'hard bargaining' strategies such as threats against the member states, because it relies on their support - it is the member states which must propose the projects that form the substance of the Mobility Partnerships, and they must agree (on a voluntary basis) to take part in a partnership. Without member state participation, there can be no Mobility Partnership. The concerns of the Cape Verdean government about the readmission agreement might easily have been assuaged by removing the clause relating to third country nationals; this is a move that the Commission advocates in general in relation to readmission agreements (Commission, 2011c, p.9), however the member states in the Council continue to insist that the third country national clause must stay (Council, 2011a, p.6). The Commission is therefore not in a position to make such a concession during the negotiation of a Mobility Partnership. However, it is also in no position to use 'hard bargaining' strategies against the third countries: as outlined in chapter 2, there are no sanctions for third countries 
choosing not to sign a Mobility Partnership. Making threats or criticising third countries would thus not contribute to the goal of agreeing a Mobility Partnership. In its interaction with third countries, then, the Commission finds itself in a Catch-22: it is not able to adopt a 'soft bargaining' strategy because member states control the Mobility Partnership instrument, but neither is it able to adopt a 'hard bargaining' strategy because there are no sanctions imposed on third countries for not signing a Mobility Partnership.

\subsubsection{Ratification procedure within the third countries}

For Cape Verde, the ratification procedure on the Mobility Partnerships was easy as the process was controlled by the Ministry of Foreign Affairs. This ministry could thus act autonomously. The ambassador in Brussels led the negotiations with the EU, and the minister of foreign affairs in Cape Verde created a working group which included representatives of the ministries of Labour and Interior. A secretariat within the Ministry of Foreign Affairs was set up to oversee the implementation of the partnership and coordinate the necessary input from other institutions such as the Institute of Communities or the Institute of Professional Training and Employment (Interview 51). The process in Cape Verde was therefore rather bureaucratic and apolitical, particularly given the consensus within the government on the desirability of closer relations with the EU (see sub-section 6.6.2). Cape Verdean citizens are very concerned with achieving the possibility to travel easily to Europe (especially to Portugal) to visit friends and relatives (Interview 51), but the repatriation of migrants from Europe to Cape Verde, as is possible under the readmission agreement, does not play a significant role in the public debate.

For Senegal, the story is rather different, and the government faced a potentially difficult ratification procedure for the Mobility Partnership to be agreed. The difficulties could stem from three sources: the Senegalese parliament, civil society, and public opinion. The Senegalese parliament has, in the past, demonstrated its opposition to readmission agreements. In 2003, Senegal and Switzerland signed a readmission agreement which was the first of its kind to include the return of third-country nationals. However, the Senegalese parliament refused to ratify the agreement (Ellermann, 2008, p.168; Panizzon, 2008, p.29; Di Bartolomeo et al., 2010, p.4). It is therefore unlikely that the Parliament would ratify an EU-wide readmission agreement, including provisions for returning third-country nationals, which would ultimately be a requirement for a Mobility Partnership. The Senegalese government also faces pressure from civil society groups. In 2008, CONGAD, a Senegalese grouping of NGOs, issued a statement in response to the adoption of the EU returns directive, condemning the human rights implications and underscoring the right of people to move freely in search of a better existence (CONGAD, 2008). Unions and NGOs in Senegal are also critical of the legal migration policies of European countries, which they see as a route to brain drain because these policies focus on elite and highly-skilled migration (Dia, 2009, p.24). While it is true that many Senegalese dream of migrating to Europe (e.g. Poeze, 2010), the public debate is also informed by the repatriation of migrants from Europe back to Sen- 
egal. ${ }^{90}$ Public opinion would therefore not look favourably on the government signing an agreement with the EU (Interview 1).

\subsection{Conclusion}

This chapter has accounted for the different preferences of the Cape Verdean and Senegalese governments on the Mobility Partnerships, and the outcome of their interaction with the EU. Neither Cape Verde nor Senegal were engaged in a process of dialogue and persuasion by the EU; instead, the offer of a Mobility Partnership was of a 'take it or leave it' character. Faced with this offer, the two governments reached very different conclusions about the value of a Mobility Partnership. The partnership resonated well with Cape Verdean migration policy goals, and the cost of a readmission agreement was ultimately deemed to be outweighed by the benefits being offered. In contrast, the proposed Mobility Partnership did not resonate with the Senegalese approach to migration policy, and a readmission agreement was considered too high a cost for the meagre benefits being offered. For Cape Verde, the cost of no agreement was high because closer relations with the EU are a cornerstone of Cape Verdean foreign policy. For Senegal, the cost of no agreement was low due to the availability of bilateral alternatives for migration cooperation. The ratification procedure in Cape Verde was easy, but the Senegalese government would have faced a potentially difficult ratification procedure due to public and parliamentary opposition to readmission agreements. The cost of no agreement for the EU was high in both cases. The ratification procedure in the EU was difficult due to the constraints placed on the Commission in terms of content of the Mobility Partnerships. Figure 6.5 illustrates why agreement was possible on the Mobility Partnership with Cape Verde, but not on the Mobility Partnership with Senegal. The win-sets of the EU and Cape Verde overlap, while the win-sets of the EU and Senegal do not overlap.

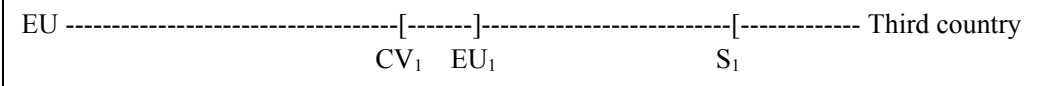

Figure 6.5: EU-third country interaction.

Tracing the process of the decision-making procedure on these Mobility Partnerships has shown that the policy conditionality model can account for the Cape Verdean and Senegalese governments' decisions on whether to cooperate with the EU. This approach highlights the difference in the cost-benefit calculations of the Cape Verdean and Senegalese governments as the reasons for their preferences on the Mobility Partnerships. In

\footnotetext{
${ }^{90}$ Coleman (2009, p.153) makes a similar argument in relation to Morocco's reluctance to sign a readmission agreement: "a repeated argument of the Moroccan authorities is that conclusion of a readmission agreement with the Community would be difficult to sell to the public". In return for signing a readmission agreement, Morocco has demanded compensation that would be clearly visible to Moroccan citizens, such as increased opportunities for labour migration to the EU.
} 
neither case was there evidence of the EU engaging these governments in a process of dialogue or persuasion. Both the Senegalese and Cape Verdean governments view EU readmission requirements as inappropriate, and yet they made different decisions on the Mobility Partnership. The social learning model cannot account for the different outcomes in the two cases. This chapter has also highlighted that the existence of bilateral relations may alter the cost of no agreement to a third country of a Mobility Partnership, as in the case of Senegal. This places the Commission in a tricky, and weak, bargaining position when negotiating Mobility Partnerships. Member states are, in effect, undermining the ability of the Commission to negotiate with third countries by maintaining more favourable bilateral relations than that which is being offered by the EU. This is demonstrated particularly well by the case of France: the French government, as all other member states' governments, did not believe that legal migration opportunities should be included in EU Mobility Partnerships (see chapter 5). However, its own bilateral migration agreement with Senegal opens up certain professions to allow Senegalese easier access to the French labour market. The Senegalese government knew that the EU Mobility Partnership would be unlikely to offer such favourable terms, due to the shared competence between the EU and the member states. 
Chapter 7
Conclusion 


\subsection{Introduction}

Immigration to the EU is not a new phenomenon, but migrants trying to reach EU territory take increasingly more dangerous routes, putting their lives at risk. The EU is popularly referred to as 'Fortress Europe', to reflect the restrictive immigration policies adopted both at EU level and by the member states. And yet there is a gap between the objectives and achievements of such restrictive migration policies: the official rhetoric may be something close to 'zero immigration', at least for low-skilled migrants, but the long sea borders in southern Europe, with the African coast not far away, tempt many migrants to make the clandestine journey to the EU. In the early 2000s, a policy context emerged at the EU level which sought to link migration policy with foreign policy: foreign policy should be employed to achieve migration control objectives. This raises many questions, both in terms of internal and external governance. Third countries do not necessarily share the interest of the EU in preventing illegal migration, so why would they choose to cooperate? And within the EU, both migration policy and foreign policy are sensitive topics for member states' sovereignty, so why would they choose to participate in such EU measures?

Against this background, the Commission introduced the Mobility Partnerships in 2007. The Mobility Partnerships are one of the tools of the EU's Global Approach to Migration. They are political agreements, signed between the Commission, interested member states, and third countries. The rationale is to offer these third countries increased legal migration opportunities for their citizens to travel to the EU, in return for their cooperation on preventing illegal migration. Mobility Partnerships are differentiated according to the third country with which they are signed, but always consist of a joint declaration followed by a list of proposed projects to be implemented. Projects are proposed by the Commission, member states, and/or the third country. A Mobility Partnership is thus an umbrella for these various projects. An example of a project from the Mobility Partnership with Cape Verde is a proposal by Portugal to establish a common visa centre for the issuance of short-stay visas in Praia (Council, 2008c, p.10).

The focus of this research was on the decision-making process on EU external migration policy. The central research question was: How does the interaction between $E U$ institutions, member states and third countries shape the governance of the EU's external migration policy? Chapter 2 argued that the decision-making process on the Mobility Partnerships can only be fully understood by applying a three-level game model. Three-level game models have been applied to EU external policies by other scholars (e.g. Larsén, 2007; Patterson, 1997; Collinson, 1999; Young, 2003), but this thesis makes two innovative contributions to the existing literature: it is the first piece to accurately conceptualise the model in terms of the preferences of the actors involved, how the levels are linked, and what the conditions are for agreements to be reached; and it is the first application of a three-level model to a field other than external trade policy, namely external migration policy. This chapter outlines the findings of the research and sets out avenues for future research. 


\subsection{The three-level game model}

This is not the first piece of research to posit that EU external policies can be thought of as an interaction between the EU institutions, the member states, and the third countries. However, previous applications of such a three-level model have been under-specified (see chapter 2). Even the important contribution by Patterson (1997) contains three important omissions: it fails to account systematically and theoretically for member states' and third countries' preference formation; it does not clearly enough indicate the link between the two interactions in the model; and it does not systematically outline the cost of no agreement and ratification procedure, which are different for the different actors in the game.

This research therefore marks a significant contribution to this fledgling literature and indicates a way forward for three-level games. It has presented a complete conceptualisation of the three-level game model, including the links between the three levels, the theoretical explanations for member states' and third countries' preferences, and the determinants of the size of the win-set for each actor (see figure 7.1). At the international level (level I), the EU and third countries negotiate on migration issues. Third countries' preferences can be accounted for either by the policy conditionality or social learning model. The policy conditionality model is a rationalist explanation which posits that third countries will cooperate with the EU if the expected benefits of doing so outweigh the expected costs. This cost-benefit calculation by third countries will depend on three factors: (i) the resonance of the EU policy with national policy objectives; (ii) the administrative capacity of the target state; and (iii) the domestic costs of adopting the EU policy. The social learning model is a constructivist explanation according to which the third country is persuaded of the legitimacy and appropriateness of EU migration initiatives in a process of dialogue with the EU.

The EU level (level II) is the decision-making process within the EU, between the EU institutions and the member states in the Council, on external migration policy. There is a tension between the Commission and the member states. The Commission seeks to expand the role of the EU in external migration policy, in order to maximise its own competences - by default, if there is no EU external migration policy, there is no role for the Commission. The member states, on the other hand, seek to maintain control over a policy area which is central to their sovereignty, straddling as it does both migration policy and foreign policy. These are both matters of 'high' politics, and the member states are reluctant to allow too much interference from the EU institutions on such matters. 


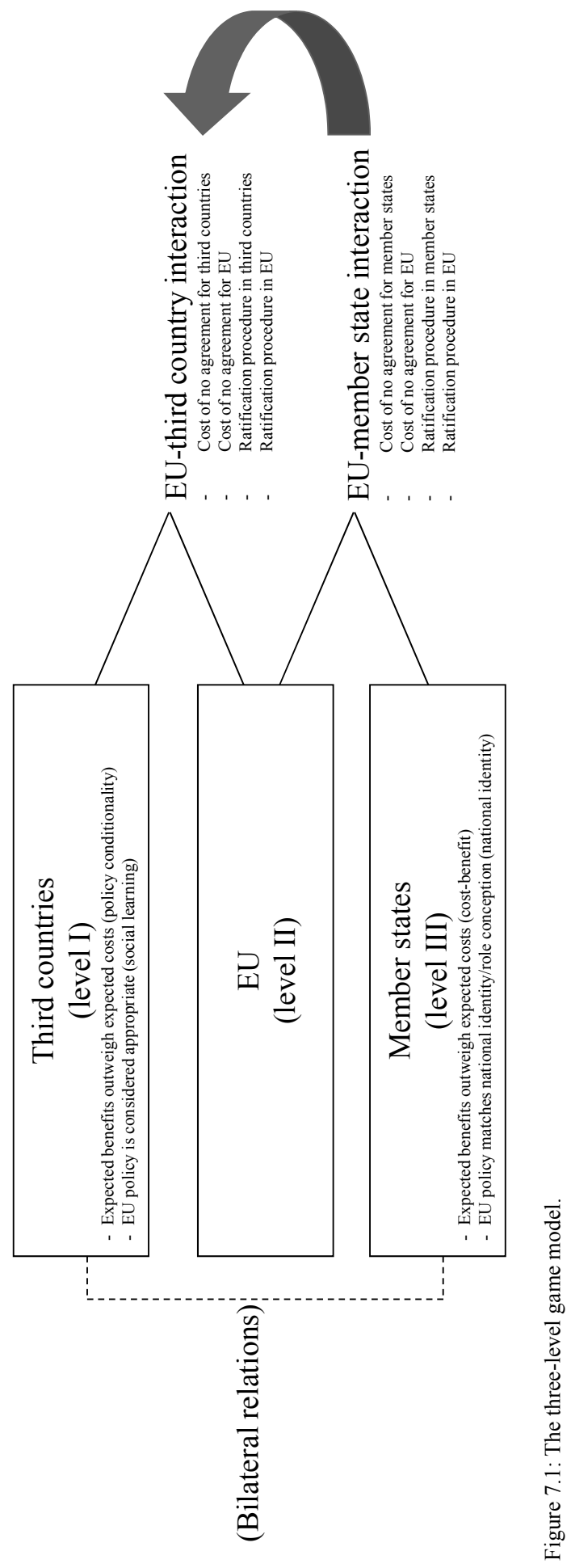


The member state level (level III) refers to the domestic preference formation of the member states on EU external migration policy. Member states' preferences can be accounted for either by a rationalist or constructivist explanation (although see section 7.4). According to a rationalist cost-benefit explanation, member states will participate in EU external migration policy when the expected benefits of doing so outweigh the expected costs. A potential benefit of participation would be the opportunity to achieve policy objectives that cannot be realised at the national level. Participation will be costly if it encroaches on a special bilateral relationship or if there is incongruence between EU external migration policy and national policy objectives. A constructivist national identity explanation of member states' preferences holds that a 'logic of appropriateness' is at play: rather than considering participation in EU external migration policy in means-end terms, member states' governments will participate if such policy measures match a national identity or role conception.

The size of the win-set for each actor is determined by the cost of no agreement and the ratification procedure. In general, a win-set is large if the cost of no agreement is high and the ratification procedure is easy. If an actor will be seriously disadvantaged by a failure to reach agreement, there will be an incentive to be flexible and open to compromises so that agreement can be reached. Ratification concerns the autonomy of the central decision-maker(s) to take a decision: if a large number of domestic political actors must approve the decision, ratification is difficult. Where the win-sets of the actors involved in an interaction overlap, agreement is possible.

The three levels of the game are linked in two ways. Firstly, they are linked through the two interactions: one interaction is between the EU and its member states, and one interaction is between the EU and the third countries. The outcome of the first interaction (agreement on an EU external migration policy) becomes the subject of negotiation in the second interaction. Secondly, the dashed line in figure 7.1 represents bilateral relations between member states and the third countries that are the targets of EU external migration policy. Such bilateral relations can alter the cost of no agreement for third countries of cooperation with the EU: if alternative, more attractive options for cooperation are offered on a bilateral basis by the member states, the cost of no agreement with the EU as a whole is low. For member states, the existence of bilateral relations might make participation in EU external migration policy unattractive because the bilateral relationship is favoured. On the other hand, if participation in an instrument of EU external migration policy would allow member states to achieve objectives that cannot be realised at the bilateral level, participation can be expected to be high.

\subsection{The governance of EU external migration policy}

The central argument of chapter 2 was that the different levels of decision-making between EU institutions and the member states, and between the EU and third countries - must be brought together and analysed as one whole, in order to explain policy outcomes. However, for practical reasons of conducting the research, it was necessary to 
divide the main research question into four sub-questions. These sub-questions related to the actors involved in the three-level game and were addressed separately in the empirical chapters. This section outlines an answer to each of the sub-questions, treating the first two together. Three main conclusions can be drawn: the Commission found itself in the weakest bargaining position, because its cost of no agreement was highest; wider, perhaps universal, participation by the member states in the Mobility Partnerships could have been ensured if only Commission officials had placed less emphasis on the aspect of legal migration - this would have raised the cost of no agreement for member states; and finally, member states' bilateral relations with third countries can undermine the Commission's ability to negotiate Mobility Partnerships, because these bilateral relations alter the cost of no agreement for third countries. These conclusions all relate to the cost of no agreement, confirming the assumption made in chapter 2 that this is a more important determinant of the size of the win-set than the ratification procedure.

\subsubsection{What was the role of the EU institutions and the member states in the negotiation of the Mobility Partnerships? What implications does this have for the form of the part- nerships?}

According to two-level game theory, the actor for whom the cost of no agreement is highest is in the weakest bargaining position (Putnam, 1988). This is clearly true of the Commission in the case of external migration policy. The reason for this is the nature of this policy area. The Commission is assumed to be competence-maximising: it seeks to expand its own role in policy-making. It therefore has a vested interest in agreement being reached, because if there is no policy agreed then its role is by default reduced to zero. On the other hand, external migration policy is a sensitive issue for the member states, sitting as it does at the crossroads of migration policy and foreign policy. These policy areas are important to member states' sovereignty, and they will therefore seek to maintain control over decision-making.

This 'tug-of-war' between the Commission and the member states was clear in the decision-making on the Mobility Partnerships, and it had a profound effect on the form that the partnerships took. The Commission for its part has been the driver of this policy instrument: from the first mentions of the notion of 'Mobility Packages' by Commissioner Frattini in 2006, through the publication of the communication on Mobility Partnerships in May 2007, to the continued promotion of Mobility Partnerships as the main framework for migration relations between the EU and third countries. However, behind the scenes the Commission and member states have had different preferences on several aspects concerning the form these partnerships should take: their legal form; their content; and the choice of partner countries. Each of these disagreements has been resolved in the member states' favour, due to the Commission's weak bargaining position. 


\subsubsection{Why do some member states choose to participate in the Mobility Partnerships while others do not?}

Chapter 5 showed that the governments of all three countries studied, no matter whether they favoured participation in the Mobility Partnerships or not, were concerned at the outset to maintain national competence over legal, and particularly labour, migration. Agreeing to a Mobility Partnership instrument including obligatory legal migration schemes would have been too high a cost for any of the member states studied. The French government nevertheless chose to participate in the Mobility Partnerships due to a fit with the national role conception of France as a leader both in the EU and in the area of external migration policy. The Austrian government decided the costs of participation outweighed the benefits, and although it was initially ambivalent the Dutch government ultimately decided that the benefits of participation outweighed the costs.

Despite the different preferences of these governments on the Mobility Partnerships, the Commission could have secured wider, perhaps even universal, participation by the member states in the partnerships. For this, Commission officials simply had to place more emphasis on the possibility for member states to propose projects relating to illegal migration under a Mobility Partnership, and less emphasis on the aspect of legal migration. This would have increased the cost of no agreement for member states. The Commission communication on Mobility Partnerships indicated that the member states' legal frameworks on the admission of third country nationals would be respected in the Mobility Partnerships (Commission, 2007a, p.4). It stated that "mechanisms to facilitate economic migration should be based on the labour needs of interested Member States, as assessed by them" (p.5). A close reading of the communication thus already implies that member states will determine whether or not they will offer legal migration opportunities to Mobility Partnership countries. This fact could have been made explicit in early meetings in the HLWG, to circumvent opposition from member states. Indeed, once officials in the Dutch Ministry of Foreign Affairs had studied the Mobility Partnership instrument more closely, they determined that the name 'Mobility Partnerships' is actually misleading because member states will not be obliged to offer legal migration schemes (Dutch Ministry of Foreign Affairs, 2008d).

The three-level model (figure 7.1) posits a link between member states and third countries because of the existence of bilateral relations in the area of migration. However, chapter 5 found no evidence that bilateral relations with the third country concerned alter member states' preferences on a Mobility Partnership. The French government agreed (although reluctantly) to participate in the proposed Mobility Partnership with Senegal, a country with which it also has a bilateral migration agreement. The Austrian government, on the other hand, refused to join the Mobility Partnership with Moldova despite carrying out bilateral migration initiatives in that country. For these two countries a 'blanket' decision to participate/not participate in the Mobility Partnerships was taken, regardless of the third country. The case of the Netherlands is different because the Dutch government determined on a case-by-case basis whether or not to participate in Mobility Partnerships: the partnerships with Cape Verde and Georgia 
were judged relevant in terms of national policy objectives, whilst the partnership with Moldova was not considered worthwhile to join.

\subsubsection{Why do third countries choose to join a Mobility Partnership?}

Chapter 6 showed that the existence of bilateral relations between member states and third countries can undermine the Commission's ability to negotiate a Mobility Partnership: if alternative, more attractive options for migration cooperation are offered on a bilateral basis by the member states, the cost of no agreement on a Mobility Partnership is low. This was shown for the case of Senegal, where the migration cooperation with Spain and France in particular incorporates more legal migration opportunities than a Mobility Partnership would. In such instances, member states are essentially mandating the Commission to approach the third country with an EU offer which is less attractive than their existing bilateral cooperation.

For both the Senegalese and Cape Verdean governments, an EU-wide readmission agreement covering also third-country nationals and stateless people is an onerous condition. The Senegalese government outright rejects such an agreement, and did not perceive enough benefits in the Mobility Partnership to compensate for a readmission agreement. The Cape Verdean government hesitated for a long time; the decision to ultimately sign the readmission agreement was a 'close call'. Readmission agreements have long been one of the central tools in EU external migration policy (see chapter 1), but both the Council and the Commission now seem to be acknowledging that it may not be feasible to expect all third countries to sign such an agreement in the framework of a Mobility Partnership. In 2011, the Commission proposed the introduction of a new policy instrument, the Common Agenda on Migration and Mobility (CAMM) (Commission, 2011b). CAMMs are in a sense 'everything but readmission and visa facilitation': they will contain many of the same elements as Mobility Partnerships, but will be concluded with "countries outside the EU neighbourhood or countries where there is no mutual interest in entering in to negotiations on readmission and/or visa facilitation agreements" (Council, 2012b, p.37).

This thesis did not aim to reach conclusions that could be generalised to Eastern European countries; indeed, chapter 1 speculated that countries with no EU membership perspective may have different considerations when choosing to cooperate with the EU than countries with some EU membership perspective (no matter how distant). The Council and Commission now seem to be drawing this same conclusion: ENP countries, which are closely linked to the EU in this and other regional/bilateral frameworks, may be persuaded to sign readmission agreements; member states may also be persuaded that it is 'safe' to offer these countries a visa facilitation agreement. This is the case for the eastern Mobility Partnership countries: Moldova, Georgia and Armenia have all agreed both readmission and visa facilitation agreements with the EU. However, sub-Saharan African countries are more loosely connected to the EU, have no real interest in signing readmission agreements, and are not candidates for visa facilitation. It seems that the experience of attempting to negotiate Mobility Partnerships with Senegal and Ghana, 
neither of which was concluded yet, may have highlighted this fact for the member states and Commission.

\subsection{Three-level games and negotiators' strategies}

In the two-level game approach (Putnam, 1988), the role of the 'chief negotiator' and the strategies that this actor adopts are assumed to play a decisive role in shaping the final agreement that is reached. Chapter 2 argued, however, that Putnam is imprecise in his conceptualisation of negotiators' strategies: his central claim seems to be that strategies determine the size of an actor's win-set, but he also makes statements that imply that strategies are the outcome of the size of an actor's win-set. In this thesis, strategies were not hypothesised to be a determinant of actors' win-sets; rather, it seems logical and plausible that they are determined by win-sets. The bargaining position that you find yourself in determines the strategy that you adopt.

This assumption has been confirmed in the case studies. The central finding in this respect is that the Commission, which has the biggest win-set and therefore the weakest bargaining position, is forced to adopt tactics reminiscent of 'soft bargaining': showing flexibility, being pragmatic, and conceding its own interests. In its interaction with the member states, the Commission was in no position to adopt a tough negotiation strategy due to the control exercised by the member states over the Mobility Partnership instrument. The win-sets of the member states were all smaller than the win-sets of the Commission; they were thus in a stronger bargaining position and dictated the shape and content of the Mobility Partnerships, whilst the Commission yielded to their preferences. In its interaction with the third countries, the Commission was severely limited in its choice of bargaining strategy, with neither 'hard' nor 'soft' tactics being available to it. There are no sanctions imposed on third countries for not signing a Mobility Partnership, making 'hard bargaining' tactics inappropriate and unproductive. However, 'soft bargaining' tactics require the negotiator to show flexibility and make concessions, and

the Commission does not have such room for manoeuvre in negotiations with third countries due to the control exercised by member states over the Mobility Partnership instrument. These findings are rather exploratory, and the effect of the size of win-sets on the strategies available to/employed by negotiators deserves further, systematic research.

\subsection{Rationalism vs. constructivism}

The empirical chapters compared the suitability of rationalist and constructivist explanations in accounting for the preferences of both member states and third countries on participation in the Mobility Partnerships. For member states, the decision to participate could be explained either by a cost-benefit analysis (rationalist) or by a match with national identity/role conception (constructivist). For third countries, the decision to sign a Mobility Partnership could be explained either by the policy conditionality (ra- 
tionalist) or social learning (constructivist) models. Rather than choosing upfront for one or the other of these approaches, these two different types of explanations were juxtaposed in order to determine which provided the most convincing account of the domestic process of preference formation. The empirical chapters highlighted the difficulty of neatly applying either a rationalist or a constructivist explanation. Despite the intensive process-tracing carried out in the framework of a case study and the high contextual validity of such a study, it is still possible that the case study researcher will not be able to determine whether one theoretical explanation is more convincing than another:

Sometimes competing explanations can be equally consistent with the available historical evidence; this makes it difficult to decide which is the correct explanation or, alternatively, whether both interpretations may be part of the overall explanations - i.e., whether the outcome may be overdetermined . . . If the data and generalisations available to the investigator do not permit him or her to choose from competing explanations, then both explanations for the case should be retained as equally plausible (George and Bennett, 2005, p.92).

This was particularly evident in chapter 5. Overall, the rationalist cost-benefit explanation was the most convincing account of member states' preference formation. Indeed, a logic of appropriateness cannot account for the difference between Austrian and Dutch preferences: both governments considered the potential for EU competence on labour migration to be inappropriate, but ultimately they made different decisions on participation in the Mobility Partnerships. These two different decisions are better explained in terms of the costs and benefits expected to accrue from participation. However, although the French case could be explained according to a rationalist logic, French government officials did not view participation in the Mobility Partnerships in a means-end framework. Rather, participation fitted well with conceptions of France as a pioneer, both within the EU in general and on external migration policy in particular.

Chapter 6 found the social learning model to be a weak explanation for third countries' preferences on the Mobility Partnerships. Dialogue, persuasion and deliberation are central to the social learning model, but there was no attempt by the EU to persuade Senegal and Cape Verde of the appropriateness of signing a Mobility Partnership. The EU approach was rather of a 'take it or leave it' nature. In addition, both the Senegalese and Cape Verdean governments viewed the EU's readmission requirements as inappropriate, and yet they made different decisions on the Mobility Partnership. Given that these decisions were reached by weighing the costs involved with a readmission agreement against the potential benefits of a Mobility Partnership, the policy conditionality approach was deemed better able to explain third countries' preferences. However, a sense of identification with Europe and the EU weighed into the Cape Verdean government's considerations, implying that the social learning model is not entirely without explanatory power, but rather that it is the least convincing explanation for these cases.

The main conclusion in this regard is that there is a need to build bridges between rationalist and constructivist thinking. Sil and Katzenstein (2010) argue that scholars 
who insist on the superiority of a particular theoretical approach for solving any and all research problems are at risk of simplifying complex social phenomena and overlooking empirical facts in order to apply their favoured theoretical approach. It is much more productive for scholars to focus on finding connections between different theoretical approaches "with an eye to generating novel insights that bear on policy debates and practical dilemmas" (p.2). There is a need to tone down the rhetoric about a great paradigmatic debate or the existence of fundamentally different world view: ultimately, rationalism and constructivism are simply two approaches to answering questions about international politics (Fearon and Wendt, 2002, p.67). As Jachtenfuchs (2002, p.654) points out: "That both material interests and ideas or identities matter for political outcomes is a truism for those not familiar with the rationalism-constructivism controversy". What is more interesting, he argues, is determining under which conditions interests, ideas and identities matter (cf. Fearon and Wendt, 2002, p.61).

Since the 1990s, scholars of international relations have begun to move beyond traditional paradigm wars and 'dialogues of the deaf'; instead, some are now arguing that rationalist and constructivist logics can and should be combined (see Checkel, 2010, for an overview). Certainly there are fundamental epistemological and empirical differences between rationalist and constructivist theory (Tallberg, 2010, p.637). Nevertheless, there is still much that connects these approaches; indeed, rationalism and 'conventional' constructivism share positivist assumptions (Jupille et al., 2003, p.15) and both are concerned with actors' preferences, although they of course differ in their explanations of how those preferences are formed. Fearon and Wendt (2002, p.62) point out that the logic of consequences and logic of appropriateness may interact over time: action that originally stems from a cost-benefit calculation may, if repeated, eventually become an internalised norm.

Sil and Katzenstein (2010) call for analytic eclecticism; in other words, scholars should "explore how diverse mechanisms posited in competing paradigm-bound theories might interact with each other, and how, under certain circumstances, they can combine to affect outcomes that interest both scholars and practitioners" (p.10). How can this call be translated into practical research design? Particularly in light of this research, how can bridges be built between rationalism and constructivism? Checkel (2001, p.558) argues that policy decisions may be the result of "a game of cost/benefit analysis, with the diffusion of new social norms changing such calculations". Norms, legitimacy, appropriateness, and national identity can be part of a cost-benefit analysis of participating in EU external migration policy. If a proposed EU policy is considered appropriate, this might be another benefit to participating in this policy. Such an approach might be a more fruitful avenue for researchers: to assume that policy-makers want to achieve an objective, so that their decisions are means-end in nature, but that these objectives can also be related to norms and identity. However, it would seem to subsume constructivism to rationalism, making constructivist understandings of norms and identity only part of a rational cost-benefit analysis. In a later contribution, Checkel (2010) argues against subsumption, outlining two alternative methods for combining rationalist and constructivist theories: firstly, a 'domain of application' approach would 
limit each theory to its explanatory 'home turf', and then bring these home turfs together in some larger picture. Jachtenfuchs (2002, p.655) hypothesises along these lines that ideas might play a decisive role in those cases where actors do not know which effects to expect from the proposed policy. In terms of this research, a 'domain of application' approach could mean applying the social learning model in cases where there is evidence of the EU engaging a third country in persuasion and dialogue, and applying the policy conditionality model in cases where the EU instead adopts a 'take it or leave it' approach. Secondly, in a 'temporal sequencing' approach, each theory depends on the other to explain a temporally prior outcome, so that the theories work together over time. In terms of this research, an in-depth analysis of member states' domestic preference formation might uncover that a particular ministry first developed its position on an EU initiative based on a logic of appropriateness, but that the ensuing discussion between ministries on the national position was based on a cost-benefit analysis.

These suggestions for combining rationalist and constructivist theorising are likely to incur methodological difficulties, as Checkel acknowledges (2010, p.24). In particular, different independent variables may become difficult to distinguish from one another, despite the fact that this is an essential precondition for empirical research (Gerring, 2003, p.9). However, social science research must reflect the reality of the world in which we live, and that reality is complex: decision-makers do not base their decisions on only one factor, but rather take into account many considerations. It is a widely-held and compelling premise in case study research that different causes can produce the same outcome - in other words, that equifinality is a reality in the social world (Rohlfing, 2012, p.7). It is unrealistic and unhelpful to assume monocausality because 'overdetermined' outcomes, where different interpretations are equally consistent with the process-tracing evidence, are simply empirical reality. Confirming evidence for one hypothesis is not necessarily contradictory evidence for competing hypotheses (p.185). Employing a rationalist/constructivist framework is still a useful exercise because it provides a framework for understanding and interpreting policy-makers' decisions and therefore for comparing cases according to shared logics; it may just not be possible to firmly conclude that one explanation is superior to the other. Scholars therefore need to adopt a "let's just get on with it" approach in order to develop better explanations of political behaviour and policy outcomes (Checkel, 2010; cf. Sil and Katzenstein, 2010).

\subsection{Suggestions for further research}

This thesis represents the first attempt at a full conceptualisation of the three-level game model, including explanations for the preferences of member states and third countries, and the conditions for agreement to be reached. It is also the first systematic analysis of the EU Mobility Partnerships (see chapter 1). There are therefore many avenues of research still to be explored. 


\subsubsection{The three-level game model}

It is generally accepted in academic research that a theory should not be developed based on a set of evidence, and then tested against that same evidence (e.g. George and Bennett, 2005, p.111). This research aimed to provide the first full conceptualisation of the links between the three levels, theoretical explanations for the preferences of member states and third countries, and the conditions for agreement to be reached. The threelevel game model should now be tested on a different policy instrument or a different policy area in order to assess its explanatory value.

The model could be applied to another instrument of external migration policy. Mobility Partnerships are often preceded by a migration mission by the EU to the third country concerned (see chapter 1). Chapter 2 gave an overview of member states' participation in some of these migration missions. Future research might address questions such as: why do member states decide to participate? Why does the third country accept the suggestion by the EU to conduct a migration mission? What is the role of the Commission, for example in selecting the third countries? These questions could be addressed in the three-level framework.

The three-level game model could also be applied to a legally binding instrument of external migration policy, if focussing on certain member states: Denmark, Ireland and the UK have opted out of the EU's area of freedom, security and justice. Ireland and the UK retain the possibility of opting in to measures on a case-by-case basis, although they do not participate in visa facilitation agreements due to their non-membership of the Schengen area. Table 7.1 shows the decisions taken by Ireland and the UK on the EU readmission agreements as of February 2011. With the exception of the agreements with Hong Kong and Macao, Ireland has decided not to participate in any readmission agreements. The UK participates in all the agreements. Why do these two member states display different preferences? Such a research question could be addressed by applying the three-level model, and thus also examining the interest of the third countries concerned in signing a readmission agreement. 
Table 7.1: Participation by Ireland and the UK in EU readmission agreements.

\begin{tabular}{lll}
\hline Third country & Ireland participating? & UK participating? \\
\hline Hong Kong $^{91}$ & Yes & Yes \\
Macao $^{92}$ & Yes & Yes \\
Sri Lanka $^{93}$ & No & Yes \\
Albania $^{94}$ & No & Yes \\
Russia $^{95}$ & No & Yes \\
Ukraine $^{96}$ & No & Yes \\
Macedonia $^{97}$ & No & Yes \\
Bosnia and Herzegovina $^{98}$ & No & Yes \\
Montenegro $^{99}$ & No & Yes \\
Serbia $^{100}$ & No & Yes \\
Moldova $^{101}$ & No & Yes \\
Pakistan $^{102}$ & No & Yes \\
Georgia $^{103}$ & No & Yes \\
\hline
\end{tabular}

Previous applications of the three-level game model have focused on external trade policy (Larsén, 2007; Patterson, 1997; Collinson, 1999; Young, 2003). The three-level game models applied in these studies were not fully conceptualised (see chapter 2), and this policy area could thus usefully be revisited based on the comprehensive three-level game model developed in this thesis. External trade policy is a very different type of policy to external migration policy because the EU has long had significant competences in trade policy by extension of the internal market. The conceptualisation of the three-level game model presented in this research is predicated on voluntary participation in the policy instrument by both member states and third countries. There is little sense in determining how member states make their decision to participate in an EU external policy instrument when that policy by default applies to all member states. However, the member states must still issue negotiating instructions to the Commission for trade agreements with third countries:

How much room for manoeuvre the Commission has when conducting negotiations varies according to the circumstances. Usually, differences of both principle and

\footnotetext{
${ }^{91}$ Council Decision of 17 December 2003 (2004/80/EC)

${ }^{92}$ Council Decision of 21 April 2004 (2004/424/EC)

${ }^{93}$ Council Decision of 3 March 2005 (2005/372/EC)

${ }^{94}$ Council Decision of 7 November 2005 (2005/809/EC)

${ }^{95}$ Council Decision of 19 April 2007 (2007/341/EC)

${ }^{96}$ Council Decision of 29 November 2007 (2007/839/EC)

${ }^{97}$ Council Decision of 8 November 2007 (2007/817/EC)

${ }^{98}$ Council Decision of 8 November 2007 (2007/820/EC)

${ }^{99}$ Council Decision of 8 November 2007 (2007/818/EC)

${ }^{100}$ Council Decision of 8 November 2007 (2007/819/EC)

${ }^{101}$ Council Decision of 22 November 2007 (2007/826/EC)

${ }^{102}$ Council Decision of 7 October 2010 (2010/649/EU)

${ }^{103}$ Council Decision of 18 January 2011 (2011/118/EU)
} 
special interest between the member states result in negotiating directives being fairly tightly drawn - often reflecting a compromise between those countries tending towards protectionism and those favouring a more free trade approach . . . The Commission's flexibility in negotiations can be constrained by the necessity of not disturbing compromises that have been agreed only with difficulty in the Council (Nugent, 2010, p.374).

The three-level game model could be used to arrive at a better understanding of how the member states, the Commission, and third countries interact in trade negotiations.

It would of course also be empirically worthwhile to apply the three-level game model to an entirely different external policy area. Many EU internal policies have external dimensions. One example is the Common Fisheries Policy (CFP). The EU concludes fisheries partnership agreements with third countries; these agreements allocate financial and technical support for sustainable fisheries in the third countries in return for fishing rights for the EU fishing fleet (Commission, 2012f). This quid pro quo approach closely resembles that seen in Mobility Partnerships, where the promise of increased legal migration opportunities is traded for third countries' cooperation on illegal migration. Fisheries agreements are in place between the EU and many countries in the global south (ibid.). If applying a three-level game model to explain decisionmaking in the CFP, the question at level I would be why third countries' governments decide to sign such agreements - are they persuaded by the EU that this instrument is appropriate? Or do they believe that the benefits offered outweigh the cost of allowing EU trawlers to fish their waters? In the CFP there is exclusive EU competence and so negotiations with third countries are conducted by the Commission on behalf of the member states (Nugent, 2010, p.351). The Council mandates the Commission to conduct these negotiations, but within the Council the member states benefit differently from, and therefore presumably have different preferences on, such fishing agreements: "Some $80 \%$ of the economic benefits of the EU's external fishing agreements go to the Spanish fleet, with Portugal, France, Italy, the Netherlands, Greece, Poland and Lithuania also benefiting" (Hudson, 2006, p.124). How do member states arrive at their domestic preference, and how are the various domestic preferences translated (through negotiation) into a Council mandate for the Commission?

\subsubsection{The Mobility Partnerships}

In terms of the Mobility Partnerships, this sub-section recommends three avenues for future research: focussing on different third countries; analysing a larger number of member states; or conducting research on the implementation of the partnerships.

In order to compare a 'positive' and a 'negative' case, this thesis focused on the first two Mobility Partnerships to be negotiated with African countries: Senegal and Cape Verde. The thesis does not claim that the conclusions reached here will hold for all third countries, because different groups of third countries have different considerations when they decide whether or not to cooperate with the EU on migration issues (see chapter 1). Indeed, there are important differences between African and Eastern European countries in this respect. Eastern European countries can justify their cooperation 
with the EU in terms of "their planned accession to the EU . . . or to expected benefits from a rapprochement with the EU" (Cassarino, 2010, p.27). With particular reference to the Mobility Partnerships, Lavenex and Stucky (2011, p.131) argue that "at least for Georgia and Moldova, the motivation to participate is linked to the countries' more general efforts to perform well under the ENP'. Four 'circles' of third countries can be identified in the EU's external migration policy: Western European non-EU countries; candidate countries for EU membership; the Mediterranean and Balkan countries; and all other countries that have concluded agreements with the EU that incorporate migration (Uçarer and Lavenex, 2002). The third-country case studies examined here are 'fourth circle' countries. There are now four Mobility Partnerships in place with 'third circle' countries: Moldova, Georgia, Armenia and Morocco. Further Mobility Partnerships are planned with other 'third circle' countries in North Africa. Future research on the Mobility Partnerships as a policy instrument could compare the motivations of these different types of countries to cooperate with the EU in such a forum. Are Mobility Partnerships more likely to be successfully concluded with 'third circle' countries than 'fourth circle' countries?

In terms of member states' participation in the Mobility Partnerships, future research could analyse different member states or a larger number of member states. There are certain inherent strengths of case studies, as outlined in chapter 3 . Nevertheless, there is ultimately a trade-off between depth and breadth in empirical research: given the depth and detail of case studies, a single research project can only deal with a limited number of cases. For this research, three cases were selected at the member-state level: France, Austria and the Netherlands. There is, however, an analytical technique which aims to combine the strengths of both qualitative and quantitative research: Qualitative Comparative Analysis (QCA) (see Ragin, 2008; Rihoux and Ragin, 2009). Unlike quantitative research, QCA is not concerned with measuring the individual impact of a variable on an outcome. Rather, variables act in combination to produce an outcome. It is this set-relational view which links QCA more closely with case studies, as opposed to the correlational approach of quantitative research. However, QCA can deal with a larger number of cases than case studies: it is an appropriate method for analysing between 10 and 50 cases. Given that it has 27 member states, the EU is the ideal testing ground for applying a QCA analysis. Future research on the Mobility Partnerships could thus apply such an approach to studying member states' motivations for participating.

This thesis covers the period of time from the publication of the Commission communication on Mobility Partnerships to the end of 2009, when three partnerships had been signed and negotiations with Senegal had stalled. The interest in this research has been to uncover and model the process of decision-making on this still relatively recent policy instrument. Now that five years have passed since the first Mobility Partnerships were signed, future research should examine the process of implementation of these agreements. Two avenues of research are possible. A first option is to focus on the effect of the Mobility Partnerships. Lavenex (2012, p.131) describes the Mobility Partnership with Moldova as "hardly consequential". Does this observation hold true for the other 
Mobility Partnerships? What have been the practical consequences (if any) of implementing Mobility Partnerships? A second option concerns the process of implementation. Given that the vast majority of projects were proposed and are being implemented by member states (see chapter 4), but that the Commission has a general coordinating role, the question arises whether the same institutional dynamics are seen between the Commission and the member states in the implementation phase as during decisionmaking. Implementation dynamics have not been the topic of this research, but interviewees nevertheless on occasion offered some insights in this direction. These insights relate to the Mobility Partnership with Cape Verde, because this is the only case studied where a partnership was actually concluded.

The tension amongst member states and between member states and the Commission in the decision-making process is duplicated in the tug-of-war over the EU common visa centre, established in Praia. The visa centre is run by the Portuguese government, and issues visas also for Austria, Belgium, the Czech Republic, Finland, Luxembourg and Slovenia. Commission officials would have preferred all member states to be represented at the centre in order for it to have real added value as the single place for Cape Verdeans to apply for EU visas (Interview 52). However, France and Spain, the only two EU member states besides Portugal to have full embassies in Praia, decided not to participate in the centre. Rather than transferring their visa operation to the common visa centre, these member states "prefer to decide for themselves" (Interview 63). The symbolism of having an own embassy issuing visas is too important to sacrifice for the greater efficiency of having a single EU common visa centre.

There have been problems of communication between member states and the Commission, resulting in the duplication of some projects. In Cape Verde, two projects, CAMPO (Centro de Apoio ao Migrante no País de Origem) and Diaspora Contributo, both created opportunities for Cape Verdean migrants living in Europe to return to Cape Verde and provide training to Cape Verdean institutions (Interview 64). Originally, the Dutch government planned to create a migration profile for Cape Verde as its contribution to the Mobility Partnership, but only late in the process did it become clear that such a migration profile had already been created by IOM. The Dutch government therefore decided instead to fund a consultant to assist the interministerial commission on migration created by the Cape Verdean government (Reslow, 2012, p.7). Such overlaps are not surprising given that member states are not timely with providing input for the scoreboards for each Mobility Partnership maintained by the Commission. For this reason, the partnerships end up as a collection of projects, rather than a coherent package (Interview 21).

Finally, the commitment by some member states seems to be lacking, or maybe waning. The Spanish government, for instance, was supposed to be a partner in the CAMPO project, but did not provide training for the mediators who should give information on possibilities for migration to Spain (Interview 64). The governments of Luxembourg and Belgium are officially partners with Portugal in the common visa centre in Praia, but neither government has sent officials to work in the centre, despite the fact that office space has been reserved for them (Interview 63). Future research could inves- 
tigate whether questionable commitment to the implementation of the Mobility Partnerships can be traced back to hesitation in joining the partnerships. The Netherlands, which specifically changed its policy and joined the partnership with Cape Verde after it was already signed, could be a test case: how can Dutch involvement in the implementation of the Mobility Partnership be characterised?

\subsection{The human impact of EU external migration policy}

The title of this thesis is 'Partnering for mobility'. The use of the term mobility in the name of the Mobility Partnerships implies migration opportunities; however, chapter 4 showed that so far very few projects have been proposed that actually create new opportunities for migration. Visa facilitation agreements may be signed as part of a Mobility Partnership, but such an agreement does not remove the visa requirement or change the criteria for a visa to be issued - it simply makes the application procedure faster and/or cheaper. There is general acknowledgement both amongst academics and policy-makers that African countries need substantial incentives if they are to agree to cooperate with the EU on preventing illegal migration (see chapter 1). So the lack of real migration opportunities would seem to undermine the effectiveness of the Mobility Partnerships. The EU is, as it were, 'shooting itself in the foot' by seeking cooperation with third countries whilst simultaneously jeopardising it by not offering these countries attractive terms. $^{104}$

The question is whether this is problematic, from a normative point of view. Is it actually desirable for instruments like the Mobility Partnerships to be effective in terms of the cooperation between the EU and third countries? This research has concerned the process of decision-making on EU external migration policy, but it is important not to lose sight of the fact that migration is about people moving across borders. External migration policy therefore has a human impact. When the EU cooperates with third countries on migration issues in order to control and prevent immigration to the EU, it makes these third countries responsible for dealing with migrants. Not all third countries are equipped for such responsibilities. The starting point for this thesis was the story of migrants dying in their attempts to cross from Morocco into the Spanish enclave of Ceuta (see chapter 1). Morocco has increasingly become a country of transit for subSaharan African migrants attempting to enter Europe. Since 2004, Morocco has cooperated with Spain in conducting joint naval patrols, in return for increased development aid (de Haas, 2005). Migrants who, as a result of this cooperation, fail to reach Europe, sometimes end up settling in Morocco instead. However, here they face "substantial xenophobia and aggressive . . . border authorities. Since most of them have no legal status, they are vulnerable to social and economic marginalisation" (ibid.). Unauthorised migrants are regularly deported by the Moroccan authorities to the Algerian border and

\footnotetext{
104 This is, of course, a simplification of the decision-making procedure within the EU. Chapter 4 showed that it is the member states which want to maintain control over legal migration and therefore exclude this as a topic in the Mobility Partnerships.
} 
just left there to their fate (de Haas, 2009, p.5). Even asylum-seekers are rejected at the border, despite Morocco being a signatory to the Geneva Convention. Spain has signed a bilateral agreement with Morocco on the readmission of unaccompanied children, despite the fact that "the Moroccan child protection system is not ready to provide adequate care for children repatriated from Spain" (Human Rights Watch, 2008, p.5).

Particular concern has been expressed by NGOs over the fate of migrants returned to Libya as a result of the cooperation between Italy and Libya. A treaty was signed between the two countries in 2008, obliging Libya to cooperate in preventing illegal migration in return for funding from the Italian government for this purpose (Aghazarm et al., 2012, p.10). Human Rights Watch accuses the Italian government of committing refoulement because "Libya has no asylum law or procedures. There is no formal mechanism for individuals seeking protection in Libya. The authorities make no distinction between refugees, asylum seekers, and other migrants" (Human Rights Watch, 2009, p.10). The International Federation for Human Rights (FIDH) conducted an investigation in 2012 which found that migrants in Libya are 'hounded': those considered to be illegal migrants are held in detention centres where "living conditions are deplorable. The mission heard numerous accounts of degrading treatment, physical violence and humiliation . . . Migrants and refugees live in fear without any prospect of legal redress and no access to national or international bodies" (FIDH, 2012). In 2012, the European Court of Human Rights ruled that the Italian government had violated migrants' human rights by returning them to Libya (Vogt, 2012).

Given that EU external migration policy potentially exposes migrants to inhuman treatment in third countries, it may not be problematic from a normative point of view if it proves to be ineffective in ensuring third countries' cooperation on migration issues. 


\section{Annex I: List of interviews}

Interview $1 \quad$ European Commission (DG JLS), Brussels, 6 February 2009

Interview 2 European Commission (DG JLS), Brussels, 6 February 2009

Interview 3 Ministry of Housing, Spatial Planning and the Environment of the Netherlands, The Hague, 14 September 2009

Interview 4 Ministry of Justice of the Netherlands, The Hague, 15 September 2009

Interview 5 Ministry of Justice of the Netherlands, The Hague, 15 September 2009

Interview 6 Ministry of Social Affairs and Employment of the Netherlands, The Hague, 17 September 2009

Interview 7 Ministry of Foreign Affairs of the Netherlands, The Hague, 17 September 2009

Interview 8 Ministry of Foreign Affairs of the Netherlands, The Hague, 29 September 2009

Interview 9 Ministry of Justice of the Netherlands, The Hague, 29 September 2009

Interview 10 Permanent Representation of Portugal to the EU, Brussels, 6 October 2009

Interview 11 Ministry of Foreign Affairs of the Netherlands, The Hague, 8 October 2009

Interview 12 European Commission (DG Development), Brussels, 12 October 2009

Interview 13 European Commission (DG JLS), Brussels, 13 October 2009

Interview 14 Permanent Representation of the Netherlands to the EU, Brussels, 16 October 2009

Interview 15 IOM The Hague, 19 October 2009

Interview 16 Permanent Representation of France to the EU, Brussels, 20 October 2009

Interview 17 European Commission (DG JLS), Brussels, 21 October 2009

Interview 18 Permanent Representation of the United Kingdom to the EU (by telephone), 22 October 2009

Interview 19 Dutch embassy Dakar (by telephone), 27 October 2009

Interview 20 European Commission (DG Development), Brussels, 29 October 2009

Interview 21 European Commission (DG JLS), Brussels, 6 November 2009

Interview 22 Permanent Representation of Austria to the EU, Brussels, 3 December 2009

Interview 23 EU delegation Senegal (by telephone), 4 March 2010

Interview 24 Ministry of Foreign Affairs of Austria, Vienna, 7 June 2010

Interview 25 Ministry of Interior of Austria, Vienna, 8 June 2010 
Interview 26 Ministry of Labour, Social Affairs and Consumer Protection of Austria, 8 June 2010

Interview 27 Ministry of Labour, Social Affairs and Consumer Protection of Austria (by telephone), 7 July 2010

Interview 28 IOM Brussels, 26 July 2010

Interview 29 European Parliament (DG Internal Policies), Brussels, 15 September 2010

Interview 30 European Commission (DG Home Affairs), Brussels, 15 September 2010

Interview 31 Ministry of Foreign Affairs of France, Paris, 5 January 2011

Interview 32 Ministry of Interior of France, Paris, 10 January 2011

Interview 33 Secretariat General for European Affairs of France, Paris, 10 January 2011

Interview 34 IOM Paris, 10 January 2011

Interview 35 Ministry of Interior of France, Paris, 12 January 2011

Interview 36 Ministry of Interior of Senegal, Dakar, 25 January 2011

Interview 37 French embassy Dakar, 26 January 2011

Interview 38 Dutch embassy Dakar, 26 January 2011

Interview 39 Spanish embassy Dakar, 27 January 2011

Interview $40 \quad$ Ministry of Senegalese Abroad, 31 January 2011

Interview 41 Ministry of Foreign Affairs of Senegal, Dakar, 14 February 2011

Interview 42 Ministry of Foreign Affairs of Senegal, Dakar, 14 February 2011

Interview 43 French Office of Immigration and Integration (OFII), Dakar, 21 February 2011

Interview 44 Ministry of Finance of Senegal, Dakar, 23 February 2011

Interview 45 Ministry of Public Service and Employment of Senegal, Dakar, 24 February 2011

Interview 46 Ministry of Foreign Affairs of Senegal, Dakar, 24 February 2011

Interview 47 Ministry of Interior of Senegal, Dakar, 25 February 2011

Interview 48 Ministry of Foreign Affairs of Senegal/Senegalese embassy The Hague, 25 March 2011

Interview 49 Ministry of Foreign Affairs of Cape Verde, Praia, 3 May 2011

Interview 50 Office of the Prime Minister of Cape Verde, Praia, 4 May 2011

Interview 51 Ministry of Foreign Affairs of Cape Verde, Praia, 4 May 2011

Interview 52 EU delegation Cape Verde, Praia, 5 May 2011

Interview 53 Luxembourg embassy Praia, 5 May 2011

Interview 54 Former Minister of Foreign Affairs of Cape Verde, Praia, 6 May 2011

Interview 55 Institute of Communities, Praia, 9 May 2011

Interview 56 Ministry of Foreign Affairs of Cape Verde, Praia, 11 May 2011

Interview 57 IOM Praia, 13 May 2011

Interview 58 Ministry of Foreign Affairs of Cape Verde, Praia, 16 May 2011

Interview 59 Ministry of Foreign Affairs of Cape Verde, Praia, 17 May 2011

Interview 60 Ministry of Communities of Cape Verde, Praia, 30 May 2011 
Interview $61 \quad$ Portuguese embassy Praia, 30 May 2011

Interview 62 National Institute for Employment and Vocational training (IEFP), Praia, 31 May 2011

Interview 63 EU common visa centre, Praia, 3 June 2011

Interview 64 CAMPO, Praia, 6 June 2011

Interview 65 Ministry of Foreign Affairs of Cape Verde, Praia, 7 June 2011

Interview 66 Ministry of Foreign Affairs of Cape Verde, Praia, 7 June 2011 


\section{Annex II: Projects proposed in the Mobility Partnerships}

1. The Mobility Partnership with Moldova (Council, 2008b)

Monitoring of migration flows:

- Proposal to elaborate a monitoring mechanism on migratory flows and stocks

Consolidation of the national migration management system:

- Proposal by Sweden to expand and extend the Söderköping process

- Proposal by Germany and Romania to build capacity in the area of migration

- Proposal by Greece to organise a training workshop on residence/work permits

- Proposal by Hungary to build capacity in the area of residence of foreigners

- Proposal by Poland to organise seminars on illegal migration

- Proposal by Czech Republic to organise training in border management

- Proposal by Slovakia to train police officers on illegal migration

- $\quad$ Proposal by Hungary and Slovakia to offer training and support on asylum policy

- Proposal by Slovenia to exchange knowledge and best practices on asylum

- Proposal by Czech Republic, Hungary, Poland, Romania, Slovakia and Sweden to organise study visits and exchange of best practices

- $\quad$ Proposal by Italy to train public officials

- Proposal by Slovenia to exchange knowledge and experiences

- Proposal by Germany to evaluate the Moldovan border authority

- $\quad$ Proposal by Hungary to share best practices on border management

- Proposal by Portugal to provide assistance and training on document security

- Proposal by Poland and Hungary to strengthen capacities in identifying forged travel documents

Information on legal migration and assistance for returning migrants:

- Proposal by Bulgaria, Cyprus, Hungary, Lithuania, Italy, Germany, Greece, Poland, Romania, Slovakia and Sweden to provide information on legal migration to the EU

- $\quad$ Proposal by Greece and Italy to offer pre-departure training to Moldovan migrants

- Proposal by Italy to provide a handbook on entry and integration policies

- $\quad$ Proposal by Greece, Poland, Germany and Lithuania to create a website on legal migration

Labour migration schemes:

- Proposal by Romania and the Veneto region to support labour migration and development

- Proposal by Czech Republic and Cyprus to offer circular migration projects

- Proposal by Bulgaria to sign an agreement on labour migration with Moldova

- Proposal by Romania to sign a convention on local border traffic with Moldova

- Proposal by Italy to support potential Moldovan labour immigrants

- Proposal by Sweden to inform about changes to Sweden labour migration law

- Proposal by Poland to offer admission for temporary work without a work permit

Voluntary return and reintegration schemes:

- Proposal by Germany to support voluntary return projects

- Proposal by Romania to support reintegration of migrants in Moldova

Diaspora consolidation and co-development:

- Proposal by the Commission to strengthen the development aspect of migration

- Proposal by Moldova to strengthen the Information Centres for Moldovan migrants in Moldovan embassies

- Proposal by Germany to allow Moldovans in Germany extended absence without loss of residence rights

- Proposal by Romania and Veneto region to design an instrument to encourage migrants to invest remittances and return to Moldova

- Proposal by Germany to extend a remittances website

- Proposal by Sweden to facilitate exchange of experiences on remittances 
- Proposal by Hungary to strengthen capacity of Moldovan consular personnel

Social protection of migrants and their families:

- Proposal by Romania to strengthen capacity on social security benefits

- Proposal by Bulgaria to sign a treaty on social insurance with Moldova

- Proposal by Romania to sign an agreement on social security with Moldova

- Proposal by Italy to address the social dimension of migration

Development of the Moldovan labour market:

- Proposal by Czech Republic to develop to Moldovan labour market

- Proposal by Sweden to reform vocational training

- Proposal by Sweden, Romania and Lithuania to strengthen Moldovan public employment service

- Proposal by the Commission to strengthen the development aspect of migration

- Proposal by Moldova to promote the quality of its higher education

- Proposal by the Commission to promote participation of Moldova in the Erasmus Mundus programme

- Proposal by Romania offer scholarships to Moldovan students

- Proposal by Moldova and Sweden to provide incentives on local job opportunities

- Proposal by Czech Republic to support private and small enterprises

- Proposal by Romania to promote job creation in tourism and rural development

- Proposal by all signatories to promote bilateral recognition of skills and qualifications

Visa and readmission:

- Proposal to enlarge the Common Visa Application Centre in Moldova

Cooperation in border management, identity and travel documents, fight against illegal/irregular migration and trafficking in human beings:

- Proposal by Portugal for authorities to cooperate in area of document security, fraud, border control, and trafficking in human beings

- Proposal by France to continue a programme on trafficking in human beings

- Proposal that Moldova take measures to improve border management

- Proposal by Hungary to cooperate on local level on border management

- Proposal by Germany to offer an audit of the Moldovan border control structure

- Proposal by Czech Republic to support border management structures

- Proposal by Frontex and Moldova to train the Moldovan border guard service

- Proposal by Moldova to improve travel and identity document security

- Proposal by Germany and Portugal to provide technical assistance to Moldova

- Proposal by the Commission to provide advice on biometric passports

- Proposal that Moldova implement the Palermo Convention 
Monitoring and awareness of migration flows:

- Proposal for a migration profile for Cape Verde

Employment, management and facilitation of legal migration and integration:

- $\quad$ Proposal by Portugal to develop CAMPO (an information centre for prospective Cape Verdean migrants)

- Proposal by Portugal to sign a new protocol with Cape Verde to promote temporary and circular migration

- Proposal by Portugal for cooperation between the Portuguese and Cape Verdean employment and vocational training institutes

- Proposal by Spain to launch a schools/workshops programme

- Proposal by Spain to strengthen the development of business initiatives by women

- Proposal by France to open up certain professions to Cape Verdean migrants (part of the accord de gestion concertée des flux migratoires)

- $\quad$ Proposal by the member states to foster cooperation between higher education institutions

- Proposal by Cape Verde and the member states to develop a dialogue on reintegration of migrants

- Proposal by Luxembourg to consider a circular migration scheme

- Proposal by Luxembourg to strengthen the programme 'Migrer les yeux ouverts' (information for migrants about life in Luxembourg)

- $\quad$ Proposal by Luxembourg to offer twinning between universities

Mobility and short-stay visas:

- Proposal by the Commission to negotiate a visa facilitation agreement

- $\quad$ Proposal by Portugal to set up a common visa application centre in Praia for short-term visas

Links between migration and development, diasporas, money transfers:

- Proposal by Portugal to develop DIAS de Cabo Verde (foster circulation of highly qualified Cape Verdean migrants)

- Proposal by Cape Verde and the member states to foster cooperation between hospitals and research institutions

- $\quad$ Proposal by Spain to strengthen capacities of Cape Verdean national health system

- Proposal by Portugal to support the Cape Verdean national health system

- Proposal by France for a co-development programme

Asylum and immigration:

- Proposal that Cape Verde ratifies the Geneva convention

- $\quad$ Proposal by Portugal to help Cape Verde develop its asylum system

Cooperation on border management, identity and travel documents, and the fight against illegal migration and trafficking in human beings:

- Proposal that Cape Verde implements the UN Convention against Transnational Organised Crime

- Proposal that work agreement between Frontex and Cape Verdean national police should include information exchange and joint operational measures

- Proposal by Frontex and Cape Verde that the Cape Verdean national police should implement training programmes for border guards and on the falsification of documents

- $\quad$ Proposal by the European Community and the member states to facilitate police cooperation

- $\quad$ Proposal by the Commission to negotiate a readmission agreement

- Proposal by Portugal to build capacity of Cape Verdean authorities in areas such as biometrics

- $\quad$ Proposal by Spain to build capacity of Cape Verdean authorities in maritime security

- $\quad$ Proposal by Spain to strengthen the Cape Verdean national Red Cross

- Proposal by Spain to build capacity of Ministry of Defence

- $\quad$ Proposal by France to cooperate with Cape Verde on security and document control 
Mobility, legal migration, integration and migration and development:

- Proposal by Bulgaria, Czech Republic, Denmark, Germany, Greece, France, Italy, Lithuania, Poland, Sweden and the ETF to provide information on legal migration routes to the EU

- Proposal by France and Poland to facilitate access to national labour markets

- Proposal by France to encourage circular mobility of young professionals

- Proposal by Poland to provide information on voluntary return

- Proposal by Belgium and Czech Republic to support assisted voluntary return

- Proposal by Netherlands to provide legal advice and psycho-social support

- Proposal by Germany to support highly-skilled migrants returning to Georgia

- Proposal by Germany to provide support to Georgian office for diaspora issues

- Proposal by Czech Republic to enlarge advisory centre in Tbilisi

- Proposal by Netherlands to support Georgia to implement a national return and reintegration programme

- $\quad$ Proposal by Belgium to support reintegration of vulnerable groups

- Proposal by Germany to allow Georgians in Germany extended absence without loss of residence rights

- Proposal by Netherlands to support temporary return of qualified nationals

- Proposal by Bulgaria to sign a bilateral agreement on social security

- $\quad$ Proposal by Belgium, Netherlands and Sweden to support the Georgian Civil Registry Agency

Asylum policy and protection of refugees:

- $\quad$ Proposal by Germany and Poland to share best practices on asylum

Border management, identity and travel documents, fight against illegal migration and trafficking in human beings:

- Proposal by Frontex, Bulgaria, Czech Republic, Germany, Estonia, Latvia, Lithuania, Poland and UK to create a steering committee to develop activities (e.g. information exchange, training, research and development) in the area of border management

Readmission policy:

- $\quad$ Proposal by Belgium, Estonia, Netherlands and Poland to organise study visits on readmission and return policy 
Mobility, legal migration and integration:

- $\quad$ Proposal by the EU provide capacity building on migration management and a migration profile

- Proposal by Bulgaria, France, Netherlands, Romania and Sweden to share experience on legal migration and train Armenian officials

- Proposal by France to promote circular migration of young professionals

- Proposal by Italy, Poland and Sweden to inform on possibilities for legal migration

- Proposal by Romania to inform on possibilities for legal migration and risks of irregular migration

- $\quad$ Proposal by Romania to offer pre-departure training and joint study programmes

- $\quad$ Proposal by Italy to provide a handbook on entry and integration policies

- Proposal by Germany to facilitate mobility of Armenians in Germany

- Proposal to collect labour market information on Armenia

- Proposal by Bulgaria to negotiate a bilateral agreement on social security and management of labour migration

Migration and development:

- Proposal by France to support use of migrants' skills acquired abroad for the development of Armenia

- Proposal by Belgium, Czech Republic, France, Germany, Netherlands, Sweden, the EU, the ETF to support reintegration of migrants in Armenia

- $\quad$ Proposal by Germany to promote cost-effective channels for remittances

- $\quad$ Proposal to share experience in employment and education policies

- Proposal by Romania to foster cooperation between NGOs

Fight against irregular immigration and trafficking in human beings, readmission, identity and travel documents' security, border management:

- Proposal by Belgium, Bulgaria, Germany, Netherlands, Poland, Romania and the EU to exchange best practices on readmission processes

- Proposal by Belgium and Poland to share knowledge on combating trafficking in human beings

- Proposal by Bulgaria, Netherlands, Poland and the EU to reinforce Armenia's border management capacities

Asylum and international protection:

- Proposal by the EU to support capacity of Armenia to implement an asylum policy

- Proposal by Sweden to organise a workshop on the European Asylum Curriculum

- Proposal by Poland to share knowledge on countries of origin information systems 


\section{Annex III: Legal and illegal immigration to the EU from Global Approach to Migration countries}

Legal immigration flows to the EU 27 in 2007 (source: Eurostat)

\begin{tabular}{|c|c|}
\hline Country & Number of immigrants entering EU 27 in 2007 \\
\hline Morocco & 131203 \\
\hline Albania & 125746 \\
\hline Ukraine & 88143 \\
\hline Turkey & 49463 \\
\hline Russia & 46730 \\
\hline Serbia & 30826 \\
\hline South Africa & 26903 \\
\hline Bosnia & 25722 \\
\hline Nigeria & 22681 \\
\hline Moldova & 22280 \\
\hline Algeria & 20953 \\
\hline Senegal & 15602 \\
\hline Croatia & 14449 \\
\hline Macedonia & 12341 \\
\hline Tunisia & 11617 \\
\hline Egypt & 11320 \\
\hline Somalia & 7998 \\
\hline Ghana & 7973 \\
\hline Georgia & 7646 \\
\hline Belarus & 5886 \\
\hline Cameroon & 5500 \\
\hline Ethiopia & 4998 \\
\hline Armenia & 4957 \\
\hline Zimbabwe & 4854 \\
\hline Kenya & 4540 \\
\hline Mali & 4372 \\
\hline Eritrea & 4236 \\
\hline Gambia & 3729 \\
\hline Côte d'Ivoire & 3193 \\
\hline Guinea & 3080 \\
\hline Equatorial Guinea & 2840 \\
\hline Democratic Republic of Congo & 2281 \\
\hline Mauritius & 2222 \\
\hline Republic of Congo & 1833 \\
\hline Mauritania & 1720 \\
\hline Sudan & 1646 \\
\hline
\end{tabular}




\begin{tabular}{ll}
\hline Country & Number of immigrants entering EU 27 in 2007 \\
\hline Azerbaijan & 1639 \\
Uganda & 1443 \\
Libya & 1422 \\
Togo & 1401 \\
Guinea-Bissau & 1311 \\
Cape Verde & 1279 \\
Tanzania & 1263 \\
Angola & 1228 \\
Seychelles & 1210 \\
Zambia & 1205 \\
Malawi & 1134 \\
Montenegro & 935 \\
Burkina Faso & 849 \\
Rwanda & 845 \\
Madagascar & 804 \\
Namibia & 785 \\
Burundi & 761 \\
Sierra Leone & 689 \\
Liberia & 635 \\
Benin & 624 \\
Niger & 316 \\
Comoros & 275 \\
Mozambique & 261 \\
Gabon & 210 \\
Central African Republic & 126 \\
Chad & 108 \\
Botswana & 67 \\
Djibouti & 65 \\
São Tomé and Príncipe & 47 \\
Lesotho & 29 \\
Swaziland &
\end{tabular}


Illegal migration flows to the EU 27 in 2008 (source: Eurostat)

\begin{tabular}{|c|c|}
\hline Country & Number of persons illegally present in EU 27 in 2008 \\
\hline Albania & 72670 \\
\hline Morocco & 39775 \\
\hline Eritrea & 21055 \\
\hline Nigeria & 16575 \\
\hline Algeria & 15775 \\
\hline Tunisia & 14085 \\
\hline Ukraine & 13985 \\
\hline Turkey & 13925 \\
\hline Serbia & 13315 \\
\hline Somalia & 10945 \\
\hline Senegal & 10700 \\
\hline Russia & 10210 \\
\hline Moldova & 7100 \\
\hline Egypt & 6800 \\
\hline Georgia & 5130 \\
\hline Ghana & 4910 \\
\hline Zimbabwe & 4215 \\
\hline Mali & 3050 \\
\hline FYROM & 2780 \\
\hline Bosnia & 2535 \\
\hline Guinea & 2435 \\
\hline Sudan & 2425 \\
\hline Gambia & 2360 \\
\hline Cameroon & 2190 \\
\hline Croatia & 1965 \\
\hline Armenia & 1940 \\
\hline Angola & 1915 \\
\hline Côte d'Ivoire & 1870 \\
\hline Cape Verde & 1855 \\
\hline Guinea-Bissau & 1705 \\
\hline Belarus & 1355 \\
\hline Mauritania & 1280 \\
\hline Democratic Republic of Congo & 1270 \\
\hline South Africa & 1175 \\
\hline Republic of Congo & 1125 \\
\hline Sierra Leone & 1105 \\
\hline Ethiopia & 1015 \\
\hline Kenya & 850 \\
\hline Libya & 830 \\
\hline Liberia & 740 \\
\hline
\end{tabular}




\begin{tabular}{ll}
\hline Country & Number of persons illegally present in EU 27 in 2008 \\
\hline Mauritius & 695 \\
Uganda & 665 \\
Azerbaijan & 660 \\
Gabon & 565 \\
Togo & 565 \\
Equatorial Guinea & 555 \\
Malawi & 515 \\
Burkina Faso & 440 \\
Montenegro & 350 \\
Niger & 295 \\
Benin & 290 \\
Comoros & 250 \\
São Tomé and Príncipe & 240 \\
Tanzania & 240 \\
Burundi & 210 \\
Rwanda & 205 \\
Zambia & 200 \\
Chad & 160 \\
Mozambique & 145 \\
Madagascar & 140 \\
Namibia & 120 \\
Botswana & 105 \\
Central African Republic & 95 \\
Swaziland & 30 \\
Djibouti & 20 \\
Lesotho & 20 \\
Seychelles & 20 \\
\hline
\end{tabular}




\section{References}

Aberbach, J. D., Chesney, J. D. and Rockman, B. A. (1975). Exploring Elite Political Attitudes: Some Methodological Lessons. Political Methodology, 2, pp.1-27.

Aberbach, J. D. and Rockman, B. A. (2002). Conducting and Coding Elite Interviews. Political Science and Politics, 35 (4), pp.673-676.

Acosta, D. (2009) The Good, the Bad and the Ugly in EU Migration Law: Is the European Parliament Becoming Bad and Ugly? (The Adoption of Directive 2008/15: The Returns Directive), European Journal of Migration and Law, 11, pp.19-39.

Adepoju, A., van Noorloss, F. and Zoomers, A. (2010). Europe's Migration Agreements with MigrantSending Countries in the Global South: A Critical Review. International Migration, 48 (3), pp.42-75.

Agence de Presse Sénégalaise (2007). Gestion des flux migratoires : le Sénégal réaffirme sa disponibilité à coopérer avec l'UE. Retrieved 3 May 2012 from http://www.aps.sn/spip.php?article35519

Agence Française de Développement (n.d.). L'AFD et le Sénégal: Un partenariat renouvelé. Retrieved 12 January 2012 from http://www.afd.fr/webdav/site/afd/shared/PORTAILS/PUBLICATIONS/ PLAQUETTES/AFD-Senegal.pdf

Aggestam, L. (2004). Role identity and the Europeanisation of foreign policy: a political-cultural approach. In B. Tonra and T. Christiansen (Eds.), Rethinking European Union Foreign Policy (pp.81-98). Manchester: Manchester University Press.

Aghazarm, C., Quesada, P. and Tishler, S. (2012). Migrants Caught in Crisis: The IOM Experience in Libya. Geneva: IOM. Retrieved 25 October 2012 from http://publications.iom.int/bookstore/free/MigrationCaughtinCrisis_forweb.pdf

Åkesson, L. (2008). The Resilience of the Cape Verdean Migration Tradition. In L. Batalha and J. Carling (Eds.), Transnational Archipelago. Perspectives on Cape Verdean Migration and Diaspora (pp.269283). Amsterdam: Amsterdam University Press.

Allison, G. T. (1971). Essence of Decision. Explaining the Cuban Missile Crisis. Boston: Little, Brown and Company.

Allison, G. T. and Halperin, M. H. (1972). Bureaucratic Politics. A Paradigm and Some Policy Implications. World Politics, 24, pp.40-79.

Alons, G. C. (2007). Predicting a State's Foreign Policy: State Preferences between Domestic and International Constraints. Foreign Policy Analysis, 3 (3), pp.211-232.

Ambler, J. S. and Reicher, M. S. (2001). France: Europeanism, Nationalism and the Planned Economy. In E. E. Zeff and E. B. Pirro (Eds.), The European Union and the Member States. Cooperation, Coordination, and Compromise (pp.29-57). Boulder: Lynne Rienner.

Andreas, P. (2003). Redrawing the Line. Borders and Security in the Twenty-first Century. International Security, 28 (2), pp.78-111.

Angenendt, S. (2007). Circular Migration. A Sustainable Concept for Migration Policy? SWP Comments 11. Berlin: SWP.

Assemblée Nationale (2009). Rapport fait au nom de la commission des affaires étrangères sur: le projet de loi, adopté par le Sénat, autorisant l'approbation de l'accord entre le Gouvernement de la République française et le Gouvernement de la République du Bénin relatif à la gestion concertée des flux migratoires et au codéveloppement; le projet de loi, adopté par le Sénat, autorisant l'approbation de l'accord entre le Gouvernement de la République française et le Gouvernement de la République du Congo relatif à la gestion concertée des flux migratoires et au codéveloppement; projet de loi, adopté par le Sénat, autorisant l'approbation de l'accord relatif à la gestion concertée des flux migratoires entre le Gouvernement de la République française et le Gouvernement de la République du Sénégal et de son avenant. 1471. Paris: Assemblée Nationale.

Austrian Federal Chamber of Labour (2007). Issues Paper on Circular Migration. Retrieved 12 March 2012 from http://www.akeuropa.eu/_includes/mods/akeu/docs/main_report_en_24.pdf

Austrian Integration Fund (2008). Migrationspolitik ist Wirtschaftspolitik. Integration im Fokus 1/2008. Vienna: Austrian Integration Fund.

Austrian Ministry of Interior (2008). Sicherheitsbericht 2008. Bericht der Bundesregierung über die innere Sicherheit in Österreich. Vienna: Austrian Ministry of Interior. 
Austrian Ministry of Interior (2007). Sicherheitsbericht 2007. Bericht der Bundesregierung über die innere Sicherheit in Österreich. Vienna: Austrian Ministry of Interior.

Austrian Ministry of Interior (n.d.). Das BM.I-Engagement in der Europäischen Union. 10 Punkte warum Europa für die Sicherheit Österreichs wichtig ist. Retrieved 17 January 2011 from http://www.bmi.gv.at/cms/EU_Engagement/sicherheit/start.aspx

Austrian Parliament (2009). V-5 der Beilagen zu den Stenographischen Protokollen des Nationalrates XXIV. GP. Beratungen des Ständigen Unterausschusses des Hauptausschusses in Angelegenheiten der Europäischen Union. Dienstag, 20. Oktober 2009. Retrieved 5 March 2012 from http://www.parlament.gv.at/ PAKT/VHG/XXIV/V/V_00005/fnameorig_169936.html

Bakewell, O. (2008). 'Keeping Them in Their Place': the ambivalent relationship between development and migration in Africa. Third World Quarterly, 29 (7), pp.1341-1358.

Balme, R. and Woll, C. (2005). France: Between Integration and National Sovereignty. In S. Bulmer and C. Lequesne (Eds.), The Member States of the European Union (pp.97-118). Oxford: Oxford University Press.

Barbou des Places, S. and Oger, H. (2005). Making the European Migration Regime: Decoding Member States' Legal Strategies. European Journal of Migration and Law, 6, pp.353-379.

Barkin, J. S. (2003). Realist constructivism. International Studies Review, 5 (3), pp.325-342.

Barnes, I. and Cherino, C. (2011). The Role of Circular Migration and Mobility Partnerships - Integrating Legal Migration Opportunities in the Union's External Policies. Paper presented at the UACES $41^{\text {st }}$ Annual Conference, Cambridge, UK, 5-7 September.

BBC (2006a, 5 October). Migrants drown on Canaries trip. BBC News. Retrieved 8 August 2011 from http://news.bbc.co.uk/2/hi/europe/5410342.stm

BBC (2066b, 28 December). Canaries migrant death toll soars. BBC News. Retrieved 8 August 2011 from http://news.bbc.co.uk/2/hi/europe/6213495.stm

Bendel, P. (2007). Everything under Control? The European Union's Policies and Politics of Immigration. In T. Faist and A. Ette (eds.), The Europeanization of National Policies and Politics of Immigration. Between Autonomy and the European Union (pp.32-47). Basingstoke: Palgrave Macmillan.

Bendel, P. (2005). Immigration Policy in the European Union: Still bringing up the walls for fortress Europe? Migration Letters, 2 (1), pp.20-31.

Berry, J. M. (2002). Validity and Reliability Issues in Elite Interviewing. Political Science and Politics, 35 (4), pp.679-682.

Betts, A. (2011). The global governance of migration and the role of trans-regionalism. In R. Kunz, S. Lavenex and M. Panizzon (Eds.), Multilayered Migration Governance. The promise of partnership (pp.2345). London: Routledge.

Betts, A. and Milner, J. (2007). The Externalisation of EU Asylum Policy: The Position of African States. DIIS Brief. Copenhagen: Danish Institute for International Studies.

BNC (2007). Fiche 2: Mededeling Circulaire migratie en mobiliteitspartnerschappen tussen de Europese Unie en derde landen. BNC-fiche DIE-1252/07. Retrieved 19 November 2012 from http://www.eerstekamer.nl/eu/behandeling/20070907/bnc_fiche_die_1252_07/info

Bonjour, S. (2005). The Politics of Migration and Development. The migration-development connection in Dutch political discourse and policy since 1970. Retrieved 26 April 2012 from http://www.fdcw.unimaas.nl/staff/files/users/143/Saskia\%20Bonjour\%20-

\%20Final\%20Paper\%20Florence\%20School\%20on\%20Euro-

Mediterranean\%20Migration\%20and\%20Development.doc

Börzel, T. A. (2005). Mind the gap! European integration between level and scope. Journal of European Public Policy, 12 (2), pp.217-236.

Börzel, T. A. (2002). Pace-Setting, Foot-Dragging, and Fence-Sitting: Member State Responses to Europeanisation. Journal of Common Market Studies, 40 (2), pp.193-214.

Börzel, T. A. and Risse, T. (2000). When Europe Hits Home: Europeanisation and Domestic Change. European Integration Online Papers, 4 (15).

Bosch, P. and Haddad, E. (2007). Migration and asylum: an integral part of the EU's external policies. Forum natolinskie, 3 (11).

Boswell, C. (2008). Evasion, Reinterpretation and Decoupling: European Commission Responses to the 'External Dimension' of Immigration and Asylum. West European Politics, 31 (3), pp.491-512. 
Boswell, C. (2007). Migration Control in Europe After 9/11: Explaining the Absence of Securitisation. Journal of Common Market Studies, 45 (3), pp.589-610.

Boswell, C. (2003). The 'external dimension' of EU immigration and asylum policy. International Affairs, 79 (3), pp.619-638.

Boswell, C. and Geddes, A. (2011). Migration and Mobility in the European Union. Basingstoke: Palgrave Macmillan.

Bouteillet-Paquet, D. (2003). Passing the Buck: A Critical Analysis of the Readmission Policy Implemented by the European Union and Its Member States. European Journal of Migration and Law, 5, pp.359-377.

Büchs, M. (2008). The Open Method of Coordination as a 'two-level game'. Policy \& Politics, 36 (1), pp.2137.

Bulmer, S. (2007). Theorising Europeanisaton. In P. Graziano and M. Vink (Eds.), Europeanisation. New Research Agendas (pp.46-58). Basingstoke: Palgrave Macmillan.

Bulmer, S. (1994). The Governance of the European Union. A New Institutionalist Approach. Journal of Public Policy, 13 (4), pp.351-380.

Bulmer, S, (1983). Domestic Politics and European Community Policy-Making. Journal of Common Market Studies, 21 (4), pp.349-363.

Bulmer, S. and Lequesne, C. (2005). The European Union and its Member States: An Overview. In S. Bulmer and C. Lequesne (Eds.), The Member States of the European Union (pp.1-20). Oxford: Oxford University Press.

Bundeskanzleramt Österreich (2007). Regierungsprogramm 2007-2010. Retrieved 6 March 2012 from http://www.austria.gv.at/DocView.axd?CobId=19542

Cameron, F. (2003). The Future of the Common Foreign and Security Policy. The Brown Journal of World Affairs, 9 (2), pp.115-124.

Cape Verde-European Community (2008). Document de stratégie pays et Programme indicatif national pour la période 2008-2013. Retrieved 14 June 2011 from http://ec.europa.eu/europeaid/where/acp/overview/ csp/csp_10th_edf_en.htm

Carling, J. (2008). Policy Challenges Facing Cape Verde in the Areas of Migration and Diaspora Contributions to Development. Oslo: PRIO.

Carling, J. (2007a). Unauthorized Migration from Africa to Spain. International Migration, 45 (4), pp.3-36.

Carling, J. (2007b). Migration Control and Migrant Fatalities at the Spanish-African Borders. International Migration Review, 41 (2), pp.316-343.

Carling, J. (2002). Migration in the age of involuntary immobility: theoretical reflections and Cape Verdean experiences. Journal of Ethnic and Migration Studies, 28 (1), pp.5-42.

Carling, J. and Åkesson, L. (2009). Mobility at the Heart of a Nation: Patterns and Meanings of Cape Verdean Migration. International Migration, 47 (3), pp.123-155.

Carling, J. and Batalha, L. (2008). Cape Verdean Migration and Diaspora. In L. Batalha and J. Carling (Eds.), Transnational Archipelago. Perspectives on Cape Verdean Migration and Diaspora (pp.13-31). Amsterdam: Amsterdam University Press.

Carment, D. and James, P. (1996). Two-Level Games and Third-Party Intervention: Evidence from Ethnic Conflict in the Balkans and South Asia. Canadian Journal of Political Science, 29 (3), pp.521-554.

Carrell, M. and Heavrin, C. (2008). Negotiating Essentials. Theory, Skills, and Practices. New Jersey: Pearson Prentice Hall.

Carrera, S. and Hernández i Sagrera, R. (2011). Mobility Partnerships. 'Insecurity partnerships' for policy coherence and migrant workers' human rights in the EU. In R. Kunz, S. Lavenex and M. Panizzon (Eds.), Multilayered Migration Governance. The promise of partnership (pp.97-115). London: Routledge.

Carrera, S. and Hernández i Sagrera, R. (2009). The Externalisation of the EU's Labour Immigration Policy. Towards Mobility or Insecurity Partnerships? Working Document No. 321. Brussels: CEPS.

Cassarino, J.-P. (2012). Resilient Bilateralism in the Cooperation on Readmission. In M. Cremona, J. Monar and S. Poli (Eds.), The External Dimension of the European Union's Area of Freedom, Security and Justice (pp.191-208). College of Europe Studies No. 13. Brussels: Peter Lang.

Cassarino, J.-P. (2010). Readmission Policy in the European Union. Briefing paper prepared for the European Parliament's committee on Civil Liberties, Justice and Home Affairs. PE 425.632. Brussels: European Parliament. 
Cassarino, J.-P. (2009). EU Mobility Partnerships: Expression of a New Compromise. Migration Information Source, 15 September.

Castles, S. (2006). Guestworkers in Europe: A Resurrection? International Migration Review, 40 (4), pp.741766.

Castles, S. and Miller, M. J. (2003). The Age of Migration. International Population Movements in the Modern World. Basingstoke: Palgrave Macmillan.

Caviedes, A. (2004). The open method of co-ordination in immigration policy: a tool for prying open Fortress Europe? Journal of European Public Policy, 11 (2), pp.289-310.

Checkel, J. T. (2010). Theoretical Synthesis in IR: Possibilities and Limits. Simons Papers in Security and Development No. 6/2010. Vancouver: Simon Fraser University.

Checkel, J. T. (2005). It's the Process Stupid! Process Tracing in the Study of European and International Politics. Arena Working Paper No. 26. Oslo: Arena.

Checkel, J. T. (2001). Why Comply? Social Learning and European Identity Change. International Organisation, 55 (3), pp.553-588.

Checkel, J. T. (2000). Compliance and Conditionality. ARENA Working Papers 00/18. Retrieved $4^{\text {th }}$ July 2011 from http://www.sv.uio.no/arena/english/research/publications/arena-publications/workingpapers/ working-papers2000/00_18.xml

Checkel, J. T. (1997). International Norms and Domestic Politics: Bridging the Rationalist Constructivist Divide. European Journal of International Relations, 3 (4), pp.473-495.

Chou, M.-H. (2009a). The European Security Agenda and the 'External Dimension' of EU Asylum and Migration Cooperation. Perspectives on European Politics and Society, 10 (4), pp.541-559.

Chou, M.-H. (2009b). European Union Migration Strategy towards West Africa: the Origin and Outlook of 'Mobility Partnerships' with Cape Verde and Senegal. Paper presented at the EUSA Biennial Conference on 'Information and Ideas on the European Union', Los Angeles, 23-25 April.

Chou, M.-H. (2006). EU and the Migration-Development Nexus: What Prospects for EU-Wide Policies? Working Paper No. 37. Oxford: Centre on Migration, Policy and Society.

Chou, M.-H. and Gibert, M. (2012). The EU-Senegal mobility partnership: from launch to suspension and negotiation failure. Journal of Contemporary European Research, 8 (4), pp.408-427.

Chou, M.-H. and Gibert, M. (2010). From Cotonou to circular migration: the EU, Senegal and the 'Agreement Duplicity'. Paper prepared for the conference 'Migration: A World in Motion', Maastricht, 18-20 February.

CIA World Factbook (2011a). Cape Verde. Retrieved 10 June 2011 from https://www.cia.gov/library/ publications/the-world-factbook/geos/cv.html

CIA World Factbook (2011b). Senegal. Retrieved 10 June 2011 from https://www.cia.gov/library/ publications/the-world-factbook/geos/sg.html

CIA World Factbook (2011c). Mali. Retrieved 10 January 2012 from https://www.cia.gov/library/ publications/the-world-factbook/geos/ml.html

CIGEM (2009). Etude de synthèse des politiques migratoires et des cadres législatifs en matière de migration sur le continent africain. Fiche pays: Sénégal. Retrieved 12 January 2012 from http://cigem.org/documents/FicheSenegal.pdf

Citi, M. and Rhodes, M. (2007). New Modes of Governance in the EU: Common Objectives versus National Preferences. EUROGOV No. N-07-01.

Coleman, N. (2009). European Readmission Policy. Third Country Interests and Refugee Rights. Leiden: Martinus Nijhoff.

Collier, D., Brady, H. and Seawright, J. (2004). Sources of Leverage in Causal Inference: Toward An Alternative View of Methodology. In H. Brady and D. Collier (Eds.), Rethinking Social Inquiry. Diverse Tools, Shared Standards (pp.250-264). Lanham: Rowman and Littlefield.

Collier, D. and Mahoney, J. (1996). Insights and Pitfalls: Selection Bias in Qualitative Research. World Politics, 49 (1), pp.56-91.

Collinson, S. (1999). 'Issue-systems', 'multi-level games' and the analysis of the EU's external commercial and associated policies: a research agenda. Journal of European Public Policy, 6 (2), pp.206-224.

Collyer, M. (2009). Euro-African Relations in the Field of Migration, 2008. In IEMed (ed.), Mediterranean Yearbook (pp.281-285). Barcelona: IEMed. 
Commission (2012a). Non-paper (Rev 1). Mobility Partnerships \& Common Agendas. One approach - Two frameworks. Brussels: European Commission.

Commission (2012b). The EU starts a visa liberalisation dialogue with Georgia. IP/12/561. Brussels: European Commission.

Commission (2012c). Commission delivers visa roadmap to Kosovo government. IP/12/605.

Commission (2012d). Proposal for a Council Decision of [ . . . ] concerning the conclusion of the Agreement between the European Union and the Republic of Cape Verde on the readmission of persons residing without authorisation. COM (2012) 557. Brussels: European Commission.

Commission (2012e). Proposal for a Council Decision concerning the signing of the Agreement between the European Union and the Republic of Cape Verde on facilitating the issue of short-stay visa to citizens of the Republic of Cape Verde and of the European Union. COM (2012) 559. Brussels: European Commission.

Commission (2012f). Bilateral agreements with countries outside the EU. Retrieved 16 November 2012 from http://ec.europa.eu/fisheries/cfp/international/agreements/index_en.htm

Commission (2011a). Migration and asylum thematic programme. Retrieved 10 August 2011 from http://ec.europa.eu/europeaid/how/finance/dci/migration_en.htm

Commission (2011b). The Global Approach to Migration and Mobility. COM (2011) 743. Brussels: European Commission.

Commission (2011c). Evaluation of EU Readmission Agreements. COM (2011) 76. Brussels: European Commission.

Commission (2011d). The specific tools of the EU Global Approach to Migration. Retrieved 27 September 2011 from http://ec.europa.eu/home-affairs/policies/external/external ga tools en.htm

Commission (2011e). A dialogue for migration, mobility and security with the southern Mediterranean countries. COM (2011) 292. Brussels: European Commission.

Commission (2011f). Provisional list of awarded proposals - Call 2011-2012. Retrieved 15 October 2012 from http://ec.europa.eu/europeaid/what/migration-asylum/documents/20121004-provisional_list_of_ awarded_proposals_call_2011-2012.pdf

Commission (2011g). Home Affairs - Policies - External Relations - Africa. Retrieved $19^{\text {th }}$ July 2011 from http://ec.europa.eu/home-affairs/policies/external/external_africa_en.htm

Commission (2011h). Communication on Migration. COM (2011) 248. Brussels: European Commission.

Commission (2011i). EU Readmission Agreements: brief overview of state of play. SEC (2011) 209. Brussels: European Commission.

Commission (2011j). Directorate-General Home Affairs. Retrieved 8 February 2012 from http://ec.europa.eu/ dgs/home-affairs/chart/docs/organigramme_en.pdf

Commission (2011k). EU 2011 Report on Policy Coherence for Development. SEC (2011) 1627. Brussels: European Commission.

Commission (2010a). Commission Staff Working Document on the fulfilment of the 29 measures for reinforcing the protection of the external borders and combating illegal immigration adopted at the Justice and Home Affairs Council meeting, held in Brussels on 25 and 26 February 2010. SEC (2010) 1480. Brussels: European Commission.

Commission (2010b). A twelve-point EU action plan in support of the Millennium Development Goals. COM (2010) 159. Brussels: European Commission.

Commission (2010c). Partnership and Cooperation Agreements (PCAs): Russia, Eastern Europe, the Southern Caucasus and Central Asia. Retrieved 2 February 2012 from http://europa.eu/legislation_summaries/external_relations/relations_with_third_countries/eastern_europe _and_central_asia/r17002_en.htm

Commission (2010d). Provisional list of awarded full application after call for proposals EuropeAid/128764/C/ACT/Multi. Retrieved 18 October 2012 from http://ec.europa.eu/

europeaid/what/migration-asylum/documents/awarded_proposals_2010_for_website_with_selected from_the_reserve_list.pdf

Commission (2010e). Migration and Asylum. Thematic Programme on cooperation with Third Countries in the Areas of Migration and Asylum. Overview of projects funded 2007-2008. Brussels: European Commission. 
Commission (2009a). EU 2009 Report on Policy Coherence for Development. COM (2009) 461. Brussels: European Commission.

Commission (2009b). Mid-term review of the Thematic Programme 'Cooperation with Third Countries in the Areas of Migration and Asylum'. Issues Paper. Retrieved 27 September 2011 from http://www.eeas.europa.eu/migration/docs/midtermreview_migration_issues_paper_en.pdf

Commission (2009c). Implementation of the European Neighbourhood Policy in $200 \overline{8}$. Sectoral Progress Report. SEC (2009) 522. Brussels: European Commission.

Commission (2009d). Mobility partnerships as a tool of the Global Approach to Migration. SEC (2009) 1240. Brussels: European Commission.

Commission (2009e). Implementation of the Joint Africa-EU Strategy and its First Action Plan (2008-2010). Input into the mid-term progress-report. SEC (2009) 1064. Brussels: European Commission.

Commission (2009f). EU 2009 Report on Policy Coherence for Development. SEC (2009) 1137. Brussels: European Commission.

Commission $(2009 \mathrm{~g})$. Thematic programme for cooperation with third countries in the areas of migration and asylum. Restricted Call for Proposals 2009-2010. Guidelines for grant applicants. Retrieved 16 January 2012 from https://webgate.ec.europa.eu/europeaid/online-services/index.cfm?ADSSChck=1251915408 $483 \&$ do=publi.detPUB\&searchtype $=Q S \&$ orderby=upd\&orderbyad=Desc\&nbPubliList=15\&page $=1 \&$ ao ref $=128764$

Commission (2008a). A common immigration policy for Europe: principles, actions and tools. COM (2008) 359. Brussels: European Commission.

Commission (2008b). Eastern Partnership. COM (2008) 823. Brussels: European Commission.

Commission (2008c). List projects contracted TP CfP 20072008 + Direct Awards. Retrieved 17 October 2012 from http://ec.europa.eu/europeaid/what/migration-asylum/documents/list_projects_selected_tp_ 2007_2008_2009_(cfp_2007_2008_+_direct_awards)_for_publication.pdf

Commission (2008d). Justice, Freedom and Security from a European Commission Perspective. Retrieved 8 February 2012 from http://webarchive.nationalarchives.gov.uk/20100202100434/ec.europa.eu/dgs/ justice_home/index_en.htm

Commission (2008e). Strengthening the Global Approach to Migration: increasing coordination, coherence and synergies. COM (2008) 611. Brussels: European Commission.

Commission (2007a). On circular migration and Mobility Partnerships between the European Union and third countries. COM (2007) 248. Brussels: European Commission.

Commission (2007b). The future of relations between the European Union and the Republic of Cape Verde. COM (2007) 641. Brussels: European Commission.

Commission (2007c). A Strong European Neighbourhood Policy. COM (2007) 774. Brussels: European Commission.

Commission (2007d). Minutes of the $1788^{\text {th }}$ meeting of the Commission held in Brussels (Berlaymont) on Wednesday 16 May 2007 (morning). PV (2007) 1788. Brussels: European Commission.

Commission (2007e). Applying the Global Approach to Migration to the Eastern and South-Eastern Regions Neighbouring the European Union. COM (2007) 247. Brussels: European Commission.

Commission (2006a). Policy priorities in the fight against illegal immigration of third country nationals. COM (2006) 402. Brussels: European Commission.

Commission (2006b). Thematic programme for the cooperation with third countries in the areas of migration and asylum. COM (2006) 26. Brussels: European Commission.

Commission (2006c). The Global Approach to Migration one year on: Towards a comprehensive European migration policy. COM (2006) 735. Brussels: European Commission.

Commission (2005a). Migration and development: some concrete orientations. COM (2005) 390. Brussels: European Commission.

Commission (2005b). EU Strategy for Africa: Towards a Euro-African pact to accelerate Africa's development. COM (2005) 489. Brussels: European Commission.

Commission (2005c). Priority actions for responding to the challenges of migration: First follow-up to Hampton Court. COM (2005) 621. Brussels: European Commission.

Commission (2005d). Policy Plan on Legal Migration. COM (2005) 669. Brussels: European Commission.

Commission (2004a). European Neighbourhood Policy Strategy Paper. COM (2004) 373. Brussels: European Commission. 
Commission (2004b). Area of Freedom, Security and Justice: Assessment of the Tampere Programme and future orientations. COM (2004) 401. Brussels: European Commission.

Commission (2003). On the development of a common policy on illegal immigration, smuggling and trafficking of human beings, external borders and the return of illegal residents. COM (2003) 323. Brussels: European Commission.

Commission (2002a). A community return policy on illegal residents. COM (2002) 564. Brussels: European Commission.

Commission (2002b). Integrating migration issues in the European Union's relations with third countries. COM (2002) 703. Brussels: European Commission.

Commission (2001a). A common policy on illegal immigration. COM (2001) 672. Brussels: European Commission.

Commission (2001b). On an open method of coordination for the community immigration policy. COM (2001) 387. Brussels: European Commission.

Commission (2000). On a community immigration policy. COM (2000) 757. Brussels: European Commission.

Commission (1999). DG Development Mission Statement. Retrieved 8 February 2012 from http://www.accordsdepeche.com/fichiers/docs/bibli_07/210.pdf

Commission (1994). Commission communication to the Council and the European Parliament on immigration and asylum policies. COM (94) 23. Brussels: European Commission.

Commission (1991). Communication on migration. SEC (91) 1855. Brussels: European Commission.

Commission (n.d.). Annex II: Global Terms of Reference of the Framework Contract. Lot 5: Studies for Asia. Retrieved 19 December 2012 from http://ec.europa.eu/europeaid/work/framework-contract/commission/ documents/global tor 5 en.pdf

Committee of the Regions (2008). Opinion of the Committee of the Regions on a global approach to migration: developing a European policy on labour immigration in conjunction with relations with third countries. CONST-IV-014. Brussels: Committee of the Regions.

CONGAD (2008). Déclaration sur la 'Directive Retour' de l'Union Européenne sur les migrations. Retrieved 22 June 2011 from http://www.congad.sn/IMG/pdf/Declaration_sur_la_Directive_Retour de_1_Union_Europeenne_sur_les_Migrations.pdf

Cornelius, W. A. and Tsuda, T. (2004). Controlling Immigration: The Limits of Government Intervention. In W. A. Cornelius, T. Tsuda, P. L. Martin and J. F. Hollifield (Eds.), Controlling Immigration. A Global Perspective (pp.3-48). Stanford: Stanford University Press.

Council (2013). Joint Declaration establishing a Mobility Partnership between the Kingdom of Morocco and the European Union and its Member States. 6139/13. Brussels: Council of the European Union.

Council (2012a). Guidelines for Migration Missions. 14305/12. Brussels: Council of the European Union.

Council (2012b). Outcome of Proceedings of High Level Working Group on Asylum and Migration (HLWG) on 19 June 2012. 11928/12. Brussels: Council of the European Union.

Council (2012c). EU-Jordan Task Force - Co-chairs conclusions. Retrieved 29 October 2012 from http://www.consilium.europa.eu/uedocs/cms_Data/docs/pressdata/EN/foraff/128114.pdf

Council (2012d). Council Conclusions on the Republic of Moldova Action Plan on Visa Liberalisation. Retrieved 3 December 2012 from http://www.consilium.europa.eu/uedocs/cms_data/docs/pressdata/EN/ foraff/133593.pdf

Council (2011a). Draft Council Conclusions defining the European Union strategy on readmission. 10543/1/11. Brussels: Council of the European Union.

Council (2011b). Joint Declaration on a Mobility Partnership between the European Union and Armenia. 14963/11. Brussels: Council of the European Union.

Council (2011c). Migration mission to Azerbaijan (Baku, 16-17 June 2011). 12236/11. Brussels: Council of the European Union.

Council (2011d). Proposal for a Directive of the European Parliament and of the Council on conditions of entry and residence of third-country nationals in the framework of an intra-corporate transfer. 9602/11. Brussels: Council of the European Union.

Council (2011e). Proposal for a Directive of the European Parliament and of the Council on the conditions of entry and residence of third-country nationals for the purposes of seasonal employment. 10571/11. Brussels: Council of the European Union. 
Council (2011f). 2085 ${ }^{\text {th }}$ Council meeting. Justice and Home Affairs. 10011/11. Brussels: Council of the European Union.

Council (2010a). Draft Council Conclusions on the Commission Communication 'Delivering an area of freedom, security and justice for Europe's citizens - Action Plan Implementing the Stockholm Programme' (COM (2010) 171 final). 9935/10. Brussels: Council of the European Union.

Council (2010b). EU-Ukraine Visa Dialogue - Action Plan on Visa Liberalisation. 17883/10. Brussels: Council of the European Union.

Council (2010c). Visa liberalisation for Albania and Bosnia and Herzegovina. 15957/10. Brussels: Council of the European Union.

Council (2009a). Joint Declaration on a Mobility Partnership between the European Union and Georgia. 16396/09. Brussels: Council of the European Union.

Council (2009b). The Stockholm Programme - An open and secure Europe serving and protecting the citizens. 17024/09. Brussels: Council of the European Union.

Council (2009c). Implications of the Treaty of Lisbon provisions for the JHA working structures. 17653/09. Brussels: Council of the European Union.

Council (2009d). Draft Council Decision authorising the Commission to open negotiations for the conclusion of a readmission agreement between the European Community and the Republic of Cape Verde. 6048/09. Brussels: Council of the European Union.

Council (2009e). Draft Council Decision authorising the Commission to open negotiations for the conclusion of an agreement between the European Community and the Republic of Cape Verde on the facilitation of issuance of short-stay visas. 5918/09. Brussels: Council of the European Union.

Council (2008a). Implementation of the Global Approach to Migration. 6054/08. Brussels: Council of the European Union.

Council (2008b). Joint Declaration on a Mobility Partnership between the European Union and the Republic of Moldova. 9460/08 ADD 1. Brussels: Council of the European Union.

Council (2008c). Joint Declaration on a Mobility Partnership between the European Union and the Republic of Cape Verde. 9460/08 ADD 2. Brussels: Council of the European Union.

Council (2008d). Council Conclusions on enhancing the Global Approach to Migration. $2873^{\text {rd }}$ Justice and Home Affairs Council meeting, Luxembourg 5 and 6 June 2008. Brussels: Council of the European Union.

Council (2008e). Brussels European Council 14 December 2007. 16616/1/07 REV 1. Brussels: Council of the European Union.

Council (2008f). Draft Council Conclusions on enhancing the Global Approach to Migration. 9475/08. Brussels: Council of the European Union.

Council (2008g). Brussels European Council 19-20 June 2008. 11018/1/08. Brussels: Council of the European Union.

Council (2008h). Extraordinary European Council, Brussels, 1 September 2008 - Presidency Conclusions. 12594/08. Brussels: Council of the European Union.

Council (2008i). Activation for a short period of a Friends of the Presidency Group of coordination of work in the JHA-Relex field. 12693/1/08. Brussels: Council of the European Union.

Council (2008j). Creation of an information and coordination mechanism concerning the external dimension of JHA questions, including a temporary ad hoc support group. 14236/08. Brussels: Council of the European Union.

Council (2008k). Creation of an Ad Hoc Support Group concerning the external dimension of JHA questions. 14431/1/08. Brussels: Council of the European Union.

Council (20081). European Pact on Immigration and Asylum. 13440/08. Brussels: Council of the European Union.

Council (2008m). Adoption of Council Conclusions on enhancing the Global Approach to Migration. 9604/08. Brussels: Council of the European Union.

Council (2007a). Follow-up on the Implementation of the Global Approach in Africa and the MediterraneanEU missions to Africa. 8298/07. Brussels: Council of the European Union.

Council (2007b). Draft Council Conclusions on Mobility Partnerships and Circular Migration in the Framework of the Global Approach to Migration. 16283/07. Brussels: Council of the European Union. 
Council (2007c). Council Conclusions on a Communication from the Commission on the future of relations between the EU and the Republic of Cape Verde. 2830 ${ }^{\text {th }}$ General Affairs Council Meeting, Brussels, 19 November 2007. Brussels: Council of the European Union.

Council (2007d). The South Africa-European Union Strategic Partnership Joint Action Plan. 9650/07. Brussels: Council of the European Union.

Council (2007e). Draft Council Conclusions on Extending and Enhancing the Global Approach to Migration. 10746/07. Brussels: Council of the European Union.

Council (2007f). Brussels European Council 21-22 June 2007 - Presidency Conclusions. 11177/1/07. Brussels: Council of the European Union.

Council (2007g). 2839 $9^{\text {th }}$ Council meeting. General Affairs and External Relations. 16326/07. Brussels: Council of the European Union.

Council (2006). Brussels European Council 14-15 December 2006 - Presidency Conclusions. 16879/06. Brussels: Council of the European Union.

Council (2005a). Brussels European Council 15-16 December 2005. 15914/05. Brussels: Council of the European Union.

Council (2005b). Common approach on visa facilitation. 16030/05. Brussels: Council of the European Union.

Council (2005c). A Strategy for the External Dimension of JHA: Global Freedom, Security and Justice. 15446/05. Brussels: Council of the European Union.

Council (2005d). The EU and Africa: Towards a Strategic Partnership. 15577/05. Brussels: Council of the European Union.

Council (2004a). Draft Council conclusions on the priorities for the successful development of a common readmission policy. 13758/04. Brussels: Council of the European Union.

Council (2004b). Brussels European Council 4-5 November 2004 -Presidency Conclusions. 14292/1/04. Brussels: Council of the European Union.

Council (2003). Draft Council conclusions on migration and development. 8927/03. Brussels: Council of the European Union.

Council (2002a). Seville European Council 21-22 June 2002 - Presidency Conclusions. 13463/02. Brussels: Council of the European Union.

Council (2002b). Criteria for the identification of third countries with which new readmission agreements need to be negotiated. 7990/02. Brussels: Council of the European Union.

Council (2002c). Readmission Agreements concerning third-country nationals. 7669/99. Brussels: Council of the European Union.

Council (2000). High-Level Working Group on Asylum and Migration - Adoption of the report to the European Council in Nice. 13993/00. Brussels: Council of the European Union.

Council (1999a). Tampere European Council 15-16 October 1999 - Presidency Conclusions. Brussels: Council of the European Union.

Council (1999b). Summary Report of Member States' contributions on readmission questions. 7609/1/99. Brussels: Council of the European Union.

Council (1998a). Strategy paper on immigration and asylum policy. 9809/98. Brussels: Council of the European Union.

Council (1998b). Task Force on Asylum and Migration. 13344/98. Brussels: Council of the European Union.

Council (1992). European Council in Edinburgh 11-12 December 1992. Conclusions of the Presidency. SN 456/92. Brussels: Council of the European Union.

van Criekinge, T. (2010). The EU-Africa migration partnership: a case study of the EU's migration dialogue with Senegal and Ghana. Paper presented at the EUI Migration Working Group, Florence, 24 Februrary.

van Criekinge, T. (2008). The EU-Africa Migration Partnership: An assessment of EU constraints and African leverage - a case study of Ghana and Senegal. Paper presented at the EUSA conference, Los Angeles, 22-25 April.

Currle, E., Lederer, H. W. and Neske, M. (2004). Migration in Europa: Daten und Hintergründe. Stuttgart: Lucius \& Lucius.

Delegation of the European Union to Belarus (2009). Joint Statement by the EU and Belarus on the EU Migration Mission to Belarus of 7-9 September, 2009. Retrieved 15 October 2012 from http://ec.europa.eu/delegations/belarus/press_corner/all_news/news/2009/20090910_01_en.htm 
Der Standard (2009). Österreich müsse Zuwanderern zeigen, dass sie willkommen sind, fordert der Chef der Wiener Industriellen. Retrieved 6 March 2012 from http://derstandard.at/1256744317240/Interview-mitGeorg-Kapsch-Migrationspolitik-ist-nicht-wirtschaftsfreundlich?_seite $=8 \&$ sap $=2$

Deutscher Gewerkschaftsbund Bundesvorstand (2008). Beschluss des Bundesvorstandes des DGB vom 02. September 2008. Stellungnahme zum Konzept der Europäischen Kommission: Zirkuläre Migration und Mobilitätspartnerschaften zwischen der Europäischen Union und Drittstaaten, KOM (2007) 248 endg. Retrieved 8 February 2012 from http://www.dgb.de/themen/++co++3b77a572-3c0e-11df-7b76$00188 \mathrm{~b} 4 \mathrm{dc} 422$

Di Bartolomeo, A., Fakhoury, T. and Perrin, D. (2010). Senegal. CARIM Migration Profile. Retrieved 23 June 2011 from http://www.carim.org/public/migrationprofiles/MP_Senegal_EN.pdf

Dia, I. A. (2009). Evaluation nationale des politiques, législations et pratiques en migration de travail au Sénégal. Dakar: IOM.

Diatta, M. A. and Mbow, N. (1999). Releasing the Development Potential of Return Migration: The Case of Senegal. International Migration, 37 (1), pp.243-266.

Diedrichs, U. and Wessels, W. (2006). The Commission and the Council. In D. Spence (Ed.), The European Commission (pp.209-234). London: John Harper.

Dimitrova, A. (2002). Enlargement, Institution-Building and the EU's Administrative Capacity Requirement. West European Politics, 25 (4), pp.171-190.

Dowding, K. and King, D. (1995). Introduction. In K. Dowding and D. King (Eds.), Preferences, Institutions and Rational Choice (pp.1-19). Oxford: Clarendon Press.

Dür, A. and Mateo, G. (2010). Bargaining Power and Negotiation Tactics: The Negotiations on the EU's Financial Perspective, 2007-2013. Journal of Common Market Studies, 48 (3), pp.557-578.

Dutch Ministry of Foreign Affairs (2009a). Kamerbrief inzake Uitfaseringsstrategieën Partnerlanden. Retrieved 3 April 2012 from http://www.rijksoverheid.nl/documenten-en-publicaties/kamerstukken/2010/ 02/10/kamerbrief-inzake-uitfaseringsstrategieen-partnerlanden.html

Dutch Ministry of Foreign Affairs (2009b). Bilaterale consultaties Nederland-Kaapverdië 25-26 mei 2009: Nederlandse inzet binnen het EU proef-mobiliteitspartnerschap. Archives of the Ministry of Foreign Affairs, the Hague, file no. 424/08/69369.

Dutch Ministry of Foreign Affairs (2008a). EU-migratie - verslag CIE-expertbijeenkomst over mobiliteitspartnerschappen. BRE/080429/JUS/PD1. 24 April 2008. Archives of the Ministry of Foreign Affairs, the Hague, file no. 424/08/69367.

Dutch Ministry of Foreign Affairs (2008b). Note verbale. DPV/AM-549/08. 12 November 2008. Archives of the Ministry of Foreign Affairs, the Hague, file no. 424/08/69369.

Dutch Ministry of Foreign Affairs (2008c). Memorandum DAF-335/08. 14 March 2008. Archives of the Ministry of Foreign Affairs, the Hague, file no. 424/08/69369.

Dutch Ministry of Foreign Affairs (2008d). Memorandum - EU-proefmobiliteitspartnerschappen. DPV/AM388/08. 28 August 2008. Archives of the Ministry of Foreign Affairs, the Hague, file no. 424/08/69367.

Dutch Ministry of Foreign Affairs (2008e). Verslag JBZ Radengroep 5 February 2009. $B R E / 090205 / J U S / N C 1$. Archives of the Ministry of Foreign Affairs, the Hague, file no. 424/09/14053.

Dutch Ministry of Foreign Affairs (2007). Een zaak van iedereen. Investeren in ontwikkeling in een veranderende wereld. Beleidsnotitie Ontwikkelingssamenwerking 2007-2011. Retrieved 3 April 2012 from http://www.rijksoverheid.nl/documenten-en-publicaties/notas/2009/06/19/beleidsnotitie-een-zaak-vaniedereen.html

Dutch Ministry of Foreign Affairs and Ministry of Justice (2008). International Migration and Development 2008. Policy memorandum. Retrieved 24 April 2012 from http://www.gfmd.org/en/component/ simpledownload/?task=download\&fileid=ZG9jdW1lbnRzL3BmcC9NRC1 wb2xpY3ktbWVtby5wZGY $\% 3 \mathrm{D}$

Dutch Ministry of Justice (2006). Naar een modern migratiebeleid. Policy memorandum. Retrieved 3 April 2012 from http://www.rijksoverheid.nl/documenten-en-publicaties/notas/2007/07/09/naar-een-modernmigratiebeleid.html

Eckstein, H. (1975). Case Study and Theory in Political Science. In F. I. Greenstein and N. W. Polsby (Eds.), Strategies of Inquiry. Handbook of Political Science (pp.92-123). Reading: Addison-Wesley.

Economist Intelligence Unit (2008). Country Report Cape Verde. January 2008. 
Edwards, G. (2006). Introduction. The European Commission in perspective. In D. Spence (Ed.), The European Commission (pp.1-24). London: John Harper.

Ellermann, A. (2008). The Limits of Unilateral Migration Control: Deportation and Inter-state Cooperation. Government and Opposition, 43 (2), pp.168-189.

Epstein, R. (2005). Diverging Effects of Social Learning and External Incentives in Polish Central Banking and Agriculture. In F. Schimmelfennig and U. Sedelmeier (Eds.), The Europeanization of Central and Eastern Europe (pp.178-198). Ithaca: Cornell University Press.

Eurobarometer (2009). Eurobarometer 71. Public Opinion in the European Union. Retrieved 27 October 2011 from http://ec.europa.eu/public_opinion/archives/eb/eb71/eb71_std_part1.pdf

Eurobarometer (2008a). Eurobaromter 67. Public Opinion in the European Union. Retrieved 27 October 2011 from http://ec.europa.eu/public_opinion/archives/eb/eb67/eb67_en.pdf

Eurobarometer (2008b). Eurobarometer 68. Public Opinion in the European Union. Retrieved 12 March 2012 from http://ec.europa.eu/public_opinion/archives/eb/eb68/eb_68_en.pdf

European Economic and Social Committee (2007). Opinion of the European Economic and Social Committee on EU immigration and cooperation policy with countries of origin to foster development. SOC/268. Brussels: European Economic and Social Committee.

European Migration Network (2012a). Annual Policy Report 2011. Migration and Asylum in the Netherlands. Retrieved 15 October 2012 from http://emn.intrasoft-intl.com/Downloads/download.do;jsessionid= C1B3D97D38612D5C4F55C32A118593DB?fileID=3295

European Migration Network (2012b). The Organisation of Asylum and Migration Policies in the Netherlands - 2012. Retrieved 21 November 2012 from http://emn.intrasoft-intl.com/Downloads/download.do; jsessionid=794D04AEDF4C6C784C05D0D4C56F426D? fileID=777

European Migration Network (2011a). Programmes and Strategies in Austria Fostering Assisted Return to and Re-integration in Third Countries. Retrieved 7 March 2012 from http://emn.intrasoftintl.com/Downloads/prepareShowFiles.do;jsessionid=373F7D35A1408B8F5A4D34FFE92DCD02?entr yTitle=05_EU\%20Programmes\%20and\%20Strategies\%20fostering\%20ASSISTED\%20RETURN\%20 to $\% 20$ and $\% 20$ REINTEGRATION\%20in\%20third\%20countries

European Migration Network (2011b). France. Annual Policy Report 2010. Retrieved 23 March 2012 from http:/emn.intrasoft-intl.com/Downloads/prepareShowFiles.do;jsessionid=E19391A0D3C88647337F 32B626383471?entryTitle=01.\%20Annual\%20Policy\%20Report $\% 202010$

European Migration Network (2011c). France. Institutional Framework for Asylum and Immigration Policies. Retrieved 30 March 2012 from http://emn.intrasoft-intl.com/Downloads/prepareShowFiles.do? entryTitle $=0 \% 2 \mathrm{E} \% 20$ Institutional $\% 20$ Charts $\% 20$ on $\% 20$ Asylum $\% 20$ and $\% 20$ Migration

European Migration Network (2010a). Organisation of Asylum and Migration Policies in the EU Member States. Retrieved $17^{\text {th }}$ March 2011 from http://emn.intrasoft-intl.com/html/index.html

European Migration Network (2010b). Annual Policy Report on Migration and Asylum. Spain 2007. Retrieved 24 April 2012 from http://emn.intrasoft-intl.com/Downloads/prepareShowFiles.do;jsessionid= A5ED43BE6051AE5A0AFA073B14FDFD71?entryTitle=04.\%20Annual\%20Policy\%20Report\% 202007

European Migration Network (2010c). The Organisation of Asylum and Migration Policies in Austria. Retrieved 7 March 2012 from http://emn.intrasoft-intl.com/Downloads/download.do;jsessionid= D4B1C7C51E3976A41E1F5E66F0FE8A34?fileID=724

European Migration Network (2010d). Austria. Annual Policy Report 2009. Retrieved 7 March 2012 from http:/emn.intrasoft-intl.com/Downloads/prepareShowFiles.do;jsessionid=06DF6A633A5E771D188 BDA0EE585A69E?entryTitle=02.\%20Annual\%20Policy\%20Report\%202009

European Migration Network (2010e). Ad-Hoc Query on illegal migration in the Mediterranean Sea Basin. Retrieved 23 March 2012 from http://emn.intrasoft-intl.com/Downloads/prepareShowFiles.do; jsessionid=D72A14DEFAE87202A2EC9D8CD91E60DC?entryTitle=illegal\%20Immigration

European Migration Network (2010f). Political Report 2009. Retrieved 29 March 2012 from http://emn.intrasoft-intl.com/Downloads/prepareShowFiles.do;jsessionid=19D2A832AC9385106CD84 F2FCF6470C0?entryTitle=02.\%20Annual\%20Policy\%20Report\%202009

European Migration Network (2010g). Austria. Institutional Framework for Immigration and Asylum Policies. Retrieved 30 March 2012 from http://emn.intrasoft-intl.com/Downloads/prepareShowFiles.do? entryTitle $=0 \% 2 \mathrm{E} \% 20$ Institutional $\% 20$ Charts $\% 20$ on $\% 20$ Asylum $\% 20$ and $\% 20$ Migration 
European Migration Network (2010h). Annual Policy Report 2009. Developments in Dutch Migration and Asylum Policy. Retrieved 2 April 2012 from http://emn.intrasoft-intl.com/Downloads/prepareShowFiles. do;jsessionid=E1DAFBBEFF2B83CC4145B841 AC0BB6C2?entryTitle=02.\%20Annual\%20Policy $\% 20$ Report\%202009

European Migration Network (2010i). Temporary and Circular Migration. Retrieved 3 April 2012 from http:/emn.intrasoft-intl.com/Downloads/prepareShowFiles.do;jsessionid=6EFAC9A0CD09994964E 6133C1BB5EB1B?entryTitle=05_Temporary\%20and\%20CIRCULAR\%20MIGRATION:\%20empirical $\% 20$ evidence, $\% 20$ current $\% 20$ policy $\% 20$ practice $\% 20$ and $\% 20$ future $\% 20$ options

European Migration Network (2009a). Austria Tables of Data. Retrieved 9 March 2012 from http://emn.intrasoft-intl.com/Downloads/prepareShowFiles.do;jsessionid=0F1A2232A40FB70511DD49 DB3A2EF52B?entryTitle=00b.\%20Tables\%20of\%20Asylum\%20and\%20Migration $\% 20$ Statistics $\% 202$ $007 \% 20$ and $\% 20$ earlier

European Migration Network (2009b). Annual Report on Asylum and Migration Statistics for France. Retrieved 9 March 2012 from http://emn.intrasoft-intl.com/Downloads/prepareShowFiles.do;jsessionid= 0F1A2232A40FB70511DD49DB3A2EF52B?entryTitle=03_Annual\%20Report\%20on\%20Asylum\%20 and $\% 20$ Migration\%20Statistics\%202007

European Migration Network (2009c). Netherlands Tables of Data. Retrieved 9 March 2012 from http://emn.intrasoft-intl.com/Downloads/prepareShowFiles.do;jsessionid=0F1A2232A40FB70511DD 49DB3A2EF52B? entryTitle=00b.\%20Tables $\% 20$ of $\% 20$ Asylum $\% 20$ and $\% 20$ Migration $\% 20$ Statistics $\% 2$ $02007 \%$ 20and\%20earlier

European Migration Network (2009d). The organisation of policies relating to asylum and immigration. Retrieved 23 March 2012 from http://emn.intrasoft-intl.com/Downloads/prepareShowFiles.do; jsessionid=C6DF096783FE0F2676C888D5E4373F42? entryTitle=09_The\%20ORGANISATION \%20OF\%20Asylum\%20and\%20Migration\%20POLICIES\%20in\%20the\%20EU\%20Member\%20States

European Migration Network (2009e). The organisation of policies on asylum and migration. Spain. Retrieved 24 April 2012 from http://emn.intrasoft-intl.com/Downloads/download.do;jsessionid= A5ED43BE6051AE5A0AFA073B14FDFD71?fileID=714

European Migration Network (2009f). Annual Policy Report 2008. National Report Austria. Retrieved 7 March 2012 from http://emn.intrasoft-intl.com/Downloads/prepareShowFiles.do;jsessionid= 373F7D35A1408B8F5A4D34FFE92DCD02?entryTitle=03.\%20Annual\%20Policy\%20Report\%202008

European Migration Network (2009g). Annual Report on Asylum and Migration Statistics 2007. Austria. Retrieved 7 March 2012 from http://emn.intrasoft-intl.com/Downloads/prepareShowFiles.do;jsessionid= 373F7D35A1408B8F5A4D34FFE92DCD02?entryTitle=03_Annual\%20Report\%20on \%20Asylum $\% 20$ and $\% 20$ Migration $\% 20$ Statistics $\% 202007$

European Migration Network (2009h). Political Report 2008. Retrieved 29 March 2012 from http://emn.intrasoft-intl.com/Downloads/prepareShowFiles.do;jsessionid=19D2A832AC9385106CD84F 2FCF6470C0?entryTitle=03.\%20Annual\%20Policy\%20Report\%202008

European Migration Network (2009i). Annual Policy Report 2007. Developments in Dutch Migration and Asylum Policy. Retrieved 2 April 2012 from http:/emn.intrasoft-intl.com/Downloads/ prepareShowFiles.do;jsessionid=4ACB7125217AFA4006F4060F08096967?entryTitle=04.\%20Annual $\% 20$ Policy\%20Report\%202007

European Migration Network (2009j). Annual Policy Report 2008. Developments in Dutch Migration and Asylum Policy. Retrieved 2 April 2012 from http://emn.intrasoft-intl.com/Downloads/prepare Show-

Files.do;jsessionid=E1DAFBBEFF2B83CC4145B841AC0BB6C2?entryTitle=03.\%20Annual\%20Polic y\%20Report $\% 202008$

European Migration Network (2009k). Organisation of asylum and migration policies in the Netherlands. Retrieved 3 April 2012 from http://emn.intrasoft-intl.com/Downloads/prepareShowFiles.do;jsessionid= 907F74DA9BD616C0FF2F601C2A57E8A2?entryTitle=09_The\%20ORGANISATION\%20OF\%20Asy lum\%20and\%20Migration\%20POLICIES\%20in\%20the\%20EU\%20Member\%20States

European Migration Network (2007). Policy Report Immigration and Integration in Austria. Retrieved 7 March 2012 from http://emn.intrasoft-intl.com/Downloads/prepareShowFiles.do;jsessionid= 373F7D35A1408B8F5A4D34FFE92DCD02?entryTitle=04.\%20Annual\%20Policy\%20Report\%202007 
European Migration Network (2005a). Illegal Resident Third Country Nationals in the EU Member States: State approaches towards them and their profile and social situation. Contribution by the Netherlands. Retrieved 27 April 2012 from http://emn.intrasoft-intl.com/Downloads/download.do; jsessionid=24FE2BBC62C46CC050E386ECA2249A2F?fileID=277

European Migration Network (2005b). Illegal Immigration in Austria. Retrieved 7 March 2012 from http://emn.intrasoft-intl.com/Downloads/prepareShowFiles.do;jsessionid=373F7D35A1408B8F5A4D34 FFE92DCD02?entryTitle=14_ILLEGALLY\%20RESIDENT\%20Third\%20Country\%20Nationals\%20in $\%$ 20the\%20EU:\%20State\%20approaches\%20towards\%20them

European Parliament (2010). Agreement between the EC and Pakistan on readmission - Community readmission agreements with third countries (debate). CRE 20/09/2010 - 18. Brussels: European Parliament. Retrieved 24 April 2012 from http://www.europarl.europa.eu/sides/getDoc.do?pubRef=$\% 2 \mathrm{f} \% 2 \mathrm{fEP} \% 2 \mathrm{f} \% 2 \mathrm{fTEXT} \% 2 \mathrm{bCRE} \% 2 \mathrm{~b} 20100920 \%$ bITEM- $018 \% 2 \mathrm{bDOC} \% 2 \mathrm{bXML} \% 2 \mathrm{bV0} \% 2 \mathrm{f} \% 2 \mathrm{fEN}$ \&language $=\mathrm{EN}$

European Parliament (2008a). Resolution on a more effective EU policy for the South Caucasus: from promises to actions. P6_TA(2008)0016. Brussels: European Parliament. Retrieved 22 February 2012 from http://www.europarl.europa.eu/sides/getDoc.do?type=TA\&reference=P6-TA-2008-0016\&language=EN

European Parliament (2008b). Parliamentary questions 17 September 2008. Written question by Franck Vanhecke (NL) to the Commission. Retrieved 22 February 2012 from http://www.europarl.europa.eu/ sides $/$ getDoc.do? type $=$ WQ\&reference $=\mathrm{E}-2008-4918 \&$ language $=\mathrm{EN}$

European Parliament (2008c). Answer to a written question. 24 October 2008. Retrieved 22 February 2012 from http://www.europarl.europa.eu/sides/getAllAnswers.do?reference=E-2008-4918\&language=EN

European Parliament (2007). Resolution on the fight against illegal immigration of third country nationals. P6_TA(2007)0415. Brussels: European Parliament.

European Parliament (2006a). European Parliament resolution on development and migration. P6_TA(2006)0319. Brussels: European Parliament.

European Parliament (2006b). European Parliament resolution on the EU common immigration policy. P6_TA(2006)0386. Brussels: European Parliament.

European Parliament (2005). European Parliament resolution on the links between legal and illegal migration and integration of migrants. P6_TA(2005)0235. Brussels: European Parliament.

European Parliament (2002). European Parliament Resolution on the progress made in 2001 towards the establishment of the area of freedom, security and justice provided for in Article 2, fourth indent, of the TEU. P5_TA(2002)0048. Brussels: European Parliament.

Eurostat (2008). Immigration in the EU27 in 2006. Eurostat newsrelease 162/2008, 18 November. Retrieved 19 December 2012 from http://epp.eurostat.ec.europa.eu/portal/page/portal/population/documents/ Tab/3-18112008-EN-AP.PDF

Falkner, G. (2002). Introduction: EU treaty reform as a three-level process. Journal of European Public Policy, 9 (1), pp.1-11.

Falkner, G. (2001). The Europeanisation of Austria: Misfit, Adaptation and Controversies. European Integration online Papers, 5 (13).

Falkner, G. and Laffan, B. (2005). The Europeanisation of Austria and Ireland: Small can be Difficult? In S. Bulmer and C. Lequesne (Eds.), The Member States of the European Union (pp.209-228). Oxford: Oxford University Press.

Falkner, G., Muller, W. C., Eder, M., Hiller, K., Steiner, G. and Trattnigg, R. (1999). The impact of EU membership on policy networks in Austria: creeping change beneath the surface. Journal of European Public Policy, 6 (3), pp.496-516.

Fall, P. D., Carretero, M. H. and Sarr, M. Y. (2010). Senegal. Country and Research Areas Report. EUMAGINE Project Paper 2. Retrieved 27 June 2011 from http://www.imi.ox.ac.uk/pdfs/research-projectspdfs/eumagine-pdfs/eumagine-project-paper-2-senegal-country-and-research-areas-report/view

Fearon, J. and Wendt, A. (2002). Rationalism v. Constructivism: A Skeptical View. In W. Carlsnaes, T. Risse and B. A. Simmons (Eds.), Handbook of International Relations (pp.52-72). London: Sage.

Featherstone, K. (2003). In the name of Europe. In K. Featherstone and C. M. Radaelli (Eds.), The Politics of Europeanization (pp.3-26). Oxford: Oxford University Press.

FIDH (2012). Libya: Hounding of migrants continues - Preliminary findings of an investigation mission. Retrieved 25 October 2012 from http://www.fidh.org/Libya-Hounding-of-migrants 
Flyvbjerg, B. (2001). Making social science matter. Why social inquiry fails and how it can succeed again. Cambridge: Cambridge University Press.

Frattini, F. (2006). Migration and Development: time for creative and courageous approaches. Speech to the EU-Africa Ministerial Conference on Migration and Development, Tripoli, 22 November. Retrieved 7 February 2012 from http://europa.eu/rapid/pressReleasesAction.do?reference=SPEECH/06/728\&format $=$ HTML\&aged $=1$ \&language $=$ EN\&guiLanguage $=$ en

Freedom House (2011). Table of Independent Countries. Retrieved 10 January 2012 from http://www.freedomhouse.org/uploads/fiw11/TableofIndependentCountriesFIW2011.pdf

French Ministry of Interior (n.d.). Favoriser le développement solidaire. Retrieved 20 March 2012 from http://www.immigration.gouv.fr/spip.php?page=dossiers_them_dev\&numrubrique=216

French Ministry of Interior and OFII (n.d.). Accords bilatéraux. Solidarité entre la France et les pays d'origine des migrants. Retrieved 17 January 2011 from http:/www.immigrationprofessionnelle.gouv.fr/nouveaux-dispositifs/accords-bilatéraux

Frontex (2012). Archive of accomplished operations. Hera. Retrieved 15 October 2012 from http://www.frontex.europa.eu/operations/archive-of-accomplished-operations/92

Frontex (2011). RABIT Operation 2010. Evaluation Report. Retrieved 15 October 2012 from http://www.frontex.europa.eu/assets/Attachments_News/fer_rabit_2010_screen_v6.pdf

Gächter, A. (2008). Migrationspolitik in Österreich seit 1945. Arbeitspapiere Migration und soziale Mobilität, 12. Vienna: Centre for Social Innovation. Retrieved 6 March 2012 from https:/www.zsi.at/attach/ p1208vukovic.pdf

Geddes, A. (2008). Immigration and European Integration. Beyond fortress Europe? Manchester: Manchester University Press.

Geddes, A. (2005). Europe's Border Relationships and International Migration Relations. Journal of Common Market Studies, 43 (4), pp.787-806.

Geddes, A. (2004). Migration and foreign policy in the European Union. CFSP Forum, 2 (6), pp.8-10.

Geddes, A. (2003). The Politics of Migration and Immigration in Europe. London: Sage.

Geddes, A. (2001). The Shift to Europe: Explanations for and Implications of the Development of EU Migration Policy. Swiss Political Science Review, 7 (3), pp.8-15.

Geiger, M. and Pécoud, A. (2010). The Politics of International Migration Management. In M. Geiger and A. Pécoud (Eds.), The Politics of International Migration Management (pp.1-20). Basingstoke: Palgrave Macmillan.

George, A. L. and Bennett, A. (2005). Case Studies and Theory Development in the Social Sciences. Cambridge: MIT Press.

Gerdes, F. (2007). Country profile - Senegal. Focus Migration No. 10. Hamburg: HWWI.

Gerring, J. (2007). Case Study Research. Principles and Practice. Cambridge: Cambridge University Press.

Gerring. J. (2003). Causation: A Unified Framework for the Social Sciences. Paper prepared for the annual conference of the American Political Science Association, Philadelphia, August.

Ginsberg, R. H. (2001). The European Union in international politics: baptism by fire. Lanham: Rowman and Littlefield.

Goldstein, K. (2002). Getting in the Door: Sampling and Completing Elite Interviews. Political Science and Politics, 35 (4), pp.669-672.

Goldthorpe, J. H. (2001). Causation, Statistics, and Sociology. European Sociological Review, 17 (1), pp.1-20.

Guiraudon, V. (2003). The constitution of a European immigration policy domain: a political sociology approach. Journal of European Public Policy, 10 (2), pp.263-282.

Guiraudon, V. (2001). Seeking New Venues: The Europeanization of Migration Related Policies. Swiss Political Science Review, 7 (3), pp.2-8.

Guiraudon, V. (2000). European Integration and Migration Policy: Vertical Policy-making as Venue Shopping. Journal of Common Market Studies, 38 (2), pp.251-271.

Guiraudon, V. and Lahav, G. (2000). A Reappraisal of the State Sovereignty Debate. The Case of Migration Control. Comparative Political Studies, 33 (2), pp.163-195.

de Haas, H. (2009). Country profile-Morocco. Focus Migration No. 16. Hamburg: HWWI.

de Haas, H. (2008). The Myth of Invasion: the inconvenient realities of African migration to Europe. Third World Quarterly, 29 (7), pp.1305-1322. 
de Haas, H. (2005). Morocco: From Emigration Country to Africa's Migration Passage to Europe. Migration Information Source Country Profile. Retrieved 25 October 2012 from http://www.migrationinformation. org/feature/display.cfm?ID=339

Haddad, E. (2008). The External Dimension of EU Refugee Policy: A New Approach to Asylum? Government and Opposition, 43 (2), pp.190-205.

Haddadi, S. (2002). Two Cheers for Whom? The European Union and Democratisation in Morocco. Democratization, 9 (1), pp.149-169.

Henson, P. and Malhan, N. (1995). Endeavours to Export a Migration Crisis: Policy Making and Europeanisation in the German Migration Dilemma. German Politics, 4 (3), pp.128-144.

Héritier, A. (2003). New Modes of Governance in Europe: Increasing Political Capacity and Policy Effectiveness? In T. A. Börzel and R. A. Cichowski (Eds.), Law Politics, and Society (pp.105-126). The State of the European Union, volume 6. Oxford: Oxford University Press.

Hernández i Sagrera, R. and Korneev, O. (2012). Bring EU Migration Cooperation to the Eastern Neighbourhood: Convergence Beyond the Acquis Communautaire? EU Working Papers RSCAS 2012/22. Florence: Robert Schuman Centre for Advanced Studies.

Herz, D. (2006). European Immigration and Asylum Policy: Scope and Limits of Intergovernmental Europeanization. In H. Kleinschmidt (Ed.), Migration, regional integration and human security: the formation and maintenance of transnational spaces (pp.225-244). Aldershot: Ashgate.

Hettne, B. and Söderbaum, F. (2005). Civilian Power or Soft Imperialism? The EU as a Global Actor and the Role of Interregionalism. European Foreign Affairs Review, 10, pp.535-552.

Hoetjes, B. J. S. (2003). The Netherlands: a former founding father in search of control. In W. Wessels, A. Maurer and J. Mittag (Eds.), Fifteen into one? The European Union and its member states (pp.315-336).

Hoffmann, S. (1966) Obstinate or Obsolete? The Fate of the Nation-State and the Case of Western Europe. Daedalus, 95, pp.862-915.

Höll, O., Pollak, J. and Puntscher-Riekmann, S. (2003). Austria: domestic change through European integration. In W. Wessels, A. Maurer and J. Mittag (Eds.), Fifteen into one? The European Union and its member states (pp.337-354). Manchester: Manchester University Press.

Holsti, K. J. (1987). National Role Conceptions in the Study of Foreign Policy. In. S. G. Walker (Ed.), Role Theory and Foreign Policy Analysis (pp.5-43). Durham: Duke University Press.

Hosli, M. O. (2000). The creation of the European economic and monetary union (EMU): intergovernmental negotiations and two-level games. Journal of European Public Policy, 7 (5), pp.744-766.

Howlett, M. and Ramesh, M. (2003). Studying Public Policy. Policy Cycles and Policy Subsystems. Oxford: Oxford University Press.

Hubel, H. (2004). The EU's Three-level Game in Dealing with Neighbours. European Foreign Affairs Review, 9 (3), pp.347-362.

Hudson, A. (2006). Case Study of the Fisheries Partnership Agreements. In C. Egenhofer, L. van Schaik, M. Kaeding, A. Hudson and J. N. Ferrer (Eds.), Policy Coherence for Development in the EU Council. Strategies for the Way Forward (pp.124-129). Brussels: CEPS.

Human Rights Watch (2009). Pushed Back, Pushed Around. Italy's Forced Return of Boat Migrants and Asylum Seekers, Libya's Mistreatment of Migrants and Asylum Seekers. Retrieved 25 October 2012 from http://www.hrw.org/sites/default/files/reports/italy0909web_0.pdf

Human Rights Watch (2008). Returns at Any Cost. Spain's Push to Repatriate Unaccompanied Children in the Absence of Safeguards. Retrieved 25 October 2012 from http://www.hrw.org/sites/default/files/ reports/spain1008.pdf

Huysmans, J. (2000). The European Union and the Securitization of Migration. Journal of Common Market Studies, 38 (5), pp.751-777.

IOM (2011). Cape Verde. Retrieved 10 January 2012 from http://www.iom.int/jahia/Jahia/cape-verde

IOM (2010a). MIDA Ghana Health Project. Retrieved 26 April 2012 from http://www.iomnederland.nl/dsresource?objectid=1414\&type $=$ org

IOM (2010b). Project Temporary Return of Qualified Nationals II. Retrieved 26 April 2012 from http://www.iom-nederland.nl/dsresource?objectid=2211\&type=org

IOM (2009a). Migration au Sénégal. Profil National 2009. Retrieved 21 June 2011 from http://publications.iom.int/bookstore/index.php?main_page=product_info\&cPath= 41_42\&products_id $=554$ 
IOM (2009b). MIDA Ghana Health Project. Quarterly Update for September to December 2009. Retrieved 26 April 2012 from http://www.iom-nederland.nl/dsresource?objectid=3755\&type=pdf

IOM (2009c). Migração em Cabo Verde. Perfil Nacional 2009. Retrieved 16 June 2011 from http://publications.iom.int/bookstore/index.php?main_page=product_info\&cPath=41_42\&products_id= 612

Jachtenfuchs, M. (2002). Deepening and widening integration theory. Journal of European Public Policy, 9 (4), pp.650-657.

Jachtenfuchs, M. (2001). The Governance Approach to European Integration. Journal of Common Market Studies, 39 (2), pp.245-264.

Jachtenfuchs, M. and Kohler-Koch, B. (2003). Governance and Institutional Development. Paper presented at the $8^{\text {th }}$ EUSA biennial conference, Nashville, Tennessee, 27-29 March.

Jacobsen, J. K. (1996). Are All Politics Domestic? Perspectives on the Integration of Comparative Politics and International Relations Theories. Comparative Politics, 29 (1), pp.93-115.

Jandl, M and Kraler, A. (2003). Austria: A Country of Immigration? Migration Information Source. Retrieved 5 March 2012 from http://www.migrationinformation.org/Profiles/display.cfm?ID=105

Joppke, C. (1998). Immigration Challenges the Nation-State. In C. Joppke (Ed.), Challenge to the NationState. Immigration in Western Europe and the United States (pp.5-46). Oxford: Oxford University Press.

Jørgensen, K. E. (2004). Theorising the European Union's foreign policy. In B. Tonra and T. Christiansen (Eds.), Rethinking European Union foreign policy (pp.10-25). Manchester: Manchester University Press.

Jupille, J., Caporaso, J. A. and Checkel, J. T. (2003). Integrating Institutions. Rationalism, Constructivism, and the Study of the European Union. Comparative Political Studies, 36 (1/2), pp.7-40.

Kassim, H. (2001). Introduction: Coordinating National Action in Brussels. In H. Kassim, A. Menon, B. G. Peters and V. Wright (Eds.), The National Coordination of EU Policy: The European Level (pp.1-46). Oxford: Oxford University Press.

Kassim, H. and Menon, A. (2003). The principal-agent approach and the study of the European Union: promise unfulfilled? Journal of European Public Policy, 10 (1), pp.121-139.

Kassim, H., Peters, B. G. and Wright, V. (2000). Introduction. In H. Kassim, B. G. Peters and V. Wright (Eds.), The National Co-ordination of EU Policy. The Domestic Level (pp.1-21). Oxford: Oxford University Press.

Keukeleire, S. and MacNaughtan, J. (2008). The Foreign Policy of the European Union. Basingstoke: Palgrave Macmillan.

van Keulen, M. (2006). Going Europe or Going Dutch. How the Dutch government shapes European Union Policy. Ph.D. thesis: University of Twente.

Killick, T. (1997). Principals, Agents and the Failings of Conditionality. Journal of International Development, 9 (4), pp.483-495.

King, G., Keohane, R. O. and Verba, S. (1994). Designing Social Inquiry: Scientific Inference in Qualitative Inference. Princeton: Princeton University Press.

Klavert, H. and van Seters, J. (2012). ACP-EU cooperation on readmission: Where does it stand and where to go? Briefing Note no. 33 April 2012. Maastricht: European Centre for Development Policy Management.

Knopf, J. W. (1993). Beyond two-level games: domestic-international interaction in the intermediate-range nuclear forces negotiations. International Organisation, 47 (4), pp.599-628.

Kohler-Koch, B. and Rittberger, B. (2006). The 'Governance Turn' in EU Studies. Journal of Common Market Studies, 44 (annual review), pp.27-49.

Koslowski, R. (1998). European Union Migration Regimes, Established and Emergent. In C. Joppke (ed.), Challenge to the Nation-State. Immigration in Western Europe and the United States (pp.153-188). Oxford: Oxford University Press.

Kruse, I. (2006). EU Readmission Policy and its Effects on Transit Countries - The Case of Albania. European Journal of Migration and Law, 8, pp.115-142.

Kvale, S. (2007). Doing Interviews. London: Sage.

Laffan, B. (1997). From policy entrepreneur to policy manager: the challenge facing the European Commission. Journal of European Public Policy, 4 (3), pp.422-438.

Lahav, G. and Messina, A. M. (2005). The Limits of a European Immigration Policy: Elite Opinions and Agendas within the European Parliament. Journal of Common Market Studies, 43 (4), pp.851-875. 
de Lange, S. L. (2008). From Pariah to Power: The Government Participation of Radical Right-Wing Populist Parties in West European Democracies. Ph.D. thesis: University of Antwerp.

Larsén, M. F. (2007). Trade Negotiations between the EU and South Africa: A Three-level Game. Journal of Common Market Studies, 45 (4), pp.857-881.

Lavenex, S. (2012). Channels of Externalisation of EU Justice and Home Affairs. In M. Cremona, J. Monar and S. Poli (Eds.), The External Dimension of the European Union's Area of Freedom, Security and Justice (pp.119-137). College of Europe Studies No. 13. Brussels: Peter Lang.

Lavenex, S. (2011). Venue-Shopping in Global Migration Policy: Multileveling EU External Governance. Paper presented at the EUSA Twelfth Biennial conference, Boston, 3-5 March.

Lavenex, S. (2009a). Shifting Up and Out: The Foreign Policy of European Immigration Control. West European Politics, 29 (2), pp.329-350.

Lavenex, S. (2009b). Transgovernmentalism in the Area of Freedom, Security and Justice. In I. Tömmel (Ed.), Innovative governance in the European Union: the politics of multi-level policymaking (pp.255-271). Boulder: Lynne Rienner.

Lavenex, S. (2006). Shifting Up and Out: The Foreign Policy of European Immigration Control. West European Politics, 29 (2), pp.329-350.

Lavenex, S. (2004). EU external governance in 'wider Europe'. Journal of European Public Policy, 11 (4), pp.680-700.

Lavenex, S. and Kunz, R. (2008). The Migration-Development Nexus in EU External Relations. Journal of European Integration, 30 (3), pp.439-457.

Lavenex, S. and Schimmelfennig, F. (2009). EU rules beyond EU borders: theorizing external governance in European politics. Journal of European Public Policy, 16 (6), pp.791-812.

Lavenex, S. and Stucky, R. (2011). 'Partnering' for migration in EU external relations. In R. Kunz, S. Lavenex and M. Panizzon (Eds.), Multilayered Migration Governance. The promise of partnership (pp.116142). London: Routledge.

Lavenex, S. and Uçarer, E. M. (2004). The External Dimension of Europeanization. The Case of Immigration Policies. Cooperation and Conflict, 39 (4), pp.417-433.

Lavenex, S. and Wichmann, N. (2009). The External Governance of EU Internal Security. Journal of European Integration, 31 (1), pp.83-102.

Leal-Arcas, R. (2004). The EC in the WTO: The three-level game of decision-making. What multilateralism can learn from regionalism. European Integration online Papers, 8 (14).

Leech, B. L. (2002a). Interview Methods in Political Science. Political Science and Politics, 35 (4), pp.663664.

Leech, B. L. (2002b). Asking Questions: Techniques for Semistructured Interviews. Political Science and Politics, 35 (4), pp.665-668.

Levy, J. S. (2008). Case Studies: Types, Designs, and Logics of Inference. Conflict Management and Peace Studies, 25, pp.1-18.

Lewis, J. (2008). Strategic Bargaining, Norms and Deliberation. In D. Naurin and H. Wallace (Eds.), Unveiling the Council of the European Union. Games Governments Play in Brussels (pp.165-184). Basingstoke: Palgrave Macmillan.

Lewis, J. (2003). Institutional Environments and Everyday EU Decision Making. Rationalist or Constructivist? Comparative Political Studies, 36 (1/2), pp.97-124.

Lijphart, A. (1971). Comparative Politics and the Comparative Method. American Political Science Review, 65 (3), pp.682-693.

de Lobkowicz, W. (1994). Intergovernmental cooperation in the field of migration - from the Single European Act to Maastricht. In J. Monar and R. Morgan (Eds.), The Third Pillar of the European Union (pp.99122). Brussels: European Interuniversity Press.

Luedtke, A. (2009). Uncovering European Union Immigration Legislation: Policy Dynamics and Outcomes. International Migration, early view, pp.1-27.

Luif, P. (1998). Austria: Adaptation through Anticipation. In K. Hanf and B. Soetendorp (Eds.), Adapting to European Integration. Small States and the European Union (pp.116-130). London: Longman.

Magoni, R. (2004). France. In J. Niessen and Y. Schibel (Eds.), International migration and relations with third countries: European and US approaches. Brussels: Migration Policy Group. 
Mahoney, J. and Goertz, G. (2006). A Tale of Two Cultures: Contrasting Quantitative and Qualitative Research. Political Analysis, 14 (3), pp.227-249.

Mahoney, J., Kimball, E. and Koivu, K. L. (2009). The Logic of Historical Explanation in the Social Sciences. Comparative Political Studies, 42 (1), pp.114-146.

Manners, I. and Whitman, R. (2000a). Conclusion. In I. Manners and R. Whitman (Eds.), The Foreign Policies of European Union Member States (pp.243-273). Manchester: Manchester University Press.

Manners, I. and Whitman, R. (2000b). Introduction. In I. Manners and R. Whitman (Eds.), The foreign policies of European Union Member States (pp.1-16). Manchester: Manchester University Press.

March, J. G. and Olsen, J. P. (1998). The Institutional Dynamics of International Political Orders. International Organisation, 52 (4), pp.943-969.

Marks, G., Hooghe, L. and Blank, K. (1996). European Integration from the 1980s: State-Centric v. Multilevel Governance. Journal of Common Market Studies, 34 (3), pp.341-378.

Marthaler. S. (2008). Nicolas Sarkozy and the politics of French immigration policy. Journal of European Public Policy, 15 (3), pp.382-397.

Martin, P, Martin, S. and Weil, P. (2006). Managing Migration. The Promise of Cooperation. Lanham: Rowman and Littlefield.

Mastenbroek, E. And Kaeding, M. (2006). Europeanisation Beyond the Goodness of Fit: Domestic Politics in the Forefront. Comparative European Politics, 4, pp.331-354.

Menon, A. (2001). The French Administration in Brussels. In H. Kassim, A. Menon and B. G. Peters (Eds.), The National Co-ordination of EU Policy. The European Level (pp.75-100). Oxford: Oxford University Press.

Menon, A. (2000). France. In H. Kassim, B. G. Peters and V. Wright (Eds.), The National Co-ordination of EU Policy. The Domestic Level (pp.79-98). Oxford: Oxford University Press.

Menz, G. (2011). Stopping, Shaping and Moulding Europe: Two-Level Games, Non-state Actors and the Europeanization of Migration Policies. Journal of Common Market Studies, 49 (2), pp.437-462.

Messina, A. M. (2007). The Logics and Politics of Post-WWII Migration to Western Europe. Cambridge: Cambridge University Press.

Metcalfe, D. (1998). Leadership in European Union Negotiations: The Presidency of the Council. International Negotiations, 3, pp.414-434.

Ministry of Senegalese Abroad (n.d. a). Présentation du Ministère des Sénégalais de l'Extérieur.

Ministry of Senegalese Abroad (n.d. b). Programme d'Appui aux Initiatives de Solidarité pour le Développement.

Mo, J. (1995). Domestic institutions and international bargaining: the role of agent veto in two-level games. The American Political Science Review, 89 (4), pp.914-924.

Moravcsik, A. (1998). Europe's Integration at Century's End. In A. Moravcsik (Ed.), Centralization or Fragmentation? Europe Facing the Challenges of Deepening, Diversity, and Democracy (pp.1-58). New York: Council on Foreign Relations.

Moravcsik, A. (1993a). Introduction. Integrating International and Domestic Theories of International Bargaining. In P. B. Evans, H. K. Jacobson and R. D. Putnam (Eds.), Double-Edged Diplomacy. International Bargaining and Domestic Politics (pp.3-42). Berkeley: University of California Press.

Moravcsik, A. (1993b). Preferences and Power in the European Community: A Liberal Intergovernmentalist Approach. Journal of Common Market Studies, 31 (4), pp.473-524.

Moravcsik, A. and Nicolaïdis, K. (1999) Explaining the Treaty of Amsterdam: Interests, Influence, Institutions, Journal of Common Market Studies, 37 (1), pp.59-85.

Moyer, H. W. (1993). The European Community and the GATT Uruguay Round: Preserving the Common Agricultural Policy at All Costs. In W. P. Avery (Ed.), World Agriculture and the GATT (pp.95-119). Boulder: Lynne Rienner.

Müller, W. C. (2001). Ministerial Government at the European Level: The Case of Austria. In H. Kassim, A. Menon and V. Wright (Eds.), The National Co-ordination of EU Policy. The European Level (pp.229255). Oxford: Oxford University Press.

Müller, W. C. (2000). Austria. In H. Kassim, B. Guy Peters and V. Wright (Eds.), The National Co-ordination of EU Policy. The Domestic Level (pp.201-218). Oxford: Oxford University Press. 
Nash, E. (2005, 30 September). Five killed as migrants storm Spain's foothold on African soil. The Independent. Retrieved 8 August 2011 from http://www.independent.co.uk/news/world/europe/five-killed-asmigrants-storm-spains-foothold-on-african-soil-508972.html

Ndione, B. and Broekhuis, A. (2006). Migration international et développement. Points de vue et initiatives au Sénégal. Working Papers Migration and Development Series. Report No. 8.

Nugent, N. (2010). The Government and Politics of the European Union. Basingstoke: Palgrave Macmillan.

Nuttall, S. (1992). European Political Cooperation. Oxford: Clarendon.

Olesen, H. (2002). Migration, Return, and Development: An Institutional Perspective. International Migration, 40 (5), pp. 125-149.

Oliver, D. G., Serovich, J. M. and Mason, T. L. (2005). Constraints and Opportunities with Interview Transcription: Towards Reflection in Qualitative Research. Social Forces, 84 (2), pp.1273-1289.

Olsen, J. P. (2007). Europe in Search of Political Order. An institutional perspective on unity/diversity, citizens/their helpers, democratic design/historical drift and the co-existence of orders. Oxford: Oxford University Press.

Österreichische Sozialversicherung (2012). Sonstige Vertragsstaaten und Adressen. Retrieved 6 March 2012 from http://www.sozialversicherung.at/portal27/portal/esvportal/channel_content/cmsWindow?action $=2 \&$ p_menuid $=62123 \&$ p_tabid $=4$

Pahre, R. (1997). Endogenous Domestic Institutions in Two-Level Games and Parliamentary Oversight of the European Union. Journal of Conflict Resolution, 41 (4), pp.147-174.

Panizzon, M. (2012). Readmission agreements of EU member states: a case for EU subsidiarity or dualism? Refugee Survey Quarterly, 31 (4), pp.101-133.

Panizzon, M. (2008). Labour Mobility : A win-win-win model for trade and development. The case of Senegal. Bern: NCCR.

Panke, D. (2013). The European Union in the United Nations. Effectively Speaking With One Voice? Paper presented at the EUSA Thirteenth Biennial Conference, Baltimore, 9-11 May.

Panke, D. (2004). How To Combine Rationalist and Constructivist Accounts of International Politics. Building Bridges on Terra Firma. Unpublished paper. Retrieved 1 February 2013 from http://userpage.fuberlin.de/ europe/team/PankeD/panke_2005c.pdf

Papagianni, G. (2006). Institutional and Policy Dynamics of EU Migration Law. Leiden: Martinus Nijhoff.

Parkes, R. (2009a). EU Mobility Partnerships: A Model of Policy Coordination? European Journal of Migration and Law, 11, pp.327-345.

Parkes, R. (2009b). Mobility Partnerships: valuable addition to the ENP repertoire? SWP Working Papers FG 1 2009/03. Berlin: Stiftung Wissenschaft und Politik.

Pastore, F. (2007). Europe, Migration and Development. Critical remarks on an emerging policy field. Rome: CeSPI.

Pastore, F. (2002). Aeneas's Route: Euro-Mediterranean Relations and International Migration. In S. Lavenex and E. M. Uçarer (Eds.), Migration and the Externalities of European Integration (pp.105-123). Oxford: Lexington.

Patterson, L. A. (1997). Agricultural policy reform in the European Community: a three-level game analysis. International Organisation, 51 (1), pp.135-165.

Pawlak, P. (2009). The External Dimension of the Area of Freedom, Security and Justice: Hijacker or Hostage of Cross-pillarization. Journal of European Integration, 31 (1), pp.25-44.

Peters, B. G. and Pierre, J. (2009). Governance Approaches. In A. Wiener and T. Diez (Eds.), European Integration Theory (pp.91-104). Oxford: Oxford University Press.

Poeze, M. (2010). In search of greener pastures? Boat migrants from Senegal to the Canary Islands. Leiden: African Studies Centre.

Poli, S. (2012). The Institutional Setting and the Legal Toolkit. In M. Cremona, J. Monar and S. Poli (Eds.), The External Dimension of the European Union's Area of Freedom, Security and Justice (pp.25-76). College of Europe Studies No. 13. Brussels: Peter Lang.

Pollack, M. A. (2003). The Engines of European Integration. Delegation, Agency and Agenda Setting in the $E U$. Oxford: Oxford University Press.

Pollak, J. and Puntscher-Riekmann, S. (2002). Small States-Big States: Who Has the Political Clout in the European Union? In G. Bischof, A. Pelinka and M. Gehler (Eds.), Austria in the European Union (pp.67-91). Contemporary Austrian Studies, volume 10. New Brunswick: Transaction Publishers. 
Potaux, C. (2011). The current role of the International Organization for Migration in developing and implementing Migration and Mobility Partnerships. In R. Kunz, S. Lavenex and M. Panizzon (Eds.), Multilayered Migration Governance. The promise of partnership (pp.183-204). London: Routledge.

Pruitt, D. G. (2002). Strategy in Negotiation. In V. A. Kremenyuk (Ed.), International Negotiation. Analysis, Approaches, Issues (pp.85-96). San Francisco: Jossey-Bass.

Public Radio of Armenia (2008). Joint Statement by Armenia and the European Union on the EU Migration Mission to Armenia. Retrieved 15 October 2012 from http://www.gab-ibn.com/IMG/pdf/Ar23_Joint_Statement_By_Armenia_And_The_European_Union_On_The_EU_Migration_Mission_To_Arm enia.pdf

Putnam, R. D. (1988). Diplomacy and domestic politics: the logic of two-level games. International Organization, 42 (3), pp.427-460.

Ragin, C. C. (2008). Redesigning Social Inquiry: Fuzzy Sets and Beyond. Chicago: University of Chicago Press.

van Reisen, M. (2007). The Enlarged EU and the Developing World. In A. Mold (Ed.), EU Development Policy in a Changing World (pp.29-65). Amsterdam: Amsterdam University Press.

Republik Österreich (2007). Regierungsprogramm 2008-2013. Gemeinsam für Österreich. Retrieved 6 March 2012 from http://www.austria.gv.at/DocView.axd?CobId=32965

République Française (2007). Les accords de gestion concertée des flux migratoires et de codéveloppement. Retrieved 29 March 2012 from http://www.gouvernement.fr/gouvernement/les-accords-de-gestionconcertee-des-flux-migratoires-et-de-codeveloppement

République Française (n.d.). Accords bilatéraux sur les migrations professionnelles et échanges des jeunes professionnels. Retrieved 29 March 2012 from http://www.immigration-professionnelle.gouv.fr/ proc\%C3\%A9dures/accords-bilat\%C3\%A9raux-et-\%C3\%A9changes-de-jeunes-professionnels

Reslow, N. (2012). EU Migration cooperation with Cape Verde. Migration Policy Brief No. 7. Retrieved 16 November 2012 from http://mgsog.merit.unu.edu/ISacademie/docs/PB7.pdf

Reslow, N. (2010). Migration and development? An assessment of recent EU policy Initiatives. Journal of Contemporary European Research, 6 (1), pp.3-21.

Reynolds, C. (2004). Irreconcilable Differences? National Convergence and Divergence in the CFSP. In D. Mahncke, A. Ambos and C. Reynolds (Eds.), European Foreign Policy. From Rhetoric to Reality? (pp.43-59) Brussels: P.I.E.-Peter Lang.

Rihoux, B. and Ragin, C. C. (2009) (Eds.). Configurational Comparative Methods: Qualitative Comparative Analysis (QCA) and Related Techniques. London: Sage.

Rijksoverheid (2007). Coalitieakkoord tussen de Tweede Kamerfracties van CDA, PvdA en ChristenUnie. Retrieved 3 April 2012 from http://www.rijksoverheid.nl/documenten-en-publicaties/rapporten/ 2007/02/07/coalitieakkoord-balkenende-iv.html

Risse, T. (1999). International Norms and Domestic Change: Arguing and Communicative Behaviour in the Human Rights Area. Politics \& Society, 27 (4), pp.529-559.

Rittener, O., Losada, R. M., Perriard, L. and Toscano, S. (2011). Swiss Migration Partnerships. A paradigm shift. In R. Kunz, S. Lavenex and M. Panizzon (Eds.), Multilayered Migration Governance. The promise of partnership (pp.249-264). London: Routledge.

Rodier, C. (2006). Analysis of the external dimension of the EU's asylum and immigration policies - summary and recommendations for the European Parliament. PE 374.366. Brussels: European Parliament.

Rohlfing, I. (2012). Case Studies and Causal Inference. Basingstoke: Palgrave Macmillan.

Roig, A. and Huddleston, T. (2007). EC Readmission Agreements: A Re-evaluation of the Political Impasse. European Journal of Migration and Law, 9, pp.363-387.

Rosamond, B. (2000). Theories of European Integration. Basingstoke: Palgrave Macmillan.

Samers, M. (2004). An Emerging Geopolitics of 'Illegal' Immigration in the European Union. European Journal of Migration and Law, 6, pp.27-45.

Schain, M. A. (2010). The shaping of European immigration policy during the past decade. International Journal of Economics and Business Research, 2 (1-2), pp.112-124.

Schain, M. A. (2009). The State Strikes Back: Immigration Policy in the European Union. The European Journal of International Law, 20 (1), pp.93-109. 
Schäuble, W. and Sarkozy, N. (2006). Deutsch-französische Initiative für eine neue Migrationspolitik. Retrieved 8 February 2012 from http://www.proasyl.de/fileadmin/proasyl/fm_redakteure/

Newsletter_Anhaenge/117/franz_ini.pdf

Schimmelfennig, F. (2009). Europeanisation beyond Europe. Living Reviews in European Governance, 4 (3). Retrieved 3 March 2011 from http://www.livingreviews.org/lreg-2009-3

Schimmelfennig, F. and Sedelmeier, U. (2004). Governance by conditionality: EU rule transfer to the candidate countries of Central and Eastern Europe. Journal of European Public Policy, 11 (4), pp.661-679.

Schoppa, L. J. (1993). Two-level games and bargaining outcomes: why 'gaiatsu' succeeds in Japan in some cases but not others. International Organisation, 47 (3), pp.353-386.

Selm, J. van (2005). Where migration policy is made: starting to expose the labyrinth of national institutional settings for migration policy making and implementation. Global Migration Perspectives, 37. Geneva: Global Commission on International Migration.

Selm, J. van (2002). Immigration and Asylum or Foreign Policy: The EU's Approach to Migrants and Their Countries of Origin. In S. Lavenex and E. M. Uçarer (Eds.), Migration and the Externalities of European Integration (pp.143-160). Oxford: Lexington.

Senegal-European Community (2008). Document de stratégie pays et Programme indicatif national pour la période 2008-2013. Retrieved 20 June 2011 from http://ec.europa.eu/development/icenter/ repository/scanned_sn_csp10_fr.pdf

Senegalese Ministry of Economics and Finance (2002). Déclaration de la Politique de Population. Adoptée le 5 mars 2002 en Conseil Interministériel présidé par le Premier Ministre.

Servent, A. (2010). Adapt or die: How co-decision shaped the fate of the 'Returns' directive in the European Parliament. Paper presented at the ECPR Fifth Pan-European Conference on EU Politics, Porto, 23-26 June.

SGAE (n.d.). Historique. Retrieved 13 March 2012 from http:/www.sgae.gouv.fr/gcp/pages/site/sgaeinternet-sgae/lang/fr/SGAE/Le-SGAE/Historique

Siegel, M. and Vorst, V. van der (2012). Evaluation of the 'Blue Birds' Circular Migration Pilot in the Netherlands. Maastricht: Maastricht Graduate School of Governance.

Sil, R. and Katzenstein, P. J. (2010). Beyond Paradigms. Analytic Eclecticism in the Study of World Politics. Basingstoke: Palgrave Macmillan.

Smith, K. E. (1998). The Use of Political Conditionality in the EU's Relations with Third Countries: How Effective? European Foreign Affairs Review, 3 (2), pp.253-274.

Smith, M. E. (2004). Toward a theory of EU foreign policy-making: multi-level governance, domestic politics, and national adaptation to Europe's common foreign and security policy. Journal of European Public Policy, 11 (4), pp.740-758.

Smith, S. (1986). Theories of foreign policy: an historical overview. Review of International Studies, 12 (1), pp.13-29.

Soetendorp, B. and Andeweg, R. B. (2001). Dual Loyalties: The Boundary Role of the Dutch Permanent Representation to the EU. In H. Kassim, A. Menon, B. G. Peters and V. Wright (Eds.), The National Coordination of EU Policy. The European Level (pp.211-228). Oxford: Oxford University Press.

Soetendorp, B. and Hanf, K. (1998). The Netherlands: Growing Doubts of a Loyal Member. In K. Hanf and B. Soetendorp (Eds.), Adapting to European Integration. Small States and the European Union (pp.3651). London: Longman.

Spanish Ministry of Foreign Affairs (2009). Africa Plan 2009-2012. Retrieved 22 June 2011 from http://www.maec.es/es/Home/Documents/PLANAFRICA09_12EN.pdf

Sterkx, S. (2008). The External Dimension of EU Asylum and Migration Policy: Expanding Fortress Europe? In J. Orbie (ed.), Europe's Global Role: External Policies of the European Union (pp.117-138). Farnham: Ashgate.

Stetter, S. (2000). Regulating migration: authority delegation in justice and home affairs. Journal of European Public Policy, 7 (1), pp.80-103.

Stone Sweet, A. and Sandholtz, W. (1997). European integration and supranational governance. Journal of European Public Policy, 4 (3), pp.297-317.

Straubhaar, T. (2000). New Migration Needs a NEMP (A New European Migration Policy). HWWA Discussion Paper 95. Hamburg: HWWA. 
Szukala, A. (2003). France: the European transformation of the French model. In W. Wessels, A. Maurer and J. Mittag (Eds.), Fifteen into one? The European Union and its member states (pp.216-247). Manchester: Manchester University Press.

Tallberg, J. (2010). Explaining the institutional foundations of European Union negotiations. Journal of European Public Policy, 17 (5), pp.633-647.

Tallberg, J. (2003). The agenda-shaping powers of the EU Council Presidency. Journal of European Public Policy, 10 (1), pp.1-19.

Thielemann, E. (2003). Between Interests and Norms: Explaining Burden-Sharing in the European Union. Journal of Refugee Studies, 16 (3), pp.253-273.

Thies, C. G. (2002). A Pragmatic Guide to Qualitative Historical Analysis in the Study of International Relations. International Studies Perspectives, 3, pp.351-372.

Thomson, R. (2008). The Council Presidency in the European Union: Responsibility with Power. Journal of Common Market Studies, 46 (3), pp.593-617.

Tonra, B. and Christiansen, T. (2004). The study of EU foreign policy: between international relations and European studies. In B. Tonra and T. Christiansen (Eds.), Rethinking European Union foreign policy (pp.1-9). Manchester: Manchester University Press.

Trachtenberg, M. (2006). The Craft of International History. A Guide to Method. Princeton: Princeton University Press.

Trauner, F. (2009). From membership conditionality to policy conditionality: EU external governance in South Eastern Europe. Journal of European Public Policy, 16 (5), pp.774-790.

Trauner, F. and Kruse, I. (2008a). EC Visa Facilitation and Readmission Agreements: A New Standard EU Foreign Policy Tool? European Journal of Migration and Law, 10, pp.411-438.

Trauner, F. and Kruse, I. (2008b). EC Visa Facilitation and Readmission Agreements: Implementing a New EU Security Approach in the Neighbourhood. CEPS Working Document No. 290. Brussels: CEPS.

Trumbore, P. F. (1998). Public Opinion as a Domestic Constraint in International Negotiations: Two-Level Games in the Anglo-Irish Peace Process. International Studies Quarterly, 42 (3), pp.545-565.

Trumbore, P. F. and Boyer, M. A. (2000). International Crisis Decisionmaking as a Two-Level Process. Journal of Peace Research, 37 (6), pp.679-697.

Tweede Kamer (2007). Brief van de minister voor ontwikkelingssamenwerking en de staatssecretaris van justitie. Vergaderjaar 2007-2008, 29 693, No. 14. Retrieved 19 November 2012 from http://www.eerstekamer.nl/eu/behandeling/20070919/brief_minister_met_toelichting/info

Tweede Kamer (2008a). Verslag van een algemeen overleg. Vergaderjaar 2007-2008, 23 490, No. 487. Retrieved 19 November 2012 from http://www.eerstekamer.nl/eu/behandeling/20071205/ algemeen_overleg_tk/info

Tweede Kamer (2008b). Verslag van een algemeen overleg. Vergaderjaar 2007-2008, 23 490, No. 510. Retrieved 19 November 2012 from http://www.eerstekamer.nl/eu/behandeling/20081126/ algemeen_overleg_tk/info

Uçarer, E. M. (2001). From Sidelines to Center Stage: Sidekick No More? The European Commission in Justice and Home Affairs. European Integration Online Papers, 5 (9).

Uçarer, E. M. and Lavenex, S. (2002). Conclusion. Ripples of European Integration: Modes and Consequences of Migration Policy Transfer. In S. Lavenex and E. M. Uçarer (Eds.), Migration and the Externalities of European Integration (pp.209-221). Oxford: Lexington.

UNDP (2011). Human Development Report 2011. Retrieved 10 January 2012 from http://hdr.undp.org/ en/media/HDR_2011_EN_Complete.pdf

UNODC (2005). UNODC Teams with Government of Cape Verde and European Commission to Combat Crime and Narco-Trafficking. Retrieved 9 June 2011 from http://www.unis.unvienna.org/unis/ pressrels/2005/unisnar918.html

Usher, J. A. (2006). The Commission and the Law. In D. Spence (Ed.), The European Commission (pp.103127). London: John Harper.

Versluis, E., Keulen, M. van and Stephenson, P. (2010). Analyzing the European Union Policy Process. Basingstoke: Palgrave Macmillan.

Vogt, A. (2012, 23 February). Italy violated human rights by returning migrants to Libya, court rules. The Guardian. Retrieved 25 October 2012 from http:/www.guardian.co.uk/world/2012/feb/23/italy-humanrights-migrants-libya 
Wagbou, M. (2008). Governance of migration in Senegal: The role of government in formulating migration policies. In A. Adepoju, T. van Naerssen and A. Zoomers (Eds.), International Migration and National Development in sub-Saharan Africa. Viewpoints and Policy Initiatives in the Countries of Origin (pp.141-160). Leiden: Brill.

Wagner, W. (2003). Why the EU's common foreign and security policy will remain intergovernmental: a rational institutional choice analysis of European crisis management policy. Journal of European Public Policy, 10 (4), pp.576-595.

ter Wal, J. (2007). The Netherlands. In A. Triandafyllidou and R. Gropas (Eds.), European Immigration. A Sourcebook (pp.249-261). London: Ashgate.

Wallace, H. (2005a). An Institutional Anatomy and Five Policy Modes. In H. Wallace, W. Wallace and M. A. Pollack (Eds.), Policy-Making in the European Union (pp.49-90). Oxford: Oxford University Press.

Wallace, H. (2005b). Exercising Power and Influence in the European Union: The Roles of Member States. In S. Bulmer and C. Lequesne (Eds.), The Member States of the European Union (pp.25-44). Oxford: Oxford University Press.

Wallace, H. (2000). The Institutional Setting. Five Variations on a Theme. In H. Wallace and W. Wallace (Eds.), Policy-making in the European Union (pp.3-37). Oxford: Oxford University Press.

Wallace, H., Pollack, M. and Young, A. (2010) (Eds.). Policy-Making in the European Union. Oxford: Oxford University Press.

Wallace, W. (2005). Foreign and Security Policy. In H. Wallace, W. Wallace and M. Pollack (Eds.), Policymaking in the European Union (pp.429-456). Oxford: Oxford University Press.

Walters, W. (2010). Imagined Migration World: The European Union's Anti-Illegal Immigration Discourse. In M. Geiger and A. Pécoud (Eds.), The Politics of International Migration Management (pp.73-95). Basingstoke: Palgrave Macmillan.

Ward, N. (2011). Facilitating the temporary movement of natural persons. Economic partnership agreements versus bilateral migration agreements and Mobility Partnerships. In R. Kunz, S. Lavenex and M. Panizzon (Eds.), Multilayered Migration Governance. The promise of partnership (pp.143-182). London: Routledge.

Ward, N. (2008). Comparing EU-Mobility Partnerships and the provisions for temporary movement of labour in the Cariforum-EC Economic Partnership. Paper presented at the conference 'Swiss migration and EU mobility partnerships: unveiling the promise', Bern, 12-13 December.

Weinar, A. (2011). EU Cooperation Challenges in External Migration Policy. Florence: Robert Schuman Centre for Advanced Studies.

Weiss, R. S. (1994). Learning from Strangers. The Art and Method of Qualitative Interview Studies. New York: The Free Press.

Wiesbrock, A. and Schneider, H. (2009). Circular migration and mobility partnerships. Briefing paper. PE 410.680. Brussels: European Parliament.

Wolff, S. (2009). The Mediterranean Dimension of EU Counter-Terrorism. Journal of European Integration, 31 (1), pp.137-156.

Wolff, S., Wichmann, N., and Mounier, G. (2009). The External Dimension of Justice and Home Affairs: A Different Security Agenda for the EU? Journal of European Integration, 31 (1), pp.9-23.

Woliver, L. R. (2002). Ethical Dilemmas in Personal Interviewing. Political Science and Politics, 35 (4), pp.677-678.

Wong, R. (2007). Foreign Policy. In P. Graziano and M. Vink (Eds.), Europeanization. New Research Agendas (pp.321-334). Basingstoke: Palgrave.

Wood, S. (2004). The EU and Turkey: Political Machinations in a Three-Level Game. Working Paper 139. Canberra: Australian National University.

World Bank (2011). The Migration and Remittances Factbook 2011. Retrieved 16 June 2011 from http://siteresources.worldbank.org/INTLAC/Resources/Factbook2011-Ebook.pdf

Wunderlich, D. (2010). Differentiation and Policy Convergence against Long Odds: Lessons from Implementing EU Migration Policy in Morocco. Mediterranean Politics, 15 (2), pp.249-272.

Yanow, D. (2000). Conducting Interpretive Policy Analysis. Qualitative Research Methods no. 47. Thousand Oaks: Sage. 
Young, A. R. (2003). What game? By which rules? Adaptation and flexibility in the EC's foreign economic policy. In M. Knodt and S. Princen (Eds.), Understanding the European Union's External Relations (pp.54-71). London: Routledge.

Zaslove, A. (2004). Closing the Door? The ideology and impact of radical right populism on immigration policy in Austria and Italy. Journal of Political Ideologies, 9 (1), pp.99-118. 


\section{Samenvatting}

Dit onderzoek bestudeert het proces van het nemen van beleidsbeslissingen tussen de EU, de EU-lidstaten en derde landen op het gebied van migratie. De vraag wordt gesteld waarom overeenkomsten op het gebied van migratie worden gesloten, gezien het feit dat zowel EU-lidstaten als derde landen mogelijk terughoudend zijn wanneer het draait om samenwerking met de EU op het gebied van migratie. Het belangrijkste argument, om volledig inzicht te krijgen in dit beleidsproces, is dat het noodzakelijk is om naast de Europese instituties zowel de voorkeuren van EU-lidstaten als derde landen in overweging te nemen. Deze actoren zijn aan elkaar gerelateerd in een 'three-level-game'. De bevindingen tonen aan dat de Europese Commissie zich in een lastige onderhandelingspositie bevindt: zij is gebonden aan de voorkeuren van de lidstaten wat betreft migratie overeenkomsten en ontbeert autonomie om concessies te doen aan derde landen tijdens onderhandelingen. Tegelijkertijd ondermijnen lidstaten de onderhandelingspositie van de Commissie door derde landen een meer aantrekkelijke samenwerking te bieden op bilateraal niveau.

Migratie is zonder enige twijfel het grootste sociale fenomeen van onze tijd - tot 2000 werd het aantal migranten wereldwijd geschat op 150 miljoen. Door de grote inkomensongelijkheden tussen ontwikkelings- en ontwikkelde landen, zijn migranten bereid een toenemend risico te nemen om door middel van onrechtmatigheden ontwikkelde landen te bereiken. Ontwikkelde landen zijn niet in staat om deze migratiestroom door unilaterale beleidsmaatregelen tegen te houden. Daarom zoeken zij samenwerking met derde landen op het gebied van migratie om te komen tot het stoppen van de migratiestroom bij de bron. De behoefte om samen te werken met derde landen om effectief migratiebeleid te voeren, is duidelijk uitgesproken binnen Europese beleidsdocumenten. Het is echter niet vanzelfsprekend dat op Europees extern migratiebeleid overeenstemming kan worden gevonden. Lidstaten kunnen terughoudend zijn om de bevoegdheid op dit beleidsveld over te dragen aan de Europese instituties. Dit is een beleidsveld wat ligt op het snijvlak van twee beleidsvelden welke cruciaal zijn voor de nationale soevereiniteit: migratiebeleid en buitenlandbeleid. Derde landen kunnen afwijzend staan tegenover samenwerking met een EU die gericht is op het voorkomen van illegale migratie en het terugsturen van illegale migranten vanuit de EU.

Toch worden er overeenkomsten gesloten op het gebied van migratie tussen de EU, de lidstaten en derde landen. Dit onderzoek stelt de vraag hoe dit kan, door te kijken naar één bepaald aspect van Europees extern migratiebeleid: Mobiliteitspartnerschappen. Dit beleidsinstrument is geïntroduceerd in 2007 en biedt derde landen toenemende kansen op legale migratie voor haar burgers naar de EU in ruil voor samenwerking om illegale migratie te voorkomen. Er geldt een vrijwillige deelname voor lidstaten aan de Mobiliteitspartnerschappen: geïnteresseerde lidstaten nemen hieraan deel door aan te geven welke projecten zij willen implementeren. Elk partnerschap heeft de vorm van een politieke verklaring; getekend door zowel de Commissie, de participerende lidstaten en het derde land. Deze politieke verklaring, welke niet wettelijk bindend is, geeft de 
intentie tot samenwerking van de partners weer. Toegevoegd aan de verklaring is een lijst van voorgestelde projecten - de implementatie van deze projecten geeft de inhoud van het Mobiliteitspartnerschap weer. Aan het eind van 2009 (het einde van de periode waarin de casusselectie voor dit onderzoek heeft plaatsgevonden) zijn er Mobiliteitspartnerschappen ondertekend met Moldavië, Kaapverdië en Georgië. De onderhandelingen met Senegal zijn opgeschort. De EU-lidstaten hebben verschillende voorkeuren aangegeven betreffende de Mobiliteitspartnerschappen. Frankrijk participeert in alle drie mobiliteitspartnerschappen, de meeste lidstaten participeren in één of twee partnerschappen, en vier lidstaten (Oostenrijk, Finland, Ierland en Malta) nemen aan geen enkel Mobiliteitspartnerschap deel.

Dit onderzoek heeft als doel een toevoeging te zijn op de bestaande literatuur over Mobiliteitspartnerschappen, door als eerste op basis van uitgebreide interviews, een systematische analyse van de voorkeuren van lidstaten en derde landen te maken. Het samenbrengen van drie niveaus van analyse is tevens een doelstelling: het niveau van de lidstaat, de EU en het internationale (derde land) niveau. Hoofdstuk 2 van dit onderzoek beargumenteert dat het proces van het nemen van beleidsbeslissingen op het gebied van Europees extern migratiebeleid, een 'three-level-game' is.

Op het eerste niveau onderhandelen de EU en derde landen over migratieproblematiek. Om de uitkomsten van deze internationale onderhandelingen te begrijpen, is het van essentieel belang om de binnenlandse voorkeuren van deze derde landen op het gebeid van onderhandelen met de EU te begrijpen. Dit onderzoek past twee concurrerende verklaringen voor de voorkeuren van derde landen toe: de 'policy conditionality' verklaring (een rationele kosten-baten verklaring) en 'social learning' (een constructivistisch verslag gebaseerd op de logica van het gepaste handelen. Het EU niveau (niveau 2 ) is het proces van het nemen van beleidsbeslissingen op het gebied van Europees extern migratiebeleid binnen de EU, tussen de Europese instituties en de lidstaten in de (Europese) Raad. Dit onderzoek past een beleidsmatige aanpak toe, door het patroon van beleid op Europees niveau in kaart te brengen en vervolgens dit patroon te verklaren in termen van de rol die Europese instituties en de lidstaten spelen. Hoewel lidstaten een centrale rol hebben in dit beleidsveld, proberen Europese instituties zoveel mogelijk competenties naar zich toe te trekken. Het niveau van de lidstaat (niveau 3) in de 'three level game' refereert naar de formatie van binnenlandse voorkeuren van de lidstaat op het gebeid van Europees extern migratiebeleid. Het is van belang de binnenlandse voorkeuren van lidstaten te begrijpen om inzicht te krijgen in de uitkomsten van beslissingen binnen de EU. Dit onderzoek past twee concurrerende verklaringen voor de voorkeuren op het gebied van Mobiliteitspartnerschappen van lidstaten toe: een rationele kostenbaten verklaring en een constructivistische verklaring van nationale identiteit.

De drie niveaus in deze 'three level game' zijn aan elkaar gerelateerd door een tweetal interacties: de eerste tussen de lidstaten en de Europese instituties, de tweede tussen de EU en derde landen. De twee interacties zijn gerelateerd omdat het beleid dat wordt bepaald in de eerste interactie (tussen lidstaten en de Europese instituties), het onderwerp wordt van onderhandeling in de tweede interactie (tussen de EU en het derde land). Niveaus 1 en 3 zijn ook direct gerelateerd, onafhankelijk van de EU, door bilate- 
rale overeenkomsten op het gebied van migratie. Tenslotte zijn lidstaten 'aanwezig' in de interactie tussen de EU en het derde land, door de centrale rol die zij innemen in het bepalen van de inhoud van het beleid dat ter onderhandeling ligt.

Om de onderzoeksvragen te beantwoorden, zijn case studies voor vijf landen uitgevoerd. Ten eerste zijn op het niveau van de lidstaten, case studies uitgevoerd voor Frankrijk, Oostenrijk en Nederland. Frankrijk is geselecteerd als een 'positieve' casus, omdat het deelneemt in alle Mobiliteitspartnerschappen die overeen zijn gekomen tot aan het eind van 2009. Oostenrijk is geselecteerd als een 'negatieve' casus, omdat zij aan geen enkele mobiliteitspartnerschap deelnam; de Oostenrijkse overheid heeft de Europese Commissie zelfs beschuldigd van het ondermijnen van de bevoegdheden van lidstaten met dit beleidsinstrument. Nederland is een 'ambivalente' casus - de Nederlandse overheid was initieel tegenstander van de Mobiliteitspartnerschappen, maar heeft naderhand haar positie gewijzigd en deelgenomen aan het partnerschap met Georgië en Kaapverdië. Op het niveau van het derde land, is Senegal geselecteerd als een 'negatieve' casus omdat het land de gestarte onderhandelingen hierover heeft gestaakt. Kaapverdië is geselecteerd als een 'positieve' casus, omdat zij toestemden met een mobiliteitspartnerschap. Om data te verzamelen, zijn er 66 interviews uitgevoerd met beleidsmakers in de Europese Commissie, de overheden van Frankrijk, Oostenrijk, Nederland, Senegal en Kaapverdië. Daarnaast zijn er interviews gehouden met delegaties van de EU in derde landen en lokale delegaties van de Internationale Organisatie voor Migratie (IOM).

Hoofdstuk 4 van dit onderzoek brengt het beleidspatroon onderliggend aan Mobiliteitspartnerschappen op Europees niveau in kaart. Het toont aan dat de lidstaten en de Europese Commissie met elkaar worstelen over de controle van dit beleidsinstrument. Voor de schermen leek de Commissie een centrale rol te hebben gespeeld: de Commissie was verantwoordelijk voor de communicatie over Mobiliteitspartnerschappen, heeft potentiële partnerlanden voorgesteld, heeft de interesse in deelname van lidstaten gepeild, discussies gevoerd met vertegenwoordigers van derde landen en continue de Mobiliteitspartnerschappen als beleidsinstrument van de Europese relatie met derde landen gepromoot. Desondanks bleven de lidstaten achter de schermen controle houden over de inhoud, richting en vorm van de Mobiliteitspartnerschappen. De lidstaten hebben de periode van beleidsformulering beïnvloed door hun eigen beleidsinitiatieven. Gedurende de periode van het nemen van beslissingen, hebben de lidstaten de Commissie gemandateerd en controleerden zij het selectieproces van derde landen. De invloed van de lidstaten op het proces van het nemen van beslissingen, heeft zichzelf gemanifesteerd in de vorm van de partnerschappen: Mobiliteitspartnerschappen worden getekend als politieke verklaringen (in plaats van wettelijk bindende internationale overeenkomsten); deelname is vrijwillig voor de lidstaten; en de lidstaten controleren de inhoud van de partnerschappen door de projecten die zij voorstellen.

$\mathrm{Nu}$ de dominante rol van de lidstaten op Europees niveau is vastgesteld, is hoofdstuk 5 een verhandeling over de voorkeuren van lidstaten wat betreft de Mobiliteitspartnerschappen. De Oostenrijkse overheid had besloten niet deel te nemen omdat de Mobiliteitspartnerschappen met hun gelijkenis van de 'gastarbeiter' opzet, niet pasten binnen 
de nationaal gestelde beleidsdoelen voor migratie. De Nederlandse overheid was in het begin terughoudend omdat de kosten en baten van dit nieuwe beleidsinstrument nog niet inzichtelijk waren. Desalniettemin, toen het nationale beleid was geformuleerd, is er vastgesteld dat de baten van deelname aan de partnerschappen de kosten overstegen. Door de Franse overheid werd deelname aan de partnerschappen als 'gepast' gezien omdat het goed paste in het beeld van Frankrijk als leider, zowel binnen de EU als breder in het domein van extern migratiebeleid. Voorts heeft dit hoofdstuk niet bewezen dat het bestaan van bilaterale relaties met het voorgestelde partnerschapsland de voorkeuren van de overheden van lidstaten heeft beïnvloed.

Hoofdstuk 6 analyseert de voorkeuren van derde landen. Noch Kaapverdië, noch Senegal waren betrokken in een proces van dialoog en overtuiging door de EU: in plaats daarvan had het voorstel voor een Mobiliteitspartnerschap een hoog 'slikken of stikken' gehalte. Het partnerschap paste goed binnen de Kaapverdische beleidsdoelen op het gebied van migratie, en de kosten die betaald moesten worden in de vorm van een overnameovereenkomst van onderdanen werden uiteindelijk lager geacht dan de voorgestelde voordelen. Dit in tegenstelling tot Senegal, waar het partnerschap niet goed paste binnen de gestelde migratiedoelen en de kosten voor overname van onderdanen te hoog werden geacht voor de voorgestelde, magere voordelen. Bilaterale alternatieven die de voorkeur hadden, sterkten de voorkeur van de Senegalese overheid om 'nee' te zeggen tegen de EU.

De conclusie pleit voor het slaan van bruggen tussen rationeel en constructivistisch denken, zodat academisch onderzoek de empirische waarheid kan weergeven. Verder onderzoek kan het 'three level game' model nuttig toepassen op andere beleidsinstrumenten van Europees extern migratiebeleid, of op compleet andere externe beleidsvelden als bijvoorbeeld het gemeenschappelijk visserijbeleid. Toekomstig onderzoek naar Mobiliteitspartnerschappen zou een nuttige vergelijking kunnen maken tussen Afrikaanse en Oost-Europese partnerlanden, of een analyse kunnen uitvoeren op meer lidstaten. Tenslotte is het belangrijk niet uit het oog te verliezen dat extern migratiebeleid van invloed is op mensen, namelijk migranten die proberen de Europese Unie te bereiken. Gezien de dubieuze situatie wat betreft mensenrechten van sommige van de derde landen waarmee de EU samenwerkt (Libië in het bijzonder), is het de vraag of het wenselijk is voor het Europees extern migratiebeleid om effectief geïmplementeerd te worden. 


\section{Curriculum vitae}

Natasja Reslow (1984) studied Modern European Languages and European Union studies at the University of Edinburgh, and graduated with first class honours in June 2007. She spent one semester each at the University of Copenhagen and the University of Vienna on the Erasmus programme. In September 2007 Reslow moved to Maastricht University to begin the postgraduate MA in European Studies at Maastricht University. She specialised in European International Politics, and her thesis was entitled 'The EU's Common Foreign and Security Policy: Lessons from Iraq'. She graduated cum laude in August 2008, and was one of the top 3\% of students in her cohort.

Following short stints as a research assistant, Reslow took up her Ph.D. position at the Faculty of Arts and Social Sciences in December 2008. Her research project on EU external migration policy was part of the IS-Academy cooperation on migration and development, funded by the Dutch Ministry of Foreign Affairs. The findings of her research have been published in the Journal of Contemporary European Research, the Journal of European Integration and the European Journal of Migration and Law. She has also written three policy briefs for the ministry on the topic of her research.

Besides her research, Reslow has also been active in teaching, twice coordinating the course 'Negotiation Skills' in the Minor European Studies. She was invited to be a teaching assistant for the course on case study analysis at the ECPR summer school on methodology, and has given lectures on case study research to both the Research Master European Studies and the faculty's Graduate School (with Claudia Engelmann). Reslow was also a member of the Faculty Council from 2009 to 2011.

Currently, Reslow is a lecturer at the Department of Political Science at Maastricht University. 